\title{
Raimund Sesterhenn
}

\section{Das Bogostroitel'stvo bei Gor'kij und Lunačarskij bis 1909}

\section{Zur ideologischen und literarischen Vorgeschichte der Parteischule von Capri}

Verlag Otto Sagner München · Berlin - Washington D.C.

Digitalisiert im Rahmen der Kooperation mit dem DFG-Projekt „Digi20“

der Bayerischen Staatsbibliothek, München. OCR-Bearbeitung und Erstellung des eBooks durch den Verlag Otto Sagner:

http://verlag.kubon-sagner.de

( bei Verlag Otto Sagner. Eine Verwertung oder Weitergabe der Texte und Abbildungen, insbesondere durch Vervielfältigung, ist ohne vorherige schriftliche Genehmigung des Verlages unzulässig. 


\title{
SLAVISTISCHE BEITRÄGE
}

\author{
BEGRÜNDET VON \\ ALOIS SCHMAUS \\ HERAUSGEGEBEN VON \\ JOHANNES HOLTHUSEN · HEINRICH KUNSTMANN \\ PETER REHDER · JOSEF SCHRENK \\ REDAKTION \\ PETER REHDER
}

Band 158

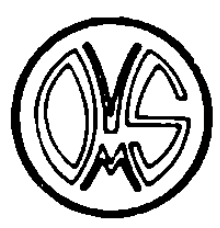

VERLAG OTTO SAGNER

MÜNCHEN 


\section{RAIMUND SESTERHENN}

\section{DAS BOGOSTROITEL'STVO \\ BEI GOR'KIJ UND LUNAČARSKIJ BIS 1909 \\ Zur ideologischen und literarischen \\ Vorgeschichte der Parteischule von Capri}

\section{VERLAG OTTO SAGNER - MÜNCHEN \\ 1982}


Bayerische
8taatsblbliothek
Münction

\section{ISBN 3-87690-240.1 \\ (c) Verlag Otto Sagner, München 1982 \\ Abteilung der Firma Kubon \& Sagner, München \\ Druck: UNI-Druck, München}


Die erste Idee zu dieser Arbelt, die 1981 von den Philosophischen Fakultäten der Universität Freiburg als Dissertation angenommen wurde, stammt aus einem Seminar über das Verhältnis von Gor'kif und Lenin, das Professor Gottfried Schramm und Gernot Erler gemeinsam veranstalteten. Gernot Erler machte mich damals auf die Tatsache aufmerksam, daß das 'Ereignis' Bogostroltel'stvo zwar durch allerlei Veröffentlichungen spukte, die sich mit der gelstigen und (parte1-) poIitischen vorgeschichte des Sowjetstaates befaßten, daß Jedoch eine wirkliche Elnschätzung der Bedeutung des Gotterbauertums nicht möglich sel, solange es nur als welBer Fleck auf der Forschungslandkarte erschelne.

Daß die damit geweckte Neugler in Arbelt umgesetzt werden konnte, verdanke $1 \mathrm{ch}$ dem aufmunternden Interesse, das Professor Rolf-Dieter Kluge melnem Plan entgegenbrachte, dem Stellenwert des Gotterbauertums vor allem für Gor'kijs Werk nachzugehen. Für dieses Interesse, das bis zur Fertigstellung der Arbelt nicht abriß, möchte $1 \mathrm{ch}$ mich bel $1 \mathrm{hm}$ bedanken. Ebenso bel Gernot Erler, der mir in manchen Gesprächen den pol1tisch-historischen Kontext des Bogostroitel'stvo verstehen ralf.

Für wertvolle Hinweise danke lch Professor Hans Günther, Blelefeld und Professor Aleksandr Ovcarenko, Moskau. Das Lesen der Korrekturen hat mir Frau Tatjana Großekemper-Gütschow abgenommen - dafür herzlichen Dank! Den Herausgebern der Slavistischen Beltrăge, Professor Johannes Holthusen und Dr. Peter Rehder sowle dem Verlag otto Sagner bin $1 \mathrm{ch} z \mathrm{z}$ besonderem Dank verpflichtet, da sie die Drucklegung dieser Arbelt ermöglichten.

Freiburg, im Ma1 1982

Raimund Sesterhenn 
I. Einleitung und Fragestellung

II. Überblick

1. Der Name

2. Die Schriften des Gotterbauertums und inr geistesgeschichtlicher Kontext (Chronologie)

Anmerkungen

III. Gor'kijs Religionsbegriff um 1907

(Die Umfrage des Mercure de France)

Anmerkungen

IV. Wissenschafticher Sozialismus als religionsphilosophisches System bei Lunacarskif 60

1. Die Religionskritik

2. Das Wesen der Religion 65

a) Die "religiöse Frage" 67

b) Kollektivgedanken 72

c) Zusammenf assung 74

3. Wissenschaftlicher Sozialismus als Religion 76

a) Kritik am orthodoxen Marxismus 78

b) Die neue Religion - Gefühl und Enthusiasmus

c) Das I d e a 1290

d) Ideal und Fortschritt 92

4. Nietzsche als "Gotterbauer" 101

5. Die Entfaltung der neuen Religion 112

a) Der neue Mensch 112

b) Der neue Gott 115

c) Schuld und Sühne 118

d) Glaube, Hoffnung, Liebe 121

e) Das Kollektiv ("ICh" und "Wir") 124

f) Die "neue Religion" - Zusammenfassung 130 
6. Gor'kij ein Schüler Lunacarskijs? Anmerkungen

V. Das Pathos des Menschen bei Gor'kif. Gefühl und Vernunft

1. "Celovek" (1904)

a) Der Mensch mit großem Buchstaben 164

b) Der "Gedanke" (Mysl')

c) Jie Synthese

d) Zusammenfassung und Vergleich

172

2. "Na dne" (1902)

3. "Citatel"" (1896/98)

181

4. "Konovalov" (1896/97) 186

5. "Casy" (1894/96)

189

6. "O cize, kotoryj lgal i o djatle, l jubitele istiny" (1893)

7. Gor'kif - ein Schüler Nietzsches?

8. Gor'kifs Bogostroitel'stvo (1906/07) als Ende einer eigenständigen Entwicklung

a) Das Pathos des Menschen als Ausdruck der emotionalen Seite

b) Vernunft als Korrektiv und syntheseglied

c) Der neue Mensch, eine Synthese aus Gefühl und Vernunft $=$ Gott

Anmerkungen

VI. "Mat"", "Ispoved" und "Leto" als erzählerische Ausformungen von Gor'kijs Gotterbauertum

1. "Mat""

a) Pavel Vlasov als Repräsentant der Vernunft

b) Andrej Nachodka als Repräsentant des Gefühlt

c) Der Bauer Rybin als Verteidiger der Religlosität des Volkes

d) Die Entwicklung der Mutter als narrative Entsprechung zu Lunatarskijs Religions-Philosophie und als Weg zu Gor'kijs "Synthese"

e) Zusammenfassung 
2. "I spoved" "

a) Matvej: vom Gott-Suchen zum Gott-Bauen 267

b) Die Elemente der Religion des Gott-Bauens 270

1. Vom Individuum zum Kollektiv: "Volk" 270

2. Vom "Gott" zu "Christus" 273

3. Die Synthese von Vernunft und Gefühl führt zur "Religion der Aktivität"

279

c) "Ispoved" - Kontinuität oder 'Abwe1chung'?

282

3. "Leto" (1909) 289

Anmerkungen $\quad 294$

VII. Das Narodnicestvo als Erbteil in Gor'kijs

Bogostroitel'stvo: V.V. Bervi-Flerouskif

307

1. Der revolutionäre Außenseiter 308

2. "Azbuka social'nych nauk" (1871) und

"Kak dolzno zit" po zakonu prirody 1 pravdy" (1873)

3. "Na zizn" i smert"" (1877) 314

4. Der Antell des Narodnicestvo (Bervi) in Gor'kljs Bogostroitel'stvo

Anmerkungen

VIII. SchIUß

1. Zusammenfassung 326

2. Die "Bogostroiteli" - eine Gruppe? 331

3. War das Gotterbauertum 1910 zu Ende? Ein Ausblick

Anmerkungen 


\section{Einleitung und Fragestellung}

Im kurzen biographischen Abriß am Ende ihres Gor'kijbuches schreibt Nadjeshda Ludwig über das Jahr 1906:

Im Oktober siedelte er (Gor'kij) sich auf der Insel Capri an. Den zeitweiligen Einfluß der ebenfalls auf Capri lebenden Bogdanov-Gruppe vermochte Gor'kif durch die Hilfe W.I. Lenins zu überwinden. ${ }^{1)}$

Im Kapitel "Das Jahrzehnt zwischen den Revolutionen" 2 ) lesen wir näherhin, daß Gor'kij in dieser Zeit "manchen ideologischen und politischen Irrtümern (verfiel)" ${ }^{3)}$, wobei der Einfluß einer

"Gruppe Intellektueller, die ebenfalls auf Capri lebten und unter der Führung A. Bogdanovs, B. Basarows und A. Lunatscharskijs standen", maßgeblich war. ${ }^{4}$ )

Politisch hätten diese Leute die Abberufung der sozialdemokratischen vertreter aus der III. Duma gefordert (Otzovisten); ideologisch

vertraten sie die idealistischen Auffassungen einer Bewegung, die sich Gottbildnertum oder Gottsuchertum nannte.

Lenin habe eine"klare Abgrenzung" von dieser Gruppe verlangt; diese sei dann auch erfolgt, als

die Anhänger dieser Gruppe auf Capri eine Parteischule gründeten, in der ihre Ideologie gelehrt wurde. ${ }^{6)}$

Lenins Briefwechsel mit Gor'kij in dieser Zeit wird als ein klassisches Beispiel für den Kampf der Partei um einen ihrer Genossen, für eine geduldige und beharr1 iche Überzeugungsarbeit ${ }^{7}$ )

hingestellt. Lenin habe Gor'kij auf das "antimarxistische idealistische Wesen des Gottbildnertums" verwiesen, sowie 
darauf,

daß auch eine erneuerte und verfeinerte Religion reaktionär und gegen die Demokratie und das Proletariat gerichtet ist. 8 )

Gor'klf sei es dann schließlich mit Lenins und anderer "prinzipienfester Bolschewiki" Hilfe gelungen, die ideologischen Schwankungen zu überwinden, sie machen sich jedoch in einigen seiner künstlerischen und publizistischen Werke dieser Zeit bemerkbar und treten am deutlichsten in der Erzählung "Eine Beichte" (1908) in Erscheinung.9)

Versucht man, sich anhand von sowjetischen Darstellungen (Lexika, Literaturgeschichte, Parteigeschichten usw.) näher zu informieren, wird man einiges mehr über das Bogostroitel'stvo allgemein und Gor'kijs Rolle darin speziell erfahren; man wird jedoch feststellen, daß die hier angeführte Darstellung genau dem Rezeptionsmuster entspricht, nach welchem diese Zeit der "Abirrungen" bei Gor'kij (und LunaKarskij) zur Kenntnis genommen wird.

Aus der "Filosofskaja Ėnciklopedija" beispielsweise erfahren wir unter den Stichwörtern "Bogostroitel'stvo" und "Gor'kij"10), daß es sich bei dem Gottbildnertum um eine religionsphilosophische strömung handle, die während der Zeit der Reaktion 1907 - 1910 unter der russischen sozialdemokratischen Intelligenz verbreitet gewesen sei. Es sei Ausdruck des an der gescheiterten Revolution enttäuschten kleinbürgerlichen Denkens. Als Hauptvertreter werden Lunacarskij, Bazarov, Bogdanov mit inren jeweils wichtigsten Schriften aus dieser zeit aufgezählt. Die povest" "Ispoved" Gor'kijs sei unter dem Einfluß dieser Gruppe entstanden. Hier nehme Gor'kijs "Kult des Menschen"m einen "religiösen Charakter" an, das Volk werde zum "Gott" der neuen Religion und gleichzeitig zum "Gotterbauer". 11) 
Neben "Ispoved" finden noch Gor'kijs Aufsatz "Razrusenie licnosti" (1909) und der Zusammenhang der ganzen strömung mit Bogdanovs "Empiriomonismus" Erwähnung. 12)

Man kann mit Recht sagen, daß in sowjetischen Darsteliungen das oben genannte Muster nur variiert wird. Ein besonders krasses Beispiel ist Bjalik, Revolution und Kunst. 13)

Bjalik befaßt sich mit Gor'kijs "Irrtümern", weil sich inm so die Möglichkeit biete,

die große Rolle, die Lenin und die Partei im Schicksal des Schriftstellers gespielt haben, in vollem Maße auf zudecken. 14)

Bjalik interpretiert Gor'kijs "Irrtümer" als "Abweichen von sich selbst"; der "Freund und Lehrer" Lenin führt inn "unter Schmerzen" wieder auf den "richtigen Weg" zurück. 15)

Wie sehr das sowjetische Rezeptionsmuster des Bogostroitel'stvo von der Person Lenins geprägt ist, zeigte schon das erste Beispiel 16), wo wir nur einen vagen Hinweis auf "Gottsuchertum oder Gottbildnertum" fanden. Tatsächlich werden diese beiden Bewegungen meist in einem Atemzug genannt; so besonders auffallend in der Bol'saja Sovjetskaja Enciklopedija von $1927^{17}$, wo das Bogostroitel'stvo noch unter dem Stichwort "Bogiskatel'stvo" abgehandelt wird. Hier wird das Bogostroitel'stvo dem Bogiskatel'stvo als "religija bez boga" (Religion onne Gott), als Pendant /Gegenbewegung zum letzteren, gegenübergestelit und gleichermaßen als "Idealismus" abgetan.

In der Tatsache, daß diese beiden Strömungen fast immer zusammen genannt, ja zuweilen sogar miteinander vermengt werden $^{17 a)}$, ist mit sicherheit ein Reflex des in diesem Zusammenhang immer neu zitierten Satzes aus einem Brief Lenins an Gor'kij vom November $1913 \mathrm{zu}$ sehen: 
Das Gottsuchertum unterscheidet sich von dem Gotterbauertum oder von der Gottmacherei oder Gotterschafferei (bogosozidatel'stvo) und dergleichen mehr nicht um ein Tüpfelchen mehr, als sich ein gelber Teufel von einem blauen unterscheidet. 18 )

Festzuhalten ist hier, $d a B$ für die sowjetischen Darstellungen über das Bogostroitel'stvo die Kritik Lenins, sowie deren politische und philosophische Implikationen maBgeblich geblieben sind. Meist wird der Inhalt dieser "Lehre" nur mit Leninschen Worten wiedergegeben. 19) Die Bewegung selbst kommt nur soweit zu Wort, wie sie in Lenins Schriften zitiert wurde. Das hat zur Folge, daß man immer wieder dieselben zitate aus Gor'kij und Lunałarskij zu lesen bekommt.

Das Bild, welches demgegenüber die westliche Forschung (soweit das Bogostroitel'stvo überhaupt bisher Gegenstand von Forschung war) bietet, ist nicht grundsätzlich anders. Es reicht von mehr oder weniger neutralen kurzen Darstellungen, die sich allerdings fast immer aus sekundären Quellen speisen ${ }^{20)}$, bis zu solchen, die das Leninsche Muster genau spiegelverkehrt wiederholen. 21) Hier gerät Gor'kij dann zu einem in seinem Wesen schon immer tief religiösen Menschen, für den die, von Lenin mehr oder weniger deutlich erzwungene, Parteinahme für die Bol'seviki ein "Abweichen von sich selbst" bedeutete.

In den (deutschsprachigen) Literaturgeschichten taucht das Bogostroitel'stvo im Zusammenhang mit Gor'kij meist nur sehr schemenhaft auf, wenn überhaupt. So ist dort z.B. von einer "seltsamen Religiosität" die Rede, welche den Tenor von "Ispoved" ausmacht, von

jener Verehrung des "Volkes", die ihn um 1908 so sehr bewegte und die am eigentlichen Gor'kif (.....) so bef remdet, ...22) 
Nach dieser "als bogostroitel'stvo (gesp.)" bekannt gewordenen Religion müsse Gott erst durch das Volk "aufgebaut" werden. 23)

Ähnlich im Ungefähren bleibt Holthusens Feststellung anläßlich der Erwähnung von Gor'kijs "Italienischen Märchen" und "Beichte", daß nämlich

Gor'kijs Glaube an den Menschen manchmal einer geradezu religiösen zuversicht (gleicht), die kaum mehr aus dem Marxismus allein zu erklären ist. 24)

Nach Kluge 25) geht es auf der von Gor'kij mit Lunačarskij und Bogdanov gemeinsam geleiteten Parteischule von Capri (1909) unter anderem um Fragen des "religiösen Bewußtseins der Bauern" sowie um das "Wechselverhältnis von Christentum und Marxismus". Letzteres werde auch von Gor'kij in "Ispoved" " thematisiert. 26)

Etwas deutlicher wird auf das Bogostroitel'stvo und seine Umgebung in Darstellungen eingegangen, die sich entweder năher mit Gor'kif oder mit der zeit vor der Oktoberrevolution befassen. 27 )

In seiner Geschichte des Dialektischen Materialismus behandelt G.A. Wetter "Bogoiskatel'stvo" und "Bogostroitel'stvo" gemeinsam als zwei religiös orientierte Gruppen, die etwa gleichzeitig (Bogoiskatel'stvo etwa 1900 ff, Bogostroitel' stvo etwas später) aus dem Widerstand gegen den orthodoxen russischen Marxismus entstanden seien. ${ }^{28)}$ Das Zentrum der Gottsucher war die Petersburger "Religions-philosophische Geselischaft" mit Merezkovskij, Z. Gipius, Filosofov, Minskij, Berdjaev, S. Bulgakov, vj. Ivanov, V. Rozanov - z.T. ehemalige Marxisten - als wichtigsten Repräsentanten. 29)

Y'k: Während die Bogoiskateli von der Existenz eines transzendenten Gottes ausgingen und eine Erneuerung des landläufigen 
Christentums anstrebten, suchten die Bogostroiteli im Gegenzug nach einer Erneuerung des Marxismus russischer Ausprägung. 30) Die Gotterbauer "suchten" Gott nicht als schon existent, sondern wollten ihn "bauen", "verwirklichen" durch das Kollektivwerk der Menschheit. 31) Die Hoffnung auf Glück ("Forderung der praktischen Vernunft") dürfe auch vom wissenschaftlichen Sozialismus nicht ignoriert werden - hier gelte es ein religiöses Grundbedürfnis zu befriedigen.

Wetter stelit fest, $d a B$ es sich bei Lunacarskijs Lehre (Lunałarskij verwendet sogar christliche Symbolik: die Produktionskräfte - Gottvater; das Proletariat - Gottsohn; Wissenschaftlicher Sozialismus - Hl. Geist) um einen "religiösen Atheismus" im Sinne Feuerbachs handle: "Der Mensch ist sich selbst Gott." 32 )

L. Schapiro33) stellt das Bogostroitel'stvo im Zusammenhang mit den Auseinandersetzungen zwischen Lenin und Bogdanov als einem der führenden Vertreter des linken Flügels der Bol'seviki (Otzovisten/Ultimatisten) und gleichzeitigem führenden Kopf der Capri-Gruppe (LunaCarskij, Gor'kij) dar: Lunatarskij und die literarischen Mitglieder der Gruppe entwickelten eine Religion der Zukunft, einen pseudoreligiösen, proletarischen Mystizismus der 'Kollektivität', dem der Name 'Gottesbildnerei' beigelegt wurde. 34)

Die (partei)-politische Geschichte des Bogostroitel'stvo endet, so Schapiro35), mit Lenins "Materialismus und Empiriokritizismus" - einer eher polemischen als inhaltilchen Auseinandersetzung mit Bogdanovs Lehre.

$\mathrm{Zu}$ der Art von Lenins Auseinandersetzung mit der CapriGruppe schrieb Gor'kij im Juni 1909 an Bogdanovs Frau: 
Der Mensch ist ein Lump, .... Seine Auseinandersetzung über die Wahrheit wird nicht darum geführt, daß die Wahrheit triumphiert, sondern lediglich deswegen, um zu beweisen, "ich bin ein Marxist, ich bin der beste Marxist von allen!" 36 )

Lenins Buch erschien im Frühjahr 1909 und zeitigte seine praktischen Folgen im Juni desselben Jahres: Jetzt wurden auf einer Versammlung des Bol' Sevistischen Zentrums (erweiterte Redaktion des "Proletarij") unter Lenins Leitung "Otzovismus, "Ultimatismus", sowie die Lehren Bogdanovs und Lunatarskijs verurteilt und letztere aus der Fraktion ausgeschlossen. 37 )

Seine Informationen über das Bogostroitel'stvo selbst bezieht Schapiro aus Wetter, während dieser seine Kenntnis der Lehren Lunatarskijs aus sekundären Quelien, nämlich aus den Kritiken Lenins und Plechanovs speist. Damit ist auch die crux der (noch geltenden) Forschungslage im Westen allgemein gekennzeichnet: Darstellungen, die auf einer Lektuire der authentischen Texte basieren, gibt es bisher kaum. 38)

Dies gilt auch auf dem literaturwissenschaftlichen Bereich für Arbeiten, die sich mit dem Proletkult und seiner Vorgeschichte, zu der das Gotterbauertum gehört, oder allgemein mit derzeit vor 1917 befassen - sowie für Arbeit zu Gor'kij speziell.39) Das bisher gezeichnete Bild ändert sich kaum, sieht man davon $a b$, daß hier das Bogostroitel'stvo in selner Wirkung und Bedeutung für die Literatur (Gor'kij) betrachtet wird.

Meist findet Gor'kijs gotterbauerische Phase im Zusammenhang mit dem Roman "Ispoved" Erwähnung. So sieht z.B. H. Immendörfer im Nachwort zur deutschen Ausgabe das Gott- 
erbauertum als eine Antwort auf das Gottsuchertum, als eine "fünfte", "proletarische" Religion "ohne Gott". 40)

Hare ${ }^{41)}$ sieht in Rybin (Mat') eine immer wiederkehrende Figur des Gottbildners, das Bogostroitel'stvo wird jedoch nicht näher erwähnt, und die zeit der Capri-Schule sieht Hare als einen

Versuch Gor'kijs, seine Idee einer Allianz zwischen Intelligenz und einer Arbeiter-Bauern-Elite (die einzig RuBland retten könnte) in die Tat umzusetzen. ${ }^{42}$ ) Dieses erzieherische Experiment Gor'kijs war eng verbunden mit seiner Lieblingsidee, nämlich die moderne Religion aus dem würgegriff der etablierten kirchen zu befreien und der Führung normaler menschlicher Wesen zu unterstellen. ${ }^{43)}$

Annlich urteilt Borras ${ }^{44}$, der sich mit Gor'kijs Bogoströ̈tel'stvo etwas ausführlicher befaßt unter der vorgabe, daß Gor'kijs religlöse Bestrebungen ein Grundzug seiner Natur waren und bis zum Ende seines Lebens blieben. ${ }^{45}$ ) Der Zweck der Capri-Schule sei gewesen, ein religiöses Ideal mit einem revolutionären Plan zu vereinen. ${ }^{46}$ )

Eine mögliche Verbindungslinie zu Bogdanov zeigt sich für uns in Borass' abschließendem Urteil:

Er (Gor'kij) sah im Gotterbauertum ein wesentliches Instrument für die Veränderung der Menschen durch Erziehung.

Neben zahlreichen Artikeln über Gor'kij, die u.a. zeigen, daß dieser schon mit Beginn seines Bekanntwerdens im Westen als religiöses Phänomen rezipiert wurde ${ }^{48}$, befassen sich mit Gor'kij als religiösem Frager bzw. mit dem Bogostroitel'stvo am ausfürlichsten G. Kline, J. Scherrer, B.A. Kaleps, B.D. Wolfe. 
Während Kline zwar untendenziös darstellt, dafür aber für einige seiner wichtigsten Ausführungen bezüglich Gor'kijs Gotterbauertum die Belege schuldig bleibt (Gor'kij und Nietzsche) ${ }^{50)}$, verfügt $J$. Scherrer über die fundiertesten Kenntnisse der Texte der Bogostroiteli und inres Umkreises. 51)

Kaleps 52 scheint seine Informationen zum Gottbildnertum aus zweiter und dritter Hand zu haben ${ }^{53}$ und wiederholt, ebenso wie B.D. Wolfe $\mathrm{f4}^{5}$, das oben gezeigte sowjetische Rezeptionsmuster - spiegelverkehrt.

Auf die vier zuletzt genannten Abhandlungen soll hier nicht weiter eingegangen werden - sie werden ums im Hauptteil beschäftigen.

Fassen wir zusammen, welche Informationen uns ein überblick über die einschlägige Literatur zum Bogostroitel'stvo allgemein und $z u$ Gor'kijs Rolle darin verschaffen kann, so wissen wir folgendes:

Das Gotterbauertum ist eine philosophische strömung (allerdings mit politisch of fensichtlich brisanten Implikationen), welche zeitlich etwa zwischen 1906 und 1910, räumlich auf der Insel Capri anzusiedeln ist, dem damaligen Aufenthalt Gor'kijs. Die wichtigsten Vertreter dieser Richtung waren Lunačrskij, Bazarov, Bogdanov, Juśkevic und Gor'kij. Allesamt beanspruchten für sich das Prädikat "Marxisten". Sie suchten den Marxismus russischer Ausprägung unter $\mathrm{H}$ inzunahme moderner Denkweisen zu ergänzen und zu erweitern. (Mach, Avenarius, Nietzsche). Inr Sozialismus war von einem religiösen Pathos geprägt, das dadurch bedingt schien, daß sie der Frage des Emotionalen und Irrationalen im Menschen neuen Raum gaben. Sie formulierten einen neuen, immanenten Gottesbegriff und damit einen neuen Begriff von Religiosität: Im Mittelpunkt steht der kollektiv verstandene Mensch. 
Gor'kif gehörte zu dieser Gruppe ${ }^{55}$ ), bzw. stand (nach sowjetischem Muster) unter deren Einfluß. Seine Ausprägung dieser Ideen ist am deutlichsten in "Ispoved" und dem Aufsatz "Razrusenie licnosti" zum Ausdruck gekommen. Nach der einen (sowjetischen) Version handelt es sich hier um eine "Abirrung" Gor'kijs, nach der anderen Version kommt hier der "wahre" Gor'kif zu Wort.

Den Höhepunkt der Aktivitäten dieser Gruppe bildete die Parteilschule von Capri (1909). Im gleichen Jahr kam aber auch das (politische) Ende mit dem Ausschluß Lunacarskijs und Bogdanovs aus der Partei. Für Gor'kij selbst kam das Ende selner "Abweichung" erst 1913, als noch einmal eine letzte scharfe Auseinandersetzung mit Lenin stattfand. 56)

Aus dem bisher Gesagten dürte deutlich geworden sein, daß einerseits die Rolle, die Gor'kij innerhalb der Gruppe des Bogostroitel'stvo gespielt hat, sowie andererseits die Bedeutung, die diese Gruppe mit ihren Ideen für Gor'kij und sein Schaffen hatte, mit den bisher zur Verfügung stehenden Kenntnissen kaum klar zu bestimmen sind.

Daraus ergibt sich das Ziel dieser Arbeit: Eine (Neu-) Lektüre der einschlägigen Texte der Bogostroiteli soll zeigen, daß

1. das Bogostroitel'stvo als Ganzes nicht auf die zeit von 1907 - 1910 eingeschränkt werden kann (Lunałarskij beginnt seine Gedanken wesentlich früher zu formulieren, Gor'kif äußert noch lange nach 1913 gottbildnerische Gedanken.); daß

2. das Bogostroitel'stvo nicht nur als kleinbuirgerliche Abweichung innerhalb der russischen sozialdemokratischen Intelligenz gesehen werden kann, daß es vielmehr 
in ein allgemein (west-) europäisches Erscheinungsbild der Sozialdemokratie jener zeit im besonderen, aber auch der damals herrschenden geistig-religiösen Krise allgemein integriert werden muß; daß

3. Gor'kijs 'Abweichung' nicht allein durch den EinfluB Lunałarskijs und seiner Freunde erklärt werden kann. Gor'klj hat vielmehr selbst etwas zur religiösen Frage zu sagen und bringt seine eigene 'Tradition' mit. 57)

Hierbei wird allerdings die oft unterstrichene Bedeutung der Großmutter bei der Formierung von Gor'kijs Religiosität57a) kaum zur sprache kommen; denn die GroBmutter als Beispiel für eine naive menschenfreundliche volksreligiosität (im Gegensatz zum Großvater) wird erst in dem 1913 verfaßten ersten Teil der autobiographischen Trilogie ("Detstvo") 58 ) wirklich ausgestaltet. - Berücksichtigt man, daß dieser Zeitpunkt mit dem of fiziellen Ende der gotterbauerischen Phase bei Gor'kij zusammenfält, so erscheint die in "Detstvo" gestaltete Großmutterfigur als 'Quelle' für dessen religiöse Sensibilisierung wenig tauglich (die tatsächliche Großmutter mag eine solche Rolle durchaus gespielt haben) ${ }^{59)}$; man sollte vielmehr fragen, ob diese literarische Gestalt nicht erst auf dem Hintergrund von Gor'kijs Gotterbauertum und in dessen Fortsetzung ${ }^{60}$ ) inre volle Bedeutung erlangt und ganz verständlich wird. Und

4. sollen unter diesem Aspekt Schriften Gor'kijs - und zwar nicht nur die 'gotterbauerischen Standardwerke' neu gelesen werden. Dabei ergeben sich voraussichtlich Konsequenzen für eine differenzierte Beurteilung einiger Werke speziell, sowie allgemein für Gor'kij als vater des Sozialistischen Realismus.

Das Bogostroitel'stvo als Ganzes soll vor allem im Hinblick auf seine Bedeutung für Gor'kij zur Sprache kommen. Dazu wird allerdings eine ausführliche Darstellung der zentralen Gedanken des Gotterbauertums (v.a. Lunacarskijs) unerläßlich sein. 


\section{Anmerkungen}

1) Nadjeshda Ludwig, Maxim Gork1. ( = Schriftsteller der Gegenwart Bd. 23) Berlin 1968, S. 296.

2) ebd. S. $248 \mathrm{ff}$.

3) ebd. S. 148 .

4) ebd.

5) ebd. S. 149 .

6) ebd.

7) ebd.

8) ebd. S. 250 .

9) ebd. S. 151 .

10) Filosofskaja Ėnciklopedija, t. 1. M. 1960.

11) Stichwort "Gor'k1j" in Filosof skaja Ėnciklopedija; vgl. auch P.I. Sumarev, A.M. Gor'kif o religil. M. 1960, S. 4; 6 .

12) Vgl. In diesem Sinne: Russkaja literatura $x x$. veka. Dooktjabr'skif period. Kiev ${ }^{2} 1977$, S. 82f; BSE், StIww. "Gor'kij", "Bogostroltel'stvo", "Bogolskatel'stvo"; Istorifa russkof literatury, t. X. M.-L. 1954.

13) Boris Bjalik, Revolution und Kunst. Betrachtungen über die Bezlehungen zwischen Lenin und Gor'kij. Berlin-Weimar 1974; russ.: Vlastiteli dum 1 Cuvstv. V.I. Lenin 1 M. Gor'k1j. M. 1970.

14) ebd. S. $124 \mathrm{f}$.

15) ebd. S. $126 f$.

16) N. Ludwig, s. Anm. 1).

17) BSÉ, t. 6. M. 1927; vgl. Geschichte der KPdSU (B). Kurzer Lehrgang. Berlin 1946, S. $122 \mathrm{f}$. Hier 1st von den "sogenannten 'Gottsuchern' und "Gottbildnern'" die Rede. Bezeichnenderwelse wird der Name Gor'kljs bel der Aufzählung der Mitglieder der Gruppe "Bogostrolteli" ausgespart (S. 122); diese Gruppe habe, von "Verfallstendenzen und Unglauben erfaßt", den Marxismus" nicht of fen und ehrlich, sondern versteckt und heuchlerisch" 
einer Revision unterziehen wollen. (s. 122).

17a) Vgl. J. Kobetz, Maxim Gorkijs Gottsuchertum. In: Der Remter, 7 (1961), H. 6, S. 333-343.

18) E. Kosing und E. Mirowa-Florin (Hrg.), Lenin und Gork1. Eine Freundschaft in Dokumenten. Berlinweimar ${ }^{3} 1974$, S. $175 f$.

19) Ausnahmen in der sowjetischen Forschung bilden die Darstellungen von M. Laskovaja, Bogolskatel'stvo i bogostroltel'stvo prežde 1 teper'. M. 1972; sowle M.I. Schachnowitsch, Lenin und die Fragen des Athelsmus. Berlin 1966, S. $421 \mathrm{ff}$. Hier kommen die Quellen selbst zu Wort.

20) Z.B. G.A. Wetter, Der Dialektische Materialismus. Seine Geschichte und sein System in der Sowjetunion. Frelburg ${ }^{5} 1960$, S. $104 \mathrm{ff}$.

21) So z.B. B.A. Kaleps, Gor'kijs Glaube und seine verschiedenen Konflikte mit der Umwelt. Heldelberger Dissertation 1963;

B.D. Wolfe, Brücke und Abgrund. Wien, Frankfurt, Zürich 1970; Erich Felfel, Gork1 oder der "Proletarische Humanismus". In: Wort und Wahrheit (12) Frelburg 1961, S. 792-796; J. Kobetz, a.a.0.

22) Mirskif, Geschichte der russischen Literatur. München 1964, S. $353 f$.

23) ebd. S. 354 .

24) Holthusen, Russische Gegenwartsliteratur I. Bern 1963, S. 58 .

25) R.-D. Kluge, Vom kritischen zum sozialistischen Real1smus. München 1973, S. 165.

26) ebd.

27) Vgl.G.A. Wetter, a.a.O. S. lo4ff; J. Paech, Das Theater der russischen Revolution. Kronber $g / \mathrm{Ts}$. 1974, S. 31ff; L. Schapiro, Geschichte der kommunistischen Partel der Sowjetunion. Frankfurt 1961, S. $125 \mathrm{ff}$; Th.G. Masaryk, Rußland und Europa II. 
Jena 1913; R. Fülöp-M1ller, Gelst und Gesicht des Bolschewismus. Zürich 1928; H.-J. Lieber, Die Philosophie des Bolschewismus in den Grundzügen inrer Entwicklung. Frankfurt-Berlin-Bonn ${ }^{3} 1961$, S. 43ff; P. Gorsen und E. Knödler-Bunte, Proletkult Bd. 1. Stuttgart-Bad Cannstadt 1974, S. 35f f; H. I mendörffer, Nachwort zu M. Gork1, Foma Gordejev, Elne Belchte, Das Werk der Artamonovs. München 1978 , S. 82 off.

Für alle diese Auslassungen, sowelt sle das Bogostroltel'stvo betreffen, muß elnschränkend gesagt werden, daß dieses immer im Rahmen der Auseinandersetzungen um Bogdanovs Empiriomonismus und damit um den Einfluß des Machismus auf den linken Flügel der RSdAP erwähnt wird. Diese Sicht wiederholt aber nur aufs neue das Muster der Rezeption von Empiriomonismus und Gotterbauertum durch Lenin, welcher (eher aus parteltaktischen denn aus inhaltilchen Gründen) die Ideen Gor'kljs und Lunacarskifs als Ausfluß von Bogdanovs idealistischer Schwarmere 1 verstanden wissen wollte.

28) Wetter, a.a.0.S. $104 \mathrm{ff}$.

29) Dazu ausführlich: J. Scherrer, Die Petersburger Religiös-Philosophischen Vereinigungen. Berlin 1973 (= Forschungen zur osteuropaischen Geschichte Bd. 19); dsl., Die russischen religiös-philosophischen Vereinigungen als Ausdruck des religiösen Suchens der Intelligencija. In: Forschungen zur Osteuropäischen Geschichte Bd. 20; dsl., Intell1gencifa, Religion, Révolution: Premières manifestations d'un soclalisme chrétien en Russe, 1905-1907. In: Cahiers du Monde Russe et Soviétique Vol. XVII (1976), 4 und XVIII (1977), 1. u. 2.

30) D.h. In selner Ausprägung durch Plechanov als den Repräsentanten des orthodoxen russischen Marxismus. 
31) Wetter, a.a.0. S. 105.

32) ebd.

33) Vgl. Anm. 27).

34) Schapiro, a.a.0. S. 126.

35) ebd. S. 127.

36) Zit. nach G. Haupt und J. Scherrer, Gor'kij, Bogdanov, Lenin. In: Cahiers du monde russe et soviéthique. Vol. XIX (1978), 3, S. 328 .

37) Zu der Frage, wieweit es sich hier um einen politischen schachzug Lenins handelte, mit dem dieser seinen 'Rivalen' ausschalten konnte, vgl. Grille, Lenins Rivale. Bogdanov und seine Philosophie. Köln 1966, S. $205 f f$.

38) Ausnahmen bilden die erwähnten Darstellungen von Scherrer und Grille.

39) Gorsen und Knödler-Bunte, a.a.0.; J. Paech, a.a.0.; B.D. Wolfe, a.a.O.; Kaleps, a.a.O.; R.-D. Kluge, a.a.0.; ders., Die Mutter. In: B. Zelinski (Hrg.), Der Russische Roman. Düsseldorf 1979; J.-U. Peters, Kunst als organislerte Erfahrung. Über den Zusammenhang von Kunsttheorie, Literaturkritik und Kulturpolitik bei A.V. Lunacarskij. Konstanzer Habil.Schrift (unveröff.) O.J.; R. Hare, Maxim Gorky. London 1962; Borras, Maxim Gorky. Oxford 1967; $G$. Kline, Religlous and anti-religious thought in Russia. Chikago-London 1968.

40) H. Immendörffer, a.a.O. S. 821 .

41) Hare, a.a.O. S. 74.

42) ebd. S. 79.

43) ebd.

44) Borras, a.a.0. S. $55 \mathrm{ff}$.

45) ebd. S. 56.

46) ebd.

47) ebd. S. 57. Unterstr. v.m.; Diese Verbindung bleibt in fast allen Darstellungen wenig plausibel und beschränkt sich melst auf die Fest- 
stellung, Bogdanov sel der führende Kopf der Capri-Gruppe gewesen, zu der auch Gor'kij gehörte.

48) Literatur dazu im Text weiter unten.

49) Vgl. Anm. 39).

50) Siehe in dieser Arbeit die Kapitel über Lunacarskij/Gor'kif und Nietzsche. (IV.,4. und V., 7).

51) J. Scherrer bereitet eine Arbeit über den Fragenkomplex Bogdanov-LunaCarskij-Gor'kij-Lenin in größerem Rahmen vor.

52) S. Anm. 21).

53) Darauf weisen die z.T. unkorrekte Wledergabe von Zitaten/Literaturhinweisen sowle die spärliche Verwendung von Originaltexten hin.

54) S. Anm. 21).

55) Ich spreche hier bewußt noch von einer "Gruppe", da seit Lenins Polemik von den "Gotterbauern" immer als elner solchen die Rede ist. Im Zuge der Beschaftigung mit dieser Problematik haben sich jedoch die Zweifel daran verdichtet, daß man überhaupt von "den" Bogostrolteli sprechen kann. Auch hier scheint - in der sowjetischen wie in der westlichen forschung - die Perpetulerung eines von Lenin vorgeprägten Rezeptionsmusters vorzullegen.

56) Sehr anschaulich dokumentiert in: Lenin und Gork1.

57) Dabel ist vor allem an das Narodnicestro zu denken, wie es von Bervi-Flerovskif repräsentiert wird. Hier liefert M.I. Schachnowitsch, Lenin und die Fragen des Atheismus, einiges Material, zieht aber nicht die notwendigen Schlüsse daraus. Die Ansicht, daß Gor'kij seine eigene Tradition in das Gotterbauertum mit einbringt, bzw. auf 
"eigenen Wegen" dorthin gelangte, schafft sich in letzter zeit auch in der sowjetischen Forschung Raum: N.A. Trifonov, A.V. Lunacarskif i M. Gor'kij. In: (Sbornik) Gor'kif $i$ ego sovremenniki. Leningrad 1968, S. 110-157.

57a) Z.B. sient B.D. Wolfe, a.a.O. S. 36, in der Großmutter die Urheberin für Gor'kijs "zartes Verhältnis zu Gott". Vgl. auch Borras, a.a.0. S. 23; Hare, a.a.0. S. 9; Felfel, a.a.O. S. 793; Kobetz, a.a.O. S. 334. Bezeichnenderweise wird in der sowjetischen forschung bisweilen genau spiegelverkehrt vorgegangen: Die Darstellung des unmenschlichen Großvater-Gottes dient zum Beweis für Gor'kijs in frühester Zeit beginnenden Atheismus und Kampf gegen die Religion. Vgl. P.I. Sumarev, a.a.O. S. 7ff.

58) In den ersten autobiographischen Entwirfen Gor'kijs (Izloženie faktov 1 dum; Biografija - PSS, 1, S. 451-476) finden wir zwar auch schon eine Gegenüberstellung von Großvater und Großmutter; fedoch hat hier der religiöse Aspekt nicht annähernd die Bedeutung wie in "Detstvo".

59) Gerade auch in diesem Zusammenhang muß die westliche wie die sowjetische forschung die Einsicht Muratovas beherzigen, daß Gor'kifs autoblographische Texte nicht nur als Erinnerungen zu lesen seien, sondern daß man auch den Zeitpunkt inrer Niederschrift in Anschlag bringen müsse. Möglicherweise setze Gor'kif in diesen Texten seine Polemik gegen die mesčanstvo-Literatur fort. (K.D. Muratova, M. Gor'kif na Kapri. 1911 - 1913. L. 1971, S. 85f.).

Es wird sich zeigen, daß das Bogostroltel'stvo Gor'kifs eben in diesem seinem Kampf gegen das mescanstvo zu sehen ist.

6o) Die Religiosität der Großmutter ist von derselben Art wie die Larions und Savelkas in "Ispoved" ; s. Kap. VI, 2,). 
II. Überblick

\section{Der Name}

Sieht man die ritel der Schriften durch, die mit dem Gotterbauertum in Verbindung gebracht werden, so wird man feststellen, daß der Name "Bogostroitel'stvo" selbst mit wenigen Ausnahmen so gut wie nie auftaucht. Die Tatsache, daß Bazarov in seinem Aufsatz von $1909^{1)}$, also $\mathrm{zu}$ einem Zeitpunkt, als der streit um das Bogostroitel'stvo auf seinem Höhepunkt angelangt war, diesen Begriff im Gegensatz zu Bogoiskatel'stvo in Anführungszeichen setzte, mag darauf hinweisen, daß selbst für "die Gotterbauer" diese Bezeichnung durchaus nicht selbstverständlich, möglicherweise nicht einmal für alle akzeptabel war. 2)

Geht man der Frage nach, wo dieser Begriff zum erstenmal Verwendung findet, stößt man auf Gor'kij als Namensgeber: Am Ende von "Ispoved" heißt es von den Menschen, denen sich Matvej, der Held von "Ispoved", anschließt, daß sie die Seelen inrer Nächsten aus der Gefangenschaft des Dunkels und des Aberglaubens befreien,... daß sie

das Volk zu einem Ganzen sammeln, (...), ihm helfen, sich der stärke seines willens bewußt zu werden,... und

den Menschen den einzigen, den wahren weg weisen zu der Vereinigung (slijanie) aller um der großen Sache - des universalen Gotterbauertums - willen (vsemirnogo bogostroitel'stva radi)!.3)

Was Gor'kij genau unter diesen Namen $f a ß t$, wird erst nach einer Analyse des ganzen Romans und anderer Texte Gor'kijs 
deutlich zu machen sein. Hier genügt der Hinweis darauf, daß das, was er unter "Bogostroitel'stvo" versteht, in der allernächsten Nähe der Ideen anzusiedeln ist, die Lunacarskij in "Buduscee Religii" und "Religija i socializm"4) verkündete. Für den Zugang zu dem Phänomen, für welches Gor'kif einen Namen gefunden hat, sowle zur Aufhellung seines geistigen und geschichtlichen Hintergrunds, ist eine erste sichtung und Charakterisierung der Schriften der "Gotterbauer" notwendig.

2. Die Schriften des Gotterbauertums und inr geistesgeschichtlicher Kontext (Chronologie)

Bereits 1898 hält Lunačarskij in Klev ein Referat mit dem Titel "Idealizm i Marksizm", in welchem er nach seinem eigenen Zeugnis" zum ersten Mal das Thema: Sozialismus und Religion behandelt. In diese zeit fällt auch die Konzipierung von "Religija i Socializm" in Grundzügen. 6)

1904 erscheint (bereits in zweiter Auflage) der Sammelband "Ocerki realisticeskogo mirovozzrenija". 7)

In diesem Sammelband finden wir bereits einen Hinweis auf den gesellschaftlichen und geistesgeschichtlichen Kontext, in welchem die Geschichte des Bogostroitel'stvo zu sehen ist, bzw. die Akteure selbst sie sehen:

"Unser Land erlebt eine schwere Krise."8) Es wird auf die Konflikte zwischen den $\mathrm{Klassen}$ und verschiedenen Interessengruppen verwiesen. Im Kreis der Adressaten dieses Sammelbandes (nicht allein dort) - nämlich unter der "Arbeiterintelligenz" (intelligentnyj proletariat/proletarskaja intelligencija) - besteht nach Meinung der Autoren ein starkes Bedürfnis nach einer (Erkenntnis-) Theorie, die das Bewußtsein für den Kampf mit der Realität, für das 
Bestehen der "Lebenskrise" 9 ) fähig macht. Als Instrument für den Kampf soll hier eine Philosophie der Aktivität, des Lebens - kurz, eine "Realistische Weltanschauung"10) entwickelt werden. Was an einer solchen Weltanschauung "realistisch" ist, bleibt einigermaßen unklar. 11) Deutlich wird allerdings, daß das "Leben", seine steigerung und Bejahung, den obersten Wert darstellt, in dessen Dienst Theorie und Weltanschauung genommen werden. (Realistisch mag diese gesuchte Theorie insofern sein, als die "Realität", die Praxis des Lebensvollzugs, das oberste Kriterium abgibt.): "Realismus" wird als "reiner Idealismus der Erkenntnis" (とistyj idealizm poznanija), als "monistisches Ideal der Erkenntnis" (monisticestkij ideal poznanija) gekennzeichnet. Für inn gelte nur die "reine Wahrheit" als Erkenntniskriterium. 12)

Der Realismus ist einheitlich wie die Wahrheit, aber zugleich, wie die Wahrheit, vielseitig. Im vorliegenden Buch wird der Leser vielerlei Nuancen und Vorgehensweisen des realistischen Denkens antreffen; aber diese vielgestaltigkeit wird inn nicht daran hindern, sehr deutlich hinter ihr die grundlegende Einheit zu sehen - die Einheit der Tendenz zum Leben (ziznenaja tendencija). 13)

In diesem Sammelband bemüht sich Lunararskij zum ersten Mal explizit, eine Verbindung zwischen Religion, Religiosität und religiösem Bedürfnis einerseits und wissenschaftlichem Sozialismus, Marxismus andrerseits herzustellen.

Ebenfalls 1904 veröffentlichte Bogdanov einen Aufsatz "Sobiranie celoveka", ${ }^{14}$ ) dem er als Motto drei Zitate voranstellt: 
Gott hat den Menschen nach seinem Bild geschaffen. (Bibel)

Das gesellschaftliche Sein bestimmt das Bewußtsein des Menschen. (Marx)

Der Mensch ist die Brücke zum Übermenschen. (Nietzsche) 15 )

Die Zusammenstellung dieser drei Zitate deutet an, was Lunacarskij im Vorwort $z u$ seinen "Etjudy"16) expliziert: Als mangelhaft am bisher rezipierten Marxismus wird empfunden, daß er lediglich die Kategorien für die Beschreibung des Funktionierens von Gesellschaft bereitstellt. Auch für eine neue Gesellschaft kann er nur die Bedingungen inrer Möglichkeit beschreiben. Der Entwurf eines zukunftsträchtigen Menschenbildes wie überhaupt eine zukunftsbezogene Dynamik wird aus anderen Bereichen bezogen. (Bibel, Nietzsche) 17 )

Diese Aufsatzsammlung Lunačarskijs erscheint 1905 unter dem Titel "Ėtjudy kritiŁeskie 1 polemiとeskie". 18) Hier wird der Horizont, vor welchem die Fragestellungen und Bemühungen der Bogostroiteli, den Marxismus zu überdenken, zu sehen sind, noch etwas deutlicher: Lunacarskij schickt voraus, daß er bereits mit 17 Jahren (1892) mit dem Marxismus bekannt geworden und seither überzeugter Marxist geblieben sei. Für inn sei aber der Marxismus nicht nur eine gesellschaftliche Doktrin, sondern eine "ganze Weltanschauung" (celoe mirosozercanie).19)

Jedoch

auf einige Fragen fand ich keine unmittelbare Antwort in der marxistischen Literatur. 20)

$\mathrm{Zu}$ diesen Fragen gehörte die nach der Rolle von Bewußtsein und Erkenntnis:

Lunatarskij stellt fest (und kritisiert), daß in der (ortho- 
doxen) marxistischen Wissenschaft der Mensch immer nur als "Objekt" auf taucht, als "Transmissionspunkt" (peredatoknyi punkt) 21) für außerhalb seiner und unabhängig von inm wirkende Kräfte. Dem entgegen stellt Lunatarskij die Frage nach dem erkennenden und seiner selbst bewußten subjekt (soznanie, poznanie). 22) Hier erfolgt der Griff zu der "biologistischen Erkenntnistheorie"23) Machs und Avenarius', die

sich ohne Zwang an die Wahrheiten des Marxismus anschließen lassen würde. ${ }^{24)}$

Ein weiteres Gebiet, auf welchem der Marxismus nach Lunaとarskij einer Ergänzung bedarf, ist das der Ethik und Moral; Lunacarskij nennt hier die "Frage nach der Wertung" (ocenka):

Alle menschlichen Wertungen (ocenki) standen vor mir als Weiterentwicklungen und Variationen einer Grundwertung, deren wurzel der Lebenshunger (žažda żizni) (gesp.) ist. ${ }^{25)}$

Die Frage nach den Bewertungen führt Lunacarskif auf einen dritten Fragenkomplex, der mit den vom Marxismus zur verfügung gestellten Kategorien allein nicht zu lösen ist: die Ästhetik. 26)

Eine weitere Aufsatzsammlung, die in diesen Bereich gehört, veröffentlicht Lunacarskij 1906:"Otkliki zizni".27)

Im selben Jahr erscheint Gor'kijs Roman "Mat". Hier wird zum ersten Mal in epischer Form das "Gotterbauertum" thematisiert und zentral.

Gor'kijs wichtigste und in dieser Form einzige theoretische Äußerung zum Thema Sozialismus und Religion kommt von ihm im März 1907: als Antwort auf eine Enquête des "Mercure de France" . 28) 
Im Herbst desselben Jahres faßt Lunacarskij seine Vorstellungen vom Wissenschaftichen Sozialismus als einer Religion erstmals systematisch zusammen in dem Aufsatz "Budustee Religii"29):

Es muß ein lebendiger Gott sein, allen Glück bringend und allmächtig. Wir erbauen ihn. (...)

Der Wissenschaftliche Sozlalismus ist die religiöseste aller Religionen und der echte Sozlaldemokrat eln tiefreligiöser Mensch. 30 )

Im gleichen Jahr versucht Bogdanov seinen Vorstellungen von einer kollektiv organisierten Gesellschaft, die auf der Basis von kollektiver Erfahrung, Solidarität und "kameradschaftlicher zusammenarbeit" funktioniert, literarische Form zu geben: in dem utopischen Roman "Krasnaja zvezda" (Der rote Stern).

1908 erscheint der Sammelband "OCerki po filosofil Marksizma. Sbornik. 31)

Im Vorwort geben sich die Autoren den Rahmen inrer gemeinsamen, wenn auch voneinander abweichenden überlegungen: Alle verstehen sich als Marxisten: sie sehen sich einig in der Auffassung, daß für elne Umwälzung der Gesellschaft nicht nur sogenannte "praktische Reformen" genügen - vielmehr müsse der angestrebte Sozlalismus auch den "höheren Bedürfnissen des menschlichen Geistes" genügen ${ }^{32)}$ : dem "neuen Typus gesellschaftlichen Lebens" müsse auch ein neuer Typus des Denkens entsprechen. ${ }^{33}$ )

Weiterhin wird der Anspruch betont, "progressiv" erscheinende Erkenntnisse/Methoden der exakten Wissenschaften ( = Naturwissenschaften) dem Marxismus anzueignen.

Dies bedeutet zugleich eine Kritik an "dogmatischen" Vertretern des Marxismus, die aus bestimmten Denkformen des 
Marxismus "Fesseln" gemacht hätten und die Weiterentwicklung verhinderten: d.h. sie

erweltern nicht die Sphäre der menschlichen Macht über die Natur und die Gesellschaft, sondern fixieren sie auf einer schon erreichten und von der Erkenntnis überschrittenen stufe. 34 )

Zugleich geht die Kritik auch nach der "andern Seite", d.h. gegen gängige Tendenzen, mit "Methoden, die jenseits der Vernunft liegen" auf Natur und Gesellschaft einzuwirken. 35)

Weiter erscheinen in diesem Jahr die Sammelbände "Literaturnyl raspad. Sbornik" I u. $2^{36)}$;

In diesen Sammelbänden findet auf den oben genannten Grundlagen eine Auseinandersetzung über den Zerfall der Literatur statt, wie er sich für die Autoren in der Literatur der "Moderne" zeigt. "Krise des Individuums" - so lautet das Stichwort.

Von P. JuskeviC erscheint im gleichen Jahr "Materializm 1. kritiCeskij realizm" $^{37)}$; und von M. Gor'kij: "Ispoved". Povest'".

"Der Gottschöpfer - das ist das Volk".38)

von Lunacarskij: Religija i socializm. I. (Der zweite Band erscheint 1911).

Lunatarskijs Grundidee in diesem Buch, das seine "gotterbauerischen" Vorstellungen sammeln und systematisieren soll, ist

Erforschung der Wechselbeziehung zwischen Sozialismus und Religion;

die Ortsbestimmung des Sozialismus unter den andern religiösen systemen. ${ }^{40)}$

In diesem Jahr beginnt auch die ausführliche Auseinandersetzung Lenins mit dem Gotterbauertum und dessen Vertretern: ("Marxismus und Revisionismus", "Materialismus und Empiriokritizismus"). 
Zwei weitere Sammelbände erscheinen 1909:

"Ocerki filosofii kollektivizma. I" ${ }^{41)}$ und "Versiny. I".42)

Wieder ist hier von der allumfassenden politischen und gesellschaftlichen Krise die Rede; von der bedeutenden Rolle, die dem Proletariat bei der Veränderung der Gesellschaft zukommt, und von der Notwendigkeit, inm ein(e) "celostnoe mirovozzrenie" (Monismus), eine bis zum Schluß konsequent durchgehaltene Methode und Ideologie zur Verfügung zu stellen. Für seine Praxis brauche das Proletariat einen einheitlichen Standpunkt gegenüber dem Leben. ${ }^{43}$ )

Es gehe um einen

"entschiedenen Kollektivismus, welcher eine Philosophie der Arbeit und der Vereinigung (Ob'edinenie), eine Theorie der sozialen Aktivität und der aktiven Sozialität (social'nost') ist.44)

In "Veršiny" Bd. I befaßt sich Bazarov mit der Auseinandersetzung zwischen Bogostroitel'stvo und Bogoiskatel'stvo in dem Aufsatz "Bogoiskatel'stvo i Bogostroitel'stvo". 45) Auch in diesem Band geht die Rede von einer politischen, sozialen und in deren Gefolge "schweren ideellen Krise"; vom Verlust "leitender Gesichtspunkte", von einem fleberhaften suchen nach orientierung. ${ }^{46}$ )

Um mit der Lebenskrise fertig zu werden, müsse das "Gedankenchaos" überwunden werden. ${ }^{47)}$ In diesem Sinne versteht sich "Verకiny" als eine Diskussionstribüne, die nicht von vornherein für einen der widerstreitenden Marxismen stellung bezieht. ${ }^{48}$ )

Ebenfalls in diesem Jahr (1909) findet auf Capri die vieldiskutierte und von Lunačarskij, Bogdanov und Gor'kij organisierte Parteischule statt. Ende des Jahres wird die Schule als unzulässige Fraktionsbildung von einem erweiterten Redaktionskomitee des "Proletarij" unter Lenins Leitung 
verurteilt; zugleich werden Bogdanov und Lunaxarskif aus der Partel ausgeschlossen. ${ }^{49)}$

1913 führen die beiden Artikel Gor'kijs "O karamazovకčine" und "Este o karamazovstine", die allerdings in späteren Ausgaben von den "gottbildnerischen" Äußerungen gereinigt sind, zum Höhepunkt der Auseinandersetzung zwischen Lenin und Gor'kif über dessen Gotterbauertum. ${ }^{50)}$ Lenins Haltung ist gekennzeichnet von dem Versuch, die Diskussion aus den Publikationsorganen der Sozialdemokratie auf Nebenschauplatäze zu verlagern und gleichzeitig Gor'kif als Publizisten und Schriftsteller für die Bo'lseviki zu retten. 51)

Bogdanov veröffentlicht in diesem Jahr seinen zweiten utopischen Roman "Inžener Menni", der die Vorgeschichte des "Roten Sterns" aufgreift und die Herausbildung und Durchsetzung des kollektivgedankens und einer "proletarischen Wissenschaft" beschreibt. (Marx-Xarma als Wissenschaftler, der zwar die Mechanismen und Gesetze der Gesellschaft erkannt hat, dessen system aber noch der weiterentwicklung durch Menni-Bogdanov bedarf.)

1913 endet die offizielle Geschichte des Gotterbauertums, die Diskussion über eine Weiterentwicklung des Marxismus auch mit religiösen Kategorien bricht ab. Allerdings lebt das Gotterbauertum in anderen Formen weiter: $\mathrm{Zu}$ denken ist dabei vor allem an den proletkult, der ja schon durch die Person Bogdanovs mit dem Bogostroitel'stvo direkt und personell verknüpt ist. Der zweite Hauptakteur dieser Gruppe, Lunackarskif, wird später Volkskommissar für Aufklärung - und Gor'kif wird zum Stammvater des Sozialistischen Realismus. Die Vermutung, daß Ideen oder zumindest deren Reflexe aufgrund personeller Kontinuität in veränderter Form oder unter anderen Namen weiterleben, liegt nahe und wird sich für das Gotterbauertum einigermaßen erhärten lassen. 
Der hier erfolgte Überblick über die Veröffentlichungen der "Bogostroiteli", die Themen der Aufsätze und die zielsetzungen in den verschiedenen Vorworten vermögen schon in etwa aufzuzeigen, wo der Fragehorizont zu suchen ist, vor dem die Geschichte des Gotterbauertums abläuft. Auffallend sind die stichworte:

"(realistische) Weltanschauung"

"Philosophie des Lebens"

"schwere Krise" - "Lebenskrise"

"monistisches Ideal der Erkenntnis"

"Tendenz zum Leben" - "Lebenshunger"

"Erkenntnis - Bewußtsein"

"Sozialismus, die religiöseste aller Religionen"

"Never Typus des gesellschaftlichen Lebens - neuer Typus des Denkens"

"Religion und Sozialismus"

"Zerstörung der Persönlichkeit"

"Mescyanstvo und Individualismus"

"Kollektivismus - soziale Aktivität"

usw. - Schon diese unsystematische Zusammenstellung macht deutlich:

Der Versuch, im Marxismus religiöse Elemente zu erkennen bzw. Ihn zur höchsten Religion zu erklären, ist gekoppelt mit der Erkenntnis, daß eine umfassende Krise (des Bewußtseins) es notwendig macht, sich auf die suche nach einer Weltanschauung zu begeben, die diese krise zu überwinden vermag. Die Betonung des Bedarfs an einer "einheitlichen" monistischen Weltanschauung signalisiert eine allgemeine orientierungslosigkeit.

Gleichzeitig macht sich ein Unbehagen von Marxisten am Marxismus bemerkbar: Lunacarskij hat es am deutlichsten ausgedrückt. Der orthodoxe Marxismus ist nicht mehr in der Lage, auf alle anstehenden Fragen Antwort zu geben. Juskevic diagnostiziert also richtig: 
Das Interesse an der Philosophie, das unlängst unter den russischen Marxisten begonnen hat, sich zu beleber, wächst weiter. Immer mehr und mehr wird die Notwendigkeit einer überprüfung (peresmotr) der traditionelien Position des wissenschaftlichen Sozialismus in Fragen der Weltanschauung erkannt. 52)

Aligemein läßt sich der Rahmen des Bogostroitel'stvo schon: jetzt etwa so abstecken:

Bemühen um eine neue (monistische) Weltanschauung und damit verbunden um eine Erkenntnistheorie, die die neuesten Errungenschaften der Naturwissenschaften berücksichtigt und gleichzeitig zur Aktivität (Philosophie des Lebens) fünrt.

Sodann der Versuch, mit der Konzipierung einer solchen Weltanschauung dem religiösen Bedürfnis des Menschen Rechnung zu tragen. Deutlich wird dabel, daß überhaupt der Mensch in seinem Lebensvollzug mehr ins Blickfeld rückt. Zugleich soll damit offensichtlich auch eine eigenständige marxistische Antwort auf ein allgemeines religiöses Bedürfnis gefunden werden. Die Aktivitäten der Religionsphilosophischen Geselischaften stellen eine Herausforderung dar. Das Suchen nach religlöser Erneuerung scheint so allgemein zu sein, daß es von den Marxisten nicht unberücksichtigt bleiben kann. 53 )

Falsch wäre es allerdings, das Bogostroitel'stvo nur als eine Reaktion auf das Bogoiskatel'stvo zu werten. 54 )

Bogostroitel'stvo und Bogoiskatel'stvo scheinen die beiden Möglichkeiten ideologischer Neuorientierung darzustellen, zwischen denen die (linken) Intellektuellen Rußlands in der zeit kurz nach der Jahrhundertwende zu wählen hatten. Diese Vermutung liegt jedenfalls nahe, wenn man sieht, daß ein großer Tell der Gottsucher sich aus den Reihen 
früherer ("legaler") Marxisten (P.B. Struve, S.L. Frank, N.A. Berdjaev, S. Bulgakov) rekrutierte; daß diese also z.T. den gleichen Ausgangspunkt hatten wie die späteren Gotterbauer.

Auch das Bogoiskatel'stvo nahm, wie das Bogostroitel'stvo seinen Ausgang an der Jahrhundertwende von einem Unbehagen, einem Gefühl des Ungenügens des Positivismus und Marxismus (Materialismus) in geistigen, moralischen und ästhetischen Fragen; d.h. hinsichtlich der Problematik von Individualităt und subjektivität. Und ebenso fand es seine endgültige Gestalt in den Jahren nach der Revolution von 1905.

Der Weg der früheren Marxisten im Gottsuchertum führte über eine Wendung zum Idealismus (um die Jahrhundertwende) zu einer (christlich-orthodox orientierten) Religionsphilosophie. (Die zweite - eher literarisch-ästhetische Quelle, aus der sich das Bogoiskatel'stvo speist, wird am deutlichsten durch Z. Gippius und D.S. Merezkovskif repräsentiert.)

Während die "Bogostroiteli" eine Neubelebung des marxist1schen Gedankens durch eine Revision und eine öffnung für neue Erkenntnisse der Wissenschaften $z u$ errelchen hof $f$ ten (und zugleich durch eine Rückbesinnung auf menschliche Grundbedürfnisse), erhofften sich die Bogoiskateli eine Erneuerung der gesamten Gesellschaft durch eine Rückbesinnung auf die positiven werte in der geistigen rradition Rußlands (slavophilentum, Gogol', Dostoevskij, Tolstoj, Solov'ev allgemein und durch eine Erneuerung des christlichen Gedankens. Dem rationalistischen, aktivistischanthropozentrischen Modell der "Bogostroiteli" steht also $*$ ein metaphysisches, an der christlichen offenbarungsreligion orientiertes Modell der "Bogoiskateli" gegenüber. 
Die Gottsucher wie die Gotterbauer ${ }^{55)}$ sahen sich an zwei Fronten kämpfend:

gegen das offizielle Regime, die Reaktion, sowie gegen die offizielle revolutionäre stimmung, gegen den nihilistischen "Hooliganismus" in der Revolution, da in beiden Fällen die Menschen durch die Reiche von dieser Welt in Versuchung geführt würden. 56)

Eine echte Befreiung ist nach Berdjaev nur durch den Glauben an Christus möglich. Er greift dabei Solov'evs Formel auf: Vor Christus bewegte sich die welt auf den "Gottmenschen" $2 u$, nach Christus bewegt sie sich in Richtung auf die "Gottmenschheit". 57)

Außerlich fand das Bogolskatel'stvo seine Gestalt in den verschiedenen Religiös-philosophischen Gesellschaften und Diskussionszirkeln in Petersburg, Moskau und Kiev. Ebenso wie die Bogostroiteli hatten sie inre Publikationsorgane und gaben ihren Diskussionen die Gestalt von Sammelschriften. 58)

Wichtig für unseren zusammenhang ist an dieser kurzen Charakteristik des Gottsuchertums, $2 u$ sehen, daß die Beschäftigung mit der 'religiösen' Problematik in dieser zeit in Rußland nicht auf die Gotterbauer beschränkt war, sondern in der russischen Intelligenz jener zeit allgemein breiten Raum einnahm.

Ebenso läßt die 'Chronik' der Ereignisse den Schluß 24 , daß Bogoiskatel'stvo und Bogostroitel'stvo nicht einfach als eine Reaktion auf das Scheitern der Revolution von 1905 zu erklären sind. Dafür spricht einerseits die Beobachtung, daß die Wendung zu religiösen (moralischen, ästhetischen) Fragen in der russischen Intelligenz schon um die Jahrhundertwende begann und daß sich Bogolskatel'stvo und 
und Bogostroitel'stvo - z.T. vom gleichen Ausgangspunkt her - gleichzeitig entwickelten. (Lunatarskij und Berdjaev als Beispiel). - Eine allgemeine Müdigkeit am 'grauen Materialismus' der positivistisch orientierten Industriegesellschaft und der Gründerjahre war eingetreten.

Und andererseits, was noch wesentlicher für eine angemessene Beurteilung ist, war die Tendenz zu einer religiösen Neubesinnung keineswegs auf Rußland beschränkt. Vielmehr liegt es nahe, daß die geistigen Verhältnisse in Rußland ein Teilphänomen der gesamteuropäischen situation sind.

In diesem Sinn stellt einer der Akteure, Bazarov, 1909 in dem schon erwähnten Artikel "Bogoiskatel'stvo i Bogostroltel'stvo"59) fest, die "Wendung vom Freidenkertum zum Glauben" habe sich schon lange vor der Revolution von 1905 in der radikalen politischen Intelligenz abgezeichnet.60)

Gerade damals ${ }^{61)}$ am Beginn unseres Jahrhunderts, begann eine eilige Emanzipation von den "absterbenden" Doktrinen (mertvjascich) des Positivismus und des Materialismus. 62)

Die "religiöse Suche" sei nicht nur Echo und Ausdruck der Reaktion nach 1905, sondern allgemeiner Ausdruck des "Zerfalls der kulturellen Werte". Dieses Phänomen lasse sich nicht allein mit den russischen Verhältnissen erklären es sel vielmehr Echo elner weltweiten kulturellen Krise:

Die mindere Bewertung der kulturelien Güter des Lebens und das damit verbundene religiöse Verlangen ist in der westeuropäischen Gesellschaft mit nicht geringerer stärke zu beobachten als in der russischen. ${ }^{63}$ ) 
Bazarov resümiert:

Von dem wachen, lebensf rohen Materialismus, der in der europäischen Bourgeoisie vor einem halben Jahrhundert herrschte, ist keine spur geblieben. 64)

Mit welchem Recht kann sich Bazarov bei seiner Diagnose auf eine allgemein-europäische Erscheinung berufen; gibt es so etwas wie eine "europäische Krise des Geistes" und eine allgemein-europäische "religiöse Suche", die die Kulisse abgeben für das Schauspiel, das sich uns in Rußland bietet?

Im Jahre 1907 führte der "Mercure de France" eine internationale Umfrage durch, deren Ergebnisse unter dem Titel "La Question Religieuse" in der ersten Märznummer veröf fentlicht wurden. 65 )

Im Vorspann $z u$ eingegangenen Antworten vorangestelit stellt F. Charpin fest:

Es ist unleugbar, daß die religiösen Studien während der letzten Jahre eine außerordentliche Entwicklung genommen haben; niemals, vielleicht, seit der Reformation hat man soviel Interesse für alles, was die Religion betrifft, gezeigt, soviel Mühe für Forschung, Kritik und Propaganda verwandt. ${ }^{66}$ )

Charpin erinnert an die zunehmende Beschäftigung mit religiösen Problemen an den verschiedenen französischen Hochschulen, stellt dann aber fest:

Während wir dieses Interesse und diese Arbeit auf dem Geblet der Spekulation konstatieren, sehen wir die Religion aber auch mit großen politischen und sozialen Kämpfen vermischt. In allen europäischen Völkern, 
man könnte fast sagen, in allen völkern, ist die religiöse Frage auf den ersten Plan gerückt. ${ }^{67)}$

Überall selen engaglerte Kämpfe für oder gegen die Rellgion im Gange, dabei gehe es u.a. In Frankreich um die Trennung von Staat und Kirche, in England um den Unterricht, in Deutschland um den strelt zwischen Regierung und Katholischem Centrum, in RuBland um die Feindschaft der autokratischen Orthodoxie gegen den Liberalismus usw.

Diese Beobachtung hat der "Mercure de France" zum AnlaB genommen, eine Umfrage $z u$ veranstalten unter dem Thema:

Sind wir Zeugen einer Auflösung oder einer Entfaltung der religiösen Idee und des religiösen Gefühls? ${ }^{68}$ )

$\mathrm{Zu}$ den Befragten gehörten unter anderen Plechanov und Gor'kij; die Antwort des Letzteren wird uns noch näher beschäftigen. $68 \mathrm{a}$ )

Versucht man, das Bild, das sich bietet, etwas zu differenzieren, so kommt man zu einem doppelten Tatbestand: Es herrscht ein Nebeneinander von Agnostizismus und religiöser Neuorlentierung, wobel beide Erschelnungen mit der Entwicklung der ( Natur-) wissenschaften in Zusammenhang $z u$ bringen sind.

Hatte einerseits das rasche Fortschreiten der exakten Naturwissenschaften, aber auch der historischen wissenschaften, in zunehmendem Maße elne Kritik an den Voraussetzungen und Aussagen der Religionen ( $v . a$. des Christentums) notwendig gemacht, so war andrerseits mit dem ausgehenden 19. und beginnenden 20. Jahrhundert elne starke Tendenz zu beobachten, mit Hilfe eben dieser exakten Wissenschaften - bzw. unter Berufung auf inre Erkenntnisse - elne neue Religiosität v.a. In der Gestalt monistischer systeme zu begründen. 69) 
Erinnert sei hier an Ostwald, Haeckel U.a., sowie an die verschiedenen Gründungen "positivistischer Gemeinden", des Monistenbundes, des Keplerbundes usw.

Jedenfalls zeigen alle diese Gründungen aufs klarste, daß auch im Lager der Agnostik immer mehr das Sehnen nach Schaffung neuer religiöser Werte, nach Begründung einer neuen religiösen Weltanschauung mit den Bausteinen wissenschaftlicher Erkenntnis und sozialer Imperative um sich greift. ${ }^{70}$ )

Der Frage nach den Ursachen für eine solche allgemeine "ideologische Umorientierung"71) kann hier nicht nachgegangen werden; für unseren Zusammenhang ist die Beobachtung wichtig, daß das Bild, das sich in Rußland um die Jahrhundertwende und in den Jahren danach bietet, nur im Kontext der gesamteuropäischen Verhältnisse zu verstehen ist als deren Teilphänomen. Das gilt für die Koppelung der Rezeption naturwissenschaftlicher Erkenntnisse mit der Begründung neuer weltanschaulicher/religiöser systeme (z.B. vor der Jahrhundertwende in Rußland Bervi-Flerovskij) ebenso wie für die allgemeine "christianisierende Welle". 72)

Allgemein sind diese Erscheinungen als Reaktion auf die "latent krisenhafte Stimmung der neunziger Jahre"73) - des "fin de siècle" also, zu sehen; auf die Krise des Individuums (Machs Ich-Philosophie als Ausdruck des Ich-Verlustes); auf das entstandene "Wertvakuum" 74); d.h. auf das Ungenügen am Positivismus und Materialismus der Zeit, das in den achtziger und neunziger Jahren eine Flut von Schriften hervorbrachte, die zu Besinnung, zur Umkehr aufriefen und die unterschiedlichsten Heilmittel anboten: Die Rückbesinnung auf die Kräfte des Blutes, der Rasse, des Bauerntums und der Scholle, des Handwerks und der Kunst, des Vegetarismus und der 
Wasserkur. Dieses stark empfundene Unbehagen bleibt keineswegs auf reaktionäre Kräfte beschränkt. ${ }^{75)}$

In diesem Zusammenhang seien Rilkes "Geschichten vom lieben Gott" erwähnt (1900) sowie das Aufkommen einer Gattung der "Sucherromane", z.B. Max Brods "Tycho Brahes Weg zu Gott".

In Rilkes von einem "mystischen Gottsuchertum" 76) geprägten "Stundenbuch" (1905) ${ }^{77)}$ finden sich geradezu "gotterbauerische" Texte:

Werkleute sind wir: Knappen, Jünger, Meister, und bauen dich, du hohes Mittelschiff.

Und deine kommenden Konturen dämmern. Gott, du bist groß. 78)

Aber auch die Bewegung russischer Marxisten vom "graven" orthodoxen Materialismus zu einer Neugestaltung des Marxismus, welche naturwissenschaftliche und philosophische Erkenntnisse, aber auch das religiöse Grundbedürfnis des Menschen zu integrieren sucht, hat ihre vorläufer und Parallelen in Westeuropa.

Genannt sel als einer der frühesten Joseph Dietzgen, der schon in den 70-er Jahren "Kanzelreden" unter dem Titel "Die Religion der Sozialdemokratie" veröffentlichte:

Wir fanden in der sozialdemokratischen Bewegung eine neue Form der Religion, insofern sie mit dieser dieselbe Auf gabe hat: das Menschengeschlecht von der Armut zu befreien, mit der es den Kampf um sein Dasein in einer Welt von Widerwärtigkeiten hilflos hat beginnen müssen. ${ }^{79)}$ 
Die Frage nach Unterschied und Übereinstimmung von Religion und Sozialismus ist immer wieder gestellt worden und hat inre lange Tradition in der Geschichte des Sozialismus schon seit den Frühen Sozialisten: Es läßt sich eine Linie verfolgen von Saint-Simon über Comte, Owen bis zu den "religiösen Sozialisten" ${ }^{80)}$ Bloch und den Gotterbauern. (Noch 1908 erscheint in den schon mehrfach zitierten "Dokumenten des Fortschritts" ein Aufsatz unter dem Titel "Religiöse Werte im Sozialismus". ${ }^{81)}$

Halten wir also fest, was dieser Überblick zeigten sollte:

Erstens sollte der Fragehorizont, das Problembewußtsein der Gotterbauer deutlich werden; es sollte gezeigt werden, in welch größerem Kontext die Frage nach Sozialismus und/oder Religion gestellt wurde.

Zweitens ging es darum zu sehen, daß weder die Aktivitätem der Gottsucher, noch die der Gotterbauer russische Sonderfälle waren, daß sie vielmehr als eingebettet in eine gesamteuropäische Bewegung (allerdings mit einer zeitlichen verschiebung) $\mathrm{zu}$ verstehen sind. ${ }^{82}$ ) 


\section{Anmerkungen}

1) Bazarov, Bogoiskatel'stvo 1 "Bogostroitel'stvo". In: Veršiny I, 1909, S. 331ff. Es handelt sich hier um den Abdruck eines Referats, das Bazarov 1909 vor der Peterburger Literarischen Gesellschaft gehalten hatte.

2) Vgl. Bazarov, a.a.0.; Lunacarskij, Ris, II, S. 377f; Literaturnoe nasledstvo, t. $1, S .30$.

3) M. Gor'kif, PSS, 1, S. 390. Allerdings spricht auch schon Rybin in "Mat" " von der Notwendigkeit, einen "neuen Glauben" zu "erfinden" und einen "Gott" zu "schaffen" (sotvorit" boga); PSS, 8, S. 57.

4) A.V. Lunatarskij, Budustee religli. In: Obrazovanie (1907) Nr. 10 u. 11;

drs., Religifa 1 Socializm (=RiS), tt. 1 u. 2 $\mathrm{SPb} 1908$ U. 1911.

5) RiS, I, S. 7 .

6) ebd.

7) Ocerki realisticeskogo mirovozzrenija. SPb ${ }^{2} 1905$. Darin finden sich u.a. Aufsätze folgender Verfasser: S. Suvorov, Osnovy fllosof 11 zizn1;

A.V. Lunaćarskij, Osnovy pozitivnoj èstetiki;

A. Bogdanov, Obmen 1 technika.

8) ebd. S. III.

9) ebd.

10) ebd.

11) Einen Hinwels darauf, was hier mit Realismus gemeint 1st, mag der deutlich instrumentale, bzw. funktionale Charakter dieser "Philosophle der Aktivitä" geben.

12) a.a.O. S.V, VI.

13) ebd. S. VI; Inwieweit das Prinzip Lebenssteigerung als oberstes Wahrheltskriterlum für diese spielart eines erkenntnistheoretischen Realismus 
einen Reflex der Nietzsche-Rezeption durch Lunacarskij (und Bogdanov) darstellt, wird noch zu klären sein. (Zu Lunacarskij s. Kap. IV , 4.).

14) 1925 zusammen mit zwel anderen Auf sätzen unter dem Titel "Novyj mir" neu erschienen in: A.A. Bogdanov, O proletarskoj kul'ture. L.-M. 1925, S. 12 - 93.

15) ebd. S. 13 .

16) A.V. Lunacarskij, Etjudy kritičeskie i polemičeskie. M. 1905.

17) ebd. S. 3f.

18) S. Anm. 16).

19) ebd. S. III.

20) ebd.

21) ebd. S. IV.

22) In ähnlicher Weise wird zur gleichen Zeit auch in der deutschen Sozialdemokratie die Notwendigkeit gesehen, den Menschen als erkennendes und handelndes Subjekt wieder mehr in den Blickpunkt zu rücken. Vgl. F. Trommler, Sozlalistische Literatur in Deutschland. Stuttgart 1976, S. 25. In RiS. I, S. 17 nennt Lunacarskij ROB und Reiter deutlicher: Absicht des Sborniks ("Etjudy") sel es gewesen, gegen die Tendenz im Marxismus zu kämpfen, das 'Ideal' vom Marxismus "abzutrennen, in den Himmel zu verbannen und für die Erde einen kriechenden Realismus der Reformen übrigzulassen."

23) Etfudy, S. IV.

24) ebd.

25) ebd. S. V. Wle schon oben angedeutet, stellt sich hier wiederum die Frage nach dem Elnfluß Nietzsches.

26) ebd.

27) Otkliki zizni. Sbornik stat'ej. SPb 1906.

28) Mercure de France Nr. 233, T. LXVI (1-er Mars 1907), 
S. 592 - 595. Daneben entstand vermutlich noch ein Artikel Gor'kijs "O proischozdenil našego boga", der aber unzugänglich im Archiv Gor'kogo aufbewahrt wird. Bgl. dazu Šachnovic, A.M. Gor'kijo prolschoždenil religil. In: Ežegodnik Muzeja Istorij, Religil i Ateizma, I. M.-L. 1957, S. 80; sowie drs., Lenin und die Fragen des Ateismus, S. 460 .

29) Obrazovanie XVI (1907), Nr. 10, S. 1-25, Nr. 11, S. $30-67$.

30) Obrazovanie (1907), Nr. 10, S. 17.

31) Ocerki po fllosofil Marksizma. Sbornik. SPb 1908. Darin unter anderem Aufsätze von: V. Bazarov, Misticizm I realizm našego vremeni;

A. Lunačarskij, Ateizm;

A. Bogdanov, Strana idolov 1 filosofija marksizma.

32) ebd. S. 1 .

33) ebd.

34) ebd. S. 2 .

35) ebd. Mit der "anderen Selte" düften hier die 'Bogoiskateli' gemeint sein.

36) Literaturnyj raspad. Sbornik 1 u. 2. SPb 1908. Darin enthaltene wichtige Aufsätze:

P. Juskevic, 0 sovremennych filosof sko-religioznych iskanijach; A. Lunackarskij, T'ma; M. Gor'kif, O cinizme; A. Lunacarskij, Dvadcat' tretij sbornik "Znanifa".

37) P. Juskevic, Materializm i kritičeskij realizm. SPD 1908.

38) M. Gor'k1j, PSS, 9, S. 342.

39) Schachnowitsch. Lenin.... S. 421.

40) A. Lunaciarskij, RiS, I, S. 8.

41) Ocerki fllosofil kollektivizma. Sbornik. SPb 1909. Darin: A. Lunacarsk1\}, Mešcanstvo 1 individualizm; M. Gor'kij, Razrusenie licnost1. 
42) Veršiny, Kn. I. SPb 1909.

43) Oxerki filosofil kollektivizma, S. 5.

44) ebd. S. 6; Unterstr. v. m.

45) Dazu weiter unten.

46) Versiny, I, S. 3.

47) ebd.

48) ebd. S. 4.

49) Vgl. dazu die Protokolle dieser Sitzung des erweiterten Redaktionskommitees in: Literaturnoe nasledstvo 1. M. 1931, S. $17-38$.

50) Die von Lenin monierten Textstellen finden sich zitiert bei Schachnowitsch, Lenin..., s. 457.

51) Gut zu verfolgen in Lenin und Gorki.

52) P. Juskkevic, Na temu dnja. In: Verśiny, I, S. 365.

53) Vgl. dazu G. Florovskij, Puti russkogo bogoslovija. Paris 1937, S. 452: "Das religiöse Thema stellt sich jetzt als $T h e m$ a d e s L e $b e n s$, nicht nur als $T h e m a d e s d e n-$ k e n s."

S. 454: "Im Marxismus waren krypto-religlöse Motive vorhanden. Ein utopischer Messianismus vor allem, und dann das Gefühl der gesellschaftlichen Solidarität."

54) Siehe auch Lunacarskif, Ris, I, S. 186. Daß es das auch ist, zeigen Äußerungen Lunałarskijs: Durch den Erfolg der "Idealistischen Häresie", die immer mehr Anhänger vom Marxismus trennte, sah er sich in der Absicht bestärkt, die "großen ideelien Schätze im Marxismus aufzudecken." (RiS, I, S. 18).

55) - deren Gegner Regierung einerseits und orthodoxe Marxisten andrerseits waren; Vgl. Lunacarskij, RiS, I, S. $13 f$.

56) Berdjaev, Russie Bogolskateli. In: Moskovskij ezenedel'nik, Juli 1907; zit. n. The Modern Encyklopedia of Russian and Soviet History. Vol. 5. 
1977, S. 31. Mit dem "offiziellen Regime" sind sowohl staat wie Kirche gemeint, welch letztere durch Pobedonoscev in seiner Funktion als oberprokuror des $\mathrm{Hlg}$. Synod im Sinne des staatlichen Regimes in Anspruch genommen war. Vgl. dazu:

D. Ziževskij, Russische Geistesgeschichte. München 21974 , S. 255.

57) The modern Encyklopedia..., a.a.o.

58) Dazu vgl. Kap. I, Anm. 29).

59) In: Versiny, I. SPb 1909.

6o) ebd. S. 249.

61) "Auf dem Höhepunkt des politischen Radikalismus." ebd.

62) ebd.

63) ebd. S. 350.

64) ebd.

65) Mercure de France, a.a.0. S. 577ff.

66) ebd. S. 577.

67) ebd. S. 578 .

68) ebd.

68a) Plechanov beantwortet die Frage, indem er von einem materialistisch-evolutionistischen Standpunkt aus die "Auflösung der religiösen Idee" als den "notwendigen Endpunkt ihrer Evolution" betrachtet. (a.a.0. S. 617) Mit der "religiösen Idee" werde im Verlauf des menschlichen Fortschritts auch das "religiöse Gefühl" verschwinden, wenn auch langsamer. (ebd. S. 619).

69) 2.B. E. Broda, Der religiöse Gehalt der Entwicklungslehre. In: Dokumente des Fortschritts 1 (1908), H. 4, S. 349 .

70) ebd. S. 464 .

71) R. Hamann und J. Hermand, Epochen der deutschen Kultur von 1870 bis zur Gegenwart. Bd. 4: Stilkunst um 1900. Frankfurt 1977, S. 8. 
72) ebd. S. 128 .

73) J.M. Fischer, Fin de siècle. München 1978, S. 15.

74) ebd. S. 28.

75) ebd. S. 66 .

76) Hamann-Hermand, a.a.O. S. 131.

77) Der Titel macht den Einfluß der russischen Stundisten (vgl. Ciževskij, Russische Geistesgeschichte, S. 255) und Tolstojs auf Rilke deutlich.

78) R.M. Rilke, Gedichte. Berlin-Darmstadt-Wien 1966, S. $268 f$.

79) J. Dietzgen, Das Wesen der Kopfarbeit und andere Schriften. Darmstadt-Neuwied 1973, S. 134.

80) Wilhelm Weitling, August Becker.

81) Dokumente des Fortschritts, a.a.0., S. $345 \mathrm{ff}$.

82) Detaillierter zur geistigen Situation in Ruß1 and um die Jahrhundertwende: J. Scherrer, Die Petersburger Religiös-Philosophischen Vereinigungen, S. 25 - 86; R.-D. Kluge, Vom kritischen zum sozialistischen Realismus, S. $33-36$. 
III. Gor'kijs Religionsbegriff um 1907

(Die Umfrage des Mercure des France)

Am Beginn unserer Darstellung von Gor'kijs Gotterbauertum soll ein Text stehen, der auch am Anfang seiner (offiziell) sogenannten Gotterbauerischen Phase steht. Es ist Gor'kijs einzige - uns zugängliche - theoretische und mehr oder weniger systematische Äußerung zur Frage der Religion und speziell der "neuen Religion". 1) (Aus diesem Grunde und auch wegen seiner erschwerten zugänglichkeit wird er in der Analyse sehr ausführlich zitiert werden.)

In seiner Antwort auf die Enquête des Mercure de France (März 1907) 2) unterscheidet Gor'kif der Fragestellung entsprechend zwischen "religiöser Idee" und "religiösem Gefühl".

a) Die "religiöse Idee" repräsentiert für inn das, was man allgemein unter einem wie auch immer ausgeprägten Theismus verstehen kann: Es ist dies die Vorstellung von einer überirdischen Macht - "Gott", "Höchstes Wesen", "außerhalb stehende Mächte", - "welche die Geschicke des Universums und der Menschen lenkt" ${ }^{3)}$. Kennzeichnend für solche Gottesvorstellungen, d.h. Ihnen allen gemeinsam, ist, daß sie den Menschen daranhinderten, ein "stolzes Bewußtsein" von seinem eigenen "Wert" zu entwickeln" ${ }^{4}$, daß sie inn unterordnen und zu einem Wesen degradieren, "das dem launischen und für den Geist unzugänglichen willen einer mysteriösen Macht unterworfen ist."5)

"Moses, Christus, Mahomet und alle, die den Glauben an Gott gepredigt haben, waren mehr oder weniger Fanatiker ein und derselben Idee, der Idee der Unterordnung des Menschen unter Mächte, die außerhalb seiner selbst gelegen sind." 6 ) 
Der Mensch als ein "Material, das den unbekannten Experimenten des Höchsten Wesens dient." ${ }^{7)}$

Eine solche Idee beschränkt die "geistige Freiheit" des Menschen, und daher

"erscheint mir der Atheismus als Negation des Glaubens an die Existenz eines persönlichen Gottes wünschenswert, weil er die Menschheit von einem gefährlichen Irrtum befreit." 8 )

Nicht eine "religiöse Idee" (Gott) ist es, was die Menschen verbinden und "ihnen eine geistige Einheit geben" kann, sondern wissenschaft (und Kunst).9)

Weiter zeigt Gor'kij, ähnlich wie Rybin in "Mat." , daß das Volk mit Gott, dem "Symbol der höchsten Gerechtigkelt, des unbestechlichen Richters, der guten und wohlwollenden Macht" ${ }^{10)}$ immer betrogen worden sei. Die Kirchen seien immer Komplicen der Regierungen gewesen, wenn es darum ging, "Macht auszuüben und dem Volk Gewalt anzutun". 11)

"Die Manifestationen von Gottes gnädigem Willen sind nirgends zu sehen, der Glaube an die Gerechtigkeit kommt zum Erliegen, die Vorstellung der Existenz Gottes verschwindet, der Rationalismus nimmt die stelle des Mystizismus ein, das Denken, - befreit von der Angst vor der göttlichen Macht - beginnt auf unabhängige Weise zu arbeiten. So scheint mir also die Auflösung der Idee eines persönlichen Gottes unausweichlich, im intellektuellen Milieu so gut wie in den Massen."12)

Man kann also sagen, daß Gor'kij hier "Religion" (im "schlechten" Sinne) kaum von einem marxistischen Ansatz her kritisiert, vielmehr macht er sich in aufklärerischer Weise für die Autonomie und Freiheit des menschlichen Geistes stark ${ }^{12 a)}$. Am ehesten an Marx'sche Religionskritik 
mag die Koppelung von Macht über Menschen mit (etablierter) Religion erinnern. Ebenso klingt aber Nietzsche mit, wenn es heißt, daß "das stolze Bewußtsein vom menschlichen wert" 13) sich nur unabhängig, frei von Religion entwickeln könne.

b) Das "religiöse Gefühl"

"Das religiöse Gefühl ist ein Gefühl, das freudig ist und stolz auf das Bewußtsein eines harmonischen Bandes, welches den Menschen und das Universum vereinigt."14)

Dieses religiöse Gefühl hat seinen Ursprung im Diesseits, im Leben, in Vergangenheit, Gegenwart und Zukunft des Menschen: es

"entspringt der Hoffnung auf Synthese (Zukunft), die jedem Individuum innewohnt, es nährt sich aus der Erfahrung (Vergangenheit), es manifestiert sich zu Beginn durch das Bewußtsein, welches der Mensch von seiner Rolle und seinem Platz"15)

im Leben hat (Gegenwart).

Dieses Bewußtsein weckt im Menschen ein "freudiges Gefühl innerer Freiheit"16) und wird zum "Pathos"; "das 'Pathos" ist religiös". 17)

"Die unendliche Verschiedenheit der Fakten des Lebens, die Schönheit der menschlichen Hoffnung, die darauf gerichtet ist, dessen Geheimnisse gründlich zu erforschen, die schöpferische Kraft unserer wünsche nach Freiheit, nach wahrheit, nach Gerechtigkeit, die langsame aber sichere Vorbereitung des Menschen auf seine vollendung - das sind die Quellen, aus denen die Menschhelt das 'Pathos' schöpfen wird."18) 
Gor'kij ist davon überzeugt, daß der Mensch seiner "geistigen Vollendung" entgegengeht. Wenn er sich dieses "Prozesses" bewußt wird, entsteht in inm jenes "religiöse Gefühl", nämlich das

"schöpferische und komplexe Gefühl des Glaubens an seine Kraft, der Hoffnung auf seinen Sieg, der Liebe zum Leben, der Ehrfurcht vor der weisen Harmonie, die zwischen seinem Geist und dem des ganzen Universums existiert."19)

Wie man schon sieht, ist Gor'kijs neue Religion, sein "religiöses Gefühl" völlig auf das Diesseits, auf den Menschen und seine Geschichte gerichtet. Es trägt einen stark dynamischen Charakter, der auf die Veränderung der welt, vor allem aber des Menschen zielt. - Wichtig scheint mir dabei, daß Gor'kif die drei wesentlichen christlichen Existentialien: Glaube, Hoffnung, Liebe, sowie das Element der Ehrfurcht (vor der Weisheit Gottes) beibehält und innen lediglich eine andere Richtung gibt: Glaube, Hoffnung, Liebe sind nicht gott- und jenseitsorientiert, sie richten sich vielmehr auf den Menschen, auf seinen Lebensvollzug - jetzt und in der zukunft.

Letzteres ist ein weiteres wichtiges Element in Gor'kijs 'Religion': die starke Betonung des Zukunftsbezugs:

"Ich glaube, daß wir Zeugen sind (mitarbeiten) bei der Formierung eines neuen psychologischen Typus'; ich sehe in der Zukunft ein Wesen, das ich vollkommen nenne wegen der harmonischen Entwicklung all seiner Fähigkeiten, ohne daß zwischen ihnen ein widerspruch bestünde."20)

Der Mensch, der auf seine Vollendung zuschreitet, der "neue psychologische Typus", der den heutigen Menschentypus ablösen soll, der "vollkommen" ist und sich dessen bewußt 
ist, daß er den höchsten Wert im Universum darstellt das sind Züge an Gor'kijs Zukunftsvision, die an Nietzsches Lehre vom Übermenschen denken lassen:

Ich lehre euch den Übermenschen.

Der Mensch ist etwas, das überwunden werden muß. ${ }^{21)}$

Der Übermensch ist der Sinn der Erde.

Euer Wille sage: der übermensch sei der Sinn der Erde! ${ }^{22}$ )

Schon die oben dargestellte Religionskritik Gor'kifs, die fa eine "religiöse Idee" gerade deshalb ablehnt, weil sie den Menschen in seinem Stolz verletzt ${ }^{23}$ ) und seine Aufmerksamkeit vom (politischen) Hier und Jetzt abzieht, indem sie sie auf "Hinterwelten" lenk ${ }^{24)}$, trifft sich mit der Kritik Nietzsches:

Einen neuen Stolz lehrte mich mein Ich; den lehre $1 \mathrm{ch}$ die Menschen: nicht mehr den Kopf in den Sand der himmlischen Dinge zu stecken, sondern frei ihn zu tragen, einen Erden-Kopf, der der Erde Sinn schafft. ${ }^{25}$ )

Teilt Gor'kij mit Nietzsche die Vision von einem neuen Menschen, der den gegenwärtigen Menschen überwinden und ablösen soll, so liegt doch seine Vorstellung von einer wesentlichen Voraussetzung als Bedingung dafür, daß sich der neue Menschentypus entwickeln kann, quer zu Nietzsches Denken:

Damit dieses Wesen sich formieren kann, ist eln freier und ausgedehnter Verkehr (commerce) unter den Menschen notwendig, deren stellung gleich ist - und dieses Problem ist durch den Sozialismus gelöst. ${ }^{26)}$

Dieser freie und gleichberechtigte Umgang der Menschen untereinander rat zur Folge, daß die Menschen die gleichen 
Erfahrungen machen und sich dadurch "untereinander völlig verstehen" können 27); wenn aber die verständigungsbarrieren zwischen den Menschen gefallen sind, so schaft das für Gor'kif Beziehungen,

die befreit sind von wut, Neid und Gier; er (der freie Umgang) wird jedem einzelnen erlauben, sich frei der Erfahrung aller zu bedienen, und wird alle von der Erfahrung jedes einzelnen Nutzen haben lassen. ${ }^{28}$ )

Mit "Erfahrung" meint Gor'kij nicht Lebenserfahrung in einem mehr oder weniger banalen und individuellen Sinn; Erfahrung heiBt vielmehr für ihn

die gesamte Menge unserer Kenntnisse, alle Ergebnisse, zu denen unsere schöpferischen Fähigkeiten gelangt sind auf dem Gebiet der Wissenschaft und der Kunst; dieses Gebiet ist das Erhabenste, auf welchem unser Geist arbeiten kann. 29)

Es sind also kulturelle Werte letztlich, die Voraussetzung und Ergebnis einer sozialistisch organisierten Gesellschart ausmachen: Daß das Wissen nicht von wenigen verwaltet wird und nur Privilegierten zugänglich bleibt, sondern im "freien und ausgedehnten Verkehr" Besitz aller wird ("Gleichheit in der Erfahrung"), läßt den Einzelnen frei im Kollektiv handeln und neue (kulturelle) Werte schaffen, läßt ihn so erst seiner Zeit und Raum überwindenden Kollektivität 30 ) bewußt werden:

Der Besitz dieser Erfahrung bereichert den Menschen und erweckt damit in inm das Bewußtsein seines Wertes und den königlichen Wunsch, durch seine Schöpfungen mit den Generationen der Vergangenheit zu rivalisieren und Vorbilder zu schaffen, die es wert sind, daß künftige Generationen ihnen nachfolgen.

Das Leben des Menschen wird also den Charakter eines 
schöpferischen Prozesses annehmen; nicht nur das Gefühl seiner Einheit mit der Vergangenheit wird ihm also zugänglich werden, sondern er wird ebenso eine klare Vorstellung von dem Einfluß seines Geistes auf die Zukunft haben. Man darf die Tatsache nicht vergessen, daß unser Bewußtsein ins Unendliche erweitert werden kann. Das religiöse Gefühl, wie ich es verstehe, muß folglich existieren, sich entwickeln und den Menschen vollkommen machen. 31)

Diese Antwort Gor'kijs auf die Enquête des Mercure de France ist die einzige zugängliche ausführliche Äußerung Gor'kijs zur Religiositat in theoretischer Form. ${ }^{32}$ )

Fassen wir die wichtigsten Größen und ihre Bezüge zusammen, welche Gor'kijs kritisierte/negierte alte und seine anvisierte neue "Welt" ausmachen. Das soll aber nicht in Form einer abermaligen Paraphrasierung geschehen, sondern - um einer besseren Anschaulichkeit willen - mit Hilfe eines räumlichen Modells, das sich am Raummodell des sowjetischen Semiotikers Ju. Lotman orientiert.

Dieses Modell geht davon aus, daß der Mensch seine Welt unter Zuhilfenahme einer "Sprache des Raumes" ordnet. Die Elemente dieser "Sprache" sind eine Art Kategorien, "Universalien der Kultur", nach denen der Mensch Welt erkennt und im Erkennen herstellt. ${ }^{33 \text { ) }}$

Ausgehend von den Oppositionen "Außen" (A) - "Innen" (I) und "Oben" - "Unten" müßte man also das Raummodell, das dem christlichen Kulturtext entspricht, folgendermaßen darstellen:

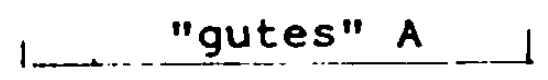

I

oder

"schlechtes" A

\begin{tabular}{|l|}
\hline Himmel \\
\hline Erde \\
\hline Hölle \\
\hline
\end{tabular}


Dieses christliche Raummodell entspricht - um zu Gor'kij zurückzukehren - der alten Welt, welche von der "religiösen Idee" beherrscht wird. Mit der Negierung der religiöser Idee durch den Atheismus wird auch die durch sie bedingte Aufteilung des universalen Raumes (Kosmos) verneint.

Die vertikale Struktur ("oben" - "unten"), die kennzeichnend für die theistische (christliche) Welt ist, bleibt in der Negation noch anwesend: "Gott", "höchstes Wesen", "übernatürliche Mächte" sind außerhalb des Menschen angesiedelt ("A" - "oben"), lenken die Geschicke der Erde und der Menschen ("I" - Raum der Menschen) und ordnen sie sich unter ${ }^{34)}$.

Innerhalb von "I" wiederholt sich diese vertikale struktur:

Die "Massen", das "Volk" werden von "Kirche" (Repräsentant von "A" in "I") und Regierung unterworfen"35). Nachdem sich aber - durch die Religionskritik - der Glaube an Gott und seine wohlwollende Lenkung als Irrtum erwiesen hat, wird auch die wiederholung dieser alten vertikalen Struktur unter den Menschen ("I") falsch. Das bedeutet, daß nach der Kritik des Theismus auch die vertikale Anordnung der Elemente von "I" (Raum der Menschen) verändert werden muß:

Wenn der Mensch sich seiner Bedeutung in der Welt, seines Wertes, bewußt wird, darf es für inn kein "Oben" und "Unten" mehr geben. Seine Welt ("I") muß horizontal organisiert werden. In der neuen Raumaufteilung sind die Elemente von "I" (die Menschen) einander auf gleicher Ebene zugeordnet, inre Bewegung bestimmen sie selbst: "freier und ausgedehnter Verkehr unter den Menschen, deren Stellung gleich ist"36). Die Verbindung unter den Menschen wird nicht unter Zwang, von "oben", hergestellt, sondern erfolgt freiwillig durch die einheitsstiftende wirkung von wissenschaft und Kunst. 
Diese antihierarchische Zuordnung der Menschen zueinander ist im heutigen Menschen schon angelegt - "Hoffnung auf Synthese, die jedem innewohnt" 37) - und kann, nachdem die Religionskritik den Blick dafür frei gemacht hat, vom Menschen erkannt werden durch das "BewuBtsein von seiner Rolle und seinem Platz" ${ }^{38)}$ ), (den der Mensch im Prozeß des Lebens hat).

Vom Erwachen dieses Bewußtseins bezieht der Mensch den Impuls, sich auf das hin zu verändern, was in ihm als ziel angelegt ist: ein "neuer psychologischer Typus" in der "zukunft"39).

Ebenso wie sich die Grenzen der Elemente von "I" erweitern - "Unser Bewußtsein kann ins Unendliche erweitert werden"40). -, so dehnt sich auch "I" selbst, die Welt des Menschen, ins Unendliche aus: es gibt kein "AuBen" und kein "Oben" mehr; den Einzelnen verbindet ein "harmonisches Band" mit dem gesamten Kosmos ${ }^{41}$ ).

Diese dynamische Sicht Gor'kijs vom Menschen erinnert sehr an die neutestamentliche Predigt vom Himmelreich, welches nahe ist. Der Anbruch des Reiches beginnt mit der Entscheidung des Einzelnen und $k$ ann von ihm erkannt werden. -

Die Orientierung in diesem neuen Raum, d.h. die Bewertung der Welt, erfolgt - und dies dürfte das wichtigste Merkmal der Gor'kijschen Religion sein - vom Menschen aus; näherhin nicht vom Menschen als "Ensemble der gesellschaftlichen Verhältnisse", sondern von seinem Bewußtsein und von seinem Gefühl aus 41 a).

Fassen wir zusammen, was sich aus diesem Text als kennzeichnend für Gor'kijs religiöses Weltbild ergibt:

Der Mensch wird dynamisch gesehen; das ziel seiner Veränderung, der "neue Mensch", ist in inm angelegt. 
Die im christlich-theistischen Weltbild nach "Oben" gerichteten Verhaltensweisen (Gefühle) Glaube, Hoffnung, Liebe, Ehrfurcht, werden durch die auf Vernunft basierende Religionskritik zunächst abgeschnitten, dann aber nach "I", auf die Welt des Menschen selbst gerichtet. Die individuelle vertikale Ausrichtung weicht einer kollektiven horizontalen.

Ausgangspunkt und zugleich erster Ort der Veränderung ist das Bewußtsein des Einzelnen, welches durch Wissenschaft und Kunst, die Betätigungsfelder des "Geistes" geweckt wird.

Das "reliqiöse Gefühl" oder "Pathos" stellt recht eigentIich eine Synthese aus Geist/Vernunft und Gefühl dar und nährt sich aus einem unerschütterlichen Glauben an den unendlichen Fortschritt der Menschheit.

Das Zentrum dieses Weltbildes ist der neue Mensch; in inm sind aber zwei Zentren zur Harmonie gebracht: Geist und Gefühl. Inre zu überwindende Dualität kommt in der "Hoffnung auf Synthese" zum Ausdruck, die "jedem Individuum innewohnt" 42 ). 
1)

Das in der von Gor'kij abgelehnten

"religiösen Idee" noch anwesende theistische Weltbild:

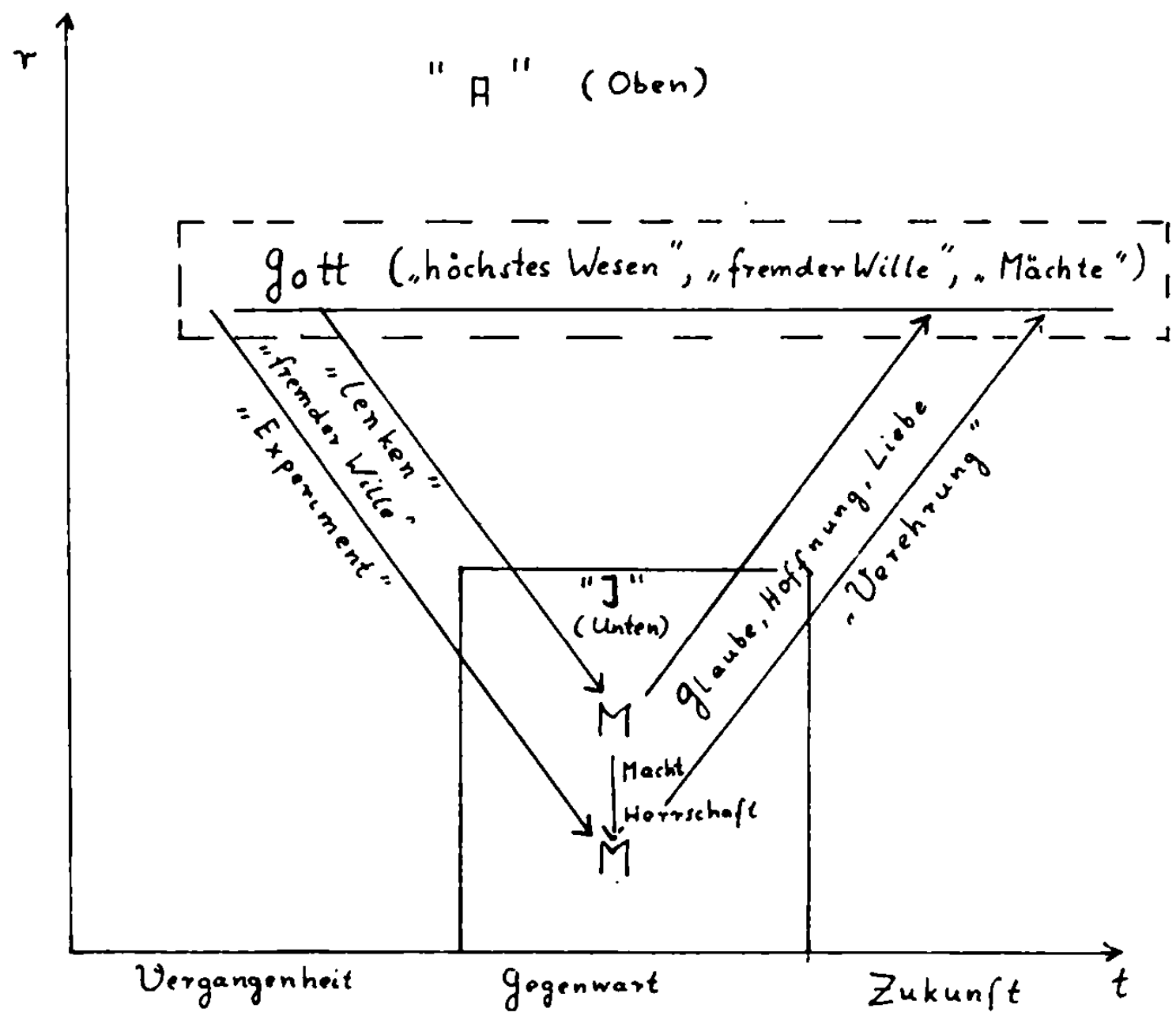
r - Raum
"I" - Innen (Welt des Menschen)
$t$ - Zeit
"A" - Außen (Zukunft, Jenseits)
M - Mensch

Die Orientierung in diesem Weltbild erfolgt ausschließlich von "oben". In der Innenwelt, der Welt des Menschen, wiederholt sich diese vertikale struktur. 
2) Das neue Weltbild, das durch die Entfaltung der "religiösen Idee" möglich wird:

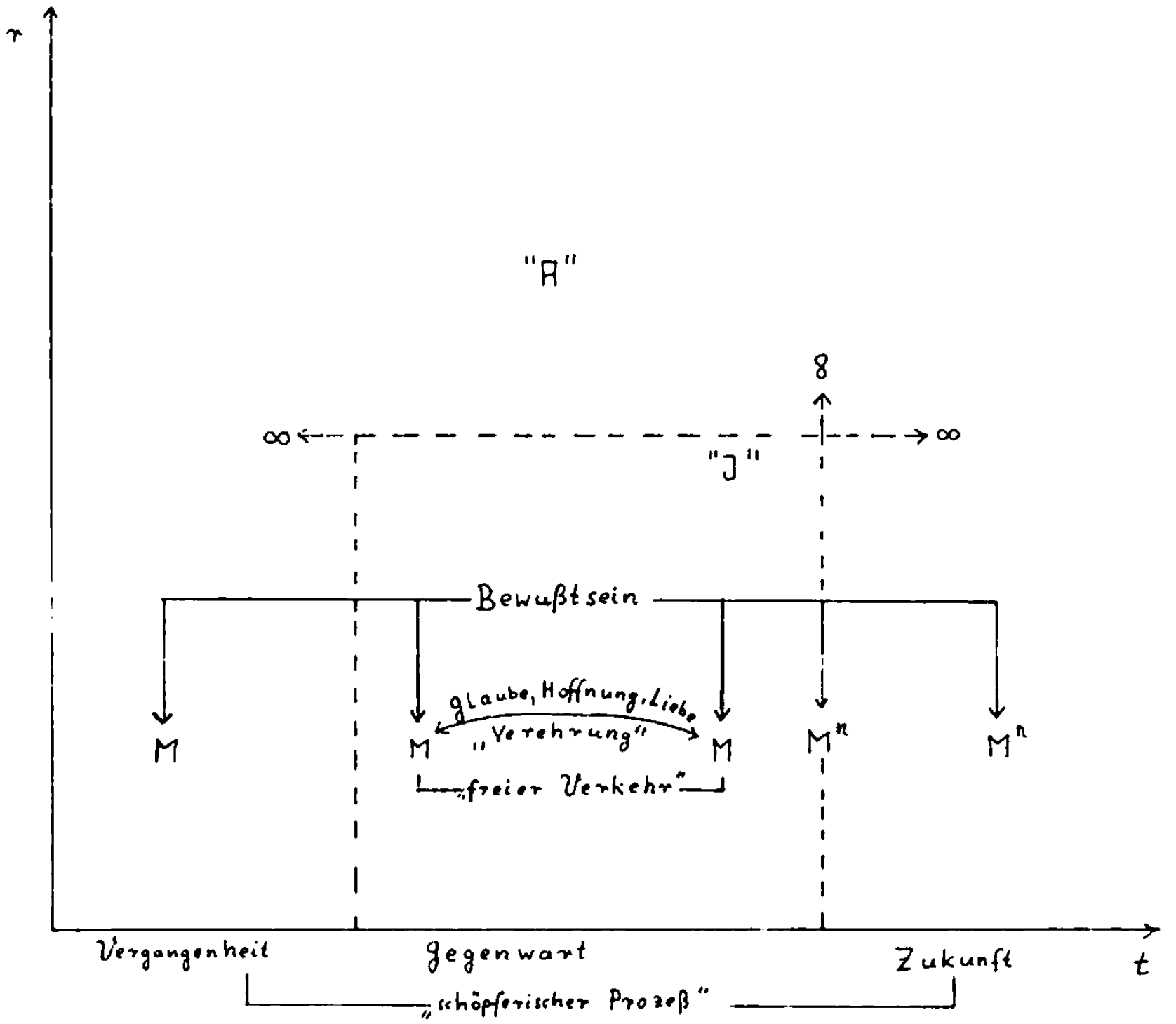

Hier erfolgt die Orientierung im Raum des Menschen ausschließlich in der Horizontalen. Der Mensch hat nichts mehr über sich, weder in der Gesellschaft noch im gesamten Kosmos. Seine Welt und sein Bewußtsein sind ins Unendiche ausdehnbar. $\left(M^{n}\right.$ - der neue Mensch) 
Im folgenden wird nun der Frage nachzugehen sein, woher Gor'kij diese - sowohl hinsichtlich des Religionsbegriffes (Religion = Gefühl), wie auch im Hinblick auf die realen Phänomene des Lebens (Tod, Liebe, Krankheit usw.) - doch recht eindimensionalen 'religionsphilosophischen'

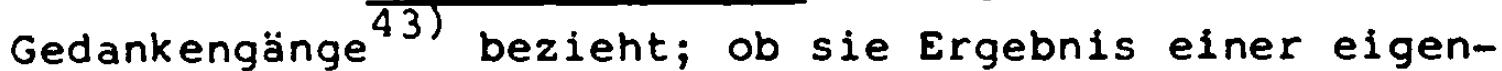
ständigen Entwicklung oder das Konglomerat von angesammeltem eigenen und $f$ remden Gedankengut sind. 


\section{Anmerkungen}

1) Die Wahl gerade dieses Textes als Ausgangspunkt für Darstellung und Analyse des Gotterbauertums in der Gor'kijschen Ausprägung gründet sich auf folgende methodischenüberlegungen: Gor'kijs (theoretischer) standpunkt von 1906/07 (also etwa zum Zeitpunkt seiner 'kopernikanischen Wende' in Sachen Sozialismus) soll als vorläuf 1ger Endpunkt elner konstanten Entwicklung - und nicht etwa als Bruch - sichtbar werden; dazu eignet sich ein retrospektives Vorgehen. Zugleich leistet dieser Text die Verknüpfung und Vergleichsmöglichkeit mit Lunacarskij; denn dieser beruft sich zu Beginn seines Aufsatzes "Buduscee religil" unter anderem ausdrücklich auf Gor'kijs Enquêten-Text und identifiziert sich weitgehend damit (Obrazovanie XVI (1907), 10, S. 5ff). Dieser Aufsatz bildet die Kurzfassung von "Rel1gija 1 soclalizm" und wurde wenlge Monate nach Gor'kijs Enqêten-Antwort veröffentlicht.

2) Mercure de France, a.a.0. S. 592 - 595.

3) ebd. S. 592 .

4) ebd.

5) ebd. S. 593.

6) ebd. S. $592 f$.

7) ebd. S. 593.

8) ebd.

9) ebd. S. 592 .

10) ebd. S. 593.

11) ebd.

12) ebd.

12a) N. Valentinov (Vol'skif), Vstreci s Gor'kim. In: Novyj zurnal (New York), Nr. 78 (1978), S. 125 nennt Gor'k1js späteres "Erzlehungsprogramm" ("stat" Ev- 
ropoj", vgl. M.G., Dve dus1) in den Jahren 1913/14, das sich hier schon abzuzeichnen beginnt, ein "durchaus nicht marxistisches, sondern rein aufklärerisches Programm, im Geiste der Weiterentwicklung der Ideen Belinskifs and Dobrol jubovs."

13) Mercure de France, a.a.O. S. 592.

14) ebd. S. 593.

15) ebd. S. $593 f$.

16) ebd. S. 594.

17) ebd.

18) ebd.

19) ebd.

20) ebd.

21) Nietzsche, Werke in 3 Bänden (hrg. v. K. Schlechta). München 61969, II, S. 279.

22) Nietzsche, II, 280; Auf Nietzsche und seine Beziehung zu Gor'kij soll an späterer stelle ausführlich eingegangen werden; soviel läßt sich aber hier schon sagen, daß die angeführten (und andere) Stellen aus dem "Zarathustra" einen Zug von Nietzsches durchaus zukunftsbezogener Philos ophie repräsentieren, der seine Analogie bei Gor'kif findet. - Man kann sagen, daß Gor'k1j den "Zarathustra" in seinem Sinne lesen und verstehen konnte.

23) Mercure de France, a.a.0. S. 592.

24) Nietzsche, II, S. 297.

25) ebd. S. 298.

26) Mercure de France, a.a.0. S. 594.

27) ebd.

28) ebd.

29) ebd.

30) Das Begriffsinstrumentarium, das Gor'kif hier gebraucht, sowie die Funktion (Organislerung), die 
bei Ihm Wissenschaft und Kunst einnehmen, lassen elne gewisse Nähe zur Philosophie und Gesellschaftslehre Bogdanovs vermuten. Diese fand ihren mehr oder weniger glücklichen literarischen Ausdruck in dem ebenfalls 1907 erschienenen utopischen Roman "Krasnaja zvezda" (Der Rote Stern).

Die Bezlehungen zwischen Bogdanov und Gor'kif, bzw. deren mögliche Bedeutung für Gor'kijs Gotterbauertum, können nlcht Gegenstand dieser Arbeit sein - aus zwei Gründen:

Erstens soll hier die Fragestellung beschränkt bleiben auf die Motivierung und Begründung des Marxismus unter religiösem Aspekt; dieser ist bei Lunačarskij und Gor'kij gegeben, nicht aber bei Bogdanov, der sich vielmehr gegen eine Vermischung des revidierten Marxismus mit religiöser Terminologle verwahrt. (Literaturnoe nasledstvo t.l, S. 30).

Zweitens müßte sich elne Darstellung und Analyse der Bezlehungen zwischen Bogdanov und Gor'kij - bei der bisherigen Quellenlage - auf das leidige Geschaft elner Text-Exegese mit fraglichem Ausgang einlassen. - Die von Jutta Scherrer und George Haupt in Angriff genommene Herausgabe des Briefwechsels zwischen Gor'kif und Bogdanov düfte hier erst Abhilfe schaffen.

31) Mercure de France, a.a.0. S. $594 f$.

32) Vgl. S. 22, Anm. 28).

33) Zu seinem Raummodel 1: Ju. Lotman, $K$ probleme tipologii kul'tury. In: Trudy po znakovym sistemam III. Tartu 1969, S. 30 - 38; drs., O metajazyke tipologiceskich opisanif kul'tury. In: Trudy po znakovym sistemam IV. Tartu 1969, S. $460-478$. 
Beide Aufsätze besprochen von Ivo Bock in:

Welt der Slaven XVII/l, S. $237 \mathrm{ff}$.

Die Anwendung des Lotmanschen Modelis erfolgt

hier, well auf diese Weise eine klarere Dar-

stellung der von Gor'kij durchaus nicht syste-

matisch dargebotenen Vorstellungen möglich wird.

34) Mercure de France, a.a.0. S. $592 f$.

35) ebd. S. 593 .

36) ebd. S. 594 .

37) ebd. S. 593 .

38) ebd. S. $593 f$.

39) ebd. S. 594 .

40) ebs. S. 595 .

41) ebd. S. 593.

4la) Auffallend hăufig sind die Vokabeln "BewuBtsein", "Gefühl", "Gelst".

42) Mercure de France, a.a.0. S. $593 f$.

43) Der Vorwurf der Eindimensional1tät kann hier natürlich nur dem 'Theoretiker' Gor'kif gelten. 
IV. Wissenschafticher Sozialismus als religionsphilosophisches system bei Lunatarski ${ }^{1)}$

Der im vorangegangenen Kapitel analysierte Text von Gor'kij nimmt in unserem Zusammenhang eine zweifach zentrale stellung ein:

Zum einen fält seine Entstehung genau zwischen die Romane "Mat'" (später zum Prototyp des Sozialistischen Realismus kanonisiert) und "Ispoved" (als "Standardwerk" der gotterbauerischen Phase Gor'kijs), die beiden Romane also, die in dieser Arbeit vor allem auf ihren gottbildnerischen Gehalt hin untersucht werden sollen.

Zum andern erscheint 1907 die kurzgefaßte systematische Darstellung von Lunačarskijs religionsphilosophischer Revision des russischen Marxismus - "Buduscee religii"2), in der sich Lunakarskif ausdrücklich auf den genannten Gor'kij-Text als eln Beispiel für das Kelmen einer neuen Religiosität in der europäischen Sozialdemokratie bezieht. Die breit ausgeführte Präsentierung seines systems folgt 1908 und 1911 unter dem Titel "Religija i Socializm"3).

Es ist zwar keineswegs so, daß Lunararskif 1907 zum ersten Mal seine Idee vom Marxismus als Religionsphilosophie entwickelte und publizierte, und daß man somit sein Gotterbauertum als Reaktion auf die gescheiterte Revolution von 1905 erklären könnte; vielmehr weist er selbst zu Beginn von "Religija 1 Socializm"4) darauf hin, daß er sich schon seit $1898 \mathrm{mit}$ dieser Thematik befaßt hat ${ }^{5}$ ).

Dennoch soll die systematisierte Endgestalt von Lunacarskijs Ideen im Zentrum der Darstellung stehen, da es hier nicht um eine Geschichte des Bogostroitel'stvo geht sondern um die Frage: 
Wie nahe oder wie fern steht der religiöse Gedanke Gor'kijs, der in dem Text von 1907 (und in späteren) zum Ausdruck kommt, den Vorstellungen Lunatarskijs? In welchem Maße kommt Lunacarskij als "Quelle" für Gor'kij in Frage und wie sehr ist dieser von jenem unabhängig?

Die Konzentration auf Lunakarskij und die beiden genannten Texte erscheint methodisch insofern gerechtfertigt und geboten, als einzig bei inm bis 1911 ungebrochen vom Wissenschaftichen Sozialismus als einer Religion die Rede geht. Bei den anderen Mitgliedern der CapriGruppe, die gemeinhin mit den Gotterbauern identifiziert wird, findet man eher wohlwollende bis kritische Distanz zu Lunatarskijs Terminologie ${ }^{6)}$.

Die Darstellung Lunacarskijs erfolgt hier etwas ausführlicher, als diese methodische Einschränkung es vielleicht erfordern würde, weil eine systematische Analyse dieser religionsphilosophischen Variante des Marxismus bisher gänzlich fehlt.

In "Religija i Socializm"7) gibt Lunacarskij einen iberblick über die Grundideen, die inn bei der Entstehung des Buches geleitet haben. Es sind dies seine Vorstellungen

über das Wesen der Religion überhaupt, über den Zusammenhang des Wissenschaftlichen Sozialismus mit den geheimen Hoffnungen der Menschheit, welche in den religiösen Mythen und Dogmen und in den sie ablösenden metaphysischen Systemen zum Ausdruck kommen, über den zentralen ort der A $r$ b $i t$ in der neuen Weltanschauung,...8)

Entsprechend sollen folgende Fragen eine Antwort in unserer Darstellung finden: 
In welcher Weise kritisiert LunaCarskij die "positiven", d.h. existierenden Formen von Religion?

Was bleibt für inn nach dieser Kritik als Konstante, als "Wesen der Religion"?

Worin liegt das "religiöse Wesen" des Wissenschaftlichen Sozialismus - Marxismus begründet?

Wie werden die alten religiösen Begriffe: Gott, Glaube, Hoffnung, Liebe, Tod und Unsterblichkeit, Sünde und Erlösung - und die mit ihnen verbundenen metaphysischen Fragen, die von Marx (und Feuerbach) als "entfremdetes Bewußtsein" abgetan wurden, neu gestellt und definiert?

\section{Die Religionskritik}

LunaCarskijs zweibändiges Werk ist zum größten Teil die Durchführung einer Religionskritik vom historisch-materialistischen Standpunkt aus, d.h. er untersucht für sämtliche ihm bekannten Religionen die Wechselwirkung zwischen ihren konkreten Erscheinungsbildern und den Gesellschaftsformen, in denen sie entstanden sind. Aber schon gleich zu Beginn wird deutlich, wodurch sich Lunatarskij in seinem religionskritischen Ansatz von den sozialdemokratischen Zeitgenossen abhebt:

Es geht inm nicht nur um den Nachweis der Abhängigkeit konkreter Religionsformen von ihren gesellschaftlichen Bedingungen - und in der Folge um den Nachweis, daß eine bestimmte Gesellschaftsformation Religion überhaupt überflüssig macht; vielmehr will Lunatarskij alle diese zu kritisierenden Erscheinungsbilder von Religion als Verzerrungen einer als "wesentlich" erkannten Konstante, des "religiösen Bedürfnisses" zeigen. Eben darum kann er auch mit vollem Recht die Frage nach dem wesen der Religion stellen - im Gegensatz zu seinem dogmatischen Gegenspieler Plechanov, für den Religion ein 'Unwesen' ist und bleibt. 
Dieser Ansatz hat zur Folge, daß Lunacarskijs Kritik der Religion nicht von seiner positiven Bestimmung von Religion zu trennen ist. Es geht inm nicht um den Nachweis des Falschen in der Geschichte der Religionen, vielmehr um die kritische Herausarbeitung des Richtigen, das diese Geschichte zeigt.

Auf der suche nach einem Religionsbegriff, der die "positiven Religionen" 9 ) aufhebt, d.h. negiert und zugleich in einer neuen Qualität bewahrt, stelit Lunacarskij die Unzulänglichkeit der meisten sozialdemokratischen zeitgenossen fest. Sie verbleiben auf der Ebene der Kritik der religiösen Formen und deren Zusammenhang mit den gesellschaftlich-ökonomischen Bedingungen, fragen aber nicht nach dem, was diese Formen hervortreten läßt: Sie fallen, so Lunacarskij, hinter die von Feuerbach erreichte Position zurück, indem sie die Religion lediglich an "ihren kleidern"10) zu fassen kriegen, wogegen Feuerbach sie an "inrem Herzen" gepackt habe ${ }^{11)}$.

Der ökonomische Materialismus kann seiner (Feuerbachs) Kritik viel hinzufügen, aber nur hinzufügen; das Wesentliche ist schon von ihm getan, und das übliche Verhältnis der sozialdemokratischen Autoren $z u$ religiösen Fragen stellt einen schritt zurück dar: vom Kritizismus Feuerbachs zu dem of sehr oberflächlichen Aufklärertum der Materialisten des 18 . Jahrhunderts ${ }^{12}$ ).

Mit Feuerbach sieht Lunacarskij die Kritik der positiven Religionen als erledigt an: "Nach Feuerbach ist die Gottesreligion philosophisch tot"13). Indem dieser die religiösen Inhalte als Projektionen des Menschen entlarvt und damit den Menschen als "Wesen der Religion" erkannt hat, hat er die "Theologie zur Anthropologie erniedrigt", 
bzw. "vielmehr die Anthropologie zur Theologie erhoben"

Wenn nun Marx gezeigt hat, daß dieser Mensch, der nach Feuerbach sein Wesen ins Jenseits projiziert, der gesellschaftliche Mensch ist, daß die Götter meist die "Götter der Herren" 15$)$ sind, daß somit die Kritik des Himmels zur Kritik der Erde werden muß ${ }^{16)}$, so denke ich, daß vom religionsphilosophischen standpunkt her Marx dieses Werk der Erhebung der Anthropologie auf die Stufe der Theologie glänzend fortgesetzt hat, d.h. er verhalf dem menschlichen selbstbewußtsein endgültig dazu, eine menschliche Religion zu werden 17).

Ganz im Sinne von Marx stellt Lunacarskij also fest, daß in einer $\mathrm{Kl}$ assengesellschaft die Religion zu einer "reaktionären Kraft" ${ }^{18}$ ) wird, die Klassenstruktur festigt und den "Herrschenden als stütze dient"19).

Die Verlegung des Schwerpunktes aus dem Leben in ein phantastisches Existieren nach dem Tode rechtfertigt allzu viel, es erschlägt jegliche Entrüstung, jeglichen Protest, jegliches Interesse am Leben und macht die Religion zu einer konservativen Kraft, die dem Fortschritt zutiefst feindlich gegenübersteht ${ }^{20)}$.

Es wurde schon gesagt, daß Lunatarskij an seinen sozialdemokratischen Zeitgenossen - allen voran Plechanov das Verharren auf dieser negativen Stufe der Religionskritik vorhält. Er selbst kehrt von Marx, genauer von dessen ökonomisch-gesellschaftlich bestimmter kritik noch einmal zu Feuerbach zurück und stellt die Frage nach dem "Wesen der Religion" erneut - sie gerät inm allerdings seinem Ansatz entsprechend zur Frage nach dem "religiösen Wesen des Menschen. 


\section{Das Wesen der Religion}

Lunał́arskij hält es für unabdingbar, Feuerbachs Frage nach dem Wesen der Religion wieder aufzugreifen. Mit der "rationalistischen" Kritik der Formen kann es nicht getan sein; das Gefühl für die "Kontinuität der Geschichte"22) lege nahe, daß hinter der Vielfalt der Erscheinungen ein Konstantes, inr "Wesen" liege: dem mit historischem spürsinn Begabten

scheint es seltsam und unwahrscheinlich, daß ein ganzes Gebiet des Geistes absterben sollte, daß jenes Gebäude (stroj) von Gefühlen und Gedanken, welches dem psychischen Leben einer Nation als Achse dient, spurlos zerstört werden sollte. (...)

Er sucht hinter den Formen der Religion jene Bedurfnisse, welche sie hervorgebracht naben ${ }^{23 \text { ). }}$

Sollte hinter den Formen tatsächlich ein Bedürfnis oder ein Komplex von Bedürfnissen als konstant und für den Menschen wesentlich auszumachen sein, so muß weiter gefragt werden, was mit diesen Bedürfnissen nach der endgültigen Kritik und Vernichtung der "positiven Religionen" geschieht, ob und wodurch sie befriedigt werden.

Und das, was sie befriedigt, - besitzt es nicht tiefe Analogien zu den alten Religionsformen, ungeachtet des grundlegenden Unterschieds gerade, was die Formen betrifft ${ }^{24)}$ ?

Mit diesem Frageansatz begibt sich Lunačarskij auf eine spur, die ihn zwingt, grundsätzliche anthropologische Aussagen zu machen. -

Gibt es ein "Wesen der Religion" und ist dieses Wesen über die Frage nach den Bedürfnissen, die Religion 
hervortreten lassen, zu ermitteln, so bedeutet das nichts anderes, als daß es ein religiöses Grundbedürfnis des Menschen gibt - mit anderen Worten: daß der Mensch ein religiöses Wesen ist.

So muß die Konsequenz aus den Prämissen lauten, die LunaCarskijs Fragestellung impliziert.

Welches sind aber die Funktionen, die Religion - in inrem Erscheinungsbild immer ein "Komplex aus Gefühlen, Gedanken und Taten"25) - erfüllt?

Nach Lunatarskif sind hier zwei Antworten möglich: - eine "rationalistische", derzufolge Religion die Aufgabe hat, dem Menschen die Welt zu erklären; - eine "biologistische", die der Religion praktische moralische und emotionale Aufgaben zuteilt. Sie soll die Frage nach dem Glück des Menschen lösen, also die Fragen nach Gerechtigkeit, Macht, Vollkommenheit, Unsterblichkeit ${ }^{26)}$.

Der erste - "rationalistische" - Bereich kann für LunaCarskij nicht wesentlich religiös sein, da er zwar in den frühen stadien der Menschheit ebenfalls durch die Religion abgedeckt wurde ${ }^{27}$, heute jedoch vollkommen in der wissenschaft aufgeht. Das Fortschreiten der wissenschaftlichen Erkenntnis macht Religion als Welterklärung, als systematisierung des Wissens überflüssig.

Bleibt also das Glücksstreben des Menschen als das Grundbedürfnis, das Religiosität ursprünglich und immer wieder entstehen läßt:

Ja, die Forderungen der "praktischen Vernunft", d.h. die Sehnsucht des Menschen nach Glück, können weder als nichtexistent noch für unwichtig erklärt werden, noch können sie von der wissenschaft als solcher erfüllt werden; ${ }^{28}$ ) 
Daher blelbe bei allen noch so großen Erfolgen der wissenschaft ein "Platz für die Religion" ${ }^{29)}$; denn alle religiösen Systeme (einschließlich der Sozialismus) bedeuten nichts anderes, als Versuche, "die Frage nach dem Glück, der vollendung und der Harmonie des Lebens" 30 ) zu beantworten.

a) Die "religiöse Frage"

Denn auf Hof fnung sind

wir gerettet. Rö̀m. 8,24

Indem Lunacarskij das paulinische Theologumenon vom Harren der gesamten Schöpfung auf Erlösung materialistisch interpretiert ${ }^{31)}$, sieht er also die Hauptfunktion von Religion darin, daß sie

die Sehnsucht des organischen Lebendigen nach fülle des Lebens, nach Glück (stillt); ${ }^{32}$ )

denn für ihn ist der Mensch nicht nur ein erkennendes sondern auch ein "bewertendes Wesen": "Erst aus Erkenntnis und Bewertung fließt die Handlung" ${ }^{33)}$. Erkenntnis, d.h. Wissenschaft und System genügen dem Menschen nicht, weil sie keinen Bezug zu "Gefühl, Liebe, Hoffnung" herstellen können ${ }^{34)}$. Die Welt will nicht nur erkannt sein, sie wird zugleich auch bewertet.

Bewerten heiBt, das zu Bewertende in Bezug zu unseren Lebensbedürfnissen setzen. ${ }^{35)}$

Dies aber ist für Lunatarskij das genuine Gebiet der Religion:

Die Wissenschaft fragt nach dem "Wie?" und "Was?" - die Religion aber fragt: "Ist es gut oder schlecht?" (Es zeigt sich, daß Lunacarskij hier Religion mit Ethik gleichsetzt, bzw. verwechselt.) 
Dieses Moment, daß nämlich als Voraussetzung für geschichtIiches Handeln die "objektive" Erkenntnis nicht ausreicht, daß vielmehr das "subjektive" Element der Bejahung, d.h. der positiven Bewertung hinzutreten muß, scheint mir die wichtigste 'Zutat' zu sein, um die Lunatarskij den (russischen) Marxismus durch dessen Revision unter religiösem Aspekt bereichert ${ }^{36)}$.

Wie sieht nun die Welt aus, die der Mensch erkennend bewertet?

Und nach welchem Kriterium bewertet er sie?

Das Bewertungskriterium ergibt sich aus den "Forderungen der praktischen Vernunft", aus der Sehnsucht also nach "Glück, Vollendung, Unsterblichkeit" 37 ), von Lunaxarskij zusammengefaßt unter dem Begriff des "Lebensmarxismus"; das Ideal des "Lebensmaximums" bedeutet in seiner etwas wirren Definition

die gattungsmäßige Vervolikommnung der Menschheit, (...)

die Macht der Gattung, (...)

den sieg der Vernunft über die Elemente ${ }^{38}$ ).

Praktisch bedeutet dies zunächst einmal, daß der Mensch sein Leben erhalten und dann auch erweitern w11l. Aber schon bel der Lebenserhaltung, erst recht bel der Lebensmaximierung stößt er auf Grenzen: auf die "Gesetze der Natur" 39), worunter konkret die Naturgesetze, allgemein das "Reich der Notwendigkeit" $z u$ verstehen sind.

In seiner Lebenspraxis sieht sich also der Mensch dem Widerspruch zwischen den "Gesetzen des Lebens" und den "Gesetzen der Natur" gegenüber; dem Wunsch nach Glück, Vollendung, Unsterblichkeit stehen die anthropologischen Grunderfahrungen: "Krankheit, Tod, Leiden"40) entgegen. "Alles Lebendige leidet." 41 ) 
Indem der Mensch sich dieses Widerspruchs bewußt wird, wird das Leiden für ihn zur religiösen Grunderfahrung:

Sobald der Mensch lernt zu verallgemeinern, verallgemeinert er seine Leiden: Not, Arbeit, Krankheit, Tod, er stellt fest, daß das Leben hart ist oder jedenfalls nicht so, wie es sein müßte, damit er glücklich wäre ${ }^{42)}$.

Die "religiöse Frage" ergibt sich also aus der Weltbewertung:

Die Welt ist von meinem Standpunkt aus schlecht gemacht, das Leben in ihr ist Leiden ${ }^{43}$ ).

Aus dieser Grundstellung ergibt sich für Lunatarskijs Religionsbegriff zweierlei Bedeutsames:

1. entwirft der Mensch gegen die Welt, wie sie real und schlecht 1st, eine Welt, wie sie qut ist und sein sol1, d.h. entsprechend seinem obersten Bewertungskriterium des "Lebensmaximums" schafft er sich das "Ideal"44); 2. macht er sich daran, Ideal und Realität zusammenzubringen, den Grundwiderspruch, die Ursache seines Leidens zu beseitigen. Er wird praktisch. In solcher Praxis aber liegt für Lunacarskij das Wesen aller Erscheinungsformen von Religion:

Das Ideal ist ein Traum, aber nicht ein beliebiger Traum, sondern ein Traum, der durch die unzerstörbaren (sic!) Bedürfnisse hervorgebracht wurde. Die Religion verbindet Ideal und Wirklichkeit, sucht wege von der letzteren zur ersteren ${ }^{45}$.

Daß dieser Befund für alle Religionen gilt, auch wenn sie die Verbindung zwischen Ideal und Wirklichkeit in 
noch so verzerrender form herstellen, will LunaCarskij in seinem Buch zeigen - mit dem Ziel, zu beweisen, daß einzig der wissenschaftliche Sozialismus diese Verbindung wirklich herstellen kann.

Das wesen der Religion liegt also für Lunacarskif darin, daß sie eine zukunftsbezogene Praxis ist, die mit einer bestimmten emotionalen Einstellung (die Gegenwart als schlecht zu überwinden, das Ideal als wünschenswert zu verwirklichen) einhergeht; seinem Gang durch die Geschichte der Religionen kann er daher diese Definition voranschicken:

Religion ist ein solches Denken über die Welt (Handeln setzt Erkenntnis voraus R.S.) und ein solches Weltempfinden, welches psychologisch den Kontrast zwischen den Gesetzen des Lebens und den Naturgesetzen aufhebt ${ }^{46)}$.

Konkreter gesagt:

Wer sich über diese Fragen (Krankheit, Leiden, Tod R.S.) erheben kann - hat Religion. Wer sie ignoriert und deswegen keine Religion braucht, ist ein enger Egoist, Nihilist im übelsten Sinne des wortes. Aber der, der sich über diese Fragen erheben kann ohne die Hilfe eines Gottes? - Ich denke, daß er eine Religion ohne Gott hat. Zu beweisen, daß dies für den heutigen Menschen möglich ist, bedeutet, Gott den Garaus zu machen. (Dokazat', cto ..., znacit dokanat' boga.) 47 )

Damit ist auch das Programm Lunacarskijs umrissen: Aus der Geschichte der vielerlei Lösungen, die der Menschheit zum "religiösen Problem" eingefallen sind, die sich aber 
immer als vorläufige und falsche Lösungsversuche entlarven lassen, geht der Wissenschaftliche Sozialismus - allerdings in der Deutung und Gestalt, die inm Lunatarskij gibt - als die letzte und einzig richtige Lösung hervor.

Er erweist sich vor diesem Hintergrund mit Recht als die "höchste Stufe" von Religion, als eine "neue Religion"48).

Fassen wir zusammen, was sich aus dem bisher gesagten in Lunatarskifs sicht am menschlichen Verhalten als zum religiösen Bereich gehörig darstellt:

1. das Glücksstreben oder die "Forderungen der praktischen Vernunft";

2. das "Lebensmaximum" als oberstes Kriterium für die Weltbewertung;

3. das Erlebnis des Widerspruchs zwischen den "Gesetzen des Lebens" und den "Naturgesetzen";

4. der sich daraus ergebende Entwurf eines "Ideals" (die Welt, wie sie sein soll);

5. die daraus folgende zukunftsbezogene Praxis des Versuchs einer Annäherung von Ideal und Wirklichkeit ( $=$ religiöses Verhalten);

6. die positive emotionale Einstellung, die diese Praxis begleitet und ermöglicht.

Die Praxis, zunächst begriffen als Kampf des Menschen mit der Natur zum Zwecke der Bedürfnisbefriedigung, sowohl wie die emotionale Einstellung, das

Gefühl von höherer Begeisterung, Enthusiasmus, in welchem die Persönlichkeit sich öffnet, über sich hinausgeht, in welchem sie freudig mit einem höheren Prinzip in Verbindung steht;

verweisen auf ein weiteres, Religiosität konstituierendes Element - den 
b) Kollektivgedanken

Daß das "Verbindungselement", das kollektive also, von Anfang an wesentlich zur Geschichte der Religionen gehört, belegt Lunatarskij mit Forschungen Tylors zur Frühgeschichte der Menschneit ${ }^{50}$ ).

Bei dem Bestreben, seine Bedürfnisse zu befriedigen, zunächst elnmal ganz einfach sein überleben zu sichern, stößt der Mensch auf Grenzen, die ihm die Natur setzt. Er allein kann seine Bedürfnisbefriedigung nicht gewährleisten, da er zu schwach ist. Er sucht also die Hilfe (Verbindung) anderer Individuen. Da diese aber in den früheren geschichtlichen stadien ebenfalls noch zu schwach sind, ihre Probleme gemeinsam zu lösen, suchen sie Hilfe/Verbindung außerhalb ihres Erfahrungsbereichs bei den Göttern (Animusmus).

Auch wenn im Laufe der Entwicklung der Menschheit die Götter sich als Hilfskonstruktionen erweisen, und der Mensch immer mehr darauf verwiesen wird, Hilfe nicht ausserhalb sondern innerhalb seiner erfahrbaren welt zu suchen, so bleibt doch diese Grundstruktur erhalten (und für Lunačarskij richtig!):

Religion setzt vor allem Bedürfnisse und Leiden voraus, die zu stillen der Mensch sich machtlos fühlt. Dies und nur dies führt inn jenseits der Grenzen des Individuums, zwingt inn, Verbindung außerhalb seiner zu suchen, Verbündete, Beschützer. Religion - ist Verbindung ${ }^{51)}$.

So läßt sich die Geschichte der Religionen lesen als eine Kette von Versuchen, aus der Erfahrung der 'Grenzsituationen' heraus "Verbindung" herzustellen, was Luna- 
Carskij als eine instinktive Grundahnung des Menschen deutet: $d a ß$ er nämlich sein Glück als Individuum nur im Kollektiv finden kann. Diese Konstellation bleibt, auch wenn sie im Laufe der Vorwärtsentwicklung geläutert wird.

Nachdem durch die fortschreitende Erkenntnis und die damit verbundene Kritik an der Religion die Suche nach einem "höheren Prinzip"52) im Jenseits, zu welchem die Verbindung hergestelit werden könnte, sich als illusorisch herausgestellt hat (Feuerbach), ist der Mensch nunmehr auf das Diesseits - und damit auf den Menschen verwiesen.

Die Bedürfnisse (sind) zwar gewachsen. (...), das Ideal ist anspruchsvoller geworden, aber die Hoffnung auf verbündete Mächte ist zerstört; in der Natur gibt es keinen andern Geist außer dem Menschen ${ }^{53}$ ).

Das bedeutet nichts anderes, als daß der Mensch sich mit dem Menschen wird verbünden müssen, will er als Individuum überleben und sein Glück finden.

Damit liegt für Lunatarskij die endgültige und einzig richtige, well illusionsfreie und Erkenntnis mit Praxis verbindende Lösung der "religiösen Frage" nahe:

Was heißt es also, Religion zu haben? Es heißt, fähig zu sein, die Welt so zu denken und zu fühlen, daß die Widersprüche zwischen den Lebens- und Naturgesetzen sich für uns auflösen. Der Wissenschaftliche Sozlalismus löst diese Widersprüche, indem er die Idee des Sieges des Lebens, der Unterwerfung der Elemente unter die Vernunft durch Erkenntnis und Arbeit, wissenschaft und Technik hervorhebt. 
Somit behaupten wir, daß die Religion lebt und leben wird, daß sie aber vollständig ihre Formen verändert nat ${ }^{54)}$.

\section{c) Zusammenfassung}

Bevor Lunacarskif seinen Gang durch die Geschichte der Religionen antritt, an deren Ende als ziel- und Kulminationspunkt der Wissenschaftliche Sozialismus als die "neue Religion" stehen wird, hat er also eine recht genave Vorstellung von dem, was das Wesentliche und Konstante an den verschiedenen Erscheinungsformen ist, und was somit den Menschen als 'homo religiosus' konstituiert:

Religion ist eine Praxis; und zwar eine Praxis, die darauf gerichtet ist, das Ideal (den Entwurf einer besseren Welt) mit der (am obersten Kriterium der Lebensmaximierung gemessenen und für schlecht befundenen) Realität zusammenzubringen - d.h. die wirklichkeit in Richtung auf eine bessere zukunft hin zu überwinden. Die Beschaffenheit des Ideals macht die Praxis erst möglich, indem es die notwendige Begeisterung entstehen läßt, den Enthusiasmus. Enthusiasmus und Praxis ( $=$ Arbeit) wiederum verweisen durch ihre Struktur schließlich auf eine letzte Konstante - das Kollektiv.

Erinnert man sich an dieser stelle an das Weltmodell, das sich aus der Analyse des Gor'kijschen 'religionsphilosophischen' Textes ergab, so ist die Übereinstimmung deutlich:

Was Gor'kif unter den Begriff der "religiösen Idee" $f a ß t$ und kritisiert, fällt bei Lunatarskij unter die "positiven Religionen", die "kleider" der Religionen. Was Gor'kij unter dem "religiösen Gefühl" verstanden wissen will und für notwendig hält, ist bel Lunacarskif das "Wesen" oder die "Seele" der Religion. 
Lunatarskij geht analytischer 55 ) vor, und bei Gor'kij ist vom wissenschaftlichen Sozialismus nur bedingt die Rede. Aber bei beiden stimmt die Grundstruktur überein, und am auffälligsten ist die Betonung des emotionalen Elements als genuin religiös und für den Menschen konstitutiv. Gegen die mehr oder weniger interesselose objektive Analyse der Bewegungsgesetze von Geschichte und Gesellschaft wird die subjektive Seite, der wertende Mensch in Geltung gesetzt.

Darauf beruht letztlich das Motiv Lunatarskijs, den orthodoxen Marxismus einer 'religions-philosophischen' Revision zu unterziehen. 


\section{Wissenschaftlicher Sozialismus als Religion}

Vergegenwärtigen wir uns noch einmal den Charakter von Lunačarskifs Fragestellung:

Es steht für inn gar nicht zur Debatte, ob der wissenschaftiche Sozialismus elne Religion ist oder nicht; Lunatarskif weiB von vornherein:

Der Wissenschaftliche Sozialismus ist die religiöseste aller Religionen, und der Sozialdemokrat ist ein zutiefst religiöser Mensch ${ }^{56)}$.

Dies gilt es zu beweisen. Es muß gezeigt werden, daß der Marxismus die Qualität einer Religion hat; es wird nicht gefragt, ob er sie hat. Dies zeigt die Anlage des ganzen Buches "Religija 1 socializm" (Und "Budustee religii"): Zuerst wird ein Vorbegriff von Religion als anthropologische Konstante gewonnen und danach erst wird diese Konstante verfolgt in ihren vielerlei Ausprägungen durch religiöse und metaphysische systeme - bis sie schließlich im Marxismus zu ihrem 'Wesen' gelangt.

Muß daher auf dem Hintergrund von Lunacarskijs Ansatz, der ein bestimmtes anthropologisches Verständnis - nämlich das vom Menschen als homo religiosus - enthüllt, der Nachweis, daß der Marxismus eine Religion sei, nicht richtiger zum Nachweis dessen geraten, daß er eine Religion sein oder werden muß, weil er andernfalls eine als wesentlich erkannte Seite des Menschen unberücksichtigt ließe - und somit keine Zukunft hätte? -

Diese Frage scheint umso wichtiger und berechtigter, als deutlich wurde, daß der Religionsbegriff Lunacarskijs mit dem von Marx kaum mehr etwas gemeinsam hat. 
Marx macht keinen Unterschied zwischen den "entarteten" und also zu kritisierenden Erscheinungsformen von Religion und inrem "Wesen"; für ihn ist und bleibt Religion in ihrem Wesen "verkehrtes Weltbewußtsein", "allgemeine Theorie dieser Welt", und "die Aufhebung der Religion als des illusorischen Glücks des Volkes ist die Forderung seines wirklichen Glücks "57).

Marx' Religionsbegriff ist al so eher destruktiv-kritischer Natur, während der von Lunacarskij konstruktiv-kritisch ist.

Der Vorwurf des letzteren gegen seine sozial-demokratischen Zeitgenossen, für die Religion lediglich das "Opium des Volkes" ist und somit verschwinden muß, - der Vorwurf nämlich, daß sie die Religion nur an den "kleidern" zu fassen kriegten, nicht aber an inrer "Seele", müßte also auch Marx treffen ${ }^{58}$ ).

Man muß sich deshalb fragen, weshalb Lunatarskij von Marx noch einmal zu Feuerbach und zu dessen schon abgetaner Frage nach dem "Wesen der Religion" zurückkehrt - allerdings mit dem Wissen der Marxschen Gesellschaftstheorie im Hintergrund und mit der positiven Vorgabe, daß diese Frage immer noch sinnvoll ist, daß es an der Religion ein zu Bewahrendes gibt.

Wenn Lunacarskij als begeisterter und überzeugter Marxist von Jugendjahren ${ }^{59}$ ) das Religionsproblem noch einmal aufrollt - mit dem vorgezogenen Ergebnis, daß der Marxismus eine Religion sei - so muß dem das Empfinden vorausgehen, daß der Marxismus, zumindest in der von Lunacarskij rezipierten Gestalt, Mängel aufweist und Probleme offen1 äßt. 


\section{a) Kritik am orthodoxen Marxismus}

In der Einleitung zu seiner 1905 erschienenen Sammlung von Studien "Étjudy..."61) schreibt Lunacarskij:

Zum ersten Mal lernte ich den sogenannten "Marxismus" vor relativ sehr langer zeit kennen, und zwar im Jahre $1892^{62 \text { ) }}$

Für ihn, den damals siebzehnjährigen, sei der Marxismus nicht nur "eine bestimmte Gesellschaftslehre sondern eine ganze Weltanschauung" gewesen. Dennoch habe er im Marxismus auf einige Fragen keine Antwort gefunden.

Diese Fragen zu beantworten im Geiste meiner allgemeinen Weltanschauung, Antworten auf sie zu finden, welche sich auf natürliche Weise zu meinen marxistischen Anschauungen fügten - das war das wesentliche Erfordernis, das ich empfand ${ }^{63)}$.

Aber in einem Marxismus, der im "Kampf ums Dasein" und im "Kampf um die Herrschaft über die Natur" den Hauptmotor der Geschichte sah und den Klassenkampf als ihren "Mechanismus" lehrte, trat der Mensch nur als "äußeres objekt, als eine besondere Art Transmissionspunkt" auf ${ }^{64)}$. In der wissenschaftlichen Analyse erschien, so Lunatarskij, das menschliche Leben nur als Schaltstelle "gesetzmäßiger energetischer Prozesse"65).

Daneben sei aber "als unzweifelbare Tatsache auch noch das Bewußtsein gegeben"66). Hierbei sei für ihn von besonderem Interesse die Frage nach der Erkenntnis gewesen.

Auf der Suche nach einer Anschauung von der Erkenntnis, die alle meine Anforderungen befriedigen und sich 
zugleich ohne Zwang mit den Wahrheiten des Marxismus zusammenfügen würde, hatte ich das Glück, die biologische Erkenntnistheorie Richard Avenarius' und die Ansichten Ernst Machs zu dieser Frage kennenzulernen ${ }^{67 \text { ) }}$.

Das erste Gebiet also, auf dem Lunacarskif vom Marxismus unbefriedigt war, war das der Erkenntnistheorie. Dieses Gebiet sei für inn zwar von großem Interessen gewesen (und es hat auch seine Bedeutung als Basis für wert- und religionsphilosophische Urteile); wichtiger Jedoch - auch für unseren Zusammenhang - war inm ein anderes Problem, mit dem wir auf die grundlegende Fragestellung seiner späteren 'Religionsphilosophie' treffen: das Problem des "Werturteils" (ocenka).

Bel den Bemühungen, in biologischen Termini das Problem der Schönheit zu lösen, kam ich zu der überzeugung, daß die biologischen Erscheinungen, die den ästhetischen Emotionen zugrundeliegen, auch entschieden allen Bewertungen zugrundeliegen; alle menschlichen Werturteile standen vor mir als Weiterentwicklungen und Variationen einer Grundwertung, deren wurzel die $L$ e b e $n s g i$ e $r$ ist (zazda zizni).

Um diese beiden Angelpunkte: Erkenntnis und Werturteil wird sich die Auseinandersetzung Lunatarskijs und seiner Gesinnungsgenossen mit dem orthodoxen Marxismus drehen. Dabei wird er das Gebiet der Erkenntnistheorie bald mehr in den Zuständigkeitsbereich Bogdanovs rechnen und sich selbst das Feld der Ästhetik, das bel inm auch die Ethik umfaßt, vorbehalten ${ }^{69}$ ).

In seiner nächsten, 1906 erschienenen Aufsatzsammlung "Otkliki zizni"70) präzisiert Lunaćarskif diese beiden 
Berelche als der Bearbeitung und Überarbeltung durch überzeugte Marxisten bedürftig. Hier taucht das Problem des "Werturteils" allerdings unter dem Begriff der "Psychologie" auf:

Diemenschliche Psychik, die individuelle wie die kollektive, ist ein außerordentlich feiner und komplizierter Mechanismus. Wie nämlich das "Sein" das Aufkommen, die Entwicklung und den Tod dieser oder jener Idee bestimmt, wie sich in den Herzen der Enthusiasmus entzündet, oder wie sich Apathie über sie ergießt, auf welche Weise sich kollektive ziele in ein individuelles Ideal verwandeln, das so mächtig ist, $d a ß$ vor seinen forderungen alle egoistischen Instinkte bis hin zum Selbsterhaltungstrieb verstummen - dies sind einige aus dem Meer von Aufgaben, die die Psychologie uns stellt ${ }^{71}$.

Es ist $k l a r, d a ß$ es hier trotz leicht veränderter Terminologie wieder um die eine der beiden Grundfragen LunaEarskijs geht: die des Werturteils, d.h. letztlich um die Begründbarkelt einer Ethik auf marxistischer Basis. Denn wenn gefragt wird, wie "In den Herzen" der (handelnden) Individuen "Enthusiasmus" oder "Apathie" entstehen, wie ein "kollektives ziel" zu einem "individuelien Ideal" werden kann, dann geht es um das Problem, auf welcher (ethischen) Grundlage ein Individuum eine kollektive zielsetzung positiv bewerten und zu seiner eigenen machen kann.

Dies führt Lunatarskij folgerichtig weiter zur Kritik an der "marxistischen Sozlologie". Sie beschäftige sich lediglich mit der Wirkung der Umgebung auf die Handlungen der Individuen, vor allem aber der Massen. Jedoch das, was innerhalb des Individuums vorgehe, "die Arbeit des psychischen Übertragungsmechanismus"72), Ignoriere die marxistische soziologie ${ }^{73)}$. 
Für das Gebiet der Erkenntnistheorie verweist Lunatarskij jetzt ausdrücklich auf den "Empiriomonismus" Bogdanovs:

Wenn ich auch die Ideen des Genossen Bogdanov bei weitem nicht in inrer Gesamtheit teile, so muß ich doch darauf hinweisen, wie fruchtbar die Verbindung zwischen den Resultaten der neuesten wissenschaftlich-philosophischen Gedanken und den Grundgedanken des Marxismus ist, die er seinen Forschungen zugrundelegt ${ }^{74}$ ).

Lunačarskif nennt als Vertreter dieser "neuesten wissenschaftlich-philosophischen Gedanken" unter anderen Maxwell, Hertz, Ostwald, Mach und Avenarius und stellt fest:

Der Marxismus wird diese Ideen aufnehmen, weil sie inm verwandt sind; er wird sie umarbeiten und damit den großartigen Tempel der proletarischen Philosophie festigen und erweitern ${ }^{75)}$.

Eine marxistische Erkenntnistheorie hat nach Lunacarskijs Überzeugung in die Richtung zu gehen, in die Bogdanovs Empiriomonismus weist, der "die Herbeiführung einer sozialpolitisch gemeinten prinzipiellen Einheit der Erfahrung (...) zum ziel" nat ${ }^{76)}$.

In "Religija i socializm" (Bd.I) schließlich wird die Kritik am orthodoxen Marxismus noch klarer. Hier weist Lunałarskij zunächst darauf hin, daß es neben der "proletarischen Weltanschauung" auch noch elne "proletar1sche Weltbewertung" gebe (miroocenka), welche wie die erstere

natürlich relativ vergänglich (prechodjaš̌aja) und, auf jeden Fall, eine rein menschliche, subjektive Form des Empfindens ist ${ }^{77 \text { ). }}$ 
Diese Erkenntnis erlaubt es Lunadarskij, eine "normative", "biologische Ästhetik" zu konstruieren. Damit ist eine Ethik gemeint, die auf dem obersten Kriterium der "Lebensmaximierung" gründet ${ }^{78}$ ).

An dieser stelle muß man sich erinnern, mit welchen Begriffen Lunaxarskif seinen 'religions-philosophischen' Ansatz gewonnen hat.

Es war dies zunächst das "Glücksstreben" des Menschen als Motor der Geschichte - oder, in Kantischer Formulierung: die "Forderungen der praktischen Vernunft" 79). verweist solche Terminologie schon (aus marxistischer Sicht allzu sehr) in die Nähe Kantscher und neukantianischer Ethik, so erst recht das "Ideal", welches in Lunałarskijs Religionsverständnis einen zentralen Platz einnimmt.

Religion ist nämlich "Praxis", und das "Ideal" stellt genau die Unterscheidung zwischen Sein und sollen her, die bei kant voraussetzung für eine Ethik ist ${ }^{80}$. Und es geht LunaCarskij schließlich um nichts anderes, als um das Problem, wie die subjektive Entscheidung des Individuums für das "Ideal" - wie also das werturteil, das der Praxis des Kampfes für den Sozialismus vorausgehen muß, begründbar wird.

Lunacarskif befindet sich damit in unmittelbarer Nähe der russischen Neukantianer, die sich zum ersten Mal in dem Sammelband "Problemy idealizma" (Probleme des Idealismus, 1903) ${ }^{81}$ ) artikulieren. Es ist in diesem Zusammenhang aufschlußreich, daß er seinen Begriff der "biologischen Ästhetik" vor allem in Auseinandersetzung mit und in Absetzung von Berdjaev, einem der Exponenten des russischen Neukantianismus und früheren Marxisten, gewinnt. 
Schon gleich zu Beginn von "Religija i socializm" stellt Lunararskij ja fest, daß bereits 1898 er und Berdjaev an demselben Problem gearbeitet nätten ${ }^{82}$ ). Berdjaev verläßt jedoch in den folgenden Jahren die gemeinsame Ausgangsbasis: den Marxismus, während Lunatarskij an dieser Grundlage festhält. Mit seinem Begriff der "biologischen Ästhe$t i k "$ und dem damit verbundenen obersten kriterium des "Lebensmaximums" versucht er offensichtlich, sich vor dem Sündenfall des Neukantianismus zu schützen. Dort wird nämlich die Nicht-Ableitbarkeit eines Werturteils aus der wissenschaftlichen ("objektiven") Analyse der Gesellschaft und der Geschichte zum hauptsächlichen Kritikpunkt am Marxismus:

Der erste, allgemeinste (Grundsatz des Neukantianismus) lautet, daß selbst dann, wenn die Marxsche Geschichtsphilosophie mit ihrem Glauben an die Unvermeidlichkeit des sozialismus recht hat, aus dieser Theorie nicht folgt, daß der Sozialismus ein Wert ist, den man akzeptieren muß ${ }^{83}$ ).

Indem nun Lunacarskij das oberste Kriterium des "Lebensmaximums" zunächst evolutionistisch aus den Entwicklungsgesetzen der Natur herleitet und als lenkendes Prinzip für alles Organische, das Leben überhaupt - also auch für den Menschen und seine Geschichte erkennt oder besser anerkennt, bewahrt er zumindest den Schein der Ableitbarkeit des Werturtelis aus der Erfahrungswelt, das dann zum tätigen Einsatz des Individuums für den Aufbau des Sozialismus führen soll.

Zieht man jedoch die Unbestimmtheit und Unbestimmbarkeit dieses Begriffs in Betracht, so scheint er doch in erster Linie aus dem Bedürfnis einer Grenzziehung entstanden zu sein und aus dem versuch heraus, wissenschaftlichen Sozla- 
lismus als "mirovozzrenie" - objektive Weltanschauung und Wissenschaftlichen Sozialismus als "miroocenka" subjektive Weltbewertung - aus einem gemeinsamen obersten Prinzip (Monismus!) abzuleiten. (Dies gilt für die gesamte Konstruktion des Marxismus als "Religion": Die subjektive Seite soll wieder in ihre Rechte eingesetzt werden.)

Auf seine Nähe zu den Neukantianern weist Lunatarskij selbst indirekt hin. Die "idealisierten" ehemaligen Marxisten seien sozusagen von derselben Notwendigkeit ausgegangen wie er:

Herr Berdjaev hat die Aufgabe genau formuliert: (...), ist es unmöglich zu beweisen, daß der Sozialismus das gegenwärtig denkbar höchste Gesellschaftsideal ist, ungeachtet der Interessen dieser oder jener Klasse und ungeachtet der Frage der Unvermeidbarkeit. seines Eintretens ${ }^{84)}$ ?

Und den "rechtgläubigen Marxisten" wirft Lunatarskij vor, daß sie diese "Frage und Aufgabe einfach nicht gesehen haben, wo Berdjaev sie sah"85).

Der Gegner, gegen den sich Lunatarskijs Vorwurf der Vernachlässigung der Wert-Frage vor allem richtet, ist unschwer auszumachen: Im Zusammenhang der Auseinandersetzungen mit den "Orthodoxen" fällt meist der Name Plechanovs - und als dessen westliches Pendant Kautsky ${ }^{86)}$.

Lunatarskij findet bisweilen herbe Worte für Plechanov, den "Vater des russischen Marxismus" ${ }^{87)}$ :

Er habe Marx nicht verstanden sondern "verzerrt"88); Marx sei in seiner Jugend schon weiter als Plechanov gewesen $^{89)}$; insgesamt werden die Orthodoxen als "Wächter im marxistischen Museum" 90 ) und als "Marksisty-fatalisty" (Marxisten-Fatalisten) bezeichnet ${ }^{91}$ ). 
Für den Marxismus in der Plechanovschen Verkürzung, so Lunałarskij, genügten zwei Thesen als Ausgangspunkt für die gesamte Weltanschauung:

Der Sozialismus nützt dem Proletariat;

der Sozialismus wird eintreten nach den Gesetzen der Entwicklung und der Auflösung der kapitalistischen Gesellschaft ${ }^{92)}$.

Dies ist für Lunatarskij ein "verkürzter standpunkt" (uskoe suzdenie) 93), den er als "plechanisierten Marx" (plechanizirovannyi Marks) bezeichnet und bestreitet ${ }^{94}$ ).

Im Zuge seiner Überlegungen zu Kautsky, dem 'westlichen Plechanov.95), bezweifelt Lunackarskij, daß die gesellschaftlichen Ziele ausschließlich aus der Erkenntnis der gegebenen materiellen Grundlagen erschlossen werden können ${ }^{96)}$;

und behauptet,

die Wissenschaft (= Wissenschaftlicher Sozialismus) höher als das Ideal zu stellen, ist fast dasselbe, wie wenn man das Teleskop für wichtiger als das Auge nält 97 ).

(Dieser Vergleich verdeutlicht sehr anschaulich das Anliegen Lunatarskijs: das Gewicht von der "objektiven" Seite - dem Objektiv des Teleskops - in Richtung auf die "subjektive" - das Auge des Betrachters - zu verlagern.)

Mit dem Namen Kautskys war sie schon angedeutet: Die Parallelität der Auseinandersetzungen in der russischen Sozialdemokratie und in der westeuropäischen.

Auch hier im westen ließen die "Umbrüche in der (dt.) Sozialdemokratie seit dem Ende des 19. Jahrhunderts"98) 
die Frage nach dem Menschen als Subjekt der Geschichte in never Schärfe hervortreten. Ein zeitgenössisches Zitat mag belegen, daß auch hier Kritik daran laut wurde, daß im System des Wissenschaftlichen Sozialismus der Mensch nur als "Transmissionspunkt" objektiv wirkender Kräfte vorkam ${ }^{99)}$ :

Nur wer die Bildungs- und Kulturaufgaben der Parte 1 $\mathrm{zu}$ bearbeiten hat, ist an einer theoretischen $\mathrm{Klä-}$ rung des Problems Mensch interessiert; über diesen engen Fachbereich hinaus fragt man nach dem Menschen überhaupt nicht 100 ).

In diesem Zusammenhang sel auch an die Auseinandersetzung zwischen Kautsky und Eisner 1905 im "Vorwärts" (und "Neue Ze1t") um die "ethisch-ästhetische" und "ökonomisch-historische" Denkweise erinnert ${ }^{101)}$. Die Positionen entsprechen den von Plechanov einerseits und Lunacarskij andererseits elingenommenen in RuBland.

Die zuletzt angestellten überlegungen erschienen notwendig, da Lunačarskijs Konstrukt einer neuen Religion nur dann richtig verstanden und gewürdigt werden kann, wenn der Ort der Problemstellung bekannt ist. Dieser Ort innerhalb der Diskussion in der russischen Inteligenz, aber auch im westeuropälschen Rahmen - war zu bestimmen.

Schon mit der Fragestellung, die bei Feuerbach anknüpft, war es klar: Der im "grauen Mantel des Materialismus" elnhergehende Marxismus hatte sich für Lunaxarskif als so vital zu erweisen, daß er auf die drängenden Fragen der Zeit eine Antwort geben konnte - dazu mußte man inn notfalls "weiterentwickeln" - ; und daß er damit die Qualität einer Religion bewies, den Vergleich mit konkurrierenden systemen also aufnehmen konnte. 
b) Die neue Religion - Gefühl und Enthusiasmus

Worin liegt nun also für Lunacarskij der

Zusammenhang des wissenschaftlichen Sozialismus mit den geheimen Hoffnungen der Menschheit, wie sie in den religiösen Mythen und Dogmen und in den sie ablösenden metaphysischen Systemen zum Ausdruck kommen ${ }^{102)}$ ?

Die oben umrissene Kritik am (orthodoxen) Marxismus, der die "Kraft zur synthese" und damit seine religiöse Qualität verloren hat, wird schon früher als 1909 ausgesprochen. ("Synthese" meint hier die Fähigkeit, "Ideal" und "wissenschaftliche" Analyse in der (religiösen) Praxis zusammenzubringen, vor allem aber der subjektiven, emotionalen Seite ihr Recht zu lassen.) 103) In einer vermutlich schon Ende 1903 geschriebenen Polemik gegen die Verfasser des Sammelbandes "Problemy idealizma"104) formuliert Lunatarskij sein Programm:

Wenn die Vernunft sich als stärker erweist (als das "Herz" R.S.), dann muß das Herz neue Lebensprinzipien ausarbeiten, eine neue Moral, eine neue Religion ${ }^{105)}$.

Als Beispiel für einen solchen Vorgang führt Lunacarskif Nietzsche an.

Der Stellenwert des "Gefühl" ("Herz") innerhalb eines philosophischen oder weltanschaulichen systems entscheidet, so Lunacarskij, über dessen Religiosität oder Areligiosität:

Der Schwerpunkt liegt in der gefühlsmäßigen Verbindung des Menschen mit dem einen oder andern objekt und nicht in der Weise der verstandesmässigen Erklärung dieses Objekts ${ }^{106)}$. 
Solche "lebendige Verbindung" heißt für Lunacarskij "Religion"107). Sie soll aber nicht nur zwischen dem erkennenden und handelnden Individuum einerseits und einem System, einer Sache andererseits bestehen; sie erstreckt sich auch und vor allem auf andere Individuen, auf das Kollektiv. Wenn das Band zwischen Individuum und Kollektiv "bewußt emotional" ist, ist es religiös. (Religion ist Verbindung - aber emotionale Verbindung!)

Die Verbindung ist eben das religiöse Gefühl, von dem wir sprechen; und wenn wir es ergänzen durch den religiösen praktischen Idealismus, d.h. durch das Bestreben, die Gesetze der Natur den Gesetzen des Lebens mittels Erkenntnis und Arbeit zu unterwerfen, dann werden wir die ganze Religion haben in ihrer ganzen Gestalt, in ihrer durch nichts verzerrten Schönheit ${ }^{108)}$.

Was ist es, das Lunacarskij veranlaßt, dem "emotionalen Sinn" der Marxschen Philosophie nachzuspüren, um zeigen zu können, daß "diese Philosophie religiös ist"109)?

Es geht um die (Wieder-) Entdeckung des Enthusiasmus als einer höchst intensiven Lebenseinstellung, die das Individuum seine Grenzen durchbrechen läßt. Grenzen, sowohl seinen geschichtlichen ort betreffend - von der Gegenwart zur zukunft - als auch bezüglich seiner sozialen Stelle - vom Individuum zum Kollektiv.

Enthusiasmus ist für Lunatarskij jene emotionale Einstellung, die im Individuum die Bereitschaft wecken kann, sich für ziele einzusetzen, die jenseits seiner konkreten und direkt erfahrbaren wirklichkeit liegen, und solche ziele als die eigenen anzuerkennen, die sich eine Gemeinschaft oder die "Gattung" überhaupt setzt. 
Unter diesem Blickwinkel der Freisetzung von Energien ist der Enthusiasmus das, was den alten und der neuen Religion gemeinsam ist ${ }^{110}$ ).

Lunatarskij umschreibt es mit einer von Nietzsche entliehenen Wendung: Ein "Kind des Enthusiasmus" sei die Liebe zum Fernen (ljubov' $k$ dal'nemu) mit einem Spiegel in der Hand; wer in diesen Spiegel blickt, verliebt sich besinnungslos in das anmutige Antlitz unseres Nachkommens - des Menschgottes ${ }^{111)}$.

(Bei Nietzsche heißt es entsprechend: "Höher als die Liebe zum Nächsten ist die Liebe zum Fernsten und Künftigen"112).)

Solcher Enthusiasmus, welcher Gegenwart, Egoismus und letztlich sogar den (individuellen) Tod besiegen kann, hat zweierlei zur Voraussetzung:

Erstens die Lebensbe fahung:

Früher hieß es, die Furcht Gottes sei der Anfang der Weisheit. Wir sagen: Die Liebe zum Leben ist der Anfang der Weisheit. (....)

Die Liebe zum Leben, wir wiederholen es, muß vom Tode befreien, unsterblich machen ${ }^{113}$ ).

Auf den Wissenschaftlichen Sozialismus angewandt lautet folglich die Devise: "Der Proletarier sagt 'Ja' zum Leben"114).

Zweitens tritt hier das "Ideal" in seine Funktion: Das Leben ist nicht so beschaf $f e n$, daß man sich dafür begeistern könnte ${ }^{115)}$, es sei denn, man hat dem, was 1st, etwas entgegenzusetzen, das sein soll. 


\section{c) Das I de a l}

Dieses Ideal als das Sein-Sollende durchzieht als eine, wenn nicht gar die zentrale Größe den gesamten Gedankengang Lunacarskijs - nicht erst in "Religija i socializm". Es ist das, was er dem orthodoxen Marxismus als ein dem 'echten' Marxismus eigentümliches dynamisches Element entgegensetzen will.

Wenn der Sozialismus als die Gesellschaftsform der Zukunft aus den Bewegungsgesetzen der Geschichte ableitbar ist und notwendig eintreten wird, ob er bejaht wird oder nicht, kann er schwerlich die Motivation dafür liefern, daß der einzelne Proletarier alles, möglicherweise sogar sein Leben dafür einsetzt.

Steht diesem aber der Sozialismus als ein "Sein-Sollendes", als etwas wünschenswertes, als sein "Ideal" eben, vor Augen, so wird er bereitwillig sein Leben drangeben, zumal inn dieses Ideal seine Individualităt als aufgehoben im kollektiv erleben läßt. Es geht also darum, den Nachweis zu erbringen oder den Marxismus so zu interpretieren/ergänzen, daß das, wofür er zum Kampf auffordert, vom Einzelnen als emotional wünschenswert erfahren werden kann 116).

Anhand welcher Kriterien soll dieser Nachweis erbracht werden?

In der Auseinandersetzung mit der marxistischen Orthodoxie behauptet Lunacarskij, die wissenschaftlich-ökonomische Analyse der materiellen Grundlagen der Gesellschaft kann die (gesellschaftlichen R.S.) ziele abgrenzen, sie genauer bestimmen, aber wie immer es auch sei, diese Ziele müssen Etappen auf dem Weg zum Lebensmaximum sein, zum vorantreibenden Ideal des Glücks; 
und Jene Tatsache, daß die Menschen nach Glück streben, daß sie nach einem Glück streben können, welches nicht so sehr individuell, als vielmehr gesellschaftlich ist, - all das ergibt sich nicht aus der Erkenntnis der materiellen Grundlagen, sondern wird vom Leben selbst diktiert ${ }^{117)}$.

Dem Glücksstreben, der "Sehnsucht alles Organischen, Lebendigen nach Fülle des Lebens" ${ }^{118)}$, als dem eigentlichen Motor der Geschichte, dem die verschiedenen Antworten der Religionen korrespondieren, waren wir bei der Bestimmung des Religionsbegriffs Lunacarskijs schon begegnet ${ }^{119)}$.

Das "Leben selbst" of fenbart als das inm immanente oberste Kriterium und Entwicklungsgesetz das "Lebensmaximum", die denkbar höchste Steigerung des Lebens. Dementsprechend propagiert Lunatarskif "Gier nach Leben, Macht, Aufschwung und Leidenschaft" als einen obersten Wert ${ }^{120)}$ :

Die Erbauer des Lebens, die Schöpfer seiner neuen Formen, müssen völlig andere Kriterien für die Bewertung der Menschen aufstellen. Verehren (d.h. gutheißen R.S.) kann man nur um der stärke willen.

Stärke (sila) ist alles, was das Leben intensiver macht, es verschönert, was in der Lage ist, das reale Leben an das Ideal eines mächtigen, weitausholenden mensch-göttlichen (celoveko-božeskoj) Lebens anzunähern ${ }^{122)}$.

Dieses Grundgesetz des Lebens hat für Lunatarskij jedoch nicht zur Folge, daß das Ideal der höchsten Lebenssteigerung zur totalen egoistischen Lebensverwirklichung wird. Im Gegenteil: Das Leben auf der Stufe intensivsten vollzugs und Empfindens birgt in sich ein überindividuelles Element ${ }^{123)}$ : 
Das machtvolle Leben kann nicht egoistisch sein, dafür ist es zu weit; es ergreift die andern, weckt, ruft sie, es weist auf ungeheure Taten hin, weil die Psychik des Menschen dauernder ist und weiter als sein Körper ${ }^{124}$ ).

So ergibt sich für das Ideal, wenn man es am Kriterium der höchsten Lebenssteigerung, des Lebensmaximums miBt, zweierlei: Für seine Bestimmung werden eine überindividuelle/kollektive (1) und eine praktische/ökonomische (2) Seite konstitutiv. Das "Ideal des Lebensmaximums" wird denn auch definiert als die "gattungsmäßige Vollendung der Menschheit", die "Macht der Gattung", der "Sieg der Vernunft über die Elemente" (Natur) ${ }^{125)}$; zusammengef aßt:

Die Lebensgier, die der Arbeit ( = Kampf mit der Natur R.S.) zugrundeliegt, hat als ihren natürlichen Ausdruck das Ideal der ökonomischen Mächtigkeit der Menschheit $^{126)}$.

Mit anderen worten:

Die Brücke, die Lunacarskij vom "Wesen der Religion" zum Wissenschaftlichen Sozialismus schlägt, ruht auf den Pfeilern Gattung (Kollektiv) und (ökonomischer) Fortschritt.

Kann man zeigen, daß der Marxismus mit seinem Kampf dem (allgemein-menschlichen) Fortschritt dient und damit zur Vervollkommnung der Gattung beiträgt, so beweist man damit seine religiöse Qualität.

\section{d) Ideal und Fortschritt}

Hier muß auf einen widerspruch eingegangen werden, der sich in Lunatarskijs Gedankengang auftut. Einerseits 
bildet den Ausgangspunkt für seine Revision des Marxismus die Überlegung (wie auch für Berdjaev126a), daß der Sozialismus als 'summum bonum' nicht aus der Analyse der Realität, bzw. der Bewegungsgesetze der Geschichte abgeleitet werden kann. Um diesen Punkt dreht sich die ganze Polemik gegen die Orthodoxen, allen voran Plechanov.

Andererseits versucht Lunacarskij genau dies zu tun, nämlich das "Ideal" abzuleiten, wobei seine Kriterien zunächst andere Namen haben, zuletzt aber doch der Glaube an den Fortschritt, den meß- und ableitbaren triumphiert.

Dieser widerspruch geht auch in die Bezelchnung "Idealrealist" für Marx"127) ein. Marx sei ein solcher "Idealrealist", weil er als Schüler der Utopisten und Hegels von der Frage ausgegangen sel: Wie $k$ ann das Ideal in die Realität ungesetzt werden ${ }^{128)}$ ?

\section{Marx' Ideal}

ist noch immer jenes höchste Ideal, das von allen großen Religionen der Menschheit hochgehalten wurde: Glück und Gerechtigkeit, Freiheit und Macht über die Natur ${ }^{129)}$.

Das mag zunächst so klingen, als sei das Ideal eine allgemeine, letztgültige Größe und als habe Marx nur die Bedingungen der Möglichkelt beschrleben, Wege von der Realität zum Ideal zu finden. Wenig später 130 ) aber heiBt es, Marx habe die "materielle Herkunft des 'Ideals'"131) erforscht. Aus seiner Analyse der Gesellschaft folge, daß die Entwicklung (der Produktivkräfte) in sich das Ideal des Sozialismus enthalte, was sich im Proletariat widerspiegele. Die Analyse der Gesellschaft zeige, daß der Untergang des Kapitalismus "ökonomisch" den Sozialismus 
und "politisch" die Diktatur des Proletariats notwendig macht :

Das Ideal kann nur siegen als Ideal des Proletariats. Das Proletariat kann nur siegen als Träger des Ideals, denn für dieses bedeutet das Verstehen der eigenen Lage, zu einem solchen Träger zu werden. Solcher Art ist die große marxistische synthese ${ }^{132)}$.

Wenn das Ideal auch scheinbar nicht ableitbar ist, so soll es doch seine Richtigkeit beweisen können durch den verweis auf seine "objektive" Basis: die sozial-ökonomischen Verhältnisse,

durch den Verweis auf jene objektiven Kräfte, als deren Refelx es dient ${ }^{133)}$.

Aus der Analyse jener "objektiven Kräfte" ablesbar ist aber das Gesetz des technischen und ökonomischen Fortschritts.

Genau hier, in diesem objektiven Faktum, sozusagen in der gesellschaftlichen Physiologie, im Fortschritt oder Rückschritt der Technik, in der ökonomischen Entwicklung oder im ökonomischen Zerfall, in der Annäherung an die Herrschaft über die Natur oder in der Entfernung von ihr - hier liegt für den Marxisten das objektive Kriterium für die Bewertung der Ideale.

Daher müsse für einen

ökonomischen Materialisten das höchste Ideal das Ideal der fortschrittlichen Klasse in einer möglichst schnell sich entwickelnden Gesellschaft $\operatorname{sein}^{134)}$.

Was also in den früheren Schriften Lunacarskijs ${ }^{135}$ ) noch als "Lebensmaximum", "Lebensgler", "machtvolles Leben" usw. den undeutlichen Hintergrund für das subjektive Bewerten 
der Welt abgab und dem "Wesen der Religion" zugrundelag, entpuppt sich jetzt als (platter) Glaube an den technisch-wissenschaftlichen und ökonomischen Fortschritt 135a). Und da die ökonomische Basis das gesellschaftliche Bewußtsein bestimmt, bedeutet fortschritt zugleich auch geselischaftlicher, allgemeinmenschlicher Fortschritt.

Die Annäherung an das Ideal wird somit ablesbar, meßbar an der technisch-wissenschaftlichen Entwicklung ${ }^{136)}$. (Diese Konsequenz ist bedeutsam für die Einschătzung von Gor'kijs (und Lunacarskijs) Menschenbild in seiner Entwicklung vom emphatisch beschworenen "MENSCHEN" zum "Neuen Menschen", den er in den Fabrikhallen des jungen Sowjetstaates zu sehen glaubt.)

Folgerichtig heißt es dann auch bel Lunatarskij: "Das höchste Ideal ist das der fortschrittlichsten Klasse."137) Und die fortschrittlichste Klasse ist natürlich das Proletariat ${ }^{138 \text { ) }}$.

In seiner Genese ist dieser Fortschrittsglaube Lunačarskifs allerdings weniger eindimensional als er in "Religija 1 socializm" auftritt. Wird hier faktisch die Gleichung: fortschrittlich = gut aufgemacht, so sieht Lunacarskif 1905 in seinem Artikel "Dacniki"139) den Fortschrittsglauben weniger als selbständigen und selbstverständlichen, nicht hinterfragten wert - vielmehr beurteilt er diesen in seiner positiven, Energie freisetzenden Funk$\operatorname{tion}^{140)}$.

Der Fortschrittsglaube (vera $v$ beskonecnyf progress nauki i techniki), heiBt es dort, mag eine Illusion sein; aber er macht den Menschen fähig, sich die Natur zu unterwerfen, den Kampf mit ihr aufzunehmen - es wenigstens zu versuchen. Der Mensch macht sich, ausgestattet mit 
einer solchen Illusion (Ideal, Fortschrittsglaube), daran, in "schöpferischer Arbeit" einen "Körper für seinen Traum" zu schaffen ${ }^{141 \text { ). }}$

Diese positive Funktion des hier noch als mögliche Illusion eingestandenen Fortschrittsglaubens rechtfertigt Lunatarskij mit einem Verweis auf Nietzsche:

Nietzsche lehrte, daß es dem Menschen freistehe, sich Illusionen und Träume zu schaffen, wenn sie inn nur vorwärtsführen auf dem weg schöpferischer Siege, zum Wachstum der Kräfte, zum königlichen Glück der Herrschaft über die Natur. Mag sogar der Traum sich als nicht realisierbar erweisen, mag das Ideal über die Kräfte gehen; es geht darum, daß der Mensch mutig ist und vorwärts strebt ${ }^{142 \text { ). }}$

Diese energiefreisetzende Funktion des Ideals ist noch zu spüren, wenn Lunacarskij in "Religija i socializm" 1908 schreibt, es erhöhe die Kampfmoral des Proleatariats, wenn es sehe, daß seine Sache "im Lichte der Wissenschaft betrachtet richtig und groß im Lichte des Ideals ist "143).

Das Problem des oben genannten widerspruchs wird von Lunacarskif sehr deutlich empfunden:

Der Marxismus behält einerseits seinen Charakter als Instrument der wissenschaftichen Analyse der Gesellschaft auf der anderen Seite darf aber das Ideal nicht als eine zutat zu seiner Wissenschaftichkeit erscheinen. Marxismus als Wissenschaft und Marxismus als Ideal sollen aus "einem stück" sein 144 ).

Das Verbindungsstück zwischen beiden (wissenschaft und Ideal) liefert der Glaube an den Fortschritt. Bezeichnend ist dabei, daß Marx letzten Endes doch nur die deskriptive Seite des ganzen Konstrukts zukommt: Mit seinem Begriffs- 
inventar kann er den Fortschritt beschreiben als der geschichtlichen und gesellschaftlichen Entwicklung immanent. Er kann darüberhinaus die Abhängigkeit des Ideals oder der Ideale vom jeweiligen Stand der Entwicklung der Produktivkräfte beschreiben.

Wenn es aber darum geht, zu zeigen, daß der Fortschritt, die Lebensmaximierung einen hohen, gar den höchsten Wert darstellt, selbst dann, wenn er am Ende der Geschichte vielleicht gar nicht erreicht wird, dann beruft sich Lunacarskif nicht auf Marx sondern auf - Nietzsche!

Die emotionale Verwertbarkeit des Glaubens an den Fortschritt ist es, was inm in LunaCarskijs system einen so hohen stellenwert sichert. Er kann die Entscheidung für den Sozialismus erleichtern und Begeisterung für den Kampf um dessen Verwirklichung wecken. Darin liegt seine religiöse Qualität. Darum kann Lunakarskif sagen: So wie Feuerbach die Anthropologie.zur Theologie erhoben habe, so hätten Marx und Engels der Ökonomie religiösen Charakter verliehen.

Marx und Engels ver jagten den Idealismus aus der Geschichte, die ideelle Entwicklung der Menschheit führten sie zurück auf ihre ökonomische Entwicklung; aber eben damit haben sie den Sinn und die Bedeutung des ökonomischen Fortschritts zu hohem idealistischen wert erhoben, ich würde sagen zu religiösem Wert ${ }^{145)}$.

Lunatarskif übersieht allerdings nicht das doppelte Gesicht des Fortschritts: er schafft Reichtum und Armut, proletarisiert den Produzenten und konzentriert das Eigentum bei Wenigen. Erst wenn das Proletariat die Produktionsmittel übernimmt, kommt die positive Seite des Fortschritts allein zum Tragen. Erst das Proletariat als Klasse kann 
den Wert von Technik und wissenschaft - und ihren doppelten Charakter - verstehen ${ }^{146)}$.

Der "proletarische Sozialismus" treibt also den "ökonomischen und kulturellen Fortschritt der Menschheit" voran, weil er "die einzige Kraft" ist, "die mit den Erfordernis-

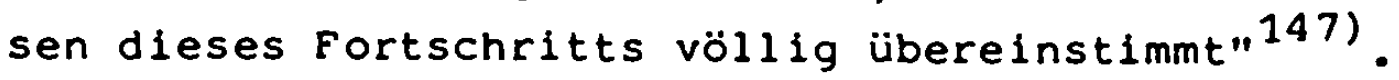

Was aber ist es am Fortschritt, das seinen religiösen Charakter ausmacht, inn zum höchsten Wert werden läßt?

Da ist zunächst die von Lunacarskij als "Seele der Religion" 148) erkannte Wurzel des Fortschritts - das streben (alles Organischen und) des Menschen, das Leben seiner vollen Entfaltung und steigerung entgegenzuführen. Dieser Drang zur Vervollkommnung hat religiöse Qualität, und die Handlung, die solche Vervollkommnung vorantreibt, ist eine religiöse Handlung ${ }^{149)}$.

Fortschritt wird dabei zunächst ${ }^{150}$ ) noch allgemein als Weiterentwicklung und Lebensentfaltung verstanden. Das "Leben" stellt den obersten Wert dar, folglich ist die Bejahung, die bedingungslose Lebensbejahung, der Beginn der Religion.

Hinzu kommt - auch nach der Kritik der positiven Religionen, nach dem Tod der Götter - die Überzeugung, daß der Mensch alles das, was er bisher in den zuständigkeitsbereich der Götter verlagert hat, selbst bewältigen kann. waren die Götter allmächtig, allwissend, so erkennt der Mensch jetzt sich selbst als allmächtig und allwissend; waren die Götter unsterblich und zu höchstem Lebensglück fähig, so ist jetzt der Mensch glücksfähig und kann den Tod besiegen. Der Fortschrittsoptimismus wird aus dem Glauben bezogen, daß der Mensch alles selbst bewerkstelligen kann: 
Für die Arbeit, die sich auf Erkenntnis stützt, ist alles möglich ${ }^{151)}$.

Für die Erkenntnis und damit auch für den auf ihr beruhenden Fortschritt gibt es keine Grenzen ${ }^{152}$ ).

Dazu tritt als drittes Element die Kategorie Zukunft.

Die gegenwärtige Realität ist schlecht und die Existenz in ihr ist Kampf (mit dem Reich der Notwendigkeit). Der Optimismus, der diesen Kampf überhaupt nur sinnvoll erscheinen läßt, nährt sich aus der Entscheidung für die Zukunft - die aber nicht notwendig die eigene individuelle Zukunft sein muß. Es sei hier an die Funktion des "Ideals" erinnert. Das "Ideal" ist nicht einfach nur ein geistiger Gegenentwurf zur Realität; als zeitlich Ausstehendes weckt es vielmehr Hoffnung auf Verwirklichung und Enthusiasmus, der zukunftorientiertes Handeln möglich macht.

Zukunft als etwas Bejahtes und Gewolltes (hierin zeigt sich der antizipatorische Charakter des "Ideals"), nicht als etwas, das ohnehin eintreten wird nach den Bewegungsgesetzen der Geschichte, ist eine der zentralsten Kategorien in Lunacarskijs system. Aus inr wird die gesamte religiöse Dynamik bezogen ${ }^{153)}$.

Im Zusammenhang mit der Kritik am orthodoxen Marxismus wurde davon gesprochen, daß ein Sozialismus, der als das notwendige und in jedem Fall eintretende Ende der geschichtlichen Entwicklung erkannt werden kann, keine Größe darstellt, die positiv bewertet, für die also eine Entscheidung gefällt werden kann. Dieser Sozialismus ist zwar auch in der zukunft angesiedelt, es fehlt inm aber die Dynamik, die Realität zu sich herüberzuziehen. Er ist kein "Ideal". 
Lunatarskijs Problem mit dem Marxismus, von dem er in seinen frühen Aufsätzen spricht, das Problem des Werturteils, läßt sich so umschrelben: Der Marxismus ist eine umfassende Weltanschauung; er stellt die Kriterien und das Begriffsinventar bereit, mit denen gezeigt werden kann, warum die Realität so ist, wie sie ist. Darüber hinaus läßt der Begriffsapparat eine Beschreibung der Bedingungen der Möglichkeit einer neuen (besseren) Gesellschaft zu. Aber eben nur eine Beschreibung. Die Dynamik, die eine Entscheidung für die bessere Gesellschaft und für den Kampf ermöglichte, sle subjektiv als wert empfinden ließ, war vielleicht vorhanden, solange die Umwälzung der Gesellschaft, die Revolution, eine "Naherwartung" darstellte. - Mit dem Eintritt der "eschatologischen Verzögerung" (die Revolution bl leb aus) ging diese Dynamik verloren. Es wurde schwierig, den Sozialismus als höchstes Gut, als Ideal eben, zu propagieren.

Mit dem Begriff des Fortschritts scheint nun Lunacarskij eine Kategorie gefunden zu haben, die dem Marxismus zugrundeliegt, und die es sozusagen systemintern erlaubt, den Sozialismus als höchsten Wert, als mit dem allgemeinmenschlichen Ideal übereinstimmend $z u$ beweisen. Dabei fiel aber auf, daß dem Marxismus vorwiegend die schon erwähnte deskriptive Rolle zugesprochen wird; während der Dynamik freisetzende Entwurf einer besseren Zukunft, eines neuen Menschen nicht aus diesem system bezogen wurde. Marx liefert die Beschreibung der Bedingungen der Möglichkeit dessen, was ist und was sein soll. Wer aber liefert den aus der Kritikder Realität erwachsenen und eine neue Realität antizipierenden Entwurf dessen, was sein soll?

Der Name Nietzsches war schon einige Male gefallen. 
4. Nietzsche als "Gotterbauer"

Wenn Nietzsche zum wichtigen Stützpfeiler eines Systems werden soll, das sich betont marxistisch gibt, so setzt dies voraus, daß das heute (und schon zur Zeit lunacarskijs) üblich gewordene Interpretationsmuster, das einen "Gegensatz von Marx und Nietzsche als Individualisten und Kollektivisten" ${ }^{154)}$ voraussetzt, nicht gilt. Ein Gegensatz, der inzwischen von manchen Nietzsche- und Marx-Interpreten als "gefährliche Halbwahrheit" erkannt wird 155).

Ein ausführliches 2 itat aus "Mestanstvo $i$ individualizm" (1909) ${ }^{156)}$, das Lunacarskijs Bekenntnis zu Nietzsche in gebündelter Form enthält, zeigt, daß dessen NietzscheVerständnis eben jenes Rezeptionsmuster unterläuft:

... die Seele von Nietzsches System, sofern es bei inm ein system gab, ist der "Machthunger", die Verliebtheit ins Leben, in sein Aufblühen, seinen Fortschritt. Nietzsche spricht gern von Menschen, die sich nach dem fernen Trugbild (prizrak) sehnen, die für die zukunft arbeiten, die sich selbst verleugnen. - Brücken-Menschen-Pfeilen, die ans andere Ufer zielen. Er ist ein Philosoph des hochgespannten Lebensaufschwungs (naprjazennyj pod'em zizni) in seiner Gesamtheit. Das Individuum selbst ist inm überhaupt nicht wichtig, es ist inm (nur) wichtig als Kraft, die die Kultur errichtet. Der Übermensch ist inm nicht ein starres 2 iel sondern das Symbol des ewig wachsenden, ewig vorwärtseilenden Ideals, in dessen Verfolgung der Mensch sich ständig übertriff $t^{157)}$. 
Nietzsche sei zwar Antidemokrat gewesen, heiBt es weiter, da er sich eine Höherentwicklung nur "pyramidenförmig" habe vorstellen können; dennoch stehe bei inm alles im Dienste des Fortschritts, der Weiterentwicklung.

\begin{abstract}
Aber eben dieses Prinzip des aktiven Fortschritts liegt der "Ethik" des Marxismus zugrunde. Auch Marx negiert die geheiligten Rechte des Individuums und erkennt faktisch den Vorrang der menschlichen Entwicklung vor inm an ${ }^{158)}$.
\end{abstract}

Mit welchem Recht kann Lunacarskij solche Gemeinsamkeit zwischen Marx und Nietzsche behaupten?

Beiden gemeinsam ist die Betonung der menschlichen Geschichte - im Hinblick auf die Zukunft der Menschheit. Bei beiden hat das Individuum zunächst nur "historisch-instrumentalen Wert"159) - für Marx als Kraft, die die neue, zukünftige kommunistische Gesellschaft schafft, für Nietzsche als Schöpfer, der die kommende "kummulative Kultur"160) bereichert.

Ebensowenig wie bei Marx die zu erkämpfende kommunistische Gesellschaft ein Selbstzweck ist, sondern die Möglichkeit der vollen Entfaltung des unentfremdeten Individuums in sich birgt - so ist umgekehrt bei Nietzsche der übermensch der zukunft kein Selbstzweck, vielmehr ein Instrument "zur Bereicherung einer hohen historischen Kultur"161).

Eben in diesem Sinne scheint auch Lunacarskij Marx und Nietzsche elnander anzunähern. Es sind vor allem zwei züge an Nietzsche, die ihn diese - für ihn notwendig erscheinende Annäherung versuchen lassen: erstens die emphatische zukunftsorientierung, symbolisiert im "übermenschen", zweitens Nietzsches vorbehaltlose Bejahung des Lebens, die sich in der Aufforderung ausspricht, der Mensch 
solle keinen Sinn in der Welt suchen, sondern ihr seinen Sinn geben - in einer Aufforderung zum Handeln al so ${ }^{162}$ ).

Aus dem einleitenden 2 itat geht zwar hervor, daß LunaCarskij diese Kategorien der zukunft und der lebensbejahenden, sinnschaffenden Aktivität für genuin marxistische hält, dennoch erfolgt gerade bei inrer Begründung immer wieder der Griff zu Nietzsche.

Dies soll ein stück weit verfolgt werden, wobei zwei methodische und inhaltliche Gesichtspunkte $z u$ beachten sind:

Es geht hier nicht um einen Vergleich zwischen Marx und Nietzsche; wichtig ist für unseren zusammenhang vielmehr 1. die Tatsache, daß Lunacarskij in Nietzsches Philosophie offensichtlich etwas finden konnte, das inm erlaubte, eine als Lücke empfundene stelle im marxistischen system auszufülien. Diese Stelle wird hier mit dem Begriff 'Entwurf' bezeichnet.

2. kommt Nietzsche hier einzig unter dem Blickwinkel seiner Interpretation und Auswertung durch Lunatarskij zur Sprache, d.h. nur in jenen Begriffen, Kategorien oder Symbolen, die für eine Annäherung oder eine Umdeutung in den Marxismus offen sein könnten.

Die Zukunftsorientiertheit des Wissenschaftlichen Sozialismus war schon im Zusammenhang mit Lunatarskijs Neubetonung der Wertfrage ${ }^{163)}$ als Problem aufgetaucht: Die Analyse der Geschichte offenbart zwar den Sozialismus als inren zielpunkt - zeigt sie inn aber auch als etwas wünschenswertes, wofür sich der Kampf lohnt? Daß dies so sei, versuchte Lunacarskij $z u$ begründen mit dem obersten Kriterium für alle Werturteile: dem "Lebensmaximum". 
Läßt schon LunaCarskijs Prämisse: der Mensch als "erkennendes und wertendes Wesen"164) an Zarathustras Rede "Von tausend und einem ziele" denken, wo es heiBt:

Werte legte erst der Mensch in die Dinge, sich zu erhalten, - er schuf erst den Dingen Sinn, einen Menschen-sinn! Darum nennt er sich "Mensch", das ist: der Schätzende ${ }^{165)}$.

- so gilt dies erst recht für jenes 'oberste Kriterium' mit welchem Lunaxarskij operiert. "Lebensmaximum", "Lebensgier", "machtvolles Leben", "Ja zum Leben", "Macht des Lebens" usw.; dies alles sind direkte Verweise auf Nietzsche als den Philosophen der "Verliebtheit ins Leben"166). Dementsprechend benutzt Lunacarskij auch Nietzsches Bild vom Leben als "Wille zur Macht"167). Wenn es ihm darum geht, den Kampf für eine bessere zukunft auch wenn sie noch weit aussteht - als eine Sache darzustellen, die Begeisterung voraussetzt (eben weil die Zukunft als wünschenswert erkannt ist), verläßt er in auffälliger Weise die argumentative Ebene und verfällt auch eine Anleihe bei Nietzsche? - in einen suggestiven Sprachstil:

Es gibt kein größeres Glück für das Individuum, es gibt keine größere Harmonie seines Lebens, als der leidenschaftliche, alles vergessende, alles umfassende Kampf: Es geht nicht um ein langes Leben, nicht um ein kärgliches Dahinexistieren, sondern um die Tage, stunden, wo man sich an der bedingungslosen Ganzheit, der Hingabe an ein grundlegendes, mächtiges Gefühl berauscht: Es verzehnfacht sich dadurch, daß von inm ringsum Tausende, Millionen anderer Individuen erfaßt sind. Weg mit der Berechnung (rastet), es lebe die Begeisterung, es erstarke der wille zur Macht, der kämpferische Instinkt ${ }^{168}$ ). 
(Dieser suggestive Sprachgestus ${ }^{169}$ ), der eben mehr appelativen als argumentativen Charakter hat, macht glaubhaft, daß LunaCarskij ein glänzender und mitreißender Redner war 170), stellt jedoch das Haupthindernis für den Versuch dar, seine Gedanken als 'System' darzulegen.)

Wird der gegenwärtige Kampf für die bessere zukunft als einen Wert, der keiner Rechtfertigung durch ebendiese $\mathrm{Zu}-$ kunft bedarf 171), mit Nietzscheanischen 'Argumenten' belegt, so gilt dies erst recht für die zukunft selbst.

Was den Anstoß zur Selbsttranszendierung des Menschen wie der Gesellschaft überhaupt gibt, ist die "Liebe zum Fernen" (ljubov' $k$ dal'nemu) 172 ) oder die "Liebe zum Künftigen" (Ijubov' k grjaduscemu) 173). Sie macht die erstrebte Synthese von "enthusiastischem Sozialismus" und Marxismus 174) möglich; d.h. die synthese der objektiven, beschreibenden und analysierenden seite des wissenschaftilchen Sozialismus mit seiner subjektiven, der des wertenden Individuums ${ }^{175)}$.

Dazu heiBt es bei Nietzsche:

Die Zukunft und das Fernste sei dir die Ursache deines Heute: in deinem Freund sollst du den übermenschen als deine Ursache lleben.

Meine Brüder, zur Nächstenliebe rate ich euch nicht: ich rate euch zur Fernstenl iebe ${ }^{176)}$.

Mehr noch als die "Fernstenliebe" in Nietzsches Zarathustra steht das symbol des "übermenschen" für die Dynamik der Selbsttranszendierung des Menschen: der Mensch als die "Brücke zum übermenschen". Im Sinne solcher Dynamik, d.h. dessen, was oben der 'Entwurf' genannt wurde, hat Lunacarskij das "Übermenschen"-symbol voll assimiliert"177). 
Der Übermensch als Bild des 'Entwurfs.178) hat auch andere Namen: der "wachsende Gott"179), der "noch nicht vollendete Gott"180), der "Menschgott"181), usw.

Lunacarskij beansprucht Nietzsche nicht nur, wenn es darum geht, die Dynamik des Transzendierens der Gegenwart in Richtung auf eine bessere zukunft zu beschreiben. Auch für den Entwurf eines "neuen Menschen", des 'Gottes' der neuen Religion, für den Entwurf des kollektivistischen Menschen also, beruft er sich auf Nietzsche; zumindest behauptet er ${ }^{182)}$ die kollektivistische Interpretierbarkeit des N1etzscheschen Übermenschen-Symbols: Nietzsche bedarf nur noch der Ergänzung/Korrektur durch Marx, und er wird zum 'Gotterbauer' :

Nietzsche hat gelitten, und, voll schrecken sich umsehend, sah er nicht jene gesellschaftliche Kraft welche die Gesellschaft vor der Auflösung retten könnte; im Himmel eine solche Kraft suchen konnte und wollte er nicht. - Die Marxisten leiden (ebenfalls am widerspruch dieser welt R.S.), aber sie sehen auf der Erde eine solche Kraft und $k a ̈ m p f e n$ an ihrer seite, wobei sie im Kampf Trost und Vertraven finden. (...) Nietzsche liebte (im Menschen R.S.) den noch nicht vollendeten Gott, (...), er liebte inn, wie er einst sein würde ${ }^{183)}$.

Ist Nietzsche als 'Gotterbauer' denkbar? Der Übermensch als Symbol für die neue Menschheit, die "göttliche" Gattung, das künftige Kollektiv? -

Eine solche Synthese von Marx und Nietzsche scheint kühn; und Lunacarskij war sich darüber durchaus im klaren. So kritisiert er zwar die nach seiner Meinung einseitige Rezeption Nietzsches als Philosophen eines übersteigerten Egoismus, wendet sich also gegen das damals schon gängige 
Übermenschenklischee, er räumt jedoch andererseits ein, daß das Vorhandensein von "imperialistischen Elementen" und "Elementen der Gewalt" in Nietzsches Philosophie eine differenzierte Aufnahme erschweren ${ }^{184}$ ).

Dennoch setzt Lunacarskij der üblichen individualistischen seine eigene kollektivistische Lesart entgegen. Er unterläuft sogar die erstere, indem er dem 'schlechten', kleinbürgerlichen Individualismus der "Schwachen" Nietzsches "Ultraindividualismus" der "starken Persönlichkeit" entgegensetzt ${ }^{185)}$. Diese Spielart des Individualismus, die vom Prinzip der absoluten Lebenssteigerung geleitet ist, kann nach Lunacarskijs Meinung solche Extensität und Intensität erreichen, daß sie die Grenze des Individuums zum Kollektiv hin durchschlägt aufgrund der ihr innewohnenden Dynamik und Eigengesetzlichkeit.

Es sei daher nicht verwunderlich, wenn "Ultra-Individualisten"

die das Recht des starken, auf den Schwachen zu treten, verkünden, um ihres kulturellen Wachsens und der Entwicklung der höchsten Formen ihres menschlichen Genius willen, - wenn diese also recht leicht, nachdem sie inre Fehler eingesehen haben, direkt zum sozialistischen Antilndividualismus übergehen ${ }^{186)}$.

wird der "Ultra-Individualist" Nietzsche also zum Philosophen eines latenten Kollektivismus?

Daß dies möglich sei, versucht Lunacarskij mit einem Aphorismus aus dem 4. Buch der "Fröhlichen wissenschaft"187) zu belegen. In diesem Aphorismus über "Die zukünftige "Menschlichkeit" spricht Nietzsche von dem aufkeimenden "historischen Sinn": 
Wir Gegenwärtigen fangen eben an, die Kette eines zukünftigen sehr mächtigen Gefühls zu bilden, Glied um Glied - wir wissen kaum, was wir tun ${ }^{188}$ ).

Dieses "Gefühl", der "historische Sinn", führe in seiner Entwicklung dahin, die Geschichte der Menschheit mit allen ihren Siegen und Niederlagen als "eigene Geschichte zu fühlen"189).

Dies alles auf seine Seele nehmen, Ältestes, Neuestes, Verluste, Hof fnungen, Eroberungen, Siege der Menschheit; dies alles endlich in einer seele haben und in ein Gefühl zusammendrängen - dies müßte doch ein Glück ergeben, das bisher der Mensch noch nicht kannte - eines Gottes Glück voller Macht und Liebe, voller Tränen und voll Lachens, (...). Dieses göttliche Gefühl hieße dann - Menschlichkeit! 190)

In der Tat wäre es ein zu enges Verständnis, würde man das "Gefühl", von dem Nietzsche hier spricht, als die emphatische Beschreibung eines nur individuellen Bewußtseinsaufschwungs verstehen. Der Charakter dieses Gefühls läßt Lunatarskijs kollektive Lesart als naheliegend erscheinen. Überdies finden sich in diesem Aphorismus auch die wichtigsten züge von dessen Geschichts- und Menschenbild wieder:

Die Geschichte als ein Kampf mit den "Gesetzen der Natur"191), als ein Kampf, der vorwiegend Niederlagen zeitigt, den der Mensch aber dennoch immer wieder aufnimmt. Der neue Mensch schließlich (im gegenwärtigen als Potenz enthalten) ${ }^{192)}$ als ein Wesen, in dessen Bewußtsein/Gefühl die vergangene und zukünftige Geschichte der Menschheit anwesend ist, ein Wesen mit einem kollektiven Bewußtsein also, das sich als Teil eines umfassenden Ganzen fühlt und versteht - als Teil der "Gattung". 
Dieses kollektive Bewußtsein/Gefühl, das die sozialistische Praxis begleitet und sie ermöglicht, hat für Lunacarskij religiösen Charakter, ist "göttlich"; denn die Gattung ist der neue "Gott"193):

Für den Sozialisten

heißt die Realität Gattung, Menschheit; und das Individuum ist nur der einzelne Ausdruck dieses Wesens. Sozialismus ist zusammenarbeit in Raum und zeit. Aber indem sich das Individuum um der Gattung willen verleugnet, findet es sich zehnmal so stark 194 ).

So gelesen erscheint es durchaus nicht abwegig, wenn Lunacarskij behauptet, daß Nietzsches "Ultra-Individualismus" an seinen Gipfelpunkten an den Kollektivismus angrenzt oder gar in diesen übergeht. Das bedeutet nicht, daß er aus Nietzsche etwa einen verkappten sozialisten zu machen versucht; er weiß sehr genau den Kollektivismus der Aristokraten, der "Herren"195) vom sozialistischen proletarischen Kollektivismus zu unterscheiden. Es ist der "historische Instinkt", der inn Nietzsche als Geistesverwandten erkennen läßt:

Der Ultra-Individualismus solcher begabter Naturen, wie Nietzsche wächst, entsprechend dem Gesetz vom übergang intensiven Lebens in extensives, welches Guyau entdeckt hat, bisweilen über sich hinaus und geht in einen gattungsbezogenen historischen Instinkt über (rodovoj istoriceskij instinkt) 196).

Im Kontext seines Aufgreifens von Nietzsches Philosophie als einer dynamischen, die Gegenwart überwindenden, versteht Lunacarskif auch dessen Amoral1smus. Nietzsche ist Amoralist, weil die Moral das Leben negiert; darum kann Lunacarskij sich auf ihn berufen, wenn er das (dekadente) Kleinbürgertum (mescanstvo) bekämpft: Nietzsche als "ein 
großer Feind der Dekadenz, ein großer Verteldiger des Lebens"197).

Im Sinne dieser Nietzscheschen Lebensbejahung wird der Amoralismus in Lunacarskijs 'System' sogar zum Baustein für den künftigen Sozlalismus. Er ist notwendig, weil er den Weg frel macht für die Schaffung einer neuen, lebensbejahenden Moral und somit eines neven Menschen und einer neuen Gesellschaft; er hat also eine positive Funktion ${ }^{198}$ ):

Nietzsche würde sagen: der Egoismus des Menschgottes (Übermensch, Herrenmensch R.S.) ist wohltuend wie ein Gewitter ${ }^{199)}$.

Fassen wir zusammen:

Lunatarskijs Umgang mit Nietzsche ist von Beginn seiner publizistischen Tätigkeit dokumentiert ${ }^{200)}$. Dieser Umgang ist aber nicht kritisch-abweisend, sondern, wie sich gezeigt hat, kritisch-integrierend. Lunatarskij hat von Nietzsche offensichtlich wichtige Impulse für seine Welterentwicklung als Marxist bezogen; und mit der Einschränkung auf die Zeit bis 1915 etwa ist die Bezeichnung "Nietzschean Marxist"201) durchaus zutreffend. Lunacarskij assimiliert Nietzsche mehr oder weniger organisch seinem marxistischen Weltbild nach dem oben schon angedeuteten Prinzip:

Der (orthodoxe) Marxismus hat seine stärke auf der objektiven, deskriptiven Seite. Er liefert die Beschreibung der Bewegungsgesetze von Geschichte und Gesellschaft, wie sie war und ist; und er kann die Bedingungen der Möglichkelt elner zukünftigen Geselischaft beschreiben, sogar den Sozialismus als zielpunkt der Geschichte erkennen. Aber eben nur soviel:

Was wissenschaftlich kommen soll, die notwendig ökonomisch-institutionelle Änderung, ist bei Marx bestimmt, 
aber dem neuen Menschen, dem Sprung, der Kraft der Liebe und des Lichts, dem Sittlichen selber ist noch nicht die wünschenswerte Selbständigkeit in der end-

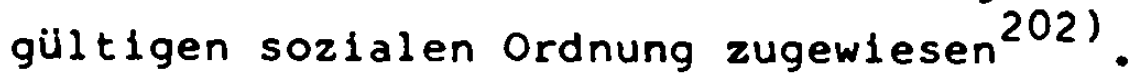

So lautet in den worten Ernst Blochs Lunatarskijs Problem. In den Fragen der Ethik zeigt sich die objektivität des Marxismus als Schwachpunkt: Das wertende subjekt kommt in diesem Weltmodell nicht vor, droht zumindest, $z u$ einer negligeablen Größe zu werden. Das Individuum, der Proletarier, muß aber die Geschichte als seine Geschichte, die Zukunft als seine Zukunft begreifen und bewerten können, damit er sich für den Kampf jetzt und den sozialismus danach entscheiden kann.

Die Dynamik (bei Bloch der "Sprung"), die durch die Besinnung auf den Selbstwert des Menschen, durch seinen "Stolz"203), durch die vorbehaltlose Bejahung des Lebens und des Kampfes (auch ohne Erfolgsgarantie) 204), und schließlich durch den Entwurf des Menschen in die Zukunft hinein (der Mensch als Übergang) 205) freigesetzt wird diese Dynamik bezieht Lunaxarskij von Nietzsche. Hier finden sich die Wurzeln für selne neise, wahre "Religion des Fortschritts"206)! In seinem Kampf gegen den statischen, entwurfslosen orthodoxen Marxismus (aber auch gegen den Neukantianismus) wird Nietzsche zum wichtigsten Waffenlieferanten.

Es gilt also, Nietzsche als eine wichtige Quelle festzuhalten, aus der sich das "Gotterbauertum" Lunacarskijs 207) speist:

Die Kraft von Nietzsches Ultra-Individualismus beruht im verdeckten oder potentiellen "Anti-Individualismus", in der Religion der Gattung, deren leidenschaftlicher Adept er war ${ }^{209)}$. 
5. Die Entfaltung der neven Religion

\section{a) Der neue Mensch}

Lunacarskij zeichnet - ebenso wie Gor'kij - eine dynamische Sicht des Menschen aus. Der Mensch, der "des Menschen Gott" ist, ist nicht bloß der Alltagsmensch, wie er begegnet, sondern der Mensch in seinen "Möglichkeiten"210). Diese Möglichkeiten gilt es zu entdecken und aktiv zu entwickeln; darin besteht die neue Religiosität:

Der Glaube des aktiven Menschen ist ein Glaube an die Zukunft der Menschheit, seine Religion ist ein Gesamtheit von Gefühlen und Gedanken, die inm zum Teilnehmer am Leben der Menschheit und zum Glied in jener Kette machen, welche sich zum übermenschen hin erstreckt, zu einem schönen und mächtigen Wesen, zu einem vollendeten Organismus, in welchem Leben und Vernunft den Sieg über die Elemente $(=$ Natur) feiern werden 211$)$.

Die Entwicklung zum kollektiven Übermenschen ist im Menschen "biologisch" und "sozial" angelegt"12). Ihn kennzeichnet

1. der wunsch, sich allseitig und ganz zu entwickeln, alle seine Empfindungen und Fähigkeiten "integral" auszubauen. Dies ist aber letztlich nur in dem durch das Proletariat erkämpften Kollektiv möglich ${ }^{213)}$.

2. das Streben nach Glück - ursprünglich ein "biologisches" Faktum, wie das allem Organischen innewohnende Prinzip der Lebenssteigerung zeigt ${ }^{214}$ ). Dies Glücksstreben führt aber notwendig über das Individuum hinaus zum Kollektiv. Glück bekommt "ästhetischen Wert"215) ; letzten Endes füht auch dieses oberste Prinzip zum Sozialismus, denn "der Mensch ist des Menschen - Genuß"216); 
3. das Streben - vor allem bel "großen Persönlichkeiten"-, etwas Großes zu schaffen. Daraus resultieren die "großen Gefüle", das "Verlangen nach Zusammenarbe1t"217).

LunaCarskij vertritt also die Meinung, daß der Mensch seinem innersten Wesen, seiner innersten Veranlagung nach und in seinem aktiven Verhalten auf das Kollektiv hin angelegt se1. Der Wissenschaftliche Sozlalismus als die Religion des wahren Kollektivismus führt den Menschen somit seiner eigentlichen Bestimmung entgegen. Ist die "Menschheit", die "Gattung", das Kollektiv als der wahre "Gott" erkannt, so heißt es folgerichtig:

Wir alle sind Teilhaber (des neuen Gottes): die Verneigung vor ihm ist keine Vernelgung mehr, sondern in Wahrheit ein Zusammenfließen, der brüderliche Kuß der Liebe zur eigenen Gattung, ein Vorgeschmack vom ganzheitlichen (cel'nyj) Menschen, der in unseren noch armen und ohnmächtigen Körpern $1 \mathrm{ebt}^{218)}$.

Wurde bei der allgemeinen Bestimmung des "Wesens der Religion" das Gefühl der "Verbindung mit einem höheren Prinzip" als konstitutiv erkannt ${ }^{219}$, so kann sich jetzt der Wissenschaftliche Sozlalismus als die "religiöseste aller Religionen" bezeichnen ${ }^{20)}$; denn das "höhere Prinzip", mit dem sich der Sozlaldemokrat verbunden fühlt, ist nicht ein abstraktes, eingebildetes, inn beherrschendes Wesen, sondern die "Menschheit", als deren Teil und Ausdruck er sich weiB 221 ).

Wenn der Proletarier/Sozialdemokrat sich für die Verwirklichung dieses höheren Prinzips einsetzt, kann er nicht, wie in den früheren Religionen, betrogen werden; denn der Gegenstand seiner Verehrung ist in der Realität schon im Keim vorfindbar und in der aufbauenden (stroit') Praxis 
zu verwirklichen. Versteht sich der Mensch (Proletarier) als die "Brücke zum Übermenschen", zum neuen, kollektiv organisierten Menschen, $z u$ seinem eigenen 'Entwurf' also, den er gutheiBt, so wird er auch bereit sein, sich für dieses ziel zu opfern; denn er tut dies für sich selbst:

Wo Selbstaufopferung im Namen eines großen Zieles zur normalen Erscheinung wird - dort weht der religiöse Geist über den Häuptern der Menschen, dort herrscht der Geist der Gattung, das Streben nach großen Errungenschaf ten der Zukunft, dort schmieden sich die Individuen zusammen im Aufbruch $z u$ künftigem Glück und künftiger Vollendung, dort unternimmt der Mensch Anstrengungen, seine Begrenztheit zu besiegen und Gott zu schaffen (sozdat' boga) aus sich und seinen Brüdern ${ }^{222}$.

Das "große Ziel", dem sich der Einzelne zu opfern bereit sein soll, ist der Sozialismus; und der "Gott", den er durch seinen tätigen Einsatz schafft, ist die Menschheit, die Gattung - jenes "höhere Prinzip", mit dem er sich verbunden und als dessen Ausdruck er sich weiß 223). Lunatarskij verwendet die Begriffe "Gattung" und "Menschheit" meist synonym, wobei er sich mit dem Terminus "Gattung" bewußt an Feuerbach anschließt. Allerdings erhält dieser Begriff eine betont historische Dimension; er soll

das Bestreben des Sozialismus unterstreichen, die ganze Menschheit in inrer Vergangenheit und zukunft und in ihrem gesamten Umfang zu einer großen Einheit zu organisieren 224 ).

Ebenso wie bei dem Begriff "Mensch" ist bei jenen von "Gattung" und "Menschheit" eine eigentümliche Ambivalenz zu beobachten: 
Man könnte sie als 'eschatologische Spannung' bezeichnen. Der Mensch ist einerseits das real existierende Wesen mit seinem Unglück und Sehnen nach Glück, seinen Bedürfnissen und seiner Begrenztheit; zugleich aber ist er ein Anspruch, eine Potenz, die über sich selbst hinausweist: Der Mensch als die Brücke zum Übermenschen ist dieser Übermensch als Entwurf. Solche Eschatologie muß als christliches Erbe im atheistischen System der neuen Religion erkannt werden.

Gleichermaßen verhält es sich mit der "Menschheit"; sie ist real erfahrbar als aufgesplittert in Individuen mit einander widerstreitenden Interessen. Zugleich aber enthält sie in sich den Keim zur "Gottwerdung", die Möglichkeit, sich zur "Gattung", zum neuen "Gott" zu organisieren. Die Menschheit braucht nicht mehr auf ein Jenseits zu hoffen, wo sich alles fiktiv zum Guten wenden wird, sie besitzt vielmehr in sich die Dynamik zur selbsttranszendierung, zur Neuschaffung ihrer selbst als "Gattung", d.h. als "Gott":

Aber es kommt eine zeit des religiösen Realismus; alles wird an seinen Platz gestellt; das einzig Göttliche ist die menschliche Gesellschaft selbst, allerdings natürlich in Ihrer Entwicklung, in inrer Potenz 225 ).

"Mensch" und "Menschheit" (Gattung) bewahren also in ihrer säkularisierten Gestalt die christliche/neutestamentliche Eschatologie der Predigt vom (nahen) "Gottesreich".

\section{b) Der neue Gott}

Die "Idee Gottes"226) im Sinne der "religiösen Idee" bei Gor'kij227) hat sich für Lunatarskij selbstverständlich erledigt: Es gibt keine Götter über oder neben dem Menschen. Die Arbeit, verstanden als erkennendes und ziel- 
gerichtetes Handeln des Menschen an der Natur, hat den "Tod der Götter" herbeigeführt ${ }^{228}$ ). Im Gefolge von Feuerbachs Religionskritik bleibt "Gott" jedoch das Symbol für das "Menschliche" in seiner "höchsten Potenz"229). - Der einzige Fehler des christlichen Gottes: es gibt inn nicht 230)!

Der Gott (das "Ideal") des Judentums und des Christentums war einerseits das "Ideal der sozialen Gerechtigkeit"231) und andererseits Ausdruck für den "Triumph des Gelstes über die Materie" 232 ).

Dieses "Ideal", so Lunatarskij, bringt Marx in "gereinigter, rein-anthropologischer Form" 233) wieder; "rein-anthropologisch" im Sinne der Feuerbachschen Reduzierung der Theologie auf die Anthropologie, bereichert um das historisch-dynamische Element:

Das soziale Leben ist Kampf mit der Natur um der Unterwerfung der Elemente unter die Vernunft willen, deren Träger der Mensch ist, die menschliche Gattung. ("Triumph des Geistes" R.S.) Die menschliche Gattung - das ist Gott. Ein wachsender Gott, ein Gott, der fast noch in der Krippe liegt zwischen Ochs und Esel, aber der einzige. Der Mensch ist des Menschen Gott ${ }^{234)}$.

Unter diesem (nur unter diesem) Gesichtspunkt hält Lunacarskij die "Theorie des sozialen Mythos" Sorells 235 ) auf das "neue religiöse Bewußtsein" des Proletariers für anwendbar:

Gott als Allwissenheit, Allglückseligkeit, Allmacht, als allumfassendes ewiges Leben - ist in der Tat alles Menschliche in höchster Potenz ${ }^{236)}$. 
Indem der Mensch den Kampf mit der Natur vorantreibt, sie sich zu unterwerfen weiß, um inr "Herr" (chozjain) zu werden, wird er zum "Gott". Aber nicht als einzelnes Individuum sondern als "Mensch überhaupt, in seinem sieghaften und ewigen Aufstieg"237). Die alte "religiöse Frage", auf die alle Religionen eine Antwort zu geben versucht haben: Wie können die Gesetze der Natur und die Gesetze des Lebens miteinander versöhnt werden? Wie kann die "Unterwerfung der Natur" und das "Maximum der Lebensentfaltung" erreicht werden ${ }^{239)}$; diese Frage läßt sich jetzt übersetzen: Wie kann der Mensch zum "Menschen", d.h. zur "Menschheit" oder "Gattung" erlöst werden? Und die Antwort lautet: Die Menschheit wird nicht erlöst durch die Menschwerdung Gottes - denn Gott gibt es nicht -; sondern durch die Gottwerdung des Menschen.

Diese Gottwerdung, Erlösung, ist gleichbedeutend mit der immer volikommener werdenden Herrschaft des Menschen über die Natur, d.h. mit dem Fortschritt, der durch die Arbeit erreicht wird. Christlich-neutestamentliche Heilsgeschichte hat hier die säkularisierte Gestalt einer Entwicklungsgeschichte (im wissenschaftlich-technischen und ökonomischen Sinne) angenommen. Die frbeit - urid somit der sie am vollkommensten ausdrückende Proletarier erscheint als der neue Messias:

Die Versöhnung der Gesetze des Lebens und der Naturgesetze wird erfolgen durch den sieg des Lebens mit Hilfe von Erkenntnis und Technik. Arbeit, breit angelegte Gesellschaftlichkeit (obłcestvennost'), das entwickelte Gefühl der Gattung, die Hoffnung auf ununterbrochenen Fortschritt - das ist es, was in unserer Zeit religiösen Trost spendet.(...) Wenn es hier einen Gott gibt, dann ist es das Leben und sein höchster Repräsentant, die menschliche Gattung $^{240)}$. 
Wie in den alten, überwundenen Religionen hat auch der neue Mensch sein "Ideal", seine Vorstellung von Glück, die er verwirklicht sehen will, Aber für inn ist diese Verwirklichung nicht mehr bloß durch "Träumerei" oder Illusion möglich; sein "Ideal" hat die Basis in der Realität, es ist

für ihn der Plan, nach welchem er die Welt umbauen muß. In der Arbeit, in der Technik hat er sich als Gott gefunden und beschlossen, der Welt seinen willen zu diktieren 241 ).

Hier - wie schon weiter oben - wird eine Verbindungslinie von Lunacarskijs Bogostroitel'stvo zum Proletkul't erkennbar: Kollektivismus, Verherrlichung von Arbeit und Technik sowie Zukunfts-(Fortschritts-)glaube bilden die "drei Eckpfeiler unter den inhaltlichen Bestimmungen der proletarischen Literatur"242).

(Mit dieser Verbindung zum Proletkul't zeigt sich zugleich ein wichtiger Aspekt für die Beantwortung der Frage, wo die gemeinsame Basis für Lunacarskif und Gor'kif einerseits und Bogdanov andererseits während ihrer $\mathrm{Zu}-$ sammenarbelt auf Capri zu suchen wäre.)

Die Arbeit also erlöst den "alten Menschen" zum "neuen Menschen", organisiert die Menschheit zur Gattung, zum neuen "Gott"243). Der Wissenschaftliche Sozialismus ist daher wesentlich eine "Religion der Arbeit" und das "Proletariat ist der einzige in Frage kommende Träger dieser neuen Religion"244).

\section{c) Schuld und sühne}

Wenn die Menschhelt das Proletariat als den wahren Messias braucht, um erlöst $z u$ werden - worin besteht dann inr 'sündenfall'?

Die kritisch-aufhebende (bewahrende) Methode Lunacarskijs 
findet auch hier inre Anwendung, wie dies bel der Erarbeitung des Religions- und Gottesbegriffes der Fall war.

Für Lunatarskij hat der jüdisch-christliche Mythos vom Sündenfall und der damit verbundene Messianismus eine reale und richtige Basis: Reinigt man den Gottesbegriff von seiner falschen Verkleidung und Ansiedlung im Jenseits, so verkörpert er (in der jüdisch-christlichen Tradition) die "ideale Menschneit"245). Gott, der ja alle guten Eigenschaften und Sehnsüchte des Menschen in höchster Potenz repräsentiert, folglich auch zum Symbol der Gerechtigkeit wird ${ }^{246)}$, kann nicht für das Leiden in der Welt verantwortlich gemacht werden. Im Mythos unbewuBt, gibt der Mensch ganz richtig sich selbst als real Existierendem die Schuld an seinem Leiden und an der Ungerechtigkeit in der Welt. Würde er Gott beschuldigen, so hieße das, die "Ideale Menschheit" (die er im Keim in sich beherbergt) $\mathrm{zu}$ beschuldigen.

Das Böse in der Welt, das Leiden, wird (im Mythos) daher als kollektive strafe für eine kollektive schuld: den ersten sündenfall verstanden. Bedingung für eine glückliche Gesellschaft wird die Sühne dieser Kollektivschuld.

Wie aber können 'Sündenfall' und 'Sühne' neu, aus Lunacarskijs marxistischer sicht, definiert werden, nachdem sie von inrem mythologischen Ballast befreit sind?

Alles, was das Leben fördert, ist Wahrheit, (istina), Gut (blago) und Schönheit; alles, was das Leben zerstört oder mindert und es einschränkt, ist Lüge, Böses, und HäBlichkeit, ...247)

"Wahrheit", "Gutes" und "Schönhelt" sind für Lunacarskij identisch. 'Sünde' - und damit auch das 'Gute' bestimmen 
sich für ihn nach Maßgabe des obersten Kriteriums für alle Wertsetzungen: des Lebensmaximums, der absoluten Lebenssteigerung.

Alles, sei es auch ein Genuß, was zur Verminderung und Verarmung des Lebens führt, ist sünde ${ }^{248)}$.

Dabei beruft sich Lunatarskij ausdrücklich auf Nietzsche, der solche sünde wider das Leben als einzig reale Sünde anerkenne ${ }^{249)}$. Allerdings stehe das traditionelle sündenbewußtsein der Erkenntnis der wahren Sünde im Wege. Hier hat Nietzsches Amoralismus die wichtige Funktion, den Menschen von der Moral, dem "irrationalen Sündenbewußtsein" zu befreien, damit der Blick auf die reale Sünde wider das Leben frei werde. Diese Sünde gründet im Egoismus des Individuums.

Das Individuum muß völlig von der Moral befreit werden, von allem irrationalen Sündenbewußtsein (Nietzsches 'Ressentiment': R.S.), und dann muß es auch noch von dem anderen Erbe der Vergangenheit befreit werden: von den Abgrenzungen, die jedes Individuum in Einzelhaft gefangen halten, wo es nur das "Ich und sein Eigentum" sieht. Aber die sünde gibt es. Es gibt eine reale sünde in der Welt: das Fehlen von Einheit und leichtem Umgang der Menschen miteinander; und es gibt den Sündenfall: das ist das Privateigentum $^{250 \text { ) }}$.

Ist das Privateigentum so einfach als der "Sündenfall" erkannt, so

of fenbart (die Suhne) inr Geheimnis: Es ist das Geheimnis der Arbeit und inrer internationalen klassenlosen Organisierung ${ }^{251)}$. 
Der Proletarier als die Inkarnation der Arbeit und als Keim der neuen Menschheit wird somit zum wahren Messias ${ }^{252)}$. Lunakarskif kann daher sagen, daß Marx die Idee der Erlösung auf inre reale Grundlage bringt, indem er sie mit dem wahren "Gottessohn" - der Gattung, bzw. deren Ausdruck dem Proletariat verbindet. Der Idealismus Marx' bestehe in der Hoffnung auf die "Apotheose" dieses Erlösers" 253).

d) Glaube, Hof fnung, Liebe

Es wurde schon deutlich, wie Lunatarskif Begriffe aus dem jüdisch-christlichen theologischen Inventar aufgreift, um sie in seinem säkularen Sinne umzudeuten: Schuld und Erlösung, Gott, Mensch (in seiner eschatologischen Dimension), schließlich der Begriff der Religion selbst.

So erfahren auch die zentralen christlichen Tugenden: Glaube, Hoffnung, Liebe ihre 'Aufhebung'; und dies jeweils aus ihrer zukunftsbezogenen Dynamik heraus.

Die neue Religion ist 'realistisch'; denn das 'Gottesreich', auf das sie wartet, und der Gegenstand inrer Verehrung sind real: der Mensch, die menschliche Gesellschaft, wie sie sein können und sein sollen.

Der Proletarier glaubt nicht an Gott, er hält das Leben für einzig und dabei real; an ein Jenseits glaubt er nicht, aber er glaubt an die zukunft, und von dorther ergießt sich inm das Morgenlicht ins Herz ${ }^{255)}$.

Zieht man in Betracht, daß der Gott, welcher den Gegenstand dieses Glaubens bildet, der neue kollektiv organisierte Mensch ist - eine Größe also, deren Ursprung zwar in der real erfahrbaren Gegenwart liegt, die aber erst 
noch geschaffen werden (stroit') muß; beachtet man ferner, daß in Lunałarskijs Deutung eben dieses "Schaffen" (des Sozialismus) die einzig wahre religiöse Praxis ist, daß der Sinn dieses Handelns aber im Handeln selbst besteht und nicht gerechtfertigt wird durch die Garantie, daß am Ende der Geschichte tatsächlich der Sozialismus stehen wird ${ }^{256)}$; zieht man dies alles in Betracht, so wird deutlich, daß der proletarische Glaube, von dem Lunacarskij spricht, die struktur des jüdisch-christlichen Glaubens vollständig beibehält 257 ).

Die christliche Kategorie "Liebe" erscheint in der neuen Religion in zwel Formen: Zum einen ist es die "Möglichkelt" am Menschen, die geliebt werden kann; das, was Lunacarskij unter Berufung auf Nietzsche als "Liebe zum Fernen" bezeichnet hat. Das "Ferne" ist "unser Nachkomme", der "Mensch-Gott"258).

Dies wäre die dynamische Gestalt der "Liebe" als Liebe des Menschen zu seinem 'Entwurf' Von inrer Genese her ist sie als Antithese zur christlichen Nächstenliebe zu verstehen.

Dennoch erscheint auch die Letztere, in leicht veränderter form zwar, doch mit demselben ethischen Anspruch: bei Lunatarskij unter dem stichwort "Selbstaufopferung".

Das Problem der Selbstaufopferung wird von inm immer wieder aufgegriffen im Zusammenhang mit der Entstehung des neuen religiösen Gefühls. Daß seine Erörterungen immer neu um diese frage kreisen, ist nicht weiter verwunderlich; denn genau hier kann die Probe aufs Exempel angesetzt werden:

Wenn der Wissenschaftliche Sozialismus eine, besser die wahre Religion ist, wenn also die 'neue Gesellschaft', 
der 'neue Mensch', die 'Gattung' usw. Kategorien sind, die dem konkreten, hier und jetzt lebenden Individuum als zu bejahende Werte erscheinen, die bei ihm religiösen Enthusiasmus auslösen, dann wird der Einzelne auch bereit sein, für die Schaffung dleser neven Menschheit, für die "Geburt des neuen Gottes " sich selbst zu opfern; selbst wenn er weiß, daß weder er noch seine $k i n d e r$ die sozialistische Gesellschaft tatsächlich erleben werden. Die Selbstaufopferung wird konsequentenweise zu einer religiösen Handlung und hat ethischen Wert, weil sie das Leben in seiner Höher- und Weiterentwicklung bejaht und vorantreibt.

Lunacarskij zitiert Nietzsche:

Das Individuum kann nicht schöner leben als reif werdend für den Tod (Untergang = Übergang R.S.), für die Selbstaufopferung im Namen von Gerechtigkeit und Liebe 259 ).

Man kann hier ohne weiteres von einer Radikalisierung der christlichen Nächstenliebe sprechen. Rührt das Problem der selbstaufopferung schon an den Lebensnerv von Lunacarskijs never Religion, so gilt dies erst recht und in weit höherem Maße für die Kategorie "Hoffnung".

Um die Eindimensionalität des deterministischen (orthodoxen) Materialismus zu überwinden, setzt Lunacarskij bei der Entscheidung des Einzelnen für den Sozialismus - einem grundsätzlichen anthropologischen Problem des Marxismus - an:

Die religiöse (ethische) Qualität dieser Entscheidung wird gerade darin sichtbar, daß der Einzelne den Kampf aufnimmt (siehe "Selbstaufopferung"), ohne die Gewähr zu haben, daß dieser Kampf - vielleicht nach Generationen - tatsächlich den Sozialismus hervorbringt. Der So- 
zialismus kann aus Lunatarskijs religiös-ethischer sicht nicht ( $b l O B$ ) Gegenstand von Wissen im wissenschaftlichen Sinne sein; so beruft er sich auf Paulus Röm 8, 18-24: "Wir sind auf Hoffnung gerettet."260) - und definiert den Sozialismus als eine "Religion der Hoffnung" 261 ).

\begin{abstract}
Unsere Religion kann nur die Wahrscheinlichkeit neuer Erfolge nahelegen, neuer Schritte zur physischen, psychischen und sozialen vollendung in der Fülle des Lebens. Und als Etappe - den großen revolutionären übergang vom Kapitalismus. Hoffe, arbeite, kämpfe $e^{262)}$ !
\end{abstract}

Ebenso wie die jüdisch-christliche eschatologische Struktur der Geschichte als 'Hellsgeschichte' beibehalten wird ${ }^{263)}$, so behält auch die Kategorie "Hoffnung" ihren alten Platz - als die Stelle nämlich, wo Gegenwart und Zukunft in der Entscheidung des Individuums für die Zukunft zusammentreffen ${ }^{264}$ ).

Das Proletariat

hat die Hof fnungslosigkeit der individuellen Lage überwunden durch die strahlende Hoffnung, die seiner Klasse leuchtet ${ }^{265)}$.

e) Das Kollektiv ("Ich" und "Wir")

Es hat sich mehrfach gezeigt: Während in der alten Religion der Gott im Jenseits den sinnstiftenden Horizont für den Gang der Geschichte und die Handlungen des Menschen darin, für seine Ordnungen und Wertsetzungen abgab, ist diese sinngebende Funktion jetzt dem neuen "Gott", der Menschheit, der Gattung, kurz - dem Kollektiv anheimgegeben $^{266)}$. 
Die Fragen, wie sich der Einzelne im Kosmos, gegenüber der Gesellschaft, angesichts der Tatsache des individuellen Todes und des gleichzeitigen wunsches nach Unsterblichkeit, in Kunst und wissenschaft $z u$ verstehen hat, finden vom Kollektiv her inre Beantwortung.

Dabei geht es Lunatarskij nicht um die Aufgabe des "Ich" zugunsten des "Wir", vielmehr um eine Neubestimmung des "Wir" als "größeres Ich"267). Zwar schließt er sich dem im 19. Jahrhundert üblich gewordenen Vergleich der Gesellschaft mit einem biologischen organismus an ${ }^{267 a), ~}$ versucht jedoch gleichzeitig einer Preisgabe der Individualität vorzubauen: Während der Organismus die Individualität.seiner Elemente negiere, setze der "Überorganismus" (sverchorganizm) eben diese Individualität voraus und verstärke sie 268 ).

Der Mensch, der in der Vereinzelung verharrt, geht an seiner wahren Bestimmung vorbei, denn er ist auf das Kollektiv hin angelegt ${ }^{269)}$.

Bei uns (den Sozialdemokraten R.S.) wird dem vergänglichen und beschränkten Individuum der Mensch entgegengesetzt, als Teil, als Mitarbeiter an der großen Realität der Gattung, der menschlichen Gesellschaft im weitesten sinne des Wortes 270 ).

Zunächst ist der reale Mensch zwar nur unter biologischem Gesichtspunkt als Einzelerscheinung der Gattung zu sehen, aber dann, im sozialistischen Bewußtsein, (ist er) der stolze und bewußte Ausdruck dieser Gattung, in Raum und zeit umgeben von anderen Individuen, die mit inm ihre Bemühungen um den immer harmonischeren Bau des Tempels des mächtigen Lebens zusammenfließen lassen ${ }^{271)}$. 
Dieser "Bau des Tempels" hat sonst den Namen "Sozialismus", und das "Zusammenfließenlassen" der individuellen Bemühungen heiBt "Zusammenarbeit in Raum und Zeit"272).

Letzteres dient Lunatarskij (sowie Bogdanov und Gor'kij) als Leitbegriff, der anzeigt, daß das Problem des Verhältnisses von Individuum und Kollektiv sowie die Frage des individuellen Todes auf der Ebene von Praxis/Handlung und Gefühl gelöst wird.

In "Voprosy morali 1 Meterlink"273) heißt es über das "große Ich" (= "Wir"):

Es vergrößert tausendfach die Oberfläche des Empfindens, es gibt die Möglichkelt, sich an Siegen zu freuen, die ein Jahrhundert nach dem Tod des "kleinen Ich" verwirklicht werden, das Leben länst untergegangener Geschlechter zu leben, welche ebenfalls zum "Wir" gehörten, einen reil von ihm bilde$\operatorname{ten}^{274)}$.

Diese (Gefühls-)Einstellung nennt Lunararskij "Individualismus", denn das "Ich" finde sich hier innerhalb des "Wir" wieder, welches kein inm Fremdes, Außeres sei. Aber solcher Individualismus sei ein

makropsychischer Individual ismus, Weitherzigkeit, im Unterschied zum Egoismus, der zwar "vernüntig" sein mag, aber dennoch Mikropsychik - Engherzigkeit ist ${ }^{275)}$.

Der "makropsychische Individualismus" - als Gefühlseinstellung - gibt einerseits das reale Individuum nicht auf, erlaubt inm andererseits aber auch, den individuellen Rahmen $z u$ sprengen und im Gefühl des Aufgehobenseins im großen "Wir", im Gefühl der Mitarbeit am "großen Bau" 
den individuellen Tod zu kompensieren. Geschichtliche selbsttranszendierung ("lujubov' $k$ dal'nemu") und direkte Hinwendung zum anderen Ich (Nächstenliebe - "ljubov' $k$ bližnemu") finden ihren Platz in diesem kollektiven Individualismus 276 ).

Mit seinem ständigen Kreisen um das Problem der Unsterblichkeit und seinem Glauben an die Möglichkeit der überwindung des individuelien Todes befindet sich das Gotterbauertum (Lunacarskijs und Gor'kijs) in einer langen Tradition: Seit Descartes, R. Bacon, Condorcet usw. gehört die Idee der Lebensverlängerung zum ständigen Bestand der Fortschrittstheorien 277). - Auch in diesem Punkt gibt sich das Bogostroitel'stvo als eine Fortschrittsreligion:

Die Rettung vom Tode ist die Verlagerung des Schwerpunktes von sich selbst, seinem psychischen "Ich" auf das große "Wir", die schöpferische, kämpferische, fortschrittliche Menschheit ${ }^{278)}$.

Um die Überwindung des Todes durch die Aufhebung des "Ich" Im "WIr" und die Auffassung vom "Wir" als dem elgentlichen, "größeren Ich" plausibel zu machen, sucht Lunacarskij Argumentationshilfe bei Ernst Mach $^{279)}$ : Nach Mach ist das "Ich" nichts anderes als eine bestimmte Menge von "Elementen" in elner bestimmten Kombination. Beim individuellen Tod wird lediglich die Kombination aufgelöst, die Elemente selbst (z.B. die Bestandtelle der Erfahrung) bleiben erhalten ${ }^{280)}$.

Das Problem der Kontinuität, mit anderen Worten: das der Unsterblichkeit, wird über die Inhalte, die "Elemente" gelöst; diese werden durch den individuellen Tod zwar aus inrer Kombination (= "Ich") befreit, existieren aber weiterhin. Der "Inhalt" bleibt erhalten - gereinigt von den 
"unwichtigen" persönlichen Erinnerungen. Die Elemente treten in neue Kombinationen ( = Individuen) ein. Über die Kontinuität der Elemente geschieht der Durchbruch vom Individuum zum "unpersönlichen, überpersönlichen Leben" 281).

Der Summe solcher Elemente etwas hinzuzufügen, ist das qrößte Glück des Künstlers, Forschers, Erfinders, sozialen Reformers 282 ).

Jeder Beitrag zur Bereicherung des "Inhalts" ist somit ein Beitrag zur überwindung des Todes. Der "Sieg über den Tod" wächst mit der Zunahme des "Inhalts", d.h. mit der kollektiven Erfahrung ${ }^{283)}$.

In "Budustee religil" wendet Lunatarskij diese Argumentation auf das Bewußtsein, bzw. das religiöse Gefühl des Proletariers an: Der "religlöse Proletarier" sieht im Sozlalismus das "große Gebäude, das über Jahrhunderte erbaut wird"284). ("Zusammenarbeit in Raum und Zeit") Er glaubt, die neue Gesellschaft wird "an jenem Tag" (religiös-eschatologische sprache!) wie die "Sonne aus den Wolken treten":

Mich (den Proletarier R.S.) wird es dann vielleicht nicht mehr geben. Aber was bin ich außerhalb der großen Klasse, des Vorkämpfers der Menschheit, ihres Heilands (spasitel'), ihres Erlösers? Das Beste in mir lebt eng verflochten mit meiner Klasse ${ }^{285}$ ).

Das Verhältnis zwischen Individuum und Kollektiv wird inhaltilch also über die Praxis - "Zusammenarbeit in Raum und Zeit" - und über das Gefühl bestimmt: Das "kollektiv gestimmte Individuum"286) ist mit der "Menschheit" verbunden über das 
Gefühl für Gattung und Geschichte; das

Gefühl der solidarität und das

Gefühl der Freude am Wachstum von Technik, wissenschaft und Kunst 287).

Lunacarskif nennt dies an anderer stelle "psychologischen Kollektivismus"288), nämlich

das Gefühl, Glied einer langen Kette zu sein, eine Einheit (edinica) des in sich ganzheitlichen kollektiven Schaffens 289 ).

Wahre Kunst - ebenso wie Fortschritt in wissenschaft und Technik - ist daher nicht individuell:

"Der wahre Künstler ist Kollektivist"290).

Die Idee eines so verstandenen Kollektivismus beinhaltet daher

das Ideal der allmenschlichen Organisation der Arbeit, als Grundlage für eine wahrhaft menschliche Kultur ${ }^{291)}$.

Die Arbeit ist in inrem Wesen kollektiv organisiert und stellt schon immer ein Potential dar, welches die einzelnen Individuen zum Kollektiv (oder zu dessen Vorformen) organisierer kann. Das gleiche gilt für die Kunst: sie hat organisierende Funktion 292 ).

Die Kraft des Sozialismus besteht darin, daß er dieses Kollektivierungspotential der Arbeit den Proletariern bewuBt macht und ihre wirkung so zur Entfaltung bringt:

Gerade die Zusammenarbeit in Werk und Fabrik, die gleichmäßig und systematisch ist und als Resultat ein gemeinsames Arbeitsprodukt ergibt, begründet im Proletarier eine völlig andere Arbeitseinstellung, veranlaßt ihn, nicht sein "Ich" sondern sein "Wir" als Ausgangspunkt zu nehmen"293). 
Was den Kollektivismus Lunatarskijs (und Gor'kijs und Bogdanovs) von dem seiner orthodoxen Zeitgenossen abhebt, ist das, was jener mit 'Religiosität' umschreibt: Die Einbindung des Individuums in das kollektiv, die Unterordnung des Einzelnen unter die kollektiven zielsetzungen sind nicht Ergebnis eines naturgesetzlich ablaufenden Prozesses, auch nicht Resultat der Machtübernahme durch das Kollektiv; sie erfolgen vielmehr auf der Basis einer freiwilligen Entscheidung des "kleinen Ich" für das "große Ich". In der Freiwilligkeit dieser von Enthusiasmus getragenen Entscheidung liegt für Lunacarskij die Religiosität des proletarischen Sozialismus beschlossen ${ }^{294)}$.

\section{f) Die "neue Religion" - Zusammenfassung}

Fassen wir die wichtigsten züge von Lunazarskijs Religions-Philosophie zusammen:

Er selbst nennt den Wissenschaftlichen Sozialismus eine "Religion des Fortschritts" - und wie in allen Fortschrittsreligionen wird auch hier das Schema von Geschichte als "Heilsgeschichte" beibehalten ${ }^{295)}$. Auf die hierin liegende Verwandtschaft - nicht nur struktureller Art - des Marxismus mit der jüdisch-christlichen Religion weist Lunačarskij selbst hin, wenn er die Jahwe-Religion als ein "Märchen" bezelchnet, das sich "der Mensch vom Menschen, dem König der Welt" geschaffen habe ${ }^{296)}$; und wenn er

im jüdischen biblischen Spiritualismus den mythischen, keimhaften Ausdruck der großen, wahren Religion der Religion der menschlichen Gattung oder, was dasselbe ist, des wissenschaftlichen Sozialismus 297 ) sieht.

Der Wissenschaftliche Sozlalismus ist die letzte und wahre Fortschrittsreligion, die auf dem jüdisch-christlichen Fundament entstanden ist - und Marx ist der letzte "Prophet"298). 
Die Geschichte ist Hellsgeschichte, und dem Proletariat als der Verkörperung der (bewußten) Arbeit kommt die Rolle des Erlösers und Retters (spasitel', vykupitel') zu. Allerdings - und darin unterscheidet sich Lunacars$k i j$ von den orthodoxen Marxisten - dieser Geschichte ist ein wesentlich "tragisches" Moment eigen: Ihr positiver Ausgang ist keineswegs gewiB. Sie bezieht daher inren Sinn und ihre Rechtfertigung nicht aus dem 'Jenseits', dem positiven Ende, sondern aus der gegenwärtigen kämpferischen und lebensbejahenden Praxis, die sich der Ungewißheit des Ergebnisses stets bewußt bleibt ${ }^{299}$ ).

Dennoch bleibt die Zukunft, für die das Proletariat kämpft, "reilig"300).

Das Bewußtsein eines möglichen Scheiterns der Geschichte hält dem enthusiastischen Glauben an den unbegrenzten Fortschritt, an die Machbarkeit des Glücks der Menschen, die Waage. Dies zeigt sich in den früheren Texten Lunacarskijs deutlicher als in den späteren, bleibt jedoch immer gegenwärtig. Dennoch besteht die sehr ausgeprägte Neigung zur Verherrlichung von Wissenschaft und Technik, eine Linie, auf der der Proletkul't das Werk des Gotterbauert.ums fortsetzt 301 ).

Das abermalige Zurückgehen von Marx oder dem Marxismus zu Feuerbach hat zwei Gründe:

Erstens soll die Geschichte wieder mehr als Gattungsgeschichte, Geschichte des "Menschen" ins Bewußtsein gerückt werden. So steht denn auch der Mensch als Gattungswesen 302 ) im Mittelpunkt der neuen Religion; er ist der wahre Gott. Entsprechend interpretiert Lunacarskij die drei sätze aus dem "Vater unser": Dein Reich komme; dein wille geschehe; geheiligt werde dein Name - als die "Apotheose des Menschen", seinen Sieg über die Natur; dem Willen des Menschen seien keine Grenzen gesetzt; auf dem "Weltenthron sitzt ein Menschenähnlicher" 303). 
Zweitens dient der Rückgriff auf Feuerbach dazu, zu zeigen, daß es mit der Marxschen Kritik der positiven Religionen nicht getan sel, daß vielmehr der Mensch wesentlich religiös sel: Die "Hellige stelle" (svjato mesto) darf nicht leer bleiben - das hat Feuerbach schon gezeigt ${ }^{304}$ ). Hierbei sieht Lunatarskij in ähnlicher Weise wie E. Bloch die lebensbejahende und um solcher Lebensbejahung willen bisweilen systemsprendende Kraft des "religiösen Urwunsches"

als welcher durchaus, in allen Bewegungen und zielen des Weltumbaus, dem Leben Raum schaffen wollte, um sich göttlich $z u$ verwesentlichen, sich chiliastisch in Güte, Freiheit, Licht des Telos endlich einzu bauen $^{305 \text { ). }}$

Weiterhin ist kennzeichnend für die neue Religion der ethische (in Lunacarskijs Terminologie auch "ästhetische") Anspruch:

Hier übt Lunatarskij Kritik am orthodoxen Marxismus wegen eines wesentlichen Mangels. Der "Rationalist" könne sich allenfalls ethisch verhalten; aber der Versuch des rationalistischen Marxisten, eine Ethik zu konstituieren, müsse notwendig "komisch" wirken, gerate gar zur "Idiotie"306). Daraus folgt für Lunacarskij: Der Mensch als wertendes Subjekt der Geschichte muß wieder in seine Rechte eingesetzt werden. (Hier findet er Argumentationshilfe bei Nietzsche.) 307 )

Schließlich muß das Verhaltnis zwischen Individuum und Kollektiv als ein religiöses, von Enthusiasmus getragenes begriffen werden. Das wahre "Ich", ist das "Wir" der neue "Gott", dem alle Verehrung und aufbauende Praxis gilt 308 ). 
Um solche religiöse Begeisterung zu wecken, braucht es einen 'Entwurf' vom neuen Menschen, ein "Ideal". Es hat die Funktion, die gegenwartsüberwindende Praxis, das Suchen nach realen Ansätzen für die gewünschte zukunft in Gang $z u$ setzen. (Auch hier argumentiert Lunacarskij mit Nietzsche.) 309 )

Mit seinem Unternehmen, den Wissenschaftlichen Sozialismus als Religion zu interpretieren, oder besser, inn zur 'Religion' zu erweitern, geht es Lunacarskij darum, fijr den Marxismus ein Terrain zu gewinnen, von dem auch $E$. Bloch in "Geist der Utopie"310) spricht:

Wenn die primitive Bedarfsdeckung, die feudale und dann die kapitalistische Wirtschaftsweise nacheinander ein bestimmtes moralisches und kulturelies Leben wenigstens der Sphäre nach determinieren, so muß doch auch der wegfall aller eigenen ökonomischen Komponenten, also die endich gelingende wirtschaftsweise des Sozialismus, eine bestimmte moralische und kulturelle Konsequenz, eine ebenfalis "richtige", apriorische Gesinnungs- und Kulturweise nach sich ziehen, die nicht nur ohne weiteres, gemäß den sozialistischerseits übernommenen Philisteridealen der Bourgeoisie, freigeistig und banalatheistisch bestimmt sein kann 311 ).

Es wurde schon darauf hingewiesen, wie problematisch es ist, Lunaxarskifs "System" als argumentativen Zusammenhang darzustellen. Dort, wo es um die überwindung des orthodoxen, mit 'Gesetzen' argumentierenden Marxismus geht, verläßt er fast immer die Ebene der systematisierenden sprache; sein sprachgestus wird dann emphatisch und appellativ, mehr überredend als überzeugend. Dies kann allerdings kein Vorwurf, sondern lediglich die Feststellung eines allgemeinen sprachproblems sein, das sich 
hier manifestiert ${ }^{312)}$. Ein abschließendes ausführliches zitat soll das zuletzt gesagte noch einmal verdeutlichen.

Ich habe versucht, die Türen des inneren Heiligtums, des emotionalen Allerheiligsten des Marxismus aufzureißen. Mein Buch bildet die Schwelle an diesen Türen. Mögen die Eintretenden wütend darauftreten: Wichtig ist, daß sie in das Innere des sich öffnenden Tempels blicken. Das wird nicht umsonst sein. Es wird helfen beim Bau Jener Regenbogen-Brücke, welche die romantische, sich selbst verleugnende, religiös-überindividuelle sozlaldemokratische Pra$x$ is mit ihrer Philosophie verbindet, welch letztere sich bemüht, in strenger Bescheidenheit sich ein trockenes und genügsames Äußeres zu geben - zum nicht geringen Schaden für ihre Sache. Diese äusserlich pedantische, statistische, fatalistische, vorzüglich prosaische Gestalt ist für mich eine leere, abgelebte Ästhetik, eine Art hochgradigen Resignierens, eine Art Bazarovscher Romantismus (Turgenev R.S.); Jedoch die Anerkennung des wissenschaftlichen Sozialismus als Licht der Welt, als flammendes Zentrum menschlicher Hoffnungen, als großartigste Poesie, als großartigsten Enthusiasmus, als großerartigste Religion - das ist für mich unmittelbarer Realismus, der, mit Lasalle zu sprechen, sagt, was ist ${ }^{313}$ ). 


\section{Gor'kij ein Schüler Lunacarskijs?}

Vergegenwärtigt man sich an dieser Stelle den eingangs besprochenen Text (Kap. III) von Gor'kij - seine Antwort auf die Umfrage des Mercure de France vom März 1907 so wird die Verwandtschaft der dort geäußerten Vorstellungen mit denen Lunatarskijs in der Frage nach dem religiösen Wesen des Menschen, bzw. nach dem Wesen der Religion of fensichtlich.

Unter dem Begriff der "religiösen Idee" kritisiert Gor'kij ebenso wie Lunačarskij die bestehenden "positiven" Religionen; allerdings weniger von einem materialistisch fundierten, marxistischen standpunkt aus, als vielmehr im Namen der "stolzen" Freiheit des Menschen und im $\mathrm{Na}-$ men der Gerechtigkelt, um die das Volk von den Herrschenden meist im Verein mit der herrschenden Religion betrogen wird 314 ).

Aber wie Lunacarskij verteidigt Gor'kij das Vorhandensein und die Notwendigkeit einer dem Menschen wesentlichen wahren Religiosität, und wie bei jenem ist diese Religiosität im emotionalen Bereich angesiedelt: Das "Pathos" des "freudigen Gefühls innerer Freiheit" 315 ) nat religiöse Qualität.

Gleichermaßen gründet diese Religiosität auf der christlichen Trias: Glaube, Hoffnung, Liebe - Glaube des Menschen an seine "Kraft", d.h. an seine schöpferische Praxis; "Liebe zum Leben" und Hoffnung auf "seinen Sieg"316)" wie bei Lunacarskij ist Geschichte hier Heilsgeschichte: Der Mensch geht seiner (zunächst geistigen) Vollendung entgegen. Der Prozeß dieser Vervollkommnung - Fortschritt ist ein Prozeß der Selbsttranszendierung des Menschen; auch Gor'kij sucht/sieht in der Zukunft den 'Entwurf' eines "neuen psychologischen Typus" ${ }^{317)}$, den neuen Menschen. 
Dieser neue Mensch wird seine Făhigkeiten und Möglichke1ten im Kollektiv voll entfalten, er wird seine individuellen Grenzen überschreiten, und die kollektive Erfahrung (Kunst, Wissenschaft) seiner Gegenwart - aber auch seiner Vergangenheit - steht inm zur verfügung und wird für die Zukunft durch inn bereichert. Bei Lunatarskij heiBt das stichwort "Zusammenarbeit in Raum und Zeit".

Schließlich ist es der Sozialismus als eine spezifische herrschaftsfreie wirtschaftswelse und Regelung der zwischenmenschlichen Beziehungen ("freler, ausgedehnter Verkehr"318), der die organisatorischen Bedingungen für die Entstehung des neuen Menschentypus beschreibt und schaff $t^{319)}$.

Hinter beiden 'religions-philosophischen systemen' steht der Versuch, eine synthese herbeizuführen:

Was bei Lunacarskij die letztlich mit der Wiedereinführung des wertenden subjekts in die Geschichte angestrebte Synthese von subjektivität ("Ich") und Objektivität (Beschreibungs- und Analysesystem des orthodoxen Marxismus) im grossen "Wir" ist, begegnet bei Gor'kif als die synthese jener zwei Zentren seines Menschen- und Weltbildes - Gefühl und vernunft ${ }^{320)}$.

Die Nachbarschaft der Gedankengänge Lunacarskijs und Gor'kijs liegt auf der Hand; und so schelnt nichts gegen die vor allem in der sowjetischen Literaturwissenschaft seit Lenins Verdikt immer sich von neuem reproduzierende - Behauptung zu sprechen, daß Gor'kij in der zeit seines Gotterbauertums, also auch zur Zeit der Enquête, sich unter dem theoretischen, ideellen Elnfluß Lunacarskijs (und Bogdanovs) befunden habe - was seine 'Abweichungen' erklären wïrde 321 ). Jedoch schon bei der Betrachtung der biographischen Fakten - erst recht der inhaltlichen - melden sich Bedenken gegen das Rezeptionsmuster: Gor'kij, der (ver- 
führte) Schüler Lunatarskijs und Lenin, der wahre Lehrer und Freund, der inn wieder auf den richtigen Weg zurückfunst ${ }^{322 \text { ) }}$.

Nach "Letopis" zizni i tvortestva Gor'kogo"323) fand der erste Kontakt zwischen Gor'kij und Lunacarskij im November 1907 in Florenz statt - also über ein halbes Jahr nach Gor'kijs Antwort auf die Enquête. Trifonov ${ }^{324}$ ) führt zwar elne andere Quelle an, nach welcher sich die belden Ende 1905 schon ein erstes Mal in St. Petersburg gesehen haben sollen; jedoch kann dieser Kontakt nur sehr kurz gewesen sein - auf keinen Fall ausreichend für einen intensiven und befruchtenden Gedankenaustausch. Dieser begann erst Ende 1907 auf Capri ${ }^{325)}$, also nach der Umfrage und nach Gor'kijs "Mat".

Es sind aber nicht nur die blographischen Tatsachen, die gegen die Übernahme jenes vereinfachten und gradiinigen Rezeptionsmusters sprechen: Die inhaltilchen Unterschiede zwischen Lunatarskijs 'und Gor'kijs 'Systemen' fallen mindestens ebenso sehr ins Gewicht.

Gor'kif spricht in dem analysierten Text davon, daß der Fortschritt ins Unendliche vorangetrieben werden könne; seinem Fortschrittsglauben liegt das Vertrauen in die zukünftige Harmonie zwischen Mensch und Kosmos zugrunde. Dagegen fügt Lunatarskij seinem Geschichtsbild ein 'tragisches' Element ein: Der zukünftige sieg ist keineswegs gewiB 326).

Gor'kij nennt zwar den Sozialismus als die Bedingung der Möglichkeit einer neuen Gesellschaft, aber es geht inm nicht - wie Lunatarskij - darum,zu beweisen, daß der Wissenschaftliche Sozialismus eine Religion sei. Beider Anliegen sind so verschieden wie inre Ausgangspunkte. 
Bel Gor'kif vermischt sich das kollektivistische mit einem von Lunatarskif so genannten "kosmistischen" Element: Neben der Menschheit (Gattung) gewinnt der Kosmos (Natur) als weitere, allumfassende überindividuelle Größe an Bedeutung - er wird sogar Gegenstand der Verehrung. Lunatarskif lehnt diese sicht Gor'kijs als potentiell pantheistisch $a b^{327)}$.

Schließlich spricht Gor'kif im Zusammenhang mit dem religlösen Gefühl nirgends vom Proletariat als dem Träger der neuen Religion.

Die Vermutung, daß Gor'kij zu seinem Gotterbauertum "auf eigenem Wege" gekommen sei ${ }^{328}$ ), liegt somit näher als die traditionelle sicht; und es soll hier versucht werden, diesen eigenen weg zu rekonstruieren. Dabei gilt es als gesichert festzuhalten, daß Gor'kijs Enquêten-Text mehr als ein halbes Jahr vor Lunatarskijs "Buduscee religii"329) erschien; d.h. kurz vor Beginn ihrer zusammenarbeit auf Capri. Darüber, ob Gor'kij schon vor 1907 Texte von Lunacarskif kannte und so von ihm Ideen bezogen haben könnte, läßt sich nichts mit sicherheit sagen.

Es muß deshalb - trotz der auffallenden übereinstimmungen davon ausgegangen werden, daß der im Mercure de France 1907 erschienene Text einen standpunkt repräsentiert, den Gor'kij weitgehend unabhängig von Einflüssen Lunatarskijs oder Bogdanovs erreicht haben dürfte 330 ). Für die Texte nach 1907, die gewöhnlich mit dem Bogostroltel'stvo Gor'kijs in Verbindung gebracht werden (vor allem "Ispoved"" und "Razrusenie licnosti")331) mögen die Verhältnisse etwas anders liegen, da ab November 1907 eine gegenseitige 'Beeinflussung' der Mitglieder der Capri-Gruppe als selbstverständlich anzunehmen 1st. - Jedoch wäre dies vergleichsweise irrelevant, wenn es gelänge, zu zeigen, 
daß das, was unter Gotterbauertum bei Lunatarskij und Gor'kij zu verstehen ist, schon Anfang 1907 seine Ausprägung gefunden hatte; und zwar bei Lunatarskij und Gor'kij jeweils auf eigenem Wege. Die während der Capri-zeit entstandenen Texte wären dann lediglich Ausformungen und Entfaltungen schon gewonnener Positionen - sofern diese Texte überhaupt etwas mit dem Bogostroitel'stvo gemeinsam haben und nicht wegen der (lokalen) Nähe Bogdanovs unter ein ideologisches verdikt fielen, das eigentlich nur diesem galt ${ }^{332}$ ).

Diesem Problem soll nun in einer genauen Analyse Gor'kijscher Texte nachgegangen werden. 


\section{Anmerkungen}

1) Die Beschränkung auf Lunacarskif und die Vernachlässigung der anderen 'Bogostroiteli' ist gerechtfertigt, da v.a. Bogdanov, der oft als Kopf der Gruppe reklamiert wird, niemals ein Gotterbauer in dem Sinne gewesen ist, daß er ein religionsphilosophisches system konstrulert hätte; vom Gotterbauertum Lunatarskijs hat er sich im Gegentell distanziert, (Vgl. III, Anm. 30)). Das Verhältnis Gor'kij-Bogdanov, das hier eine Rolle spielen könnte, wird erst zur Capri-zeit relevant, zu einer zeit, als Gor'kif längt zu seinem Gotterbauertum gefunden hatte. Von einer 'Gruppe' der Gotterbauer zu sprechen, erscheint ohnehin fragwürdig; dieser Sprachgebrauch reflektiert eher ein Bedürfnis Lenins, aus einer verglelchsweise lockeren Grupplerung eine für die Partelarbeit gefährliche Fraktion zu machen und damit einen Ansatz für die Liquidierung inres führenden Kopfes zu gewinnen.

Selbst Plechanov macht in seiner Polemik gegen Bogdanov einen Unterschied zwischen dessen "nicht mehr neuer Philosophle nach Ernst (Mach)" und dem "neuen Evangelium nach Anatolif (Lun.)". Plechanov, Materialismus militans. In: drs., Sotinenija, t. XVII. M. 1924, S. 7 .

Dementsprechend sind in diesem Band die Polemiken gegen Bogdanov unter der Rubrik 'Philosophie' eingeordnet, während die Abrechnung mit dem Bogostroltel'stvo unter der Abteilung 'Religion' erscheint. ("O tak nazyvaemych religioznych iskanijach v Rossil", a.a.0. S. $238-272$ ).

2) Obrazovanie, 10/11, 1907. 
3) Religija 1 socializm (= RiS). SPb $1908 / 11$.

4) R1S, I, S. 7.

5) Vgl. Et judy kriticeskie... M. 1905;

Otkliki zizni. Sbornik stat'ej. SPb 1906.

Schon in diesen ersten Auf satzsammlungen wird die grundlegende Fragestellung herausgearbeitet.

6) Vgl. Bazarov, Bogoiskatel'stvo i "Bogostroitel'stvo". In: Versiny, I, SPb 1909.

7) Frühere Texte Lunacarskijs, soweit sie die Fragestellung von $1907 / 11$ verdeutlichen helfen, werden natürlich ebenfalls herangezogen.

8) RiS, I, S. 7 .

9) ebd. S. 31 .

10) ebd. S. 32 .

11) ebd.

12) ebd. S. 30. Ebenso wenig wie Plechanov konnte LunaCarskif Marx' "Kritik der Hegelschen Rechtsphilosophie. Einleltung." kennen; allerdings gelten seine Attacken hauptsächlich den eigenen Zeitgenossen.

13) ebd. S. 317.

14) L. Feuerbach, Das Wesen der Religion. Hrg. A. Esser, Köln 1967, S. 66.

15) RiS, I, S. 64.

16) Vgl. RIS, II, S. 327.

17) RiS, I, S. 31 .

18) ebd. S. 64 .

19) ebd.

20) ebd. S. 79 .

21) So lautet eine Kapiteluberschrift in dem Aufsatz "Buduscee religil", womit Lunacarskif selbst auf die Nähe seiner Gedanken zu Feuerbach hinweist.

22) RiS, I, S. 20.

23) RIS, I, S. 21.

24) ebd. 
25) Lunacarskij, Buduscee religil. Obrazovanie 10 (1907) S. 8.

26) Vgl. Buduscee religli, a.a.0.S. 8; S. 19; RIS, I, S. 21 .

27) Buduscee religil, a.a.0.S. 19.

28) RiS, I, S. 29.

29) Buduscee religil, a.a.0. S. 11 .

30) RIS, I, S. 80 .

31) Buduscee religil, a.a.O. S. 20.

32) ebd.

33) RiS, I, S. 10.

34) Buduscee relig11, a.a.O. S. 24.

35) ebd.

36) Dieser Ansatz Lunacarsk1 is findet seine Entsprechung im "ethischen Sozlalismus" der Neukantlaner. Vgl. L. Kolakowsk1, Die Hauptströmungen des Marxismus, Bd. 2, München-zürich, 1978, S. 271f.; sowie I. Fetscher, Der Marxismus. Selne Geschichte in Dokumenten. Bd. 1, München-zürich 1976, S. $230 f$. (zu Lunacarskij und Kant s.u.!)

37) Buduscee relig11, a.a.0., S. 12 .

38) RIS, I, S. 13.

39) RiS, I, Kap. $1+2$.

40) Buduscee religil, Obrazovanie ll (= Bud. rel. (2)) S. 35 .

41) RiS, I, S. 536 .

42) Budusčee religil, a.a.0., S. 35.

43) R1S, I, S. 56.

44) Buduscee religil, a.a.0., S. 20 u. pass.; RiS, I, S. 12 U. pass.

45) RiS, I, S. 39; Unterstr. V. mir; vgl. Buduscee religil, Obr. lo (= Bud.rel. (1)), S. 20.

46) Buduscee religil, a.a.0., S. 21; Unterstr. v. m1r.

47) RIS, I, S. 29; vgl. Buduscee relig1i (1) S. 12.

48) RIS, I, S. 95; Ateism, S. 156; Bud. rel. (1), S. 12. 
49) Bud. rel. (2), S. 30.

50) Lunatarskif bezieht sich bel seinen ethnologischen Begründungen wie Plechanov auf die Forschungen Edward Tylors zur Kulturanthropologie. ("Die Anfänge der Kultur" - $1873 \mathrm{dt.}$ ) Vor allem die von inm entwickelte Theorie des "Animismus" hatte starken EInfluß auf die um 1900 erschienene Literatur zur Entstehung der Religion. Vgl. R. Girtler, Kulturanthropologie. München 1979, S. $218 \mathrm{ff}$.

51) Bud. rel. (1) S. 20; vgl. a. ebd. S. 22; RIS, I, S. 39; RiS, II, S. 295. Die Definition von Religion als "Verbindung", ethymologislerend von religare hergeleitet, wurde auch schon von Comte und Schlelermacher bemüht.

52) Bud. rel. (1), S. 22 .

53) ebd.

54) ebd.; vgl. a. Ris, I, S. 41. Dieser Religionsbegriff weist Parallelen zu dem des Austromarxisten Max Adler auf! Vgl. Leszek Kolakowski, Die Hauptströmungen des Marxismus, Bd. 2, S. $320 \mathrm{f}$.

55) Dies sei mit aller Vorsicht und mit Vorbehalt gesagt; denn ein - unter systematischen und philosophiegeschichtlichen Gesichtspunkten - wirrer Eklektizismus in Lunacarskijs Denken kann nicht bestritten werden.

Allerdings - und damit ist eine methodische Kernfrage dieser Arbelt berührt - ist es sehr fraglich, ob eine Analyse unter "systematischen" Prämissen dem hier darzustellenden Gegenstand gerecht würde. Eine solche Vorgehensweise wäre lediglich in der Lage, eben diesen Eklektizismus im Einzelnen nachzuweisen (was überflüssig 1st, da er längst nicht mehr bestritten werden kann); sie hätte aber keinen Erkenntniswert für 
die hier behandelte Sache. Es kann nicht unser Erkenntnisinteresse sein, ob, wie und wie falsch Lunacarskij diesen oder jenen Philosophen verarbeltet hat - dies wäre ein bloß 'akademischer' Zugang. Wichtiger und von größerem Interesse ist es m.E. zu fragen, warum und mit welchem ziel Lunacarskij diese oder jene Anleithe aufgenommen hat. Dies sind jedenfalis Fragestellungen, die auch heute noch in Sachen Religion und Marxismus/Religion (Mensch) und Geselischaft relevant sein könnten. Hierzu gehört auch die Frage der Originalität von Lunacarskijs Ideen. Sicher ist das Bestreben nach einer säkularisierten Form von Religion nicht neu, wie sich spätestens seit den Frühen Sozlalisten beobachten läßt. Aber es wurde eben offensichtilch auch keine befriedigende Antwort auf die Frage gefunden, was denn der Mensch ohne 'Religion' machen solle. Und diese Tatsache schon rechtfertigt Lunaciarskijs Versuch und das Unternehmen, ihm nachzudenken.

56) Bud. rel. (1), S. 23.

57) K. Marx, Zur Kritik der Hegelschen Rechtsphilosophie. Einleitung. In: drs., Die Frühschriften. Hrg. S. Landshut. Stuttgart 1968, S. $207 f$.

58) Dies gilt auch dann, wenn fur Marx eine Religion ohne Gott kelne 'Religion' mehr ist - eine bloß terminologische Frage. Lunacarskif geht es aber nicht um Terminologie, sondern um das Problem, ob die Marxsche Relgionskritik mit der Entschleierung der negativen Funktionen von Religion (Oplum des Volkes) zugleich deren mögliche positiven Funktionen vernachlässigt und damit den Menschen in seinen wesentlichen Lebensvollzügen verkennt.

59) Etjudy..., S. 111 . 
60) Vgl. N.A. Trifonov, A.V. Lunatarskif i M. Gor'kij. $K$ istoril licnych 1 literaturnych otnosenij. In: Gor'kif 1 ego sovremenik1. Leningrad 1968, S. 132.

61) Etjudy kriticeskie 1 polemiceskie. Moskau 1905.

62) ebd. S. 111. Vgl. G.V. Bulackij 1 A.A. Plavnik, Lunacarskif - revol fucioner-publicist (1905-1907gg). Minsk 1971, S. 5; I.P. Kochno, Certy portreta. Stranicy zizni 1 dejatel'nosti A. V. Lunacarskogo. Minsk 1972, S. 7 .

63) Et judy, S. III.

64) ebd. S. IV.

65) ebd.

66) ebd.

67) ebd.

68) ebd. S.V.

69) Vgl. Otkliki zizni. Predislovie.

70) Otkliki zizni. SPb 1906.

71) ebd. S. IV.

72) ebd.

73) ebd.

74) ebd. S. V.

75) ebd. S. VI.

76) Grille, Lenins Rivale. Bogdanov und seine Philosophie. Köln 1966 (= Abhandlungen des Burdesinstituts für ostwissenschaftliche und internationale Studien Bd. XII), S. 127.

77) Ris, I, S. 12 Unterstr. v. mir.

78) ebd. S. $12 / 13$.

79) s.o. Kap. IV, 2 .

80) Vgl. Kolakowsk1, Die Hauptströmungen. Bd. 2, S . 471.

81) Problemy Idealiszma. Moskau 0.J.

82) RiS, I, S. 7.

83) Kolakowsk1, a.a.O. S. 282.

84) RiS, I, S. $13 f$. Diese Nachbarschaft Lunaxarskijs zu den Neukantianern gilt Jedoch nur in der 
Fragestellung; die neukantianische Lösung wurde von inm heftig bekämpft, wie seine Auseinandersetzung mit Berdjaev zeigt. Vgl.a. G. Kline, Religious and Antireligious Thought in Russia. Chikago-London 1968. S. 106.

85) RIS, I, S. 14.

86) Vgl. RiS, II, S. 382 ; Kline, a.a.O. S. 117.

87) Masaryk, Russische Geschichts- und Religionsphilosophle, II, S. 309 U. pass.

88) RIS, II, S. 382 .

89) ebd. S. 259.

90) ebd. S. 371 .

91) ebd. S. 311 .

92) RiS, I, S. 14 .

93) ebd.

94) R1S, II, S. 371.

95) Vgl. Kolakowski, a.a.0. Bd. 2, S. 383.

96) RiS, II, S. 382 .

97) ebd.

98) F. Trommler, Sozialistische Literatur in Deutschland. Stuttgart 1976, S. 247.

99) $\nabla$ gl oben Lunatarskij.

100) Hildegard Reiser, zit. bei F. Trommler, a.a.0. S. 252 .

101) dazu näher F. Trommler, a.a.0.S. $261 \mathrm{ff}$.

102) RiS, I, S. 7 .

103) Vgl. Bud. rel. (2), S. 55.

104) Problemy 1dealizma, Moskau 0.J.; zur Zeitbestimmung vgl. Scherrer, Die Petersburger Religions-Philosophischen Vereinigungen. Berlin 1973, S. 87 Anm. 4. (= Forschungen zur osteuropäischen Geschichte Bd. 19).

105) O "Problemach Idealiszma". In: Ėtjudy Moskau 1905, S. 226.

106) RiS, I, S. 51. 
107) ebd.

108) RiS, I, S. 369.

lo9) RiS, I, S. 326; vgl. ebd. S. 310.

110) Vgl. RiS, I, S. 299.

111) O cest1. In: Otklik1... SPb 1906, S. 97.

112) Zarathustra II, 324.

113) O cesti. S. 80.

114) Ateizm. In: Ocerki po filosofil marksizma. SPb 1908, S. 129.

115) vgl. oben.

116) Vgl. Die Fragestellung Berdfaevs. Hier S. $82-84$.

117) RiS, I, S. 382. Unterstr. v. mir.

118) Bud. rel. (1), S. 20.

119) Hier S. $64 \mathrm{ff}$.

120) Lun., Russkif Faust. In: Voprosy filosof 11, 63 (1902) S. 794.

121) drs., Dacniki. In: O Gor'kom. Moskau 1975, S. 38. (Der Text stammt von 1905).

122) ebd.

123) Vgl. weiter unten Nietzsche/Guyau, Lunacarskif! (Kap. V, 4).

124) Russkif Faust, a.a.0.S. 793.

125) RiS, I, S. 13.

126) RiS, II, S. 332 .

126a) Wie auch für andere ehemalige legale Marxisten:

P.B. Struve, S.L. Frank, S.N. Bulgakov, die inre neue Position in dem Sammelband "Problemy Idealizma". M.O.J. (1903) dargelegt hatten. Vgl. dazu J. Scherrer, a.a.0. S. $86 \mathrm{ff}$.

127) Bud. rel. (2), S. 53.

128) ebd.

129) ebd.

130) ebd. S. 55 .

131) ebd. 
132) ebd.

133) R1S, I, S. 17 .

134) RiS, I, S. 16. Unterstr. v. mir.

135) Et judy; Otk1ik1 usw.

135a) Gerade dies 1st mit kennzelchnend für das Bogostroltel'stvo Lunacarsk1js; im Gegensatz zu der Behauptung in Vol'fson/Gak, die "Gotterbauer glaubten nicht an die Wissenschaft." (M.B. Vol'fson 1 G.M. Gak, OCerk1 Istor lCeskogo Materializma. Moskau 21931, S. 214l.

136) "Materielle Evolution und geistiger Fortschritt fallen in eins." Ateizm, a.a.0., S. 148; vgl. auch Mescanstvo 1 individualizm. In: oxerki po fllosofi1 kollektivizma. SPb 1909, S. 239.

137) RiS, I, S. 16 .

138) ebd.

139) S. Anm. 121.

140) Aber man muß dennoch sagen, daß Luncarskif hier vollständig in der europälschen rradition der Evolutions- und Fortschrittsideologien steht, welche "organische Differenzlerung in eine Ebene mit zivilisatorischem Fortschritt (stellt) und (diesen) wiederum mit sittlicher Höherentwicklung glelchsetzt." H.-G. Zmarzlik, Sozialdarwinismus. In: SDG, 5, Sp. 907f.

Zur Geschichte des Fortschrittsglaubens in Rußland: Peter Brang, Fortschrittsglauben in Rußland einst und jetzt. In: Rudolf W. Meyer (Hg.), Das Problem des Fortschritts - heute. Darmstadt 1969, S. 29 - 53.

141) Dacnik1, S. 22 .

142) ebd.

143) RiS, I, S. 14.

144) RiS, I, S. 17 .

145) Ateizm, S. 140. 
146) RIS, II, S. 308.

147) ebd. S. 309.

148) vgl. hier S. 67.

149) s.o.

150) In den früheren Schriften Lunacarskijs.

151) R1S, I, S. 88 .

152) RiS, I, S. 48 .

153) "Ihr (der 'Gottbildner') primäres Anliegen ist auf die zukunft gerichtet. Sle błeten nicht so sehr eine Interpretation der Geschichte der positiven Religionen als vielmehr eln Programm für eine neue, gereinigte 'humanistische' Religion." G.L. Kline, Religious and anti-religious thought in Russia. Chikago-London 1968, S. 105.

154) G.L. Kline, "Nietzschean Marxism" in Russia. In: Boston College Studies in Philosophy 2, 1969, S. 166; Vgl. auch D. Bathrick und P. Breines, Marx und/oder Nietzsche. Anmerkungen zur $K r i s e$ des Marxismus. In: Karl Marx und Friedrich Nietzsche. Acht Beiträge. (Hrg. R. Grimm, J. Hermand)

Königstein/Ts 1978, S. $119-135$.

155) Kline a.a.0. S. 166.

156) In: Ocerk1 filosof 11 kollektivizma, I. SPb 1909, S. $219-349$.

157) ebd. S. $238 f$.

158) ebd. S. 239.

159) Kline, a.a.0. S. 167 .

160) ebd. S. 166.

161) ebd. S. 167 .

162) Vgl. RiS, I, S. 46.

163) S.S. $67 f f$.

164) RiS, I, S. 10 .

165) Nietzsche, II, S. 323.

166) Mescanstvo 1 individualizm, S. 238; vgl. Ateizm, S. 155; Bud.rel. (1), S. 21; V mire nejasnogo. 
In: Otklik1, S. 45. Vgl. Nietzsche, Vom Nutzen und Nachteil der Historle. I, S. 209 - 285; v.a.S. 209, 218f, 229, 230!, 277, 282.

167) Nietzsche, II, S. 578; II, S. 215; II, S. 371.

168) Ocest1. In: Otkliki, S. 96; vgl. Russkif Faust S. 792. Lunacarskif versteht den "Willen zur Macht" nicht als "Wunsch zu beherrschen", verme1det also eines der "vier möglichen Mißverständnisse über Nietzsche". (Gilies Deleuze, Nietzsche. Ein Lesebuch. Berlin 1979, S. 43.).

169) Es ist konsequent nietzscheanisch, daß Lunacarskijs sprache suggestiv, also wertend und interpretierend wird, wenn es inm um die zukunftsgerichtete Dynamik geht, die auf den neuen Menschen zielt. Das Sprachproblem: Die Sprache selbst wird zur Botschaft, daher inr affirmativer Gestus. Vgl. G. Deleuze, a.a.O. S. 19.

170) Vgl. Bulackif und Plavnik, Lunacarskif - revolfucioner-publicist (1905 - 1907). Minsk 1971.S. 28 u. 61.

171) Russkif Faust, a.a.0., s. 787.

172) 0 cest1, a.a.0., s. 97.

173) Ate12m, S. 124.

174) ebd.

175) s.o.

176) Nietzsche, II, S. 325.

177) Vgl. Kline, Religlous and anti-religious thought in Russia, s. 107.

178) Vgl. Anm. 157).

179) Ate1zm, S. 160.

180) V mire nejasnogo, a.a.0. S. 71.

181) O cest1,a.a.0. S.97; Russkif Faust, a.a.0. S. 793.

182) m.E. zu Recht.

183) V mire nejasnogo, a.a.0.S. 7of; vgl.a. Ateizm, S. 108. Plechanov (Soc., t. XII, S. 25I) und der inn bestätigende Grille (Lenins Rivale, S. 35) 
haben unrecht mit der Behauptung, bel Lunacarskij sel der "Mensch der Zukunft ein blologischer "Übermensch" - Im Gegensatz zu Bogdanov, der den Übermenschen kollektivistisch, als die "kommunistische Übermenschheit" Interpretiere. Belde, Lunacarskif und Bogdanov, gebrauchen das Übermensch-symbol in der gleichen Weise.

184) Mescanstvo 1 individual1zm, S. 298/299; vgl.a. ebd. S. 320. Dieser Aufsatz wurde von Lunacarskif 1909 geschrieben; er kann also unmöglich (wie von D. Angres, Die Bezlehungen Lunačarskijs zur deutschen Literatur. Berlin 1970, S. 16 und ähnlich von Kochno, Certy portreta..., s. 30 versucht) zum Beweis dafür genommen werden, daß Lunacarskif erst 1923 zur richtigen Einschätzung Nietzsches gekommen sei.

185) Mescanstvo 1 individualizm, S. $238 \mathrm{f}$.

186) ebd. S. 240.

187) Nietzsche II, S. 197 (Nr. 337); Lun., R1S, II, S. $365 f$.

188) drS. II, S. 197.

189) ebd. S. 198.

190) ebd.

191) vgl. oben S. 67ff.

192) Vgl. den Gor'kij-Text Kap. III.

193) s.U. Kap. IV, 5, b)

194) Bud. rel. (1) S. 24.

195) Mescanstvo 1 individualizm. S. 300.

196) RiS, II, S. 357.

Der französische Moral- und Religionsphllosoph M.J. Guyau (1854 - 1888) war in Rußland sehr früh bekannt; Besprechungen seiner Bücher erschienen schon ab 1894. 1908 rezensierte Plechanov (soc.,t. 17, s. 337 - 341) Guyaus 1887 erschienenes und 1908 ins Russische übersetzte Buch 
"L'irréligion de l'aventr", in welchem er eine zukünftige, harmonisch organisierte Geselischaft zeichnet, die durch eine emotional bestimmte 'Religion' gekennzelchnet ist. Die Rolle Guyaus für die Konzipierung von Lunar Carskijs 'Ethik' und Ästhetik ist möglicherwelse bisher noch nicht genügend gewürdigt worden. Auch hier findet sich das 'Leben' als oberstes Wertprinzip. Die Moral ist begründet im "Iife at its most intensive and extensive". (The Encyclopedia of Philosophy Vol. 3 (Hrg. P. Edwards), London-New York 1967, S. 398). Lunacarskif erwähnt mehrfach das "Guyausche Gesetz", wonach extreme individuelle Lebensintensität in soziale Intensität umschlägt. Mit der zitierung dieses 'Gesetzes' untermauert Lunacarskij seine kollektive Lesart Nietzsches.

197) Russkif Faust, a.a.0. S. 789.

198) vgl. unten Gor'k1j - Nietzsche.

199) Russif Faust, a.a.0. S. 793.

200) "Russkij Faust" ist 1902 geschrieben.

201) G. Kline, Nietzschean Marxism in Russia. In: Boston College Studies in Philosophy 2, 1969 , S. 166 - 183 .

202) E. Bloch, Geist der Utople, Frankfurt/M. 1973, S. 303. 203) Lunačarskij, Dačniki. In: drs., o Gor'kom. Moskau 1975, S. 20.

204) Pered licom roka. In: Étfudy..., S. 103.

205) Mescanstvo 1 individualizm, S. 238.

206) ebd., S. 250.

207) Vgl. Kline, Religious and anti-religious thought In Russia. S. $106 f f$. Die Schwäche von Klines Argumentation beruht darin, daß er die Verwandtschaft zwischen Lunacarskijs Marxismus und Nietzsche behauptet aber nicht nachweist. 
Auf die Bedeutung Nletzsches, vor allem des "Zarathustra" und der "Fröhlichen Wissenschaft" für Lunacarskijs Kunst-Konzeption weist J.-U. Peters hin. (J.-U. Peters, Kunst als Erfahrung. Über den Zusammenhang von Kunsttheorie, Literaturkritik und Kulturpolitik bel A.V. Lunacarskij. Unveröffentl . Manuskript Konstanz S. 9of).

209) Lun., Mescanstvo 1 individualizm, S. 239.

210) Mescanstvo i individualiszm, s. 330.

211) Osnovy pozitivnof estetiki. In: Ocerki realisticeskogo mirovozzrenija. SPb ${ }^{2} 1905, \mathrm{~S} .180$.

212) Mescanstvo 1 individualizm, S. $331 \mathrm{ff}$.

213) ebd., S. 332.

214) Vgl. oben S.67ff.

215) Mescanstvo $i$ individualizm, S. 333.

216) ebd.

217) ebd., S. 334 .

218) Bud. rel. (2), S. 60.

219) Vgl. oben S.72ff.

220) Bud. rel. (1), S. 229.

221) ebd.; vgl. auch Lunacarsk1j, 23-1j sbornik "Znanifa". In: Literaturnyf raspad 2, SPb 1909, S. 67.

222) RiS, I, S. 73.

223) Mesc. 1 indiv., S. 335.

224) ebd.

225) RIS, II, S. 364 .

226) RiS, I, S. 89.

227) $s .0$.

228) Vgl. RiS, I, S. 86.

229) Ateizm, S. 157 .

230) ebd., S. 158.

231) RiS, I, S. 76.

232) Bud. rel. (2), S. 40. 
233) ebd.

234) ebd. Unterstr. v. mir.

235) mit Sorell verbindet Lunacarskif die Betonung der Subjektivität.

236) Ateizm, S. 159.

237) Bud. rel. (2), S. 42. Diesen Aspekt der 'religiösmarxistischen Anthropologie', so Lunačarskij, trifft Gor'kif in seiner Antwort auf die Enquête richtig. ebd;

vgl. Gor'kif, Celovek, (1903).

Fast dieselben Motive werden auch später im dichterischen Schaffen des Proletkul't zur Interpretation der Geschichte, und der Rolle des kollektiv organisierten Proletariats in inr herangezogen: I. Jasinskij, "NaS bog". In: R. Lorenz (Hrg.), Proletarische Kulturrevolution in Sowjetrußland; 1917 - 1921). München 1969, S. 86; das Kollektiv der Arbeiter als schon immer existierend und ewig seiend, als Schaffendes und zu Schaffendes. "Aus Liebe zu den völkern bist du wieder auferstanden." (ebd.) Vgl. auch Gerasimov, "My", ebd., S. $79 f$.

239) S. Oben S. 67ff.

240) RiS, I, S. 95 (Unterstr. v. mir.).

241) ebd.

242) G. Erler, Der Proletkul't. Unver. Manuskript (Freiburg), S. 13.

243) RiS, I, S. 89.

244) ebd., S. 95.

245) ebd., S. 82 .

246) Vgl. Gor'kijs Enquêten-Text.

247) Osnovy pozitivnoj estetiki. In: oc. realn. mirovozzr. SPb ${ }^{2} 1905$, S. 38 .

248) $v$ mire nejasnogo. In: Otkliki. S. 64.

249) ebd., S. 70 
250) ebd., S. 66f.

251) RIS, I, S. 89.

252) ebd., S. lolf.

253) RiS, II, S. 347. Das Proletariat als Messias ist ebenfalls ein Topos, der seinen Weg vom Bogostroitel'stvo zum Proletkul't gefunden hat: V.T. Kiriliov, "Der eiserne Messias" (Zeleznyj Messija): "Er hilft uns das Joch unseres Schicksals abstreifen/Und auf Erden das Paradies erringen." In: "R. Lorenz, a.a.O. S. 90; und M.P. Gerasimov, "Das Kreuz" (Krest") - hier wird der Tod eines bei der Arbeit verunglückten Proletariers zum Sühne- und Erlösertod: "Gekreuzigt lag einer auf goldenem Blech/Und verbrannte/Von züngelnden Flammen umgeben." (ebd. S. 94). Die Namen Gerasimov und Gastev tauchen 1913 im Zusammenhang mit einem Arbeiterschriftstellerzirkel in Paris auf, an dem auch Lunacarskij teilnahm, (Literaturnaja Énciklopedija, t. 2, Moskau 1930, Stichwort Gerasimov.) so daß also hier eine direkte personelle Linie vom 'Bogostroltel'stvo' zum Proletkul't gezogen werden kann.

255) Ateizm, S. 128.

256) Vgl. Russkif Faust, a.a.0. S. 788; RiS, II, S. 365.

257) Vgl oben das 'eschatologische' Moment, S.115.

258) S.S. lo5f; O cesti, a.a.0. S. 97.

259) Russkif Faust, a.a.0. S. 79l; vgl. auch RiS, I, S. 73 .

260) RiS, I, S. 43.

261) ebd.

262) Bud. rel. (2), S. 44.

263) Vgl. dazu K. Löwith, Weltgeschichte und Heilsgeschehen. Stuttgart, Berlin, Köln, Mainz 61973, v.a. S. $38 \mathrm{ff}(\operatorname{Mar} x)$.

264) Vgl. auch E. Bloch, Prinzip Hoffnung. 
265) Ateizm, S. 128.

266) Die Neue Religion muß für Lunadarskif die früheren ersetzen können, "Indem sie den menschlichen Hunger nach einem Sinn des Daseins, nach elnem hohen, schönen ziel stillt, um dessentwillen es sich lohnen würde zu leben, zu kämpfen und sogar zu sterben." (Lunacarskij in Novyj Zurnal dlja vsech (1910), Nr. 23, September, S. 89, zit. bei N.A. Trifonov, Lunatarskif 1 Gor'kij... In: Gor'kij 1 ego sovremeniki. Leningrad 1968, S. 133.

267) Vgl. Lunacarskij, Voprosy morali i Meterlink. In: Etjudy...., s. $175 \mathrm{f}$.

267a) H. Spencer, P. von Lilienfeld, A. Schäffle, A. Foulliée; in Rußland u.a. auch Bervi-Flerovskij.

268) RIS, II, S. 369.

269) 5.0 .

270) 23-1j sbornik "Znanija", S. 87; Unterstr. v. mir. 271) ebd.

272) Vgl. RiS, I, S. 45 .

273) S. Anm. 267.

274) Voprosy moral1..., S. 175.

275) ebd.

276) ebd., s. 176.

277) Vgl. Stiwo "Fortschritt" In: Historisches Wörterbuch der Philosophie Bd. 2, Sp. 1042, Hrg. J. Ritter. Darmstadt 1972; s.a. K. Löwith, Weltgeschichte und Heilsgeschehen. S. $85 \mathrm{f}$.

278) V mire nejasnogo, S. 71. Zum Zusammenhang von Fortschrittsglaube, Übermensch-Vision und Unsterblichkeit in der russ. Geistesgeschichte vgl. P. Scheibert, Der übermensch in der Russischen Revolution. In: E. Benz (Hrg.), Der Übermensch. Eine Diskussion. Zürich-stuttgart $1961, \mathrm{~s} .183 \mathrm{ff}$. 
279) Vgl. Otkliki zizni, S. 84.

280) "Nicht die Körper erzeugen Empf indunge"l, sondern

Empf indungskomplexe (Elementenkomplexe) bilden die Körper (...). Nicht das Ich ist das Primäre, sondern die Elemente (bzw. Empfindungen). Die Elemente bilden das Ich". Ernst Mach, Die Analyso der Empfindungen. Jena ${ }^{3} 1903$, S. 29.

281) O cest1, S. 84 .

282) ebd.

283) ebd. S. 87 .

284) Bud. rel (2), S. 57.

285) ebd. S. 57, Unterstr. v. mir.

286) RiS, II, S. $364 \mathrm{f}$.

287) Vgl. ebd.

288) Mes. i indiv. S. $341 \mathrm{f}$.

289) ebd. S. 342 .

290) ebd. S. 344 .

291) ebd. S. $325 f$.

292) ebd. S. $344 f$.

293) Mesc. 1 indiv. S. 326.

294) Vgl. RiS, II, S. 336.

295) Vgl. Löwith, Weltgeschichte und Heilsgeschehen.

S. $62 / 63$ u. pass.

296) Bud. rel. (2), S. 38.

297) ebd. S. 60.

298) Vgl. RiS, I, S. $68 \mathrm{ff}$.

299) Vgl. Russkif Faust a.a.0. S. 787; Bud. rel. (2), S. 32; RIS, II, S. 336, 365 u.a.

300) RiS, II, S. 340 .

301) Vgl. Gerasimov, "Élektrifikacija". In: R. Lorenz, Proletarische Kulturrevolution, S. 98; Gastev, "Cudesa raboty", ebd. S. lo3ff; (auch in der Verherrlichung des Kollektivs tritt der Proletkul't das Erbe des 'Bogostroitel'stvo' an). Gerasimov. Gastev (und Kalinin) haben 1913 zu- 
sammen mit Lunacarskif an einem literarischen Arbeiterzirkel in Paris teilgenommen. - Vgl. Anm. 253.

302) s.0.S.72ff.

303) Ate1zm, S. 159; biblisch: der "Menschensohn".

304 ) Vgl. Bud. rel. (1), S. 11 .

305) E. Bloch, Geist der Utopie. S. 305.

306) RIS, II, S. 302 .

307) Die Tatsache, daß Lunacarskif sich damals vor allem der 'emotionalen Selte' des Marxismus zugewandt hat und damit den Fragen von Moral, Ethik, Ästhetik, wird ihm inzwischen in der sowjetischen Forschung vorsichtig als verdienst angerechnet; denn 1. "kämpft er gegen den Gegner (Berdjaev, Bulgakov - "Problemy Ideallzma") auf dessen elgenem Territorium", und 2. war es "Lunacarskif schon damals wichtig, zu beweisen, daß nicht nur ökonomische und soziale Interessen den Inhalt des Kampfes des Proletariats ausmachen." I.P. Kochno, Certy portreta. S. 25. In einem 1931 von $1 \mathrm{hm}$ aus dem Gedächtnis wiedergegebenen Gespräch mit Lenin über das 'Bogostroitel'stvo' hat Lunačarskif auf dessen Einwände geantwortet: "Vladimir Il'iC, Ich dachte, daß der Sozialismus gewinnt, wenn sein ethischer Wert aufgedeckt wird." (21t. nach einem unver. Artikel Lunacarskijs "K voprosu o fllosofskoj diskussi1 1908 - 1910 gg" bel N.A. Trifonov, A.V. Lunacarskif 1 M. Gor'kij. S. 138 (= Literaturnoe nasledstvo, t. 82, Moskau 1970, S. 500).

308) s.0. S.115ff.

309) Die Funktion dieses "Ideals" hat inre Entsprechung bel Gor'kij in seiner leserzentrierten, pädagogisch orlentierten Literaturauffassung: Die Literatur hat solche Ideale zu schaffen. (s.u.). 
310) Dieser Text ist fast zur gleichen zelt entstanden wie die Texte Lunacarskijs, von denen die Rede ist; dies zelgt einmal mehr, daß es sich hier kelneswegs um ein spezifisch russisches Phänomen handelt. (Vgl. Kap. II,2).

311) E. Bloch, Gelst der Utople, S. 303.

312) Vgl. S.105.

313) R1S, II, S. 395.

314) Enquête, S. 593.

315) ebd. S. 594.

316) ebd.

317) ebd.

318) ebd.

319) ebd.

320) S.S.53.

321) Eine differenziertere Betrachtungswelse findet man schon bel N.A. Trifonov, A.V. Lunacarskif 1 M. Gor'kif (In: Gor'kif 1 ego sovremennik1); drs., A.V. Lunacarskif 1 sovetskaja literatura. Moskau 1974 und M.I. Schachnowitsch, Lenin und die Fragen des Atheismus. Berlin 1966.

322) s. Einleitung; vgl. Istorifa russkof literatury, $t$. $X$, Moskau-Leningrad 1954, S. $329 f \mathrm{f}$.

323) Vyp. I, Moskau 1958, S. 683.

324) Lunacarskif 1 Gor'kif, S. 118.

325) Vgl.a. Gor'kij-30, XXIX, 32,33,34. Für die Zelt ab 1907 ist die Intensive Zusammenarbeit zwischen Gor'kif und Lunacarskif (Bogdanov) ausreichend belegt. (Partelschulen usw.; s. Scherrer, Schachnowitsch, Trifonov U.a.). In elnem Brief Gor'kljs aus jener Zelt an L.N. Vojtolovskif helBt es: "überall, wo in diesem Brief das Pronomen "Ich" steht, können Sie es durch ein anderes, nämlich "wir", ersetzen, wobel darunter Anatolif vasil'evic und Aleksandr Aleksandrovic (Bogdanov) 
zu verstehen sind." (Archiv Gor'kogo. Zit. nach Trifonov, Lunacarskif i Gor'kij, S. 129).

326) S.S. 131 .

327) Vgl. Bud. rel. (2), S. 35.

328) Trifonov, Lunačarskij i Gor'kij, S. 133.

329) Erschienen im Oktober und November 1907; die Enquête wurde im März veröffentlicht.

330) Dies gilt jedenfalls, solange kein Archivmaterial zugänglich ist, das anderes belegen könnte.

331) 1908 und 1909.

332) Die "gotterbauerischen" Texte "Razrusenie licnosti" und "Ispoved" enthalten kein Körnchen mehr 'Gotterbauertum' als die Texte von 1906/07: die Enquêten-Antwort und "Mat""! 
I 1chen Tätigkeit wissenschaft, Kunst und Technik verstanden werden können. Die Vernunft spielt die Rolle einer Kraft, die von außerhalb dem Bewußtsein des Menschen korrespondiert, sein wachsen stevert.

Im Zusammenhang mit dem Pathos des Menschen und seiner extrem dynamischen Ausrichtung auf die zukunft wurde schon auf Nietzsche verwiesen. Wenn wir also diesen strang des Gor'kijschen Menschenbildes in seiner Genese zurückverfolgen, soll damit zugleich eine klärung in der Frage nach dem Verhältnis von Gor'kij zu Nietzsche verbunden sein. Es sollte deutlich werden, ob und inwiefern in das Menschenbild des Gotterbauers Gor'kij Elemente des Nietzscheschen Menschentwurfs eingehen.

Die Aufarbeitung der Genese des Gor'kijschen Menschenbildes erfolgt hier in Umkehrung der Chronologie; vor dem Hintergrund des Textes von 1907 sollen die beiden zur Synthese strebenden Elemente Gefühl und Vernunft im Krebsgang zurückverfolgt werden, um deutlich werden $z u$ lassen, welche Synthese aus welchen Elementen - und $z u$ welchem $Z$ weck Gor'kij gesucht und im Bogostroitel'stvo schließlich gefunden hat.

\section{1. "Celovek" (1904)}

Kann man Gor'kijs Antwort auf die Umfrage des Mercure de France (1907) als sein "Credo" lesen - denn er entwickelt ja hier seinen Glauben, seine Vorstellung von Religion -, so gilt dies erst recht für das 1903 geschriebene und 1904 erschienene ${ }^{3)}$ Poem "Celovek". Gor'kij selbst nennt es mehrfach "moj kredo"4) - "den großen Traum meiner seele, meinen einzigen Glauben,.....5)

Es bietet sich daher als erste Station auf dem Weg zu den Ursprüngen von Gor'kijs Menschenbild an. Dessen zwei Zentren: Mensch/Gefühl und Vernunft sind hier noch sehr viel deutlicher auseinanderzuhal ten als in dem Raimund sesterthe chenen Text. 
"In den Stunden der Mutlosigkeit"6) läßt der Erzähler ("Ich") vor seinem geistigen Auge ein philosophischuniversalgeschichtliches Drama ablaufen, in welchem der "Mensch" (mit großen Buchstaben) und der "Gedanke" als handelnde Personen auftreten. Es ist durchaus berechtigt, von einer Art philosophischem Drama zu sprechen, sofern hier nicht nur der "Mensch" und der "Gedanke", sondern in Nebenrollen auch Glaube, Liebe, Hoffnung, Schwäche, Trauer, Verzweiflung, Wahrheit, Langeweile, Stolz, Tod, Wahnsinn und andere personifiziert (kenntlich gemacht durch die sonst nur für Eigennamen übliche Großschreibung) auftreten und miteinander agieren; alle sind - außer dem "Gedanken" und dem Tod - des "Menschen" eigene Geschöpfe ${ }^{7)}$.

\section{a) Der Mensch mit großem Buchstaben}

Die Exposition des Poems macht sogleich deutlich, in welchem funktionalen Zusammenhang der "Mensch" (mit großem Buchstaben) $2 u$ sehen ist: Er ist ein "erhabenes Bild"8), das dem realen, entmutigten (kleingeschriebenen) Menschen als Ideal $^{9)}$ entgegengesetzt wird. Diese Funktion verdeutlicht sich im Laufe des Textes: Der "Mensch" ist "Sonne", "helles Licht", "Leitstern"10). Dieses Ideal als die Antithese/Negation des kleinbürgerlichen Menschen (mescanstvo) bezeichnet das Ziel, das die real existierenden Menschen erreichen sollen: "jeder von ihnen (soll) ein "Mensch'" werden 11).

Es geht Gor'kij darum, der von inm bekämpf ten mescanstvoMentalität ${ }^{12)}$ einen 'Entwurf' vom Menschen gegenüberzustellen, dem beschränkten, schwachen, ängstlichen und hoff nungslosen Menschen das Ideal eines "erhabenen", "majestätischen", "stolzen", "freien", "mächtigen" "Menschen" vorzuhalten, für dessen Bewußtsein es keine Schranken gibt, der seine wünsche immer weiter treibt, statt sich mit der Realität zu arrangieren ${ }^{13)}$. 
So wird der "Mensch" zugleich zum Symbol für Gor'kijs Glauben an den Fortschritt: Er schreitet "immer voran und höher"14) und weist damit den Menschen den weg zur Vollkommenheit. Nicht nur der real existierende Mensch, sondern auch der 'Entwurf' selbst vom "Menschen" wird dynamisch-prozeßhaft gesehen; in seinem Gang zur Selbstvervollkommnung wird er zur Aufforderung und zum Versprechen für die Zukunft der Erde:

Zur Zeit ist es (das Bewußtsein des "Menschen" R.S.) vergleichbar nur einem Funken, aber was macht's? Ist doch der Funke die Mutter des Feuers! Ein Feuer in der Finsternis des Alls, das bin ich in der zukunft! 15)

Gor'kij beschreibt hier nicht den Neuen Menschen, wie er in einer zukünftigen (sozialistischen) Gesellschaft vielleicht einmal vorzufinden sein wird, keinen "neuen psychologischen Typus"16), sondern er bezeichnet einen Initiationsfunken, dessen Funktion es einzig ist, die Entwicklung zu jenem Neuen Menschen hin in Gang zu setzen. Das bedeutet: Der "Mensch" ist nicht das ziel der Geschichte, er markiert vielmehr Aufbruch und Weg dorthin.

Folglich sind die Aufgaben, die inm auf seinem weg gestellt werden, $z u$ lesen als Aufforderungen an den Leser, den konkreten, von Schwäche, Angst und Perspektivlosigkeit bedrohten Menschen ("Ich") 17), sich an die Lösung dieser Aufgaben zu machen und so seinem Leben den richtigen Sinn - einen Sinn überhaupt - zu geben; nämlich den Weg frei zu machen für den zukünftigen vollkommeneren Menschen.

Welches sind diese Aufgaben? 
Ich (der "Mensch" R.S.) bin zu erhellen berufen die ganze Welt, zum Schmelzen zu bringen das Dunkel ihrer geheimen Rätsel, die Harmonie zu finden zwischen inr und mir,...18)

Das heißt mit anderen Worten: Die Welt muß erkannt werden, und als erkannte Welt wird sie dem Menschen nicht mehr als feindliche Natur gegenüberstehen, sondern er wird in Harmonie mit ihr leben können ${ }^{19)}$. Das Erkennen der Welt trägt aber deutlich die Merkmale eines Kampfes (Nietzsche): Alte, vom "Menschen" selbst geschaffene Werte müssen als abgelebt erkannt und zerstört werden, damit er neue schaffen und an ihre stelle setzen kann:

Der "Mensch" ist erschaffen, umzuwerfen und zu zerstören und zu zertreten alles, was alt, was eng, was schmutzig und böse ist, um Neues an seine stelle zu setzen, ...20)

Der Ausgang dieses Kampfes gegen die alten werte, Vorurteile und wahrheiten ist unwichtig und noch keineswegs gewiß; und so sagt der "Mensch" ganz nietzscheanisch von sich:

Und ich bin mir bewußt, daß nicht diejenigen die sieger sind, die sich der Früchte des sieges bemächtigen, sondern die, die auf dem schlachtfeld fallen'21).

Der Kampf wird nicht durch den sieg erst gerechtfertigt, sondern er rechtfertigt sich selbst, weil er schöpferisch ist:

Ich sehe den Sinn des Lebens im schöpferischen Schaffen, das schöpferische schaffen aber genügt sich selbst und kennt keine schranken ${ }^{22)}$ ! 
Dieser "Mensch" hat für die realen Menschen die Funktion, inr Leben zu verändern, indem er zu Aktion, zum Verlassen der kleinbürgerlichen Lethargie aufruft, indem er dazu auffordert, sich auf den Weg zum Neuen Menschen zu machen. Er 1st dieser neue Mensch nicht. Er schreitet voran und höher, unaufhaltsam und "ruhelos"23) aber er bleibt auf seinem Weg allein ${ }^{24)}$.

Würde man also annehmen, daß Gor'kij eine gradlinige Entwicklung des Menschen zum "Menschen" fordert, so stünde am Ende dieser Entwicklung genau so ein "großer Mensch", der als "Ausnahme" $z$ u betrachten wäre 25 ) wie bel Nietzsches Zarathustra. Aber Gor'kij beschreibt - so wenig wie Nietzsche - kein endgültiges ziel (den Neuen Menschen), vielmehr ruft er - wie jener - zur aktiven selbsttranszendierung auf, und diesem Appell dient der 'Entwurf'. -

So kann man es als eine Synthese aus Danko ("Starucha Izergil'") und Zarathustra lesen, wenn der "Mensch" von sich sagt:

Ich gehe meinen Weg, um möglichst hell zu verbrennen und möglichst tief in die Finsternis des Lebens hineinzuleuchten. Und mein Untergang ist meine Belohnung 26 ).

Zwar betont der Text immer wieder, daß der "Mensch" seinen Weg allein geht 27 ) - dennoch ist er mit einem "Gefolge" ausgestattet: mit seinen Gefühlen als seinen eigenen schöpfungen ${ }^{28}$, mit einem ständigen interesselosen Begleiter - dem Tod"29), sowie mit einem "einzigen Freund" - dem "Gedanken" 30 ;.

Das "Gefolge" (Glaube, Hoffnung, Llebe, Schwäche, Trauer usw.) deckt den gesamten emotionalen Bereich (sozial und individuell) ab. Alle dlese Gefühle sind "Gebilde 
seines (des "Menschen") schöpferischen Geistes" 31 ); aber sie sind "unvollkommen" und pervertiert:

Alle Gefühle sind darauf aus, ihn (den "Menschen") zu versklaven; alle dürsten nach Macht über seine seele $e^{32 \text { l). }}$

So werden seine eigenen Gefühle in inrer pervertie:ten Form zu "Feinden" des "Menschen"33).

Der "Tod" hat in diesem Jrama eine reinigende Funktion: (er) gleicht einem Lumpensammler, der auf den $\mathrm{Hin-}$ terhöfen umhergeht und in seinen schmutzigen Sack das Abgelebte, das Faule, den unnützen Absall stopf $t$, gelegentlich aber auch unverfroren Gesundes und starkes mitgehen heißt ${ }^{34}$ ).

Welche Rolle aber spielt der "Gedanke", die Vernunft?

b) Der "Gedanke" (mysl')

Und nur der "Gedanke" ist der Freund des "Menschen", nur er ist von inm unzertrennlich ${ }^{35}$ ).

Nur der "Gedanke" ist der "freie, ungebundene Freund" des "Menschen"36).

Dies mag zunächst den Eindruck hervorrufen, als trete der "Gedanke" im allegorischen Drama dem "Menschen" in einer gleichwertigen Rolle gegenüber und zur Seite: Der "Gedanke" als die mächtige "Waffe" in der Hand des "Menschen", als Instrument der Erkenntnis:

Nur die Flamme des "Gedankens" erhellt die Hindernisse auf seinem Weg, die Rätsel des Lebens, das Dunkel um die Geheimnisse der Natur und das undurchdringliche Chaos in seinem Herzen ${ }^{37}$ ). 
Bei näherem Hinsehen zeigt sich jedoch, daß dem "Gedanken" das absolute Primat zukommt:

Der "Mensch" schreitet den Menschen voran, er selbst aber folgt dem "Gedanken" 38 ).

Der "Gedanke" ist die

Kraft, die sich in den Augenblicken der Erschlaffung Götter erschafft, um sie in den Epochen des Aufschwungs wieder zu stürzen ${ }^{39)}$;

es ist der "Gedanke", der die Geschöpfe des "Menschen" (bzw. seines Geistes): seine Gefühle und Instinkte in ihrer Negativität als abgelebt und hinderlich entlarvt ${ }^{40)}$ und den "Menschen" aus dem "Kerker des Glaubens"41), aus den Umkl ammerungen der "Liebe" 42), aus Lüge, Plattheit und Trägheit befreit, indem er in inm den stolz weckt ${ }^{43}$; der "Gedanke" und nicht der "Mensch", nimmt, von "wahnwitziger Kühnheit" erfüllt, und im "Bewußtsein seiner Unsterblichkeit" den Kampf mit dem Tod auf ${ }^{44)}$; der "Gedanke" hat den "Menschen" zu seiner Bestimmung erschaffen: alte Werte zu zerstören, um neue $z u$ schaffen ${ }^{45}$ ); und der "Gedanke" bestimmt schließlich auch das Raster der Grundwerte, nach welchem diese neuen Werte zu schaffen sind. Es sind dies die Grundsätze "der Freiheit, der Schönheit und der Achtung vor dem Menschen"

So zelgt sich eine merkwürdige Ambivalenz:

Einerseits hat der "Gedanke" für den "Menschen" deutlich instrumentale Funktion, er ist die Waffe der Erkenntnis in der Hand des Menschen. Aber zugleich ist er der gleichwertige Freund des "Menschen" und tritt andererseits sogar als dessen Schöpfer und Führer auf.

Meine Waffe ist der "Gedanke", und die feste Überzeugung von seiner Freiheit, seiner Unsterblichkeit und dem ständigen wachstum seines Wirkens ist der unerschöpfliche Quell meiner Kraft ${ }^{47)}$ : 
Der "Gedanke" als das "Leuchtfeuer im Dunkel des Daseins" und das "Licht in der Finsternis" 48) nimmt geradezu die Qualität des göttlichen Logos an, der vor allem Anbeginn ist und den Menschen und seine Welt erst schafft:

Er (der Gedanke) ist der Schöpfer alles Bestehenden, und das gibt inm das heilige, unverbrüchliche Recht, alles zu zerstören, was der Freiheit seines Wachstums hinderlich sein kann ${ }^{49)}$.

Der "Mensch", sein Bewußtsein, wächst unendlich - aber in Abhängigkeit vom unendlich wachsenden "Gedanken". Der "Mensch" schreitet ruhelos "voran und höher" - aber inm voran schreitet der "Gedanke"!

\section{c) Die Synthese}

Es wurde oben betont, daß der "Mensch", der in diesem philosophisch-allegorischen Poem/Drama auftritt, keine Zielbeschreibung darstellt; er ist nicht der Neue Mensch erst recht nicht der Neue Mensch in einer neuen Gesellschaft; denn er steht da ohne jeden sozialen Bezug, ganz zu schweigen von einem Kollektiv.

Der "Mensch", der hier auftritt, ist ein Appell an den realen Menschen (Leser). Er ist "Leitstern für die Erde" ${ }^{50)}$; er schafft neue Werte nach Maßgabe der "Achtung vor den Menschen" 51); er will, daß die Menschen zu "Menschen" werden ${ }^{52}$ ) (d.h. sich auf ihren Wert besinnen);

für inn ist das Dasein,

in dem die sklavische, die menschliche Kraft übersteigende Arbeit der einen spurlos und ohne Rest vertan wird, damit die anderen sich übersättigen können am Brot und an den Gaben des Geistes, unsinnig und widerwärtig ${ }^{53)}$. 
In dieser Textstelle mag mancher den Ansatz für ein mar$x$ istisches Verständnis des Poems sehen. Es ist durchaus möglich, daß hier ein Reflex von Gor'kijs marxistisch orientierter Gesellschaftskritik vorliegt ${ }^{54)}$, und er selbst gibt diese stelle in einem Brief an die spanischen Übersetzer von "Na dne" als Grundthema seines Poems (und von "Na dne") an 55), wobei er aber wiederum antithetisch zum kritisierten Leben die "Unabhängigkeit der Vernunft" beschwört ${ }^{56)}$. (Dies soll als Hinweis dafür festgehalten werden, daß der Sozialismus für Gor'kij die Seite der Vernunft repräsentiert.)

Aber selbst wenn schon für diese Zeit (1903) ein marxistischer gesellschafts- und religionskritischer Standpunkt angenommen werden könnte, so muß doch gesehen und betont werden, daß der gesellschaftliche widerspruch hier nicht in den Kategorien des $\mathrm{Kl}$ assenkampfs sondern als Grundkonflikt von Vernunft und Gefühl, von Rationalität und Emotionalität zur Sprache gebracht wird. Im Ausgang des Menschen aus seiner Unvernunft, $d . h$. aus der Gefangenschaf $t$ seiner Gefühle, in der Überwindung dieses Zwiespalts, in der Aufhebung der Gefühle in einer Synthese mit der Vernunft liegt für den Autor von "Celovek" die Lösung der gesellschaftlichen Probleme begründet. Das Ende des Poems spricht dafür, daß Gor'kij nach solcher Synthese sucht.

Jener "Mensch", der dem Leser als Ideal vorgestellt wird, weiß sich noch als unvollkommen und zerrissen. Diese Zerrissenheit zeigt sich in der negativen Rolle, die die Gefühle spielen. Ihre Konstellation kennzeichnet eine tiefe Entfremdung. Sie werden $z u$ Feinden des "Menschen", obwohl sie seine eigenen Geschöpfe sind. Und der "Gedanke" muß sie bekämpfen.

Das heißt, der Mensch mit seiner Gefühlswelt einerseits und die Vernunft andererseits befinden sich im Widerspruch 
zueinander; erst das ordnende Eingreifen des "Gedankens" bringt den Menschen in Einklang mit sich selbst (seinen Gefühlen). Aber trotz des sichtbaren Primats der Vernunft steht am Ende des Kampfes nicht der Sieg der Vernunft über die Gefühle, sondern beider synthese. Die Synthese erst macht den "Menschen" zum vollkommenen "Menschen"; macht Ihn zum Größten, das der "Gedanke" - jetzt "mein 'Gedanke'" - auszudenken vermag: sie macht ihn göttergleich.

Es kommt der Tag, an dem in meiner Brust zu einer einzigen großen schöpferischen Flamme verschmelzen werden die Welt meiner Gefühle und mein unsterblicher "Gedanke" und ich mit dieser Flamme alles in meiner Seele ausbrennen werde, was dunkel, herzlos und böse ist, damit ich den Göttern gleiche, die mein "Gedanke" erschaffen hat und erschaff ${ }^{57)}$ !

\section{d) Zusammenfassung und Vergleich}

Vergleichen wir das Gesagte mit dem Ausgangstext (Mercure de France).

In beiden Texten 1st das Bewußtsein als der der Vernunft korrespondierende Ort im Menschen Ausgangspunkt der Veränderung. Ebenso ist es die Vernunft - im Enquêten-Text wissenschaft und Kultur als vernüntige Praxis - die den stolz im Menschen auf sich und seine Bedeutung in der Welt entstehen läßt und inm so die Kraft und Dynamik zum tätigen verändern gibt. In beiden Texten ist diese Dynamik auf die Zukunft gerichtet. Wobei allerdings in "Človek" die Zukunft des Menschen wesentlich abstrakter und unhistorischer gefaßt ist als im Enquêten-Text.

Dieser und andere Unterschiede lassen das Poem deutlich als Vorstufe zu der 1907 erreichten Position erkennen: Während Gor'kij 1907 ganz offensichtlich glaubt, die 
Synthese gefunden zu haben, d.h. eine vernünftige ordnung (Wissenschaftlicher Sozialismus), in der die emotionale Seite des Menschen aufgehoben ist, zeigt der Text "Celovek" noch das Suchen nach dieser vernünftigen ordnung - lediglich die Notwendigkeit einer solchen Synthese ist bewußt.

1907 ist sie gewährleistet durch eine kollektiv organisierte Gesellschaft (Sozialismus), deren Glieder ein kollektives, Vergangenheit, Gegenwart und zukunft umfassendes Bewußtsein entwickelt haben. Glaube, Hof fnung und Liebe, die grundlegenden "Gefühle" des Menschen, sind nicht mehr seine Feinde, sondern integriert in eine umfassende "religiöse stimmung" 58 ).

Während der Text von 1907 ein Ideal formuliert, jedoch auch Bedingungen und Ort beschreibt, wo und wie die reale Gesellschaft und der reale Mensch sich selbst überwinden können (im Sozialismus), hat der "Mensch" mit großem Buchstaben nur Appellfunktion ${ }^{59)}$; der kollektivistische Aspekt ist aus dieser Funktion heraus allenfalls zu erahnen.

Dem Leser wird eine Antithese zur mestanstvo-Mentalität angeboten, die ihn zugleich zur Überwindung dieser von Gor'kif als individualistisch, schwach und passiv apostrophierten Haltung aufruft. Dem kleinbürgerlichen Individualismus entspricht implizit als Gegenstück ein kollektivistisches Menschenbild - dies wird jedoch in dem Text von 1903/04 nicht ausgeführt. Ebenso impliziert in "Celovek", aber nicht ausgesprochen, ist Gor'kijs Religionskritik von 1907: Die Götter sind Geschöpfe des Gedankens und als solche funktional und ablösbar.

Der "Mensch" von 1903 symbolisiert lediglich den übergang (zum Neuen Menschen) - "Mein Untergang ist meine 
Belohnung." - genau wie Nietzsches Zarathustra; und er bleibt - ebenfalls wie dieser - allein. Das Blld dieses "Menschen" bleibt, wie schon die zeitgenössische Kritik vermerkte, unklar ${ }^{60)}$.

Die Synthese von Vernunft und Gefühl, die, wie der Enquêten-Text weiß, zugleich Bedingung und Folge der kollektiven Organisation der Menschen ist, wird hier nur erahnt und erhofft. Aber auch hier hat sie schon religiöse Qualität. (Der "Mensch" der Synthese wird "göttlich".)

Es gilt also auf dieser stufe festzuhalten:

Das Pathos des Menschen, das sich letztlich rechtfertigt aus der Hoffnung auf die synthese von Vernunft und Gefühl; beide (Pathos und Synthese) haben religiöse Qualitat und gehen als solche in Gor'kijs Bogostroitel'stvo ein ${ }^{61 \text { ). }}$

2. "Na dne" (1902)

Berücksichtigt man die Tatsache, daß Gor'kij sich schon 1902 (also zur Zeit der Abfassung von "Na dne") mit dem Gedanken trug, ein Stück mit dem Titel "Celovek" zu schreiben ${ }^{62)}$, so ist es allein schon wegen der zeitlichen Nähe legitim, den großen Monolog Satins in "Na dne" mit dem Poem in Verbindung zu bringen; den inhaltlichen Zusammenhang stellt Gor'kif selbst her. In einem Brief an die spanischen Übersetzer von "Na dne" schreibt er 1906 :

Ich wäre ebenfalls froh, wenn ein anderes Werk von mir ins spanische übersetzt würde mit dem Titel "Der Mensch", in welchem der Hauptgedanke von "Na dne" umgesetzt und entwickelt wird"6).

Und im AnschluB daran weist er auf die 'marxistische' Stelle aus "Celovek" hin"64). 
Wenn Gor'kij sagt, daß in "Celovek" der Hauptgedanke von "Na dne" entwickelt werde ${ }^{65)}$, so bedeutet dies, daß für inn das Zentrum der Aussage von "Na dne" in Satins Monolog über den Menschen liegt; daß somit die Figuren des Stückes - auch Luka - ihre Bedeutung und Funktion von diesem Monolog her erhalten und entsprechend $z u$ interpretieren sind ${ }^{66)}$.

Die Gedanken, die in "Celovek" weitergedacht werden, finden sich in "Na dne" im 4. Akt. Satins Reden vom "Menschen" entzünden sich an der Auseinandersetzung der Asylbewohner um Luka: Ist Luka, weil er nicht die Wahrheit gesagt hat - oder einen eigenen (funktionalen) Begriff von Wahrheit hat - ein Scharlatan oder nicht? Satin entwickelt seine Rede vom Menschen keineswegs, indem er sich von der Haltung Lukas absetzt. Vielmehr beruft er sich ausdrücklich auf inn:

Der Alte ist kein scharlatan! Was ist die Wahrheit? Der Mensch, das ist die Wahrheit! Der Alte hat's begriffen... ihr nicht ${ }^{67)}$.

Selbst wenn Luka lügt, geht es inm um den Menschen; und in Satins Sicht sind Lügen bei diesen Menschen im Asyl angebracht:

Die Lüge ist die Religion der Sklaven und der Herren. Die Wahrheit ist der Gott des freien Menschen ${ }^{68)}$ !

Die Menschen, zu denen Luka spricht, gehören kaum zu zwei ten Kategorie, und es ist bezeichnend, daß Satin, der einzige, der sich eine stolze und unabhängige Haltung bewahrt hat, von Luka niemals mit mitleidigen Lügen bedacht wird.

Satins Aussagen über den Menschen dürfen nicht unabhängig von der Person Lukas und dessen Äußerungen gesehen werden. 
Dessen Behauptung, daß die Menschen "um des besseren Menschen willen", d.h. letztlich um des Fortschritts willen 69) leben; daß man darum, well jeder Mensch den übergang zu einer höheren Qualität "Mensch" darstellen könnte, "jeden Menschen achten" müsse ${ }^{70)}$; daß der Mensch eigentlich dazu geboren sei, etwas zu schaffen ${ }^{71)}$ diese Grundeinstellungen Lukas werden von Satin wiederholt (wobel er sogar dessen stimme und Gestik nachahmt), und sie werden von ihm bestätigt.

Lukas "Wahrheit": der Mensch gibt den Ausgangspunkt für Satins Reden $a b^{72}$ ). Daß jedoch sein Bild vom Menschen nur ein ganz entferntes und verschwommenes Ideal sein kann und bei seinen zuhörern (wie auch bei inm selbst) nichts wirklich in Gang setzen und verändern kann (Anfang und Ende des Stückes zeigen die gleiche situation), kommt unter anderem in der Tatsache zum Ausdruck, daß Satin sich zu seiner Rede erst in angetrunkenem zustand aufschwingt, einem zustand, der die Dinge eben unscharf sehen läßt.

Auch von der wirkung seiner Rede her ist es nicht angebracht, Satin in Antithese zu Luka zu setzen: Ebenso wie dessen Lügen eine tröstliche Funktion haben - etwas Schönes gegen die häßliche Wirklichkeit zu setzen -, so auch Satins Aussagen.

Am Ende seines 'Trinkspruches' auf den "Menschen" sagt er:

Trinken wir auf den Menschen, Baron. (Er steht auf) Schön ist das, sich als Mensch zu fühlen: Ich Zuchthäusler, Totschläger, Falschspieler - na ja ${ }^{73)}$ !

Und der Baron bestätigt:

Du denkst über die Dinge nach. Das ist gut... Ich glaub, das wärmt dir das Herz ${ }^{74}$ ). 
Er läßt sich durch Satin ebenso trösten, wie sich die anderen durch Luka trösten ließen:

Baron: Aber ... zu irgendetwas bin ich doch geboren, wie?

Satin (lachend): Wahrscheinlich. Der Mensch wird geboren um des Besseren willen! stimmt... gut ${ }^{75)}$ :

Ebenso wie die Reden des Alten eine vorläufige bessernde Wirkung hatten (der Schauspieler arbeitet einen $\mathrm{Tag}$ und trinkt nicht; Pepel' faßt seine Abreise ins Auge), so auch Satins 'Trinkspruch': Der Baron besinnt sich plötzlich auf eine moralische Verpflichtung gegenüber Nastasja ${ }^{76)}$.

Letzten Endes muß aber auch Satin wirkungslos bleiben, weil er sich an die falschen Adressaten wendet. Nastja spricht das Urteil über die Anwesenden aus, das in "Celovek" der Tod vollzieht." : "Man müßte euch wegkehren wie straßendreck - ab in die Grube" 78):

Aber wie sieht überhaupt dieser "Mensch", dessen Umrisse Satin in die luft zeichnet, aus?

Nicht du, nicht ich, nicht die dort... nein! Das ist alles in einem: du, ich, die dort, der Al te, Napoleon, Mohammed - alles in elnem! (...) Begreifst du? Das ist gewaltig! Darin ist aller Anfang und alles Ende. Alles ist im Menschen, alles ist für den Menschen ${ }^{79)}$ !

Dieses Bild ist ebenso abstrakt und allgemein wie der "Mensch" mit großem Buchstaben in "Celovek". Eine überindividuelle aber keine kollektive Größe. Und ebenso wie jener trägt Satins Mensch nietzscheanische züge: 
Er ist frei und eigenverantwortlich ${ }^{80)}$; Mitleid würde ihn erniedrigen, denn "Der Mensch! Das ist groß! Das klingt... stolz" 81).

Es wäre falsch, diesen Menschenentwurf Satins den mitleidigen Lügen Lukas (bzw. dem sie steuernden Menschenbild) als Antithese entgegenzusetzen, als erteile Satin (und mit inm Gor'kij) Luka eine Absage. Er tut dies ausdrücklich nicht! Satins "Mensch" gewinnt überhaupt erst zusammen mit den Aussagen Lukas über den Menschen Kontur und kommt erst durch die katalytische Wirkung Lukas zustande, hängt von ihm ab und bedarf der Ergänzung durch inn - und umgekehrt ${ }^{82}$ ).

Diese Abhängigkeit wird dadurch sinnfällig, daß Satin zu seinem Monolog erst in der Auseinandersetzung um die Person Lukas kommt; erst Luka mit seinen 'Lügen' hat bei Sa$t$ in vorübergehend den Blick auf den "Menschen" frei gemacht: "Er hat auf mich gewirkt wie Säure auf eine alte, schmutzige Münze" 83 ).

Dieser funktionale Zusammenhang ist jedoch nicht alles. Satin zitiert in seinen Reden ausdrücklich Luka. "Achten muß man den Menschen:"84) so lautet das "Gesetz", welches nach des Tataren worten der Alte in seiner seele natte ${ }^{85)}$; es ist dasselbe Gesetz, das der "Gedanke" in "Celovek" dem "Menschen" zusammen mit Freiheit und Schönheit als Grundraster vorschreibt, nach dessen Maßgabe neue Werte zu schaffen sind ${ }^{86}$ ).

Dieses Gesetz, Lukas "Wahrheit", übernimmt Satin ebenso und integriert es in seinen Entwurf ${ }^{87}$ ), wie Lukas Glauben an den Fortschritt der Menschheit: 
Jeder denkt, er lebt um seiner selbst willen, aber es zelgt sich, er lebt um des Besseren willen! Wohl hundert Jahre, vielleicht auch länger, leben sie (die Menschen) um des besseren Menschen willen ${ }^{88)}$ !

Mit anderen worten: Gor'kij konstruiert hier keine Antithese Luka-Satin, sondern er sucht - im Gegenteil eine Synthese der beiden, die nur beim ersten Hinsehen eine andere zu sein scheint, als die in "Celovek" erhoffte. Es geht um die Synthese von stolzem, selbstbewußtem Amoralismus $(S a t i n)^{89}$ ) einerseits und Liebe zum Menschen andererseits, welch letztere, wie in der Gestalt Lukas gezeigt, für sich genommen zu leicht den starken, stolzen Menschen aus dem Blick verliert und dann zur mitleidigen Lüge bereit ist. Beide Positionen müssen einander ergänzen 90 ).

Es ist leicht zu sehen, daß es sich hier um die gleiche Synthese handelt von Gefühl und Vernunft oder Gefühl und stolzem Bewußtsein wie in "Celovek" und im Enquêtentext; denn Satins Stolz auf das Menschsein wird durch eine Erkenntnis hervorgerufen: "Es besteht nur der Mensch; alles übrige ist das Werk seiner Hände und seines Genirns"91).

Wir haben also auch hier, wenn auch noch nicht in solcher Deutlichkeit jene beiden Zentren von Gor'k1js Menschenbild, die er zur synthese bringen will.

Versucht man so, die Gestalt Lukas funktional vom SatinMonolog her zu fassen, so verliert sie erheblich an Negativität und schillernder Mehrdeutigkeit. Daß Luka dennoch schwierig einzuordnen bleibt, wird nicht bestritten; aber es muß doch gesehen werden, daß Luka Positionen ver- 
tritt, die - ergänzt durch den Entwurf des stolzen, frelen Menschen Satins - Positionen Gor'kijs sind, und daß eine positive Einschätzung der Satin-Monologe die Figur Lukas im oben dargelegten sinne integrieren muB ${ }^{92}$.

So rechtfertigt die Schlüsselerzählung Lukas von dem Mann, der das "Land der Wahrheit und Gerechtigkeit" suchte, keineswegs nur die mitleidige Lüge. Vielmehr demonstriert sie völlig im Sinne Gor'kijs (und Lunacarskijs, der sich dabei auf Nietzsche beruf ${ }^{93)}$, die positive Funktion des Ideals - zunächst ungeachtet der Möglichkeit, daß dieses sich später als Illusion/Lüge entpuppt ${ }^{94)}$.

Diese positive Funktion besteht für Gor'kij (und LunaCarskij) darin, daß das Ideal die verändernde Aktivität eines Menschen (einer Gruppe/Klasse) in Gang setzt, mobilisierend und lebenserhaltend wirkt, indem es die Hoffnung auf Veränderung wachhält. Die lähmende, ja tödliche Wirkung des Verlustes eines solchen Ideals wird in Lukas Geschichte eindringlich geschildert.

Selbst die of fensichtlichen Lügen Lukas können solch positive Funktion haben und werden so durch ihren (wenn auch nur vorübergehenden) Effekt gerechtfertigt ${ }^{95}$ ). Aber ebenso wie Lukas mitleidige Lügen letztlich wirkungslos bleiben müssen -

Ich sag, es gibt Boden, der taugt nicht zur Saat, und es gibt Boden, der trägt reiche Frucht ... $($ Luka) 96 )

so bleibt auch Satins Rede vom "Menschen" wirkungslos. Denn beider Adressaten sind nicht einmal potentiell stolz, frei und aktiv, sondern gedemütigt, an ihr Milieu gefesselt und $z$ jeder Tat unfähig. 
Träfen Lukas Versicherungen: "Suchet, so werdet ihr finden. Wer sich's fest vornimmt, der findet's auch"97). "Woran du glaubst, das gibt's"98). - auf die richtigen Ohren, so wären sie ebensowenig mitleidige Lügen wie Satins Rede. Anfang und Ende des Stückes bestätigen Luka eher als Satin; seine Haltung entspricht weit mehr der sozialen und geistigen Verfassung der Asylbewohner.

Es soll hier aber nicht eine weitere Antwort auf die Frage nach der richtigen Einschätzung Lukas gesucht werden. Es gilt für uns, das Drama "Na dne" festzuhalten als eine weitere Vorstufe auf dem Weg zur Gor'kijs Menschenbild von 1907. Das bedeutet inhaltich:

- die "Wahrheit" Lukas: nämlich die Liebe zum Menschen;

- die "Wahrheit" Satins: nämlich das stolze Bewußtsein von der Größe des Menschen ${ }^{99)}$;

- das "Ideal", das als die vorweggenommene synthese der beiden "Wahrheiten" verändernde Aktivität, Bejahung des Fortschritts zur Folge haben kann ${ }^{100)}$ ).

\section{3. "Citatel"" (1896/98)}

In diesem vermutlich ab 1896 geschriebenen und schließlich 1898 veröffentlichten Prosastück ${ }^{101)}$ geht es um die Berufung des Schriftstellers, um die Rechtfertigung seiner Tätigkeit. Auch hier finden sich jene leitmotive in aller Deutlichkeit, deren Genese wir zurückverfolgen: Vernunft, Gefühl, deren Synthese und schließlich die Literatur als Lieferant des Ideals. Man kann auch diesen Text als ein Credo Gor'kijs nehmen; denn er selbst spricht davon, daß er hier selne "eigne Wahrheit" verkünden wer$d e^{102)}$

Ein junger, gerade zu Erfolg gekommener Schriftsteller (Ich-Erzähler) wird auf nächtlichem Heimweg vor ein 
strenges Gericht (den "Leser") gezogen, vor dem er seine Berufung rechtfertigen soll. Dabei wird zunächst als Voraussetzung, über die man sich elnigt, die Aufgabe der Literatur bestimmt ${ }^{103 \text { ). }}$

Literatur, das Produkt des Schriftstellers, soll "den Menschen veredeln"104); das bedeutet im Einzelnen: Durch die Elnwirkung der Literatur soll der Mensch sich selbst erkennen, den Glauben an sich gewinnen, nach der Wahrheit streben, in den anderen Menschen das Gute finden lernen, stark und edel werden und endlich sein Leben "mit dem heiligen Geist der Schönheit" erfüllen ${ }^{105)}$.

Wenn sein Schaffen diese Funktion: den Menschen zu veredeln erfülien soll, muß der Schriftsteller

beseelt ( $s e i n$ ) von einem unbändigen streben

nach Vollendung des Daseins, beseelt von einem

tiefen Glauben an den Menschen 106).

Das "Streben nach Vollendung" trägt hier den Namen "Gott": Gott ist das "Ewige, die Menschen vereinende"107), er ist das "Streben selbst"108); Gott ist

ein harmonischer und klarer Gedanke (mysl'),

der alle Erscheinungen des Lebens umfaßt ${ }^{109}$ ).

"Gott" ist demnach eine Chiffre für die Vernunft und für das streben zu inr, Weg und ziel zugleich.

Es ist dieser Gott, der den Schriftsteller zu seiner Aufgabe bestimmt (so wie in "Celovek" der "Gedanke" den "Menschen" zu seiner Aufgabe bestimmt - die übrigens der Aufgabe des Schriftstellers durchaus vergleichbar ist, wie sich zeigen wird). Er macht inn zu seinem Propheten ${ }^{110)}$; denn wie die alttestamentlichen Propheten 'vom Geist Gottes erfült' zu den Menschen sprachen, so auch die Vorbilder des Schriftstellers, die "Meister des Wortes", die 
in unbestimmter zeitlicher Ferne angesiedelt werden ${ }^{111)}$. Der Schriftsteller-Prophet wird von "Gott" "auserwählt" und "auf die Erde" gesandt 112 ), er soll

brennen (...) im Dunkel unseres Daseins, als Fackel seiner (Gottes) Macht und seines Ruhmes ${ }^{113)}$.

Das Wort des wahren Schriftstellers ist also 'Gottes Wort' - Logos ${ }^{114)}$.

Wie aber muß das Produkt des Schriftstellers beschaffen sein, daß er damit seine "Berufung"115) rechtfertige? In welcher Gestalt erfült die Literatur ihre oben bestimmte Funktion?

Negativ heiBt die Antwort: nicht durch die getreue Abbildung des menschlichen Alltags; nicht dadurch, daß der Schriftsteller dem Leser "viele kleine Wahrhelten"116) eröffnet, worin er sich selbst erblickt, "wie er häßlich ist und keine Möglichkeit sleht, besser zu werden"117).

Die Möglichkeit, besser zu werden, muß der Schriftsteller den Menschen zelgen, indem er ihnen eine "erhebende Illusion" (vozvysafustij obman) schenkt ${ }^{118}$ ); indem er Bilder schafft, "die es im Leben nicht gibt, die aber notwendig sind, um es zu belehren..."119), und, so kann man ergänzen, um die Menschen aktiv zu erhalten. Denn "ohne Ideale" gibt der Mensch den Kampf auf und "paßt sich nur noch an"120).

Hier bestätigt sich die oben gemachte Behauptung, daß die Figur Lukas unter eben diesem Aspekt zu sehen sel: Lüge/Illusion ist nicht schon deshalb verwerflich, weil sie nicht mit der Realität ("Wahrheit") 121) übereinstimmt. In ihrer Hof fnung und Aktivität erweckenden Funktion ist sie vielmehr lebensnotwendig - bedarf allerdings der Ergänzung durch das "stolze Bewußtseln". 
Letzteres kommt in diesem Text durch die Charakterisierung der "Meister des Wortes" zum Ausdruck.

Erfüllt die Literatur diese Voraussetzung: IllusionenIdeale zu schaffen und gegen das Leben zu setzen, so kann sie den "Pulsschlag des Lebens beschleunigen"122) und in den Menschen aufrichtige Gefühle wecken, durch die, wie mit Hämmern, die einen Lebensformen zerschlagen und zerstört werden müssen, um andere freiere anstelle der engen zu schaffen ${ }^{123 \text { ). }}$

Ohne Ideal verliert der Mensch "den Wunsch, mit würde zu leben"124) ; inn bewegt nicht mehr "der Geist, sondern die Instinkte"125). Ohne Ideal lebt der Mensch "wie ein Schwein"126). - Das sind Motive, die in "Celovek" ausdrücklich thematisiert werden ${ }^{127}$ ) und hier wie dort dem Kampf gegen das mescanstvo dienen.

Bedenkt man nun, wer Jene "Meister des Wortes" sind, die in der Lage sind, solche Ideale zu schaffen, deren Werke erfüllt sind "vom Leben, von der Kraft der Begelsterung", von "Mut und brennendem Zorn", von "aufrichtiger und freier Liebe" ${ }^{128)}$ - bedenkt man, daß sie Propheten des Gottes 'Vernunft' sind, daß inr Wort also 'Gottes Wort' ist, so wird deutlich, wem hier das primat zukommt: "Gott", dem

harmonischen und klaren Gedanken, der alle Erscheinungen des Lebens umfaBt ${ }^{129)}$.

Der "Geist" soll den Menschen bewegen 130), die Vernunft (bzw. die Literatur als deren Emanation) muß den "Verstand beflügeln"131); dann erst kann der Mensch die richtigen Gefühle: Liebe zum Leben, Mut, Kampfbereitschaft, Stolz entwickeln und auf das richtige ziel lenken. Dieses ziel wird umschrieben in der form eines intensiven wunsches als die synthese von Gefühl und Vernunft, die in einem 
wie ein Messias herbeigesehnten Menschen erscheinen soll:

Oh, wenn doch ein strenger und liebender Mensch erschiene mit flammendem Herzen und einem mächtigen alles umfassenden Verstand ${ }^{132)}$.

Ein solcher Mensch wäre ein wahrer Schriftsteller und könnte den Menschen Vorblld sein, die "lebenden Leichname"133) wieder zu Menschen machen, er wäre damit 'göttlich'.

Zusammengefaßt können wir festhalten: Auch wenn Gor'kij sich schon sehr bald (1902) von diesem Text als miBlungen distanziert ${ }^{134)}$ und inn leicht abändert ${ }^{135)}$, fügt sich "Citatel" doch ein in jene Kette von Versuchen Gor'kijs, über die Bestimmung der Rolle der Literatur auch das Menschenbild zu formulieren, zu dessen Verwirklichung sie dienen soll.

Die Vernunft ist göttlich, der Schriftsteller ihr Prophet. Sein Wort, 'Gottes Wort', soll das Ideal schaffen, das die Menschen dazu bringt, die Realität zu verändern, sich selbst zu transzendieren in Richtung auf eine Existenz, in der Herz und Verstand sich nicht widerstreiten, sondern eine synthese eingegangen sind. Diese Synthese trägt messianische Züge, wobei der Akzent auf der seite der vernunft liegt. 


\section{4. "Konovalov" (1896/97)}

Sind die frühen Bosjaken-Gestalten Gor'kijs von der Gesellschaft, aus deren Ordnung sie ausgeschert sind, "nicht gebrochen, sondern ihr überlegen"136), so bildet die Erzählung "Konovalov" einen deutlichen Einschnitt. Denn in Konovalov begegnet dem Leser (und dem Ich-Erzähler Maksim) eine Gestalt, die äußerlich sowie in der Lebensführung den früheren Bosjaken fast völlig gleich ist - auch Konovalov ist aus der alten Ordnung herausgefallen - ; aber er kann darauf nicht mehr stolz sein. Er sucht nach einer neuen ordnung ${ }^{137)}$.

Insofern repräsentiert Konovalov auch für uns einen Eckpunkt. In der Konzeption dieser Figur wird nämlich deutlich, wo der Ansatz für Gor'kijs Suche nach der Synthese zu finden ist.

Wenn Gor'kif Konovalov sagen läßt, er sei an seinem Los selbst schuld, weil er seinen standpunkt nicht gefunden habe ${ }^{138)}$, so wendet er sich damit gegen zwei Seiten: Zum einen wird damit das vereinfachende Erklärungsmuster einer 'objektiv' argumentierenden Gesellschaftslehre zurückgewiesen ${ }^{139)}$, die die Verantwortung für das Leben von der subjektiven Seite wegverlagert auf eine 'Organisationsfrage'. Dieses Zurückweisen wird unterstrichen durch die Ironisierende Darstellung des Aufklärers Maksim $^{140)}$, der gegenüber Konovalov seine ganz of fensichtlich angelesenen und entsprechend papieren $k l$ ingenden Ideen von einer "Reorganisation des Lebens"141) und von der Klassenkampfsituation vertritt ${ }^{142)}$. Ein solches Erklärungsmodell für Geschichte und Gesellschaft kann aber vom Einzelnen die Verantwortung für sein Leben nicht wegnehmen; denn, so Konovalov, "zuerst kommt der Mensch"143). 
Zum andern richtet sich Konovalovs Begründung für seine Schuld ("Ich habe meinen standpunkt nicht gefunden.") 144) gegen die frühere Bosjaken-Romantik Gor'kijs selbst: Konovalov zeigt, daß das bloße Heraustreten oder Herausgefallensein aus der Gesellschaft und inrer Wertordnung allein keine Rechtfertigung für das individuelle (und individualistische) Leben sei. Das überlegenheltsgefühl der früheren Bosjaki ist unbegründet, denn sie "bringen dem Leben keinen Nutzen"145). Die bloße Negation, die unter anderem den Amoralismus dieser Figuren zur Folge hat, reicht nicht aus, um ein neues "Leben aufzubauen"146). Dazu braucht es einen standpunkt ${ }^{147)}$.

Konovalov, dessen Gestalt als groß, schön, Selbstvertrauen und stärke ausstrahlend beschrieben wird ${ }^{148)}$, muß trotz dieser Voraussetzungen seine guten Gefühle als unzulänglich erfahren, da ihm sein standpunkt fehlt. Aus diesem Mangelbewußtsein resultiert seine immer nur mühsam für einige Zeit unterdrückte schwermut.

Was ist mit diesem "Standpunkt", den Konovalov so beharrlich herbeisehnt, gemeint?

Die Erwartungen, die er an Maksims Bücher stelit, machen es deutlich: Er such eine "Belehrung darüber, wie man leben soll", eine "Lebensordnung"149), eine "Ordnung des Handelns" (porjadok postupok) 150), ohne die die richtigen Gefühle fehlgehen können. Letzteres belegt seine Geschichte mit Kapitolina 151). Eine solche vernüntige Ordnung soll es möglich machen, daß "alle Menschen handeln wie einer, und daß sie einander verstehen können" ${ }^{152)}$.

In der Figur Konovalovs gestaltet Gor'kij die Erkenntnis, daß eine rein emotionale, wenn auch von guten Gefühlen getragene Lebenshaltung den Menschen in der Vereinzelung hält, daß das Prinzip der individualistischen stärke und 
Größe (romantisierte Bosjaki) der Ergänzung und Korrektur durch ein vernünftiges Prinzip der 'Ordnung' bedarf:

Man kann doch unmöglich bei einer solchen Entfernung von einem zum anderen leben ${ }^{153)}$.

Die Voraussetzung für ein neues Leben, eine neue Lebensordnung, sieht Konovalov in der synthese von Gefühl und Vernunft oder genauer in der Aufhebung des Emotionalen durch das Vernünftige:

Ich fühle doch, ich fühle alles, jede Bewegung des Lebens..... aber verstehen kann ich nichts und meinen weg kenne ich nicht... 154)

Greifen wir jetzt den Faden auf, den wir zurückverfolgen, so wird deutlich, aus welcher Richtung Gor'kijs Suche nach der Synthese kommt: "Konovalov" markiert die Nahtstelle, an der das $b l O B$ emotional begründete $P a t h o s$ des individualistischen starken Menschen, der die bestehende Gesellschaftsordnung neglert und aus dieser Negation seinen Stolz bezieht, am Ende ist ${ }^{155)}$. Dieses Ende symbolisiert der Selbstmord Konovalovs. Das Scheitern der Gefühle und der individuellen stärke wird konstatiert ebenso wie die "Entfernung des einen vom anderen"156). Von diesem 'End-Punkt' aus erfolgt der Ruf nach Aufhebung der emotionalen Seite in einer Synthese mit der Vernunft.

Die Notwendigkeit einer kollektiven Lebensordnung; die Suche nach der synthese von Gefühl und Vernunf ${ }^{157)}$; die Bedeutung des Menschen, an dessen Bewußtsein die Veränderung ansetzen muß; die Rolle des Ideals (Literatur) bel diesem Veränderungsproze ${ }^{158}$ ) - diese für das Bogostroitel'stvo Gor'kijs konstitutiven Elemente finden wir also auch an der Stelle des Umbruchs vom romantischen 
Pathos zur hinterfragenden Darstellung. Von Bedeutung für unseren Zusammenhang ist die Tatsache, daß diese Bruchstelle die Richtung sichtbar macht, aus der Gor'kij schließlich zum Gotterbauertum (der synthese von Gefühl und Vernunft) kommt: von der Selte des emotionalen Pathos.

In den nächsten beiden zu besprechenden Texten wird dieselbe Fragestellung unter dem Bl lckwinkel der Rolle der Literatur thematisiert, die das menschenverändernde Ideal zu schaffen hat.

5. "Casy" (1894/96)

Das mathematisch exakte, abzählende ricken einer Uhr Symbol für ein gleichmäßig onne Höhen und riefen ablaufendes Leben - wird zum Anlaß für die Frage: Wie soll man leben?

Inre Beantwortung setzt eine grundsätzliche Entscheldung voraus für oder gegen das Leben. Entscheidet man sich für das Leben, so muß die leldenschaftslos messende und in Inrer Gleichgültigkeit und Interesselosigkelt das Leben tötende Uhr ersetzt werden durch eine andere Uhr, voll von Gefühlen und vom Gedanken, voll von Taten $^{159)}$.

Die gegenläufige Entscheidung würde dem "Gift des Leidens"160) die Möglichkeit geben zu wirken. Der Mensch würde sich dem Lelden hingeben und aufhören zu kämpfen. Aber das Leben ist

am erfülttesten und Interessantesten dann, wenn der Mensch gegen das kämpft, was ihn am Leben hindert ${ }^{161)}$.

Leben ist nur sinnvoll als Kampf. Und sein Stolz gebietet 
es dem Menschen, sich dem Leben "völlig"162), "mit Herz und Verstand" 163) ninzugeben, damit er nicht zu einem toten "Ziegelstein"164) im Gebäude der Geschichte werde, damit er "stürmische stunden voller Gefühle und Gedanken"165) erleben könne. Mit anderen worten: damit er zu einer Existenz in der Synthese von Gefühl und Verstand komme.

Wle kann der Mensch an dieses Ziel gelangen?

Er vermag dies nicht aus sich; denn

als die Natur dem Menschen dle Fähigkeit nahm, auf allen vieren zu kriechen, gab sie inm dafür, als Krücke - das Ideal $^{166)}$.

Dieses Ideal läßt den Menschen "zum Besseren", "Immer höher" streben 167) - zunächst nur instinktiv; aber eben im Bewußtwerden dieses Strebens zum Besseren liegt das wahre Glück ${ }^{168)}$. Es wird jedoch nicht durch das Erreichen des Ziels gerechtfertigt, sondern "im Vorwärtsstreben (selbst) liegt der Sinn des Lebens"169).

Ein solches sinnerfülites, tatenreiches Leben setzt einen bestimmten Menschentypus voraus: Der Mensch muß wieder "kühn" werden wie Hiob"170), er muß sich wieder auf seinen Wert besinnen; das helBt, er muß sich wieder an dem Maßstab messen, der damit gegeben ist, daß die "Menschen Kinder Gottes und nach seinem Ebenbild geschaffen" sind ${ }^{171)}$.

Und eine weitere Bedingung muß erfülit sein - dabel kommt ein kollektivistischer Gesichtspunkt ins Spiel: Die Menschen müßten "aufeinander achten", und jeder müßte "einen Freund zu Seite haben". Denn "ein einzelner ist klein, auch wenn er groß ist"172). 
Daß die Menschen nicht in der Vereinzelung bleiben, setzt voraus, daß sle sich "unbedingt verstehen"173); und dies wiederum verlangt, daß der "Gedanke" zu Wort komme:

Achtet mehr auf den Gedanken! Helft inm, zur Welt zu kommen, er wird eure Mühe immer lohnen ${ }^{174)}$.

Zwar hat der "Gedanke" auch in diesem Text etwas von dem göttlichen Logos 175), er wohnt "überall und in allem"176); aber man kann hier kaum von einem Primat der Vernunft sprechen, wie es die bisherigen Texte nahelegten. Der erste Rang kommt hier dem Leben zu; denn wichtigste Voraussetzung für ein neues Leben, eine "neue Uhr", ist, daß die Menschen "wlllen zum Leben" und das "stolze Bewußtsein ihrer elgenen Kraft" entwickeln ${ }^{177) .}$

Dann können auch Lukas Worte nicht falsch sein: "Wenn die Menschen etwas wollen, werden sie es stets erreichen"178).

Damit aber ein solcher neuer Menschentypus überhaupt entstehen kann, braucht es einzelne Leitfiguren, die, das neue Leben vorwegnehmend, den anderen Menschen vorangehen eine Art Messias ${ }^{179)}$. Dies müssen

geistesstarke, tapfere Menschen ( $\operatorname{se}(n)$, die der Wahrheit, Gerechtigkeit und Schönheit dienen ${ }^{180)}$.

Ein so beschaffener Mensch ist "Herr über seine wünsche", er "schont sich nicht", sondern "verbraucht alle stunden seines Lebens selbstios im Kampf"181).

Es wurde oben angedeutet: Gegenüber den späteren Texten (die bisher analysiert wurden) ist hier eine Akzentverschlebung zu verzelchnen.

Während in "Citatel" der "Messias" (ein neuer "Meister 
des Wortes") Prophet und Abgesandter des Gottes 'Vernunft' ist, das Primat also auf dieser Seite liegt, finden wir es hier auf seiten des Lebens. Das Leben ist oberster Wert, an dem sich alles mißt. Sein Sinn liegt im Kampf, und der Lebenssinn des Einzelnen liegt im "Verbrennen" - die Alternative würde heißen: "verfaulen"182).

Aber trotz dieser Verschiebung ist das Welt- und Menschenbild Gor'kijs im Bestand seiner Elemente dasselbe wie in den späteren Texten:

Im stolzen Bewußtsein seines Wertes und seiner kraft soll der Mensch zu einer Existenz finden, die durch die synthese von Vernunft und Gefühl getragen und damit voller Taten 1st. Das Ideal als eine Hilfskonstruktion ("Krücke") weist den Menschen auf dieses ziel hin und treibt ihn vorwärts und höher. Darin, im Vorwärtstreben (das zugleich Kampf bedeutet), das heißt im Fortschritt liegt der Sinn des Daseins.

6. "O cize, kotoryj lgal 1 o djatle, l jubitele istiny" (1893)

Bevor wir das besprochene Textmaterial resümieren und dabel andere, bisher nicht zur sprache gebrachte Texte ergänzen, soll noch ein letztes - Gor'kljs frühestes "Credo" das Blld abrunden und zelgen, daß eine direkte Linie von seinem Gotterbauertum in sein frühestes Schaffen zurückführt.

Daß Gor'kij für diesen 1893 entstandenen Text die Fabel als Genre wählt, mag man zunächst als Schutzmaßnahme des Autors vor der Zensur nehmen ${ }^{183}$ ). Setzt man jedoch für die Begriffe und Namen aus der vogelwelt solche aus der Menschenwelt ein (Mensch, Literatur, Fortschritt, usw.), 
so wird der aktuelle Bezug, der "Sitz im Leben"184) dermaßen offensichtlich, daß die Zensur als Grund für die Genre-Wahl nicht mehr ganz einzuleuchten vermag.

Eine andere Erklärung bietet sich im Kontext der bisher erarbeiteten Ergebnisse:

Es hat sich gezeigt, daß in der Retrospektive der Gor'kijschen Texte dem 1906/07 gefundenen und textuell auf verschiedene Weise dargebotenen Welt- und Menschenbild immer mehr die suche nach demselben Platz macht. In der nach wückwärts zunehmenden Unklarheit und Undeutlichkeit der $Z$ ielbeschreibung drückt sich eben auch die Entfernung zum $Z$ iel aus. So kann die Fabel als Genre durchaus Ausdruck für die Distanz sein, die Gor'kij hier noch zu seinem späteren Weltbild hat. (Entweder weil es ihm selbst noch nicht deutlich genug ist, oder weil er noch die direkte, bisweilen agitatorische Redeweise vermeidet.) Klar und eindeutig für die kritische Wirkung der Fabel muß lediglich der Kritikansatz sein, und dies ist hier der Fall 185).

Aber noch ein dritter Aspekt ist zu beachten, weil er von der Fabel als Genre direkt zu dem in diesem Text thematisierten Problem - dem Verhältnis von Lüge und Wahrheit führt:

Die Fabel dient der Erkenntniserhellung, dem Finden der Wahrheit. Die Wahrheit ist aber meist unerträglich und schwer verdaulich und stößt auf Widerstand. Dle Fabel überwindet den Widerstand des Hörers und Lesers, indem sie die bittere pille versüßt, indem sie der Wahrheit einen Tierwanst, (...), umlegt ${ }^{186)}$.

Der in der Folge von Gor'kij immer wieder problematisierte Gegensatz/Widerspruch von 'Wahrheit', die tödlich oder zumindest lähmend sein kann ("Citatel"", "Na dne") 
und Lüge/Illusion, die als "erhebender Trug" (nas vozvysajustij obman) ${ }^{187)}$ eine aktive und positive Einstellung zum Leben bewirken kann, tritt uns hier in den Gestalten von Zeisig und specht entgegen.

Der Zeisig, der gescheiterte gefiederte Vorläufer Dankos und jener in "Citatel" beschworenen "Meister des Wortes" sowie Lukas, verkündigt elnen standpunkt, den wir - in leicht veränderter form - aus den bisher analysierten (späteren) Texten kennen.

Es ist bezeichnend, daß Gor'kif des zeisigs gereimtes und gesungenes "freies, kühnes Lied"188) der analysierend nüchternen und arroganten Prosa des spechts gegenüberstellt. Gor'kijs gegen die zeltgenössische Literatur der 'kleinen Wahrheiten' bewußt eingesetztes romantisches Erbe wird hier deutlich und verständlich als Kampfmittel $^{189)}$.

In seinem Lied verkündet der Zeisig, daß das Leben kämpferische Erkenntnis sein soll. (Das "Feuer der Vernunft" vertreibt die "Finsternis"190), Der Kampf selbst sei sinn und Rechtfertigung des Lebens - nicht der sieg ${ }^{191)}$. Wie der Stieglitz (Journalist) feststellt, will der Zeisig mit seinem Lied "gesellschaftliches Bewußtsein wecken"192) will durch seinen Appell wieder "Stolz" und "Ehrgefühl"193) im Bewußtsein der Vögel wachrufen.

Als Rechtfertigung für seinen Aufruf dient dem Zeisig die Überzeugung, daß die Vögel (Menschen) als Krone der Schöpfung zu Höchstem berufen seien ${ }^{194)}$, al so den höchsten Wert im Kosmos darstellten. Dies will er bewußt machen. Und es erinnert an Nietzsches Aphorismus von der "Zukünftigen Menschlichkeit"195), wenn er begründet: Die Vögel seien alles "Vergangene, Gegenwärtige und Zukünftige in einem"196). 
Der Zeisig glaubt an den absoluten Fortschritt:

Die Geschichte der Vögel ist ein "Weg" und ihr ziel heiBt "Vorwärts!" ("Dorthin - in jenes wunderbare "Vorwärts'!"197), In der Zukunft sieht er einen 'übermenschen" (-vogel), der "groß", "frei", "alles überwindend" ist und das "Bewußtsein seiner eigenen Kraft genießt"198). - wie in "Čelovek" und dem Enquêten-Text sollen Denken, Fühlen und Können ins Unendliche steigerbar sein. Der Mensch (Vogel) geht seiner absoluten Herrschaft über die Natur entgegen.

Ännlich wie Luka bewirkt der Zeisig mit seinen Reden bei den Zuhörern zunächst Enthusiasmus und Hoffnung auf jenes andere Land jenseits des Hains; aber die Konfrontation mit den 'kleinen wahrheiten' des spechts ("Ich ernähre mich von Würmern und liebe die Wahrhe1t"199) .) läßt die Begeisterung schnell der Enttäuschung über die Lügen des zeisigs weichen. Die "Wahrheit" des Spechts: "Wir alle sind nicht mehr als kleine Tatsächelchen"200)! legt sich in der Tat "wie ein stein auf die Flügel"201). Indem der specht die Lügen des zeisigs analysiert und entlarvt, deckt er unversehens dessen (nietzeanisches) Anliegen auf: Der Zelsig fordere die Vögel auf, sich auf einen Weg (Geschichte) zu machen, der Kampf bedeute und dessen Sinn allein im Vorwärtsfliegen bestehe. Der Weg stelle letztlich einen Kreislauf dar - "da die Erde rund ist, müssen wir notwendig wieder in diesen Hain zurückkehren..."202). Und zum dritten stellt der specht richtig fest, daß der Zeisig die vögel zu etwas auffordert, was sie gar nicht können, was sie aber wollen müssen, wenn ihr Leben Geschichte sein soll: "über sich hinauszufliegen" 203 ).

BeI Nietzsche/Zarathustra heißt es dazu: 
Ich lehre euch den übermenschen. Der Mensch ist etwas, das überwunden werden soll. Was habt ihr getan, inn zu überwinden ${ }^{204)}$ ?

Die Figur des Zeisigs und - als negativer Gegenpol die des spechts repräsentieren einen durchgehenden zug in Gor'kijs Schaffen und Kampf um eine neue Literatur von Anfang an:

Die funktionale Ankoppelung von Literatur an ein bestimmtes dynamisches Menschen- und Weltbild spielt in der Zeit des Bogostroitel'stvo eine wesentliche Rolle (und weist in Richtung auf die spätere Konzeption des Sozialistischen Realismus). Die Literatur hat die Ideale zu schaffen, die die Leser aus inrer Lethargie herausreißen, sie veredeln und $z u$ aktiven, sich selbst überwindenden Menschen machen können ${ }^{205}$ ).

Eben diese Funktion soll auch das Lied des Zeisigs haben; nämlich "Glauben und Hoffnung", "Stolz" und damit Aktivität in den vögeln zu wecken ${ }^{206}$ ).

Warum muß der Zeisig aber scheitern?

Nicht etwa, weil sein Lied als 'Lüge' entlarvt wurde ("Ich wußte nicht, was dort, jenseits des Hains ist..."207), sondern - so der Erzählerkommentar - weil er zwar "edelmütig"208) ist, aber "keinen festen Glauben besitzt und deswegen kleinmütig ist"209).

Das heiBt, der Ruf nach den "Meistern des Wortes", Konovalovs suche nach einem festen "Standpunkt" und die im Gotterbauertum gewonnene Einsicht, daß das Ideal nur von Menschen geschaffen und glaubwürdig vorgetragen werden könne, deren Glauben an sich und die Geschichte ' religiöse' Qualität hat, weil er von Emotion und Vernunft getragen ist, wird hier schon vorbereitet. 
Ebenso ist hier schon ein zug zu finden, der kennzeichnend für den Enquêten-Text (auch in Ansätzen für "Čelovek" und "Na dne") ist, daß nämlich die Veränderung der Gesellschaft und inrer Geschichte beim Bewußtsein des Einzelnen anzusetzen hat ${ }^{210)}$. Das subjekt der Geschichte muß sich seines Wertes (wieder) bewußt werden, dann erst kann die hof fnungsvolle Arbeit an der Geschichte beginnen.

Unklar bleibt in diesem Text noch das Verhältnis von Gefühl und Vernunft:

Das Lied des Zeisigs ist rein von Emotionen getragen und weckt auch Emotionen (Enthusiasmus). Dies wird zwar auch schon als Mangel artikuliert (Stieglitz und specht verlangen eine Rechtfertigung für das Lied), und der Ausgang der Fabel weist auf diesen Mangel hin. Dennoch wird die emotionale Seite hier noch nicht als der Ergänzung durch die Vernunft, eine vernünftige Ordnung usw. erkannt. Die Vernunft tritt nur in ihrer negativen, heruntergekommenen, der Emotionalität verlustig gegangenen Gestalt auf - als "kleine Wahrheit", die auf eine Ebene mit den Würmern, der Nahrung des Spechts gerückt wird.

Der Zeisig scheitert, weil er nicht im sinne Nietzsches ein "Aristokrat des Geistes" 211), sondern im Gegenteil ein "Bettler des Geistes" (nisc duchom) 212 ) ist. Er selbst besitzt nicht jene innere stärke und Größe, die seiner Rede mehr Glaubwürdigkeit und damit Wirkung verschaffen könnte. Dennoch ist sein Lied von einem stolzen - und wenigstens zeitweise Stolz und Zuversicht weckenden - Pathos getragen ${ }^{213)}$.

Es gibt mit Sicherheit mehrere Gründe für die Emphase, die Gor'kij von jeher in den Begriff des 'Menschen' legt nicht zuletzt biographische. Aber im Gang durch die ein- 
zelnen Texte wurde hier Nietzsche immer öfter genannt; und diese zuletzt besprochene Fabel hat N.K. Michajlovskij als künstlerischen Kommentar zu Nietzsches "Vom Nutzen und Nachteil der Historie für das Leben" gelesen"214).

Der möglichen Bedeutung Nietzsches für die Formierung von Gor'kijs Menschenbild, insbesondere im Hinblick auf das Menschenbild des Gotterbauertums, soll hier kurz nachgegangen werden.

\section{Gor'kij-ein schüler Nietzsches?}

Überschaut man die Literatur, die die Aufnahme Gor'kijs in RuBland wie in Westeuropa begleitete und kommentierte, so wird eines deutlich: Sogleich mit seinem Bekanntwerden wurden die Gestalten der frühen Erzählungen mit Nietzsche in Verbindung gebracht.

Es scheint eine schwer zu beantwortende Frage zu sein, ob diese Selte der Gor'kij-Rezeption eher den (Zeit-)Geist seiner Leser widerspiegelt, oder ob Gor'kijs Frühwerk in einigen zügen nur eine zufällige Analogie zu Nietzsches Philosophie darstell $t^{215)}$ - oder ob, wie vielfach behauptet, der junge Gor'kij tatsächlich Nietzscheaner war und dann

ein Vorbild des wirklichen Realismus, (...) auch sozial und moralisch, menschlich jene Wege aufgezeigt (hat), auf welchen ein jeder schriftsteller die in ihm vorhandenen dekadenten Überreste, die inn vergiftenden und irreführenden Einflüsse wirklich, im Leben und in der Literatur überwinden kann 216).

Die Tatsache, daß das Problem eines Elnflusses von Nietzsche auf Gor'kijs frühes Schaffen bis heute kontrovers 
behandelt wird, mag vor allem inren Grund in der Schwierigkeit eines eindeutigen positiven oder negativen Nachweises aus Gor'kijs Schriften haben. Erschwert wird eine Antwort auf diese Frage allerdings zusätzlich noch dadurch, daß sie allzu leicht zum Bekenntnis für oder gegen eine Glaubensrichtung gerät ${ }^{217)}$.

Gelingt es auch kaum einem Rezensenten oder Literaturwissenschaftler, den direkten Zusammenhang zwischen einer Nietzsche-Lektüre Gor'kijs und dessen frühen Gestalten aufzuzeigen, so wird doch immer wieder auf die Verwandtschaft zwischen Nietzsches 'Herrenmenschen' und den Bosjaki der ersten Erzählungen Gor'kifs verwiesen.

Dies soll kurz und exemplarisch dokumentiert werden, da der Verdacht naheliegt, daß es sich hier um die Perpetuierung eines $\mathrm{Klischees} \mathrm{-} \mathrm{sowohl} \mathrm{von} \mathrm{Nietzsche} \mathrm{als} \mathrm{auch}$ von Gor'kij (und dessen Nietzsche-Rezeption) - handelt, welches den Blick auf möglicherweise tatsächlich gegebene Verwandtschaften verspert.

In seinem Vorwort zur russischen Ausgabe von Henri Lichtenbergers "La Philosophle de Nietzsche"218) bezeichnet M.P. Nevedomskij Gor'kij als "unsern bodenständigen Nietzscheaner"219). 1903 erscheint in "Russkoe bogatstvo"220) ein Aufsatz unter dem Titel: "Nietzsche und Gor'kij: Ein Element des Nietzscheanertums im Schaffen Gor'kijs". Als Gemeinsamkeit sieht Gel'rot die Vergöttlichung des Lebens und den Appell an das Individuum, sich gegen alles zu erheben, was inm bei seinem Lebensvollzug hinderlich ist.

Auch Lunacarskij konstatiert mehrfach eine Übereinstimmung im Anliegen Gor'kijs und Nietzsches 221 ). Er sieht in inm einen "Ultra-Individualisten" vom Typ Nietzsches, 
dessen Individualismus aufgrund seiner Intensität und $E x-$ tensität zum Kollektivismus umschlägt 222 ).

In anderem Sinne entdeckt 1901 in der "Wiener Abendpost" ein Rezensent 223 ) eine "auffallende Ähnlichkeit im Denkkern zweier an Intensität und Extensität inrer Arbeit gewiß sehr verschiedener Köpfe"224). Er findet in einigen Erzählungen und in dem Roman "Foma Gordeev" dieselbe Psychologie und Moralauffassung wie bei Nietzsche (ohne allerdings einen direkten Zusammenhang $z u$ behaupten):

Es ist das anziehende Schauspiel, daß ein Primitiver (sic:) und ein Hochdifferenzierter, jeder in seiner Sprache, das gleiche sagen ${ }^{225}$ ).

"Foma Gordeev" liest der Rezensent als "Seitenstück zu Nietzsches 'Genealogie der Moral'"226). Trotz solcher Analogien hält er es für unwahrscheinlich, daß Gor'kij von Nietzsche direkt beeinflußt wurde; jedoch habe er an jenem "geistigen Fluidum" teil, das ganz Europa durchströme und "für Nietzsche so empfänglich" mache"27).

Was von weitem sich mit seinen Ideen berührt, ist der Haß gegen die Gleichmacherei, gegen das Wissensnivellement und die große Proletarisierung. (...) Tiefere übereinstimmung verbindet ihn (Gor'kij) mit dem Philosophen der Herrenmoral. (...) Das Ungestüm gesunder seelen verlangt Action, selbsteigenes Handeln. (...) Sein (Gor'kljs) übermensch ist der alle Bande der Gewohnheit höhnende Vagabund ${ }^{228 \text { ). }}$

Zu ähnlichen Urteilen kommt I.E. Poritzky 229). Das Eigentümliche an Gor'kij sieht er darin, daß sich in inm die Tradition der russischen Literatur mit einem "Extrakt der Stirner-Nietzschen Philosophie" vereine ${ }^{230)}$. Gor'kij 
schildere "Ausnahmenaturen"; er liebe im Proletariat das "Raubtier", den "Herrenmenschen"; Gor'kijs Held sei der "Einsame", der "Übermensch", der "Individualist":

Nicht nur in der Verachtung der misera plebs wanddelt Gorki in den Fußstapfen Nietzsches, sondern auch da, wo er von Verbrechen, vom Gewissen, vom Mitleid, von der Furcht usw. spricht ${ }^{231)}$.

Eine Synthese von Christus und Nietzsche (Lara, Danko, Fürst Sakro) sucht Gor'kij nach Lehbert ${ }^{232)}$. In Figuren wie Fürst Sakro sehe er das Urbild seiner Helden, des "Übermenschen", die "Saat einer besseren Zukunft"233).

I. Rühle 234) findet bei den Bosjaki der frühen Erzählungen "Gedankengänge Nietzsches"235), und Satins Monolog hält er für eine "Predigt von der Art Zarathustras"236).

Bei Gor'kijs Entwicklung vom "romantischen Anarchismus zum Bolschewismus" habe Nietzsche eine wichtige Rolle gespielt und sei, "so seltsam es klingen mag, in die Ideologie des sozialistischen Realismus eingegangen"237). Von "Na dne" zu "Meకとane" sieht Rühle eine weiterfünrung des Nietzscheschen Elitegedankens ${ }^{238)}$.

Solche und ähnliche Berufungen auf Nietzsche bel der Betrachtung von Gor'kijs frühem Schaffen ließen sich noch weiter sammeln ${ }^{239)}$; hier gilt es aber nur exemplarisch zu zeigen, welches Nietzsche-Bild zugrundeliegt, wenn der junge Gor'kij als Nietzscheaner apostrophiert wird, und wie möglicherweise dem Verständnis beider Gewalt geschieht 240 ). - Es ist dies der Nietzsche der "Herrenmoral", der "Unmoral", der Philosoph der Dekadenz und Demokratiefeindlichkeit, der "blonden Bestie", des übersteigerten Individualismus, des "übermenschen". 
Das heißt, wir sind bei dem Vergleich Gor'kijs mit Nietzsche mit einem $\mathrm{Klischee}$ von letzterem (und auch von Gor'$k i j)$ konfrontiert, das sich in seinen Hauptzügen bis heute gehalten hat, und das für Polemiken nach der einen wie nach der anderen seite gut ist ${ }^{241}$. Die Rezeption des jungen Gor'kij spiegelt also recht eigentlich die Rezeption Nietzsches wider.

Zu konstatieren bleibt, daß die Frage: Gor'kij-ein Schüler Nietzsches? immer noch strittig ist; $\mathrm{Kluge}^{242)} \mathrm{faBt}$ zus ammen :

In diesem Zusammenhang wird - besonders in der westlichen Literatur - viel auf einen möglichen Einfluß Friedrich Nietzsches hingewiesen; die sowjetische Gor'kij-Forschung verhält sich sehr skeptisch zu dieser Frage. Das Problem ist noch nicht geklärt ${ }^{243)}$.

Immerhin stellt auch Kluge fest:

Seine (Gor'kijs) vitalen und dem Durchschnittsmenschen moralisch und physisch weit überlegenen Bosjaki stellen - wie Cechov richtig bemerkt hat - eine verächtliche Herausforderung an das spießertum und seine Moral des Ressentiments dar - zumindest darin ist sich Gor'kij mit Nietzsche einig ${ }^{244}$ ).

Dies sei ohne weiteres zugestanden: Der Vergleich der starken, frelheltsliebenden und auBerhalb der Geselischaft und ihrer verlogenen Moral stehenden Bosjaki ${ }^{245}$ ) mit dem - Übermenschen' liegt nahe, aber eben auch zu nahe am gängigen Nietzsche-Klischee. Der Gang durch Gor'kijs Schaffen von 1907 bis 1893 zwingt zu der Frage, ob die hier vorgeführte Gor'kij-Nietzsche-Rezeption nicht zu einseitig ist und darum der Erweiterung auf andere Ebenen bedarf. 
Mit der Frage zunächst nach Gor'kijs Kenntnis von Nietzsche und dann nach möglichen Einflüssen soll das Problem noch einmal aufgerolit werden - allerdings mit der notwendigen Beschränkung, die unser Gesichtspunkt: Nietzsches Relevanz für das Gotterbauertum Gor'kijs nahelegt.

Die erste Nietzsche-Übersetzung ins Russische erschien $1898^{246)}$ - es ist also mehr als unwahrscheinlich, daß eine eingehendere Lektüre Nietzsches für das Werk Gor'kijs in den neunziger Jahren relevant wurde. (Immerhin wird aber der Name schon 1896 in einem Artikel erwähnt) 247).

Aufschlußreich sind spätere Selbstzeugnisse Gor'kijs: In seinem Aufsatz "Razrusenie lixnosti" (1909)248), der immer wieder mit dem Gotterbauertum in Verbindung gebracht wird, mokiert sich Gor'kij über die russischen Intellektuellen der neunziger Jahre, die in unfreier, falscher Scham den Weg inrer radikalen Lehrer verließen und sich nur heimlich über die Philosophie "des Ketzers und Antisozialisten" Nietzsche zu informieren wagten ${ }^{249)}$. Quelle ihrer Informationen sei eine 1892 erschienene Nummer der "Voprosy filosofil i psichologil" gewesen mit Artikeln von Lopatin, Grot und Trubeckoj "oder Vvedenskij"250).

Nun erschien zwar in jenem Jahr in den "Voprosy", dem "Hauptorgan der akademischen Philosophie und Psychologie im vorrevolutionären RuBland"251), von keinem der von Gor'kif genannten Autoren ein Artikel über Nietzsche. Dennoch beginnt mit diesem Band die eigentliche (breite) NietzscheRezeption in Rußland durch einen Aufsatz von V.P. Preobrazenskif, der von 1895 bis 1900 Mitherausgeber der Zeitschrift war"252). Der Titel des Aufsatzes lautet: "Friedrich Nietzsche. Kritik der Moral des Altruismus"253). Da als sicher anzunehmen ist, daß Gor'kij diesen Aufsatz gemeint hat und ihn auch aus eigener Lektüre kannte, soll er hier kurz referiert werden. Diese Kenntnis Gor'kijs 
kann um so sicherer vermutet werden, als hier Motive und Sätze begegnen, die wir zum Tell wörtlich aus (den besprochenen und anderen) Texten Gor'kijs kennen.

Preobraženskij sieht in Nietzsche einen Philosophen, der zum ersten Mal die Frage nach der Moral als "Problem" gestellt hat ${ }^{254}$ ). Sein Gang nach "Jenseits von Gut und Böse" sei erfolgt, um überhaupt die Frage nach der Moral wieder formulieren zu können.

Hier ist an Gor'kijs Fabel "Razgovor po duse" (Ein offenes Gespräch - 1893255) zu erinnern, wo "Tugend" und "Laster", die sich seit Urzeiten bekämpfen, am Strom des Lebens einander gegenüberstehen und feststellen, daß ihr Kampf keinen Sinn mehr habe. Das "Laster" schlägt eine Ehe vor und dokumentiert damit endgültig das verschwinden der Kategorien Gut und Böse. Einen Ausweg aus dieser Situation sieht der Erzähler einzig in "reinen und großen Taten, die die Sache des Lebens wiederbeleben"256).

Ein weiteres uns von Gor'kif her bekanntes Motiv sieht Preobraženskij in Nietzsches Entlarvung des Mitleids als Wurzel vermeintlichen moralischen Verhaltens ${ }^{57)}$. Mitleid als eine Form von Grausamkeit, weil sie dem anderen Schwäche bescheinigt und inn so beleidigt ${ }^{258}$ ). Preobrazenskijs Nietzsche-Interpretation deckt sich in diesem Zusammenhang auffallend mit Gor'kijs Kritik an der russischen kleinbürgerlichen Mentalität und der sie fördernden Literatur (Dostoevskij):

Preobraženskij sagt, daß nach Nietzsche die hohe Bewertung des Mitleids in einer Gesellschaft auf deren Empfänglichkeit für das Leiden verweise und auf verminderte Lebensfähigkeit schließen lasse ${ }^{259)}$. Die perverse Lust am Leiden und dessen zu-Markte-Tragen in der zeitgenössischen Literatur attackiert Gor'kij besonders deutlich in der besprochenen Meditation "Casy"260). 
Nach Nietzsche seien "neue Ideale" notwendig" ${ }^{261)}$, so Preobrazenskij weiter, um die Menschen aus ihrer Mittelmässigkeit zu reißen und vor dem Verfall zu retten; die gän-

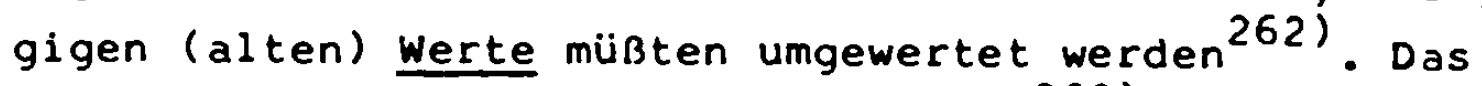
Ideal, das zum "Menschen der Zukunft"263) führe, müsse schöpferisch gewonnen werden (tvorceski postroennyj ideal) 264); dieses Ideal gebe "der Erde ihren Sinn und dem Menschen seine Hof fnung"265). Auf die Bedeutung des Ideals bei Gor'kij in eben diesem Sinne wurde schon mehrfach hingewiesen.

Wenn Konovalov auf der Eigenverantwortlichkeit des Einzelnen beharrt ("Jeder Mensch ist sein eigener Herr"266)), so beruft er sich damit auf eine Nietzsche-Paraphrase in Preobrazenskijs Aufsatz: "Wir haben uns vor uns selbst für unser Leben zu verantworten..."267) Weiterhin sei es Nietzsches Anliegen gewesen, daß die Menschen wieder zu "Aristokraten des Geistes" (dusevnymi aristokratami) würden 268) - und mit genau diesen worten stellt Gor'kij in seiner Nietzsche-Kritik 1905 ("Zametki o mescansteve") 269) das Scheitern von Nietzsche am Kleinbürgertum fest: Nietzsche sei zwar ein Genie gewesen, doch Wunder war er nicht imstande zu üben, er war nicht imstande, frisches heißes Blut in ausgedorrte Adern zu gießen, er war nicht imstande, mit dem Feuer seiner seele die kleinlichen Krämer in Aristokraten des Geistes umzuschmelzen. Der Auf ruf zur Selbstwehr fiel auf unf ruchtbaren Boden ${ }^{270)}$.

Nach Nietzsche, so Preobrazenskij, gibt es im menschlichen Leben keinen Sinn a priori ${ }^{271)}$ :

Nur durch seinen willen legt der Mensch Sinn in sein Leben: er selbst schafft seine Bedeutung und seinen wert, und rechtfertigt es sozusagen a posteriori, - dadurch, daß er inm ein hohes und edles Ziel setzt ${ }^{272)}$. 
Dazu heißt es bei Gor'kij immer wieder, daß der sinn des Lebens nicht vorfindbar sei, sondern im (wollenden) Schaffen des Menschen liege. ("Razgovor po duse", "Citatel"", "Konovalov", "Celovek" usw.)

Ausgehend von dem Zarathustra-zitat

Der übermensch ist der Sinn der Erde; Euer Wille sage,ja, der Übermensch sei der Sinn der Erde ${ }^{273)}$.

bringt Preobrazenskij auch das Motiv von der Selbsttranszendierung des Menschen. Der Mensch soll sich überwinden, über sich hinauswachsen, indem er all seine Möglichkeiten über ihre Grenzen hinaus entwickelt.

Der Zeisig("O cize..") 274) verlangt von den vögeln das Unmögliche, nämlich daß sie über sich hinausfliegen. Und in "Celovek" wird der Mensch ausdrücklich als eine sich selbst transzendierende Größe gesehen: "Die Menschen sollen zu 'Menschen' werden"275). Noch in der Antwort auf die Enquête des Mercure de France spricht Gor'kij von einem neuen Menschentypus in der Zukunft ${ }^{276)}$.

Schließlich finden wir auch das, was Preobrazenskij als den Grundgedanken in Nietzsches Philosophie ansieht nämlich das Leben als oberstes Maß, an welchem alle (moralischen) Werte sich messen müssen ${ }^{277)}$ - bei Gor'kij. ("Konovalov", "Celovek", "Casy", Enquête, "O cinizme")

So kann man also an dieser stelle schon sagen: Selbst wenn Gor'kij in den neunziger Jahren noch keine eigene TextKenntnis von Nietzsche hatte, so genügte doch die Lektüre dieses Aufsatzes und die durch inn eingeleitete Diskussion (die mit sicherheit nicht an Gor'kij vorbeiging ${ }^{27}$ ), um die Herkunft einer Reihe von Nietzscheanischen Motiven in Gor'kijs frühem schaffen zu erklären. 
Preobraženskijs Aufsatz war aber nicht die einzige Quelle, aus der sich Gor'kijs Kenntnis von Nietzsche speiste.

In seinen erst spät - 1930/31 - erschienenen "Besedy o remesle" (werkstattgespräche) 279) nimmt er zu dem Vorwurf Stellung, er habe in seinen frühen Erzählungen das Lumpenproletariat romantisiert und seinen Bosjakengestalten "nietzscheanische Mentalitat" verliehen. In seiner Entgegnung charakterisiert er zunächst Nietzsches Philosophie klischeegetreu als "Philosophie der Herren"280) und - was für uns aufschlußrelcher ist - erwähnt dann, daß er diese Philosophie 1893 durch Studenten des Jaroslaver Lyceums kennengelernt habe, die wie er als Schreiber bel Advokaten arbeiteten.

Aber noch früher, Im Winter 89/90, übersetzte mein Freund N.Z. Vasil'ev das beste Buch Nietzsches "Also sprach Zarathustra" ins Russische und erzählte mir von Nietzsche, wobel er dessen Philosophie als "schönen Zynismus" betitelte 281 ).

Gor'kijs Äußerungen zur "nietzeanischen Mentalitat" seiner früher, Gestalten wertet Rühie 282 ) als "gereizte" und den Tatbestand im Nachhinein verzerrende Reaktion des alten Gor'kij283).

In der Tat windet sich Gor'kif in befremdlicher weise um die Antwort auf die anstehende Frage herum, wenn er schreibt:

Ich habe sie wohl kaum "romantislert". Ich habe keinerlel hoffnungen in sle gelegt (in die BosJaken); aber daß ich sie, wie auch Majakin ("Foma Gordeev"), mit einigem von Nietzsches Philosophle versehen habe, werde ich nicht leugnen. Aber ich behaupte auch nicht, daß ich in 
beiden Fällen bewußt gehandelt (!) habe. Allerdings glaube ich, daß ich mit vollem Recht den gewesenen Menschen den Anarchismus des "Nietzscheanertums" zugeschrieben habe 284 ).

Gor'kij behauptet, daß er hierbei von dem Recht des Schriftstellers, das Material "zu Ende zu denken" Gebrauch gemacht und er sich dabei in Übereinstimmung mit der (politischen) Realität befunden habe und noch befindet:

Der Vagabund Promtov ("Prochodimec") und der philosophierende Falschspieler Satin sind noch immer lebendig, aber sie sind anders gekleidet und arbeiten in der Emigrantenpresse, predigen die "Moral der Herren" und rechtfertigen in jeder Weise ihr Dasein ${ }^{285}$ ).

Eine negative Einstellung Gor'kijs zu Nietzsche trat schon in den oben zitierten "Zametki o mescanstve" zutage. Dort klang aber bei aller Kritik - die ihren Hauptgrund darin zu finden schien, daß diese Philosophie so leicht in ihr Gegenteil verkehrbar, das heiBt für das mescanstvo als Ideologie offen war 286$)$ - durchaus auch noch die Faszination durch die Kraft und Dynamik dieser Philosophie mit ${ }^{287)}$.

Daß der alte Gor'kij seine ablehnende Haltung zu Nietzsche schärfer (und $k l$ ischeegetreuer) ausspricht, als dies 1905 der Fall war, ist nicht weiter verwunderlich ${ }^{288)}$; daB er aber nun auch Satin ("Celovek - eto zvucit gordo!") im selben negativen Licht erscheinen läßt, in welchem er das mex̌anstvo und dessen Nietzsche-Rezeption sah, 1 äßt Fragen offen und die Vermutung zu, daß Satins Predigt vom Menschen tatsächlich Nietzsches Pathos vom übermenschen mitschwingen läßt - und dies durchaus nicht in einem negativen Sinne. Diese Vermutung zu bestätigen, genügt 
schon der Hinweis auf die Tatsache, daß sich Gor'kij (spät) zwar von Satin lossagt, daß aber von dieser Distanzierung das Poem "Celovek", in welchem Satins Gedanken überhaupt erst vollständig ausgeführt werden, völlig unberührt bleibt 289 ).

Bleiben wir bei dieser Bestandsaufnahme und versuchen wir das Verhältnis Gor'kij-Nietzsche zu bestimmen unter dem Aspekt seiner Relevanz für das Gotterbauertum. Dabei gilt es, einen 'Vorbehalt' nicht aus dem Blick zu verlieren (der in ähnlicher Weise auch für Lunacarskij gelten muß): Gor'kij hat an keiner stelle und zu keinem zeitpunkt ein Interesse an einer 'objektiv' richtigen Paraphrase oder Interpretation der Philosophie Nietzsches; diese ist für inn (und damit auch für uns) einzig wichtig unter dem Gesichtspunkt inrer 'Verwertbarkeit. 290), das heiBt als Baustein zum Menschen- und Weltbild, welches Gor'kij bis 1906/07 gesucht und im Gotterbauertum gefunden zu haben glaubte.

Für Gor'kij sind m.E. zweierlei Nietzsche-Rezeptionen zu unterscheiden: eine eher vordergrüdige und eine subtilere, dafür umso nachhaltigere.

1. Vordergründig und mehr oder weniger unbewußt gehen in die frühen Gestalten Gor'kijs züge jenes Klischees vom "übermenschen"291) als eines Typus' ein, dessen Stärke und Überlegenheit ihn zur Ablehnung der Gesellschaft und ihrer moralischen Normen berechtigen ${ }^{292)}$.

2. Subtiler und wirksamer dürfte aber neben dieser augenfälligen Aufnahme Nietzscheanischer Motive die Offenheit der Übermensch-Metapher als Ausdruck für die Hoffnung auf einen neuen Menschen sein, der aus dem real begegnenden hervorgeht. Die Wirksamkeit des "übermenschen" als Symbol für die Utopie vom neuen Menschen liegt auf der Hand. Dafür spricht auch das immer neu verwendete Brücken- bzw. Untergangsmotiv 293 ). 
Die Entsprechungen finden sich in Nietzsches "Zarathustra":

Gott ist eine Mutmaßung; aber Ich will, daß euer Mutmaßen nicht weiter reiche, als Euer schaffender wille. Könntet Ihr einen Gott schaffen? (Sogar das Motiv des Gottschaffens, das im Bogostroitel'stvo für die Schaffung des Neuen Menschen und der neuen Gesellschaft steht, findet sich im "Zarathustra"! R.S.)

So schweigt mir doch von allen Göttern! Wohl aber konntet ihr den übermenschen schaffen. Nicht ihr vielleicht selbst, meine Brüder! Aber zu vätern und Vorfahren könntet ihr euch umschaffen des übermenschen: und dies sei euer bestes Schaffen 294) ! Was groß ist am Menschen, das ist, daß er eine Brücke und kein Zweck ist: was gellebt werden kann am Menschen, das ist, daß er ein übergang und ein Untergang ist 295 ).

Ebenso konstitutiv für Gor'kijs Gotterbauertum ist Nietzsches mit dem übermensch-symbol verbundene radikale Wendung vom 'Himmel' zur 'Erde' und der Appell an den Stolz des Menschen, der zur Kritik der Religion führt:

Euer Wille sage: der Übermensch sei der Sinn der Erde! Ich beschwöre euch, meine Brüder, blelbt der Erde treu und glaubt denen nicht, welche euch von uberirdischen Hoffnungen reden! Giftmischer sind es, ob sie es wissen oder nicht ${ }^{296)}$.

Ja dies Ich und des Ichs widerspruch und Wirrsal redet noch am redlichsten von seinem Sein, dieses schaffende, wollende, wertende Ich, welches das $M a ß$ und der wert der Dinge ist. (...) 
Einen neuen Stolz lehrte mich mein Ich, den lehre ich die Menschen: nicht mehr den Kopf in den Sand der himmlischen Dinge zu stecken, sondern frei ihn zu tragen, einen Erden-Kopf, der der Erde Sinn

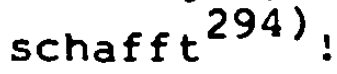

Es bedarf nicht mehr des Einzelnachweises, um die Behauptung zu erhärten, daß dies Motive und Gedankengänge sind, die von Anfang an bei Gor'kij begegnen und ihre endgütige Verwertung im Bogostroitel'stvo finden ${ }^{298 \text { ). }}$

Nicht zuletzt verbindet Gor'kij und Nietzsche-Zarathustra der Gedanke der Menschenformung durch Erziehung: Die Umwertung aller Werte, die Schaffung des Übermenschen, die Entstehung einer neuen Gesellschaft und eines neuen kollektiven Menschentypus muß mit der Arbeit am Bewußtsein des Einzelnen beginnen ${ }^{299)}$.

Schließlich sei noch auf eine letzte Gemeinsamkeit hingewiesen, die bei der Analyse der Gor'kij-Texte immer wieder im Zusammenhang mit der Rolle der Literatur zur sprache $\mathrm{kam}$.

Wenn Nietzsche in "Vom Nutzen und Nachteil der Historie für das Leben" von der Historie verlangt, daß ihren Betreibern nicht

Vermehrung der Erkenntnis das ziel selbst ist, sondern immer nur zum Zwecke des Lebens und also unter der Herrschaft und obersten Führung dieses Zwecks ${ }^{300 \text { ); }}$ und wenn er von der zeitgenössischen Historie, der "Wissenschaft des universalen Werdens" ${ }^{301}$ ), verächtlich sagt, inr Wahlspruch heiße: "Fiat veritas, pereat vita"302), so entspricht dies exakt Gor'kijs Kritik an der zeitgenössischen Literatur, bzw. seiner positiven Bestimmung inrer Funktion: Sie soll nicht die objektiven 'kleinen 
Wahrheiten' zu ihrem Gegenstand machen, da dies lähmende, ja tödliche Wirkung auf die Menschen habe; vielmehr soll sie Ideale schaffen, die dem Leben sagen, wie es sein soll - oder wenigstens einen kleinen "erhebenden Trug", der Glaube, Hoffnung, Aktivităt weckt und so dem Leben dient ${ }^{303 \text { ) }}$.

Halten wir also fest, was von Nietzsche beim jungen Gor'kij zu finden ist und in der Folge in dessen Bogostroitel'stvo eingeht.

Es ist dies zuerst und vor allem das symbol des "übermenschen" als Entwurf des Menschen in die Zukunft hinein. Damit verbunden ist das Pathos der stärke, der Aktivität, des Stolzes, sowie des Lebens als des obersten Maßstabes fuir alle Werte 304 ).

Alle von Gor'kij verwendeten Bilder und Symbole für den neuen Menschen sind, wie die Nietzsches, nicht Beschreibungen, sondern Appelle an das Bewußtsein des Einzelnen. Ebenso wie bei Nietzsche gibt der Mensch bei Gor'kij der Erde ihren Sinn durch sein schaffendes Umwerten.

Schließlich braucht er die Literatur als Schöpferin von Idealen/Illusionen; sie soll inm die Hoffnung und den Glauben an die zukunft geben und inn nicht durch das Reproduzierender Realität erschlagen ${ }^{305)}$.

In diesem Sinne wird die Philosophie Nietzsches für Gor'kij zur Waffe in seinem beständigen Kampf gegen die Mentalität des Mescanstvo und die sie stützende Literatur. 
8. Gor'kijs Bogostroitel'stvo (1906/07) als Ende einer eigenständigen Entwicklung.

Wenden wir den aus der Perspektive des Enquêten-Textes von 1907 nach rückwärts gewandten Blick wieder nach vorn, um jetzt die Frage zu beantworten, ob die Elemente und ihre Konstellation, wie wir sie in jenem ersten (theoretischen) gotterbauerischen Text vorfanden, einen 'anderen' Gor'kij (den durch Lunałarskij verführten) repräsentieren, oder ob - was als These behauptet wurde und zu beweisen war diese Position Gor'kijs der (vorläufige) logische Endpunkt einer folgerichtigen Entwicklung war.

Von Anfang an - dies wurde deutlich - ging es Gor'kij um die Suche nach einem neuen Menschenbild. Diese Suche war eingebettet in sein Bemühen um eine Neubestimmung der Funktion der Literatur, das heiBt in seinen Kampf gegen die zeitgenössische Literatur als Ausdruck der passiven, pessimistischen und an der Darstellung des eigenen Leidens sich weidenden Mentalität des mescanstvo.

Dieser Kampfaspekt macht den ausgesprochenen Appellcharakter verständlich, den Gor'kijs Schaffen von den ersten Werken an trägt, und inn gilt es nicht aus dem Blick $2 u$ verlieren, da er vor allem auch für die 'Entwürfe' Gor'kijs vom neuen Menschen oder der neuen Gesellschaft bis hin zum Bogostroitel'stvo ausschlaggebend ist. Die Literatur hat ein Ideal zu schaffen, welches der Realität eine neue Melodie vorspielt, nach der sie zu tanzen hat.

Im Gotterbauertum wird dieses Ideal von der Kunst im Verein mit der wissenschaft produziert und es veredelt den Menschen, indem es in ihm das "stolze Bewußtsein" seines wertes weckt ${ }^{306}$ ). 
Ebenso konnte gezeigt werden, daß das, was wir in unserem Ausgangstext als die beiden Zentren des Gor'kijschen Menschenbildes ausmachten: Emotionalität und Vernunft sowie die Sehnsucht nach der Aufhebung der Emotionalität in der synthese mit der Vernunft - bis in die frühesten Produkte zurückzuverfolgen ist.

a) Das Pathos des Menschen als Ausdruck der emotionalen seite

Dieses Element bildet Gor'kijs Ausgangspunkt. Er setzt den starken, vitalen, selbstbewußten und dynamischen Menschen gegen die gesellschaftliche Wirklichkeit. Dessen Attribute: Stolz, stärke, Freiheit spiegeln mit sicherheit nicht nur das 'romantische Erbe' und eine vordergründige Nietzsche-Rezeption wider; als mindestens ebenso konstitutiv für diese Seite von Gor'kijs Menschenideal muß seine Individuelle Biographie in Anschlag gebracht werden ${ }^{307)}$. Ein Blick auf die beiden frühesten autobiographischen Fragmente 308) (1893) genügt, um zu sehen, daß der junge Peskov in jenem kleinbürgermilieu weder psychisch noch physisch eine Überlebenschance gehabt hätte, wenn er nicht eben diese Eigenschaft bei sich vorgefunden und entwickelt hätte.

Schwieriger als diese Seite der Emotionalität ist Gor'kijs unerschütterlicher Glaube an den Menschen und das Gute in ihm zu erklären und der damit immer wieder verbundene Aufruf, den Menschen zu achten. Trotz der in den erwähnten autobiographischen Fragmenten zutage tretenden Distanz, ja Abkehr vom christlichen Glauben - wie er durch den Großvater vermittelt wurde - ist hier wohl dennoch der Reflex eines christlichen Erbes zu sehen.

Nicht erst zur Zeit des Gotterbauertums, sondern ebenfalls schon sehr früh erhält Gor'kijs Pathos des Menschen reli- 
giösen Charakter, wird der Mensch (als Entwurf von der Realität in die zukunft hinein) als etwas Göttliches gedeutet.

So heißt es in der Elegie "Za bortom" (Über Bod) (1896):

Indess, die "wahre Shekina309) ist der Mensch". $\mathrm{Ja}$, denn er ist das Allerheiligste, er ist eine ganze Welt - elne komplizierte, interessante, tiefe Welt... Werden die Menschen jemals lernen, wenn schon nicht, sich zu verstehen, so doch wenigstens schweigend einander zu achten? Werden sie es irgendwann einmal begreifen, daß es außer dem Menschen nichts Interessantes auf der Welt gibt, und daß der Mensch das Maß aller Dinge und der Schöpfer des Leben ist ${ }^{310)}$ ?

Kam schon in der Fabel vom "Zeisig, der log, und vom specht, der die wahrheit liebte" (1893) das Scheitern eines Ideals zum Ausdruck, welches einzig von der Emotion getragen ist, so führt diese Erkenntnis immer deutlicher zum Ruf nach der Vernunft als Korrektiv und Syntheseglied. Dazu heiBt es in der oben zitierten Elegie:

... In der Ferne brennen hell die Feuer der Hoffnung auf etwas Edles und Großes; und in der Seele des Menschen spielt der klare Regenbogen leidenschaftlicher Gedanken und Gefühle. Die Momente sind selten... Aber es gibt sie. Es gibt sie, und nur durch sie seien sie auch bloß ein "uns erhebender Trug" kann man leben ${ }^{311 \text { ). }}$ 


\section{b) Die Vernunft als Korrektiv und Syntheseqlied}

Der Ruf nach der Vernunft aus der Erkenntnis der Unzulänglichkeit von Emotionalität allein heraus wird zwar 1896 in aller Deutlichkeit formuliert ("Konovalov"), jedoch $k a n n$ man auch schon früher sehen, daß die Vernunft mit ebensolchem religiösem Pathos bedacht wird wie der Mensch. Am Ende der "Darlegung der Tatsachen" nach der schmerzhaften Schilderung des erdrückend engen und bösartigen Milieus im Haushalt des Großvaters (mescanstvo) klingt es wie die Formulierung einer Hoffnung, wenn Gor'kij schreibt:

Ich verneige mich vor der Vernunft, denn für sie gibt es nichts Heiliges, weil sie selbst das Heiligste und Gott selbst ist ${ }^{312}$ ).

Das Motiv von der Göttlichkeit der Vernunft war uns im Verlauf der Analyse immer wieder begegnet. Inre Beschwörung gerade im oben zitierten zusammenhang berechtigt zu der Annahme, daß ihr religiöses Pathos ebenfalls wie das des Menschen seine Wurzeln unter anderem in Gor'kijs eigener Biographie hat.

Erklang der Ruf nach der Vernunft zunächst nur aus einem mehr oder weniger undeutlichen Mangelerlebnis heraus ("O cize.."), so wandelte er sich allmählich zur Forderung nach einer vernünftigen "Ordnung" ("Konovalov") und mündete schließlich in die Überzeugung, daß der Wissenschaftliche Sozialismus eben diese Ordnung darstelle (EnquêtenText).

c) Der neue Mensch, eine Synthese aus Gefühl und Vernunft $=$ Gott

Es war zu beobachten, daß sich das übergewicht der emotionalen Seite (Pathos des Menschen) zugleich mit der 
Suche nach der synthese allmählich auf die Selte der Vernunft verlagerte ("Citatel'", "Celovek"), daß dann aber schon in "Celovek" am Ende visionär angedeutet - die ganze religiöse Kraft sich in der Hoffnung auf die Synthese von Vernunft und Gefihl in einem (neuen) Menschen konzentrierte (Enquête). Erst dieser Mensch der Synthese ist wirklich "göttlich" ("Celovek") 312).

In dieser letzten Phase, dem Gotterbauertum (Gott 'bauen' bedeutet also, die synthese herstellen), findet schließlich auch der Kollektivgedanke seinen endgültigen Platz. Er war zu Anfang nur dunkel angedeutet in Wendungen wie "Achtung vor dem Menschen", "Llebe zum Menschen" oder in Figuren wie Danko.

Man kann also mit Lunacarskij sagen, daß Gor'kij im Gotterbauertum letztendlich den Weg vom "Ich" zum "groBen Ich", zum "Wir" gefunden hat 314 ).

Das Erreichen der Synthese erlaubt es schlieblich auch der Literatur, nicht mehr sich mit dem Schaffen eines "erhebenden Trugs" zu bescheiden; die Synthese mit der 'vernüftigen Ordnung', konkret dem Wissenschaftlichen Sozialismus, gewăhrleistet vielmenr die Basis für die Schöpfung wirklicher Ideale, das heibt für das Finden von 'Entwüfen', die zwar die wirklichkeit transzendieren, zugleich aber den Ansatz für ihre Realisierung in der Wirklichkeit haben. (Dies weist auf die Konzeption des Sozialistischen Realismus.)

Betrachten wir dieses Ergebnis und wenden wir uns unserem Ausgangspunkt und der Frage nach Lunacarskif als Lehrer Gor'kijs zu, so ist für diesen Zeitpunkt (1906/07) die Antwort eindeutig: 
Das Gotterbauertum Gor'kijs 1st Ergebnis einer eigenständigen Entwicklung, die völlig unabhängig von Einflüssen durch Lunacarskij verlaufen ist ${ }^{315)}$. Daran können auch die frappierenden übereinstimmungen, die oben festgestellt wurden, nichts ändern.

Lunacarskifs Ausgangspunkt bildet das Erlebnis oder die Erkenntnis eines Mangels am orthodoxen Marxismus, die lähmende Wirkung eines Vernunftsmonismus. Lunacarskij mußte zeigen, daß das "religiöse Wesen" (für ihn gleichbedeutend mit dem emotionalen) im Sozialismus aufgehoben sei, daß hier eine synthese von Vernunft und Gefühl gegeben sei, die religiöse Qualität hat.

Gor'kijs Ausgangspunkt liegt auf der entgegengesetzten seite. Er mußte sehen, $d a ß$ ein bloß emotional fundiertes Menschenpathos, eine Liebe zum Menschen ohne die Absicherung durch eine 'vernünftige Ordnung' zum Scheitern verurteilt war. Insofern bot inm die Aufhebung seines emotionalen Ausgangspunktes im Wissenschaftlichen Sozialismus, die Synthese, die Möglichkeit, das religiöse Pathos des Menschen beizubehalten und gleichzeitig von der 'romanischen' (der vernünftigen Ordnung) zuzuordnen, wobel zu sehen war, daß auch der Vernunft immer göttliche Qualität zukam.

Der hier zu konstatierende Tatbestand ist also der, daß Lunacarskij und Gor'kij aus entgegengesetzter Richtung und somit auf verschiedenen Wegen zum Bogostroitel'stvo gekommen sind. Erst 1907 war der Boden für eine nun beginnende zusammenarbeit (Capri) bereitet - und das Bogostroitel'stvo hatte noch eine zeit der gemeinsamen Entfaltung vor $\operatorname{sich}^{316)}$. 
Diese weitere Entwicklung soll hier nicht verfolgt werden. Nur soviel sei bemerkt, daß in den Aufsätzen, die Gor'kif während der Zusammenarbeit mit Lunacarskif (und Bogdanov) schrieb, deren Einfluß, von dem vor allem in der sowjetischen Literaturwissenschaft gesprochen wird, nachzuweisen ist, was nicht weiter verwundern kann ${ }^{317)}$. Allerdings bringen die Jahre der Zusammenarbeit mit der Capri-Gruppe nichts qualitativ Neues in das Gotterbauertum Gor'kijs ein.

Es ist deshalb sinnvoller, sich noch elnmal dem belletristischen Werk Gor'kijs zuzuwenden und der erzählerischen Entfaltung seines Bogostroitel'stvo nachzugehen. 
Anmerkungen

1) Vgl. Mercure de France, März 1907, S. 594.

2) Dieser methodische Zugang umgeht m.E. auch eine Schwierlgkeit, die sich notwendig erglbt, wenn man Elnzeluntersuchungen zu Gor'kif anstelit z.B. Gor'kif und Nietzsche -; solche Elnzelbetrachtungen müssen Gor'kij als elnen eklektischen Leser und Verwerter zeigen, und man kann belsplelsweise zu dem Ergebnis kommen, daß er Nietzsche nicht oder nur halb verstanden hat. Mit solcher Erkenntnis 1st jedoch für das Verständnis Gor'kljs nichts gewonnen. In seiner 11 terarischen Arbeit hat Gor'klj ein ziel vor Augen, dem er konsequent zustrebt; und nur unter dem Blickwinkel der suche nach diesem Zlel erhält die Geschichte der verschiedenen 'Elnflüsse', denen Gor'kif unterlegen sein mag, inren Erkenntniswert.

3) PSS, 6, S. 460 .

4) A. Ovčarenko, Publicistika M. Gor'kogo. Moskau 1965 , S. 148.

5) PSS, 6, S. 462

6) PSS, 6, S. 35; sowe1t die von mir benutzten Texte In der dtv-Taschenbuchausgabe veröffentlicht sind, benutze ich die dort vorgelegten übersetzungen. R.S.

7) ebd., s. 36 .

8) ebd., S. 35 .

9) Vgl. das Ideal bel Lunaxarskif (S. 90ff).

10) PSS, 6, S. 35 .

11) ebd., S. 41 .

12) Ursprünglich lautete der Titel des Textes "O Celoveke 1 mescanine" (PSS,6, S. 461), woraus die Antithese "Mensch" - mestanin deutlich hervorgeht. 
13) ebd., S. 40.

14) ebd., S. 42 u. pass.

15) ebd., S. 40.

16) Mercure de France, a.a.0., s. 594.

17) PSS, 6, S. 35 .

18) ebd., S. 40.

19) Vgl. Mercure de France a.a.0., S. 593; das "religiöse Gefühl" basiert auf der "Harmonie" mit dem Kosmos.

20) PSS, 6, S. $40 \mathrm{O}$.

21) ebd., S. 41 .

22) ebd.; vgl. Lunatarskij (s. 131).

23) ebd., S. 42 .

24) ebd., S. 40.

25) H. Imendörffer, Nachwort zu: Maxim Gork1, Der Vagabund und andere Erzählungen. (dtv), München 1979, S. 710 .

26) PSS, 6, S. 41 .

27) ebd., S. 36 .

28) ebd.

29) ebd.

30) ebd.

31) ebd.

32) ebd.

33) ebd.

34) ebd.,s. 38 .

35) ebd., s. 36 .

36) ebd., s. 38 .

37) ebd., S. 36 .

38) Vgl. V.G. Korolenko in seiner Rezension in "Russkoe bogatstvo" (1904), Nr. 8, otd. II, S. 131: "Der Biograph Gor'kijs wird ein Grundmotiv in "Celovek" vermerken müssen: Die Verherrlichung des Gedankens, und zwar einzig des 
Gedankens (gesp.), als Antrieb der Menschheit auf dem Weg 'voran und höher'". Korolenko trifft genau den Kern, wenn er feststellt, daß Gor'kij hier das alte Problem um das Primat von "Geist" und "Gefühl" wieder aufnimmt. Der "Gedanke" ist keineswegs, wie M. Nevedomskif in seiner Entgegnung an Korolenko behauptet, die "synthetische Arbeit unserer Erkenntnis." ("Mir bozif" (1904), Nr. 10, otd. II, S. 138).

39) PSS, 6, S. 35 .

40) ebd., S. 38 .

41) ebd., S. 39.

42) ebd., S. 38 .

43) ebd., S. 39.

44) ebd., S. 38 .

45) ebd., S. 40.

46) ebd., S. 41 .

47) ebd., S. 41 Unterstr. v. mir.

48) ebd., S. 41 .

49) ebd.

50) ebd., S. 35 .

51) ebd., S. 41 .

52) ebd.

53) ebd.

54) Vgl. H. Imendörffer, Vorwort a.a.0. S. 711.

55) Archiv Gor'kogo, VIII, S. 231.

56) ebd.

57) PSS, 6, S. 42. Unterstr. v. mir.

58) Mercure de France a.a.0.

59) Die Aufnahme durch die zeltgenössische Kritik zeigt, daß es genau in dieser Appelifunktion als Aufruf zur Revolution - gelesen wurde. Vgl. PSS, 6, S. 461 .

60) Vgl. Korolenko Anm. 38). 
61) Zur Rezeptionsgeschichte: Diese wird hier für diesen wie für die folgenden Texte kaum berücksichtigt, da es uns nicht darum gehen kann, den verschiedenen konkurrierenden Thesen $\mathrm{zu}$ Gor'kljs werken noch eine weltere hinzuzufügen, sondern nach genauer Lektüre der Texte Bezüge und Entwicklungen im Werk (von 1892 bis 1909) aufzuzeigen und zu verfolgen - sowelt sie unsere Fragestellung (die Formierung des Bogostroitel'stvol berühren.

62) PSS, 6, S. 461 .

63) Archiv Gor'kogo, VIII, S. $230 / 31$.

64) S.S. $170 \mathrm{f}$.

65) Vgl. auch Bjalik, Revolution und Kunst, S. 129.

66) Die Tatsache, daß Gor'kif Drama und Poem in solche Nähe zuelnander rückt, ist bedeutsam auch für sein Verhältnis zu Nietzsche. Von Satin distanziert sich Gor'kif in späteren Jahren (1930/31) wegen seines "anarchischen Nietzscheanertums" (Besedy o remesle. In: M. Gor'kij, 0 11terature. Moskau 1955, S. 492f); zu seinem Poem, welches genau Satins Gedanken entfaltet, steht er nach wie vor. (Vgl. V.I. Lenín i M. Gor'kij. Pis'ma, vospominanija 1 dokumenty. Moskau 1969, S. 355). Näheres Kap. V, 7 .

67) PSS, 7, S. 173.

68) ebd.

69) ebd., S. 174 .

70) ebd.

71) ebd.

72) ebd., S. $172-178$.

73) ebd., s. 177.

74) ebd., Unterstr. v. mir.

75) ebd. S. 178. 
76) ebd.

77) Er sammelt das Abgelebte, Unwerte in seinen Lumpensack. S.0.S. 168.

78) PSS, 7, S. 175

79) ebd., S. 177, Unterstr. v. mir.

80) "Der Mensch zahlt für alles selber." - "Der Mensch steht über dem Sattwerden." ebd.

81) ebd.

82) Es ist daher falsch, Gor'kif auf eine der beiden Figuren festlegen zu wollen, wle z.B. Bjalik (Revolution und Kunst. S. 132), der Luka mit Gor'kifs Gotterbauertum identifiziert. Vgl. a. Kluge (Vom krit. z. soz. Realismus), S. 160; Rühle, Das gefesselte Theater, S. 14 usw. Orientiert an den beiden scheinbar antithetischen Figuren hält sich die Literaturwissenschaft bel der Bestimmung des (phllosophischen) Themas von "Na dne" vorrangig an die Alternative "Wahrhelt oder Lüge". Z.B.: Kluge, a.a.0. S. 158; N. Ludwig, Maxim Gork1. Berlin 1977, S. $88 \mathrm{ff}$; S.J. Juzovsk1\}, "Na dne" Gor'kogo. Moskau 1968, S. loff; A.V. Lunacarskif, Literaturnye siluety. Moskau-Leningrad 1925, S. 142.

Wenn Gor'klf in elnem Interview von 1903 (PSS, 7, S. 617f) und später 1 mmer wieder behauptet, es sel $1 \mathrm{hm}$ um die Gestaltung dieses Themas gegangen, so 1st $1 \mathrm{hm}$ das stück tatsächlich miBlungen, sofern sich nämlich hier keine Antithese ergibt, sondern eine Synthese gesucht wird.

83) PSS, 7, S. 173.

84) ebd., S. $174,177$.

85) ebd., S. 171 .

86) s.0. S. 169 .

87) Das bestatigt Gor'kif noch 1928 bel aller Distanzlerung von Luka: "Aber aus den Tröstungen 
des schlauen Luka zog Satin seinen Schluß vom Wert jedes Menschen." (G'-30, 24, S. 357f).

88) PSS, 7, S. $173 / 74$.

89) Amoralismus als Freihelt von den als falsch und verlogen erkannten kleinbürgerlichen werten. Auch im Nietzscheschen Sinne.

90) Nur so kann "Na dne" als "Gor"kifs Glaubensbekenntnis" gelesen werden. (B.D. Wolfe, Brücke und Abgrund. Wien, Frf., Zürich 1970, S. 67); und man kann nicht, wie Borras (Gorky the writer. Oxford 1967, S. 170), von el nem "Grundkonflikt" Luka - Satin sprechen. Ebenso falsch ist die Behauptung, Satin "entlarve" Luka. (P.I. Sumarev, A.M. Gor'kij o religil. Moskau 1960, S. 23.)

91) PSS, 7, S. 177.

92) Luka kann also weder einfach als der "Typus des Tolstojaners" (Rühle, a.a.0. S. 13) noch als "Sprachrohr Gor'kijs" (B.D. Wolfe, a.a.O. S. 64) klassifiziert werden. Was Gor'kifs elgene Einstellung betrifft, so fallt die Elnmütigkelt auf, mit der in Berichten von ersten Lesungen des stückes im Freundeskreis von Gor'kijs Begeisterung für die Figur des Luka gesprochen wird. Das steht in gewissem Gegensatz zu Gor'kijs späteren Äußerungen über Luka, die vielleicht auch als Reaktion auf die Rezeption des Stückes zu werten sind. Gor'kif sagte sich sehr schnell von einem zunächst geliebten KInd los, wenn die erwartete positive Reaktion ausblieb. (Z.B. "Ispoved" ) (Vgl. M.F. Andreeva, Perepiska, Vospominanija, Stat'1, Dokumenty. Moskau 1968, S. 47; N. Telesov, Zaplski Pisatelja. Moskau 1952, S. lolf.; Archiv A.M. Gor'kogo, Mo 9-2-14 (21t. In: PSS, 7, S. 611). 93) S.O. S. $90 \mathrm{f.}$ 
94) Diese Behauptung wird sich im weiteren Rückgang erhärten lassen: "Cltatel"", "Casy".

95) Die Geschichte von der Trinkerhellanstalt und des Schausplelers Glauben daran bewlrken elne wenn auch nur vorübergehende - Veränderung. PSS, 7, S. 163.

96) ebd., S. 162.

97) ebd., S. 157.

98) ebd., S. 140.

99) Daß diese 'Wahrheit' Satins zugleich Gor'kifs Absage an die Lehre Tolstojs (kein gewaltsamer Widerstand gegen das Böse) und Dostoevskijs (statt Stolz: Demut, Reue, Leiden) darstellt, sel hier nur am Rande vermerkt. (S. Kluge, a.a.0., S. 162).

100) Dies 1st das "philosophische' Thema von "Na dne", und nicht etwa das Verhältnis zwischen Mensch und Gott, wie B.D. Wolfe (a.a.0., S. 68) behauptet.

Vgl. dazu auch R. Hare (Maxim Gorky. Romant1C Realist and Conservative Revolutionary. London 1962, S. 56), der "Na dne" als "ambitioniertesten Versuch" Gor'kifs bezelchnet, "elne kohärente Philosophie der Tat (Unterstr. v. mir) aus dem abgedroschenen Vagabunden-Thema" abzuleiten.

101) PSS, 4, S. 571 .

102) Archiv Gor'kogo, V.S. 13.

103) Vgl. Borras, a.a.0., S. $47 f$.

104) PSS, 4, S. 116.

105) ebd., S. 115f.

106) ebd., S. 121.

107) ebd., S. 119.

108) ebd.

109) ebd., S. 120; Unterstr. v. mir.

110) Dazu schreibt Gor'kif (G'-30, 28, S. 38): "ICh welB - der Schriftstelier muB ein Prophet sein 
und sogar der Isalas unter den Propheten, - ich bin zu klein für dlese Rolle." Vgl. Puskin, "Prorok".

111) PSS, 4, S. 121 .

112) ebd., S. 122 .

113) ebd.

114) vgl. O. "Celovek", S. 170.

115) PSS, 4, S. 123.

116) ebd., S. 121 .

117) ebd., S. 122 .

118) ebd., S. 121; der Begriff "nas vozvysajuscij obman" wurde von Puskin für die Definition der ästhetischen Rezeption gebraucht. In der deutschen Romantik ist der "schöne Trug" elne "genuine Erkenntnisform und reale Kraft", die nicht dasselbe bedeutet wie der Begriff der Aufklärung. "Puskin definierte eben deswegen 'obman' enger, als poetische Illusion, mit den worten 'nas vozvysajiuscij obman"". D. Cizevskij, On.

Romanticism in Slavic Literatures. 's Gravenhage 1957, S. 31. Vgl. a. drs., Puskin und die Romantik. In: Slavische Rundschau (1937), 2, S. $69-80$.

119) PSS, 4, S. 123.

120) ebd., S. 119.

121) Gor'kij operiert offensichtlich mit zwei wahrheltsbegriffen: einem, der die 'Wahrheit' mit der Realität, bzw. dem inr entsprechenden gleichsetzt - und einem 'antizipatorischen', der die Realitat sich angleicht.

122) ebd., S. 123.

123) ebd., S. 125.

124) ebd.

125) ebd.

126) ebd.; gemeint ist mit den Menschen ohne Ideal das mescanstro. vgl. "Celovek".

127) S.O.S. $163 f f$. 
128) PSS, 4, S. 121.

129) ebd., S. 120; Unterstr. v. mir.

130) ebd., S. 125.

131) ebd., S. 119 .

132) ebd., S. 125.

133) ebd.

134) G'-30, 28, S. 38 u. 248 .

135) Elne Passage über Gott fällt weg. (PSS, Varlanty, 1, S. 387).

136) Kluge, a.a.0. S. 148.

137) Zur Wandlung der Bosjakenfiguren, wie sle sich In "Konovalov" abzelchnet und in "Na dne" endgültig vollzogen ist, schrelbt $L$. Andreev an N.K. Michajlovskij:

"Gor'kif nimmt immer noch seine gleichen Bosjaken und gewesenen Leute, aber es ist etwas völlig Neues in der stark veränderten und, lch würde sagen, aufgeklärten Sicht des Autors. Aus dem Romantiker, mit der ganzen unbewußten, obglelch schönen Lüge der Romantik, hat er sich gleichsam in elnen Philosophen verwandelt, der beharrlich und qualvoll den Sinn des Daseins sucht." (Literaturnoe nasledstvo, t.72, S. 495f.) Vgl. a. Kluge a.a.0. S. 157 .

138) PSS, 3, S. 25.

139) Gemeint ist der Marxismus, in der (orthodoxen) Ausprägung, wie inn Gor'klj vermutlich während seiner Kazaner Zelt, U.a. in der Blbllothek A.3. Derenkovs (PSS, 3, S. 542) kennengelernt hat.

140) Vgl. Gor'kif über sich selbst zur Kazaner zelt G'-30, 13, S. 540 .

141) PSS, 3, S. 43.

142) ebd., S. 24.

143) ebd., s. 43.

144) ebd., S. 25. 
145) ebd., S. 24.

146) ebd., s. 31 .

147) ebd.

148) ebd., S. 56.

149) ebd., S. 41.

150) ebd., S. 43 .

151) ebd.

152) ebd.; Unterstr. v. mir.

153) ebd.

154) ebd., S. 45; Unterstr. v. mir.

155) Man kann also nicht wie Hare (a.a.0., S. 61) erst in "Na dne" den Wechsel von den energischen, wlllenstarken Menschen der frühen Erzählungen zu elner "Verteldigung der schwachen und gebrochenen Individuen" vollzogen sehen. Konovalov ist solch ein "schwaches und gebrochenes Individuum". vgl. Anm. 137).

156) PSS, 3, S. 43.

157) Der Sozlalismus als eine vernunftige Organisationsweise für elne neue Gesellschaft ist hier noch nicht voll akzeptiert.

158) Konovalov wird bel der Lekture der Geschichte Stenka Razins "wie neu geboren" (Ideal!) PSS, 3, S. 27 .

159) PSS, 3, S. 457; Unterstr. v. mir.

160) ebd.

161) ebd.

162) ebd.

163) ebd., S. 458 .

164) ebd.

165) ebd.

166) ebd.; Unterstr. v. mir.

167) ebd.

168) ebd. 
169) ebd.; vgl. "Celovek"!

170) ebd., S. 459.

171) ebd.

172) ebd.

173) ebd.

174) ebd.

175) vgl. "Celovek".

176) PSS, 3, S. 459.

177) ebd., S. $459 f$.

178) ebd., S. 459; vgl. PSS, 7, S. $140,157$.

179) Vgl. In "Čelovek" den "Mensch" und In "Čltatel"" die "Meister des Wortes".

180) PSS, 3, S. 460.

181) ebd.

182) ebd.

183) Vgl. R. Dithmar, Die Fabel. Geschichte, Struktur, Didakt1k. Paderborn 1971, S. 131 .

184) ebd., S. 116.

185) Vgl. Dithmar, a.a.0., S. $143 f f$.

186) Dithmar a.a.0., S. 125.

187) S.0. Anm. 18).

188) PSS, 1, S. 46.

189) Die Wandlung dieses romantischen Erbes zur späteren Literaturtheorle und -praxis Gor'kijs läßt slch nachvollzlehen an der wandlung des Begriffes vom "erhebenden Trug" zum späteren "Ideal" In der Zelt des Bogostroltel'stvo und noch später im Sozlalistischen Realismus.

190) ebd., S. 47.

191) ebd., S. 47; 50.

192) ebd., S. 49.

193) ebd., S. 47.

194) ebd., S. 50 .

195) Nletzsche, II, 198.

196) PSS, 1, S. 50; vgl. O. Lunacarsk1f S. 108. 
197) PSS, 1, S. 50.

198) ebd.

199) ebd., S. 51 .

200) ebd.

201) ebd., S. 52; vgl. a. "Cltatel"" und "Na dne"!

202) ebd., S. $51 \mathrm{f}$.

203) ebd., S. 52.

204) Nietzsche, II, 279 (3).

205) Vgl. a. Borras, a.a.0., s. 35f, der im specht den Verkünder der "Wahrhelt der Fakten" und Im Zeisig den Propheten der "Wahrheit des Geistes" sieht.

206) PSS, 1, S. 52 .

207) ebd.

208) Vgl. Konovalov.

209) PSS, 1, S. 53.

210) Vgl. ebenfalls Konovalov.

211) Gor'k1j, Zametk1 o mescanstve, dt. S. 16.

212) PSS, 1, S. 53.

213) B.D. Wolfe. a.a.O., S. 87 sleht einen Zusammenhang 2 wischen diesem Pathos und dem "erhebenden Trug": "Der Kult vom Menschen, der sich selbst zum allmächtlgen, allwissenden, allumf assenden Gott gemacht hat,...., ist solch eine hellsame Lüge: Vielleicht kann der Mensch sie zur Wahrheit werden lassen, wenn er an sle glaubt und danach handelt. Dies ist Gorkis persönliche Lesart der Utople."

214) PSS, 1, S. 519; Nietzsche, I, 209ff.

215) Vgl. G. Mayer, Der Junge Gor'kif. Heldelberger Dissertation 1960, S. $44 f$.

216) G. Lukacz, Marx und das Problem des 1deologischen Verfalls. In: "Elnhelt", H.2, S. 46, Z1t. n.W. Lang, Gork1 und Nietzsche. In: Horlzont, 2 (1947), H.17, S. 18 . 
217) Vgl. H. Imendörffer, Nachwort zu Gork1, Konovalov und andere Erzählungen. München 1978 ( = dtv Dünndruck) S. 736; Bjal1k, Sud'ba Gor'kogo. Moskau 1968, S. $63 \mathrm{ff}$.

218) Henri Lichtenbergers, La Philosophie de Nietzsche. russ. SPb 1901.

219) ebd. S. Cxx.

220) Russkoe bogatstvo, 5 (1903), S. 24 - 68 .

221) A.V. Lunacarsk1j. "Dacnik1". In: drs., O Gor'kom. Moskau 1975, S. 2 of U. pass. (Der Aufsatz erschien zum ersten Mal 1905).

222) drs., Mescanstvo 1 Individualizm, S. 300; Religija 1 sociallzm, t. 2, S. 357; 365 u. pass.

223) "Wlener Abendpost", 1901, Nr. 151, 5.7., S. 1 - 3.

224) ebd., S. 1 .

225) ebd.

226) ebd.

227) ebd., S. 2 .

228) ebd.

229) J.E. Poritzky, Heine, Dostoevsk1\}, Gork1. Leipzig 1902 .

230) ebd., S. 100 .

231) ebd., S. 106 .

232) H. Lehbert, M. Gork1. Stuttgart 1905.

233) ebd., S. 56.

234) J. Rühle, Das gefesselte Theater. Köln-Berlin 1957.

235) ebd., S. 15 .

236) ebd.

237) ebd., S. 16 .

238) ebd., S. $18 f$.

239) Slehe die Bestandsaufnahme bel G. Mayer, a.a.0., S. $45 f$.

240) Differenzlertere Betrachtungen liefert vor allem G. Kline (s. Literaturverzeichnis). 
241) S. Anm. 3),

242) Kluge, a.a.0., s. 6.

243) Kluge, a.a.0., s. 148.

244) ebd.

245) Vgl. Lehbert, a.a.0., S. 35; 38. R. Hare, a.a.0. 25.

246) Richard D. Davies, Nietzsche in Russia, 1892 - 1917 :

A Preliminary Bibliography, Part 1. In: GermanoSlavica $(1976 / 77)$, Vol. II, Nr. 2,3, Nr. 2. S. 117 .

247) G'-3o, 23, S. 197.

248) dt.: Dle Zerstörung der Persönlichkelt. In: M. Gork1, Über Literatur. Berlin-weimar 1968, S. $29-86$.

249) ebd., S. 65.

250) ebd.

251) Nietzsche in Russia, p. 1, S. 111.

252) ebd.

253) Voprosy filosofil 1 Psichologil, 15 (1892), S. $115-160$.

254) ebd., S. $121 \mathrm{f}$.

255) PSS, 1, S. $217-227$.

256) PSS, 1, S. 227.

257) Preobrazensk1j, a.a.0., S. $127 f f$.

258) Vgl. "Na dne", Satin.

259) Preobrażenskif, a.a.0., S. 132; vgl.Gor'k1j, Zametki o mescanstve (dt. S. $21 \mathrm{ff}$ ).

260) s.o. S. $189 f f$.

261) Preobrazensk1f, a.a.0., S. $142 f$.

262) Vgl. "Celovek".

263) Preobrazenskif, a.a.0., S. 144.

264) ebd.

265) ebd.

266) PSS, 3, S. 25.

267) Preobrazenskif, a.a.0., S. 145.

268) ebd., S. 146.

269) dt.: Der Kleinbürger und die Revolution. Köln 1973.

270) ebd., S. 16; Unterstr. v. mir. 
271) Preobrazenskij, a.a.0., S. 148 .

272) ebd., S. $148 f$.

273) ebd. 21t. S. 150; Nietzsche.

274) S.O. S. $192 f f$.

275) PSS, 6, S. 41.

276) Vgl. O. S. $43 \mathrm{ff}$.

277) Preobrazenskif, a.a.0., S. 157; Vgl. a.0. Lunacarsk1j.

278) S.u. Anm. 67).

279) In: M. Gor'kij, O Literature. Moskau 1955.

280) ebd., S. 490 .

281) ebd., S. 491; Unterstr. v. mir.

Eine Nietzsche-Übersetzung von Vasil'ev ist nicht bekannt. Wohl aber übersetzte er 1889 das Vorwort von Peter Gast zu "Zarathustra" . (Nietzsche in Russia, 1, S. 118; 125). 2u den Bezlehungen zwischen Gor'kij und Vasil'ev vgl. welter "O vrede fllosofil" (G'-30, 15, S. 52 - 63); Letopis zizni 1 tvorcestva Gor'kogo. Vyp. I. Moskau 1958, S. 74; 199. Die erste russische übersetzung des "Zarathustra" erschien von Ju. M. Antonovskif 1898. (Nietzsche in Russia, 1, S. 117 ).

282) Rühle, a.a.o.

283) ebd., S. $15 f$.

284) M. Gor'kij, o literature. S. 492.

285) ebd., S. 493.

286) M. Gor'k1j, Zametki o mescanstve. dt. S. 15. 287) s. das 21tat Anm. 56).

288) Vgl. Rühle a.a.0. Von dem autorltätsgläugigen Autodidakten war wohl auch kaum zu erwarten, daß er seine Faszination von Nietzsche gegen die offizielle Lehrmeinung verteldigt hätte.

289) S.0. Anm. 71). 
290) G. Mayer, a.a.0., S. 47 bestät1gt dieses 'Verwertungsinteresse' Gor'kifs und meint, es gehe Ihm vielmehr um das symbol, das Bild.

291) Zur Fehldeutung des "übermensch"-Motivs vgl. B. Hillebrand, Einführung zu: Nietzsche und die deutsche Literatur, Bd. 1, Texte zur NietzscheRezeption 1973-1963. Tübingen 1978, S. 1 - 55. (v.a. S. $9-14$ ).

292) "Makar Cudra", "Starucha Izergil"", "Moj sputnik", "Celkas", "Kajn 1 Artem" usw. Die Herkunft dieses Stärke-Motivs muß mit Sicherhelt z.T. aus Gor'kijs elgener Blographle erklärt werden. (Z.B. "Izlozenie faktov I dum...", PSS, 1, S. 451-467). Auch Hare (a.a.0., S. 25) sleht die Notwendigke1t, für die Erklärung der vordergründigen Affinität von Gor'kijs Bosjaken zum Nietzscheanertum dessen elgene Erfahrung mit der Umwelt in Betracht ziehen.

293) Danko, "Celovek", "Det1 solnca" (PSS, 7, S. 331), Vgl. R. Meincke, Maxim Gork1, seine Persönlichkelt und seine Schriften. Hamburg 1908, S. 95.

294) Nietzsche, II, S. 344.

295) ebd., II, S. 281.

296) ebd., II, S. 280.

297) ebd., II, S. 298.

298) Vgl. O. Kap. III.

299) Z.B. Gor'k1js, Lunatarkijs und Bogdanovs Schulprojekt auf Capri; bel Bogdanov später Proletkul't.

300) N1etzsche, I, S. 230.

301) ebd., S. 231 .

302) ebd.

303) "O C1ze, kotoryj lgal...", "Cltatel"", "Kak menja otbril1" usw. Diesen Zusammenhang zwischen Gor'k1f und Nietzsche sieht auch Lehbert (a.a.0., S. $44 \mathrm{f} ; 48)$, bewertet inn aber negativ: das 
"ewige Hineinspielen Nietzschescher Reflexionen" störe die "künstlerische wirkung von Gor'kljs Erzählungen allzu oft" •

304) R. Meincke (a.a.0., S. 108) bezelchnet insofern Gor'kij zurecht als "Lebensphilosophen". Zur Bedeutung Nletzsches als Philosophen des Lebens am Ende des letzten Jahrhunderts schrelbt $H$. Rickert (Die Philosophie des Lebens. Tübingen 1922, S. 19):

"Vor allem wird Nietzsche wichtig, weil er mit seiner ungewöhnlichen sprachgewalt mehr als irgendein anderer dem Wort 'Leben' erst den Glanz verliehen hat, der bis heute an inm haftet. (...) Die Lebensstimmung der zeit ist am meisten durch Nietzsches "Also sprach Zarathustra" angeregt. In $1 \mathrm{hm}$ wird das Leben behandelt wie eln menschliches Lebewesen, genauer wie eine zärtlich geliebte Frau...".

305) Gor'kljs (subtilere) Nietzsche-Rezeption läuft also der am Ende des 19. Jahrhunderts in RuBland gängigen entgegen, von der Borras (a.a.0., S. 16) sagt, Nietzsches EInfluß ließ den "Kult des Individualismus" im Mittelstand der achtziger Jahre neu erstarken. Gor'kij wendet 'seinen' Nietzsche gegen den reziplerten. Rühle (a.a.0., S. 18): "Gor'kif hatte seine elgene Art, die Thesen Nietzsches ins Sozlale und Revolutionäre umzudenken".

306) S. den Enquêten-Text.

307) Vgl. Borras, a.a.0., S. 82.

308) "Izlozenie faktov 1 dum..." (PSS, 1, S. 451ff); "Blografija" (PSS, 1, S. 468ff).

309) Shekina 1st ein Begriff aus der jüdischen Theologie, die es bekanntlich vermeidet, den 
Namen Gottes zu nennen, und dafür Umschreibungen beispielsweise seines Erscheinens oder Wirkens gebraucht. Shekina bedeutet "Einwohnung Gottes", d.h. den Ort, wo Gott slch offenbart. Hier also der Mensch als die Erschelnungsweise Gottes.

310) PSS, 2, S. 544 .

311) ebd., S. 545; Unterstr. v. mir.

312) PSS, 1, S. 467.

313) Vgl. a. Kaleps, Gor'kifs Glaube und seine verschiedenen Konflikte mit der Umwelt. Heldelberger Dissertation 1963, S. 34 .

314) S.0., S.124f.

315) Insofern sleht B.D. Wolfe richtig, daß Gor'kif seine grundlegenden Ideen in selnen Wanderjahren entwickelt und bis zum Ende durchgehalten habe (a.a.0., S. 4lff); ebenso Kaleps (a.a.0., S. 37), der lediglich elne Affinität von Gor'kifs Bogostroltel'stvo mit Bogdanovs und Lunacarskifs Ideen konstatiert, aber kelne Abhänglgkelt konstruiert.

316) Spätestens jetzt ist es allerdings nicht mehr sinnvoll, von einer Gruppe der "Bogostrolteli" oder von dem Bogostroltel'stvo als einer gemeinsamen Entwicklung Gor'kijs, Bogdanovs und Lunacarskifs zu sprechen.

317) "O cinizme", "Razrusenie licnost1". 
VI. "Mat", "Ispoved" "und "Leto" als erzählerische Ausformungen von Gor'kijs Gotterbauertum

1. "Mat""

Nur der niederträchtige wunsch der Bourgeolsie, die Frau in Unwissenheit und Vorurteilen $2 u$ halten und die verurtellungswürdige Gleichgültigkeit der Proletarier gegenüber der Gestalt der Gedanken Ihrer Frauen geben dem Klerus die Möglichkelt, die weibliche Seele in seinen Klaven zu halten, die nach Poesie dürstet, die aber bereit ist, sich welt $z u$ öffnen für die neue Religion ${ }^{1)}$.

Ob Lunatarskij bel der Formulierung dieser sätze über die Frau als "religiöse Potenz" 2 l an Gor'kijs Roman dachte, der dann später zum Prototyp des sozialistisch-realistischen Romans kanonisiert wurde, läßt sich nicht feststellen $^{3)}$. Aber eben die Befreiung einer Frau aus Unwissenheit und (religiösen) Vorurtellen, sowle ihre Bereitschaft, sich der "neven Religion" zu öffnen, geben das Thema für Gor'kijs Roman "Die Mutter" ab.

Wäre nicht der zeltliche Abstand zwischen der Entstehung des Romans und der Abfassung von Lunacarskijs 'gottbildnerischen' Schriften, bzw. dem Beginn der Zusammenarbeit der beiden auf Capri, so könnte man vermuten, daß Gor'kij hier die erzählerische Probe auf Lunacarskijs Exempel machte.

War schon die Übereinstimmung zwischen Gor'kijs theoretischen gottbildnerischen Äußerungen (Enquête) und LunaCarskijs Religions-Philosophie so groß, daß sie AnlaB zu der gängigen Meinung gab, letzterer habe Gor'kij beeinflußt, so wird diese übereinstimmung noch frappierender, 
wenn man Gor'kijs meistgelesenen und -diskutierten Roman ${ }^{4)}$ unter dem Blickwinkel des Bogostroltel'stvo liest.

Es kann hier nicht der Ort sein, Entstehungsgeschichte, Komposition, struktur, Forschungsgeschichte usw. des Romans (erneut) zu diskutieren ${ }^{5)}$. Die hier gewainlte Fragestellung ist bewußt eng gehalten und einzig auf das Problem des Gotterbauertums, bzw. selne narrative Besetzung im Roman "Mat" konzentriert. (Diese Elnschränkung g1lt auch für "Ispoved" und "Leto".)

Die Entstehungsgeschichte des Romans fällt (...) in eine zeit, in der Gor'kij, von den politischen Ereignissen in sinem Lande zutiefst erschütert, zum aktiven Verfechter des Leninschen revolutionären Marxismus geworden war ${ }^{6}$.

Sie fällt damit aber auch in eine Zeit, in der Gor'kif endgültig zur synthese seines religiösen Gedankens gekommen war, nämlich zur Aufhebung der menschlichen Emotionalität in elner 'vernünftig' organisierten Geselischaftsform - dem Wissenschaftlichen Sozialismus. Seine Antwort auf die Umfrage des Mercure de France erschien Im März 1907 , im Jun1 desselben Jahres wurde - nach der englischen übersetzung - das russische Original von "Mat"" In Berlin veröffentilcht.

Es ist also durchaus möglich, daß das, was wir als Gor'kifs eigene Ausprägung des Gotterbauertums kennengelernt haben, in diesem Roman selnen Nlederschlag findet, wenn nicht gar Thema wird.

Pelageja Nilovna, "perspekt1visches Zentrum des ganzen Romans" "), und in dieser Funktion zugleich die einzige F1gur, die eine 1deell und psychologisch motivierte Entwicklung durchmacht, hat am Beginn des zweiten Romante1ls einen Traum: 
Sle träumte von dem gelben Sandhügel hinter dem Sumpf, auf dem Weg zur Stadt. An seinem Rande, über dem abschüssigen Hang, der zu den Sandgruben führte, stand Pavel und sang mit Andre is Stimme leise und klangvoll: "Steh auf, erhebe dich, Arbeitervolk! "8)

Geht man davon aus, daß in diesem Roman auBer der Nilovna "dle übrigen Personen belnahe ausschließlich als Träger von Ideen charakterisiert sind"9), so läßt sich dieser Traum ohne weiteres als die (erwünschte oder zu diesem Zeitpunkt bereits erreichte) Zusammenschau zweier einander widerstreitender ideeller Positionen aus der Perspektive der Mutter deuten.

\section{a) Pavel Vlasov als Repräsentant der Vernunft}

Pavels Entwicklung vom unbewußten Arbeiter, dessen Leben in den traditionelien Bahnen verläuft ${ }^{10)}$, zum Revolutionär wird sehr gerafft und schematisch dargestellt: Unzufrieden mit seinem Leben zieht er sich von den "ausgetretenen Pfaden" zurück"1) und beginnt heimlich zu lesen. Mit der zunehmenden Blldung verändert sich sein Verhalten; er wird "sauberer", "elinfacher", "sanfter" und höflicher gegenüber der Mutter, kurz - die Berührung mit der kultur veredelt seinen Charakter. Am Ende dieser Entwicklung steht Pavels revolutionärer Entschluß, ein Programm, das sein symbol im Bild des auferstandenen unerkannten Christus mit den beiden Jüngern auf dem Weg nach Emmaus findet.

Der religlöse Konflikt, den Pavels Entschluß für die Mutter mit sich bringt, wird von inr sofort erfaßt, wenn sie denkt: "Du verehrst Christus, aber in die Kirche gehst du nicht" 12 ). 
Die Geschichte der Emmaus-P1lger (LK 24, 13-35) symbolisiert in der christlichen Tradition die Suche nach der

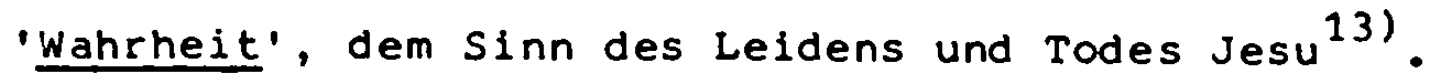

Eben diese (religiöse) Bedeutung hat es für die Mutter, daß Pavel das B1ld der Emmaus-Jünger nach Hause bringt. Von nun an wird es ihm darum gehen, zunächst der Mutter und dann den anderen Menschen "seine" Wahrheit zu erklären; und die Mutter wird versuchen, diese Wahrheit zu verstehen.

Dabei wird sich zeigen, daß dieser Wahrheitsbegriff pravda - für Pavel mehr die normativen Konnotationen von Recht und Gerechtigkeit, also von rational zu erfassenden und zu begründenden Größen, beinhaltet, währende die Nilovna dahinter den ethisch-religiösen Gehalt, die emotionalen Konnotationen also, suchen wird ${ }^{14}$ ).

Verweist schon der Werdegang Pavels bis zum Beginn seiner revolutionären Tätigkeit darauf, daß sein Zugang zum Wissenschaftlichen Sozialismus einzig auf der rationalen Ebene erfolgt, so wird dies im Romanverlauf immer mehr verdeutlicht, vornehmlich durch kontrastive Gegenüberste llung: Pavel - Rybin, Pavel - Nachodka, Pavel - Nilovna.

Sammelt man die Charakterisierungen, die er während der gesamten Romanhandlung von seiten der anderen Personen erfährt, so ergibt sich eine refrainartig wiederholte Kritik an Pavels mangelnder emotionaler Bildung.

Für die Mutter lebt er asketisch "wle ein Mönch"15). Sie sieht, daß man inn achtet oder gar füchtet, aber nicht liebt ${ }^{16)}$. Für Nachodkas Liebesproblem ${ }^{17}$ ) hat er kein verständnis und keine Zeit - er liest in einem Buch weiter, während jener noch sein Herz ausschüttet. Nach der ersten Hausdurchsuchung kritislert inn die Nilovna wegen seines 
kalten nüchternen willens, sich für die Sache der Revolution zu opfern, und wegen seiner Unfähigkeit, sie zu trösten.

Nach Pavels Scheitern in der Geschichte mit der Sumpfkopeke stellt Rybin lapidar fest: "Es (Pavels Rede) geht nicht zu Herzen"18).

Im Gespräch mit Andrej Nachodka, während Pavel noch im Gefängnis sitzt 19 ), bekennt die Mutter: "Ich liebe sie und vielleicht noch stärker als Pavel. Er ist so verschlossen"20). Und Nachodka charakterisiert inn als "eisernen Menschen"21).

Pavel muß sich sogar selbst das Zeugnis mangelnden Gefühls ausstelien, als es darum geht, Nachodka in seinen Nöten wegen des Mordes an Isaj2) zu helfen: "... Ich kann es wohl verstehen, aber nachfihlen kann ich es nicht" 23 ). Pavel wird immer deutlicher $z u$ einer Figur, die auf der emotionalen Ebene unzugänglich und unzulänglich bleibt, und nur ihrer Funktion als Führer des revolutionären Kreises lebt 24 ).

Diese 'psychologischen' Merkmale Pavels dienen allerdings lediglich dazu, die rein rational-argumentative Ausrichtung seines Pravda-Begriffes zu unterstreichen. Den Inhalt "seiner Wahrheit" faßt Pavel in der Gerichtsrede zusammen: Es ist dies die marxistische Analyse und Kritik an der bestehenden kapitalistischen Geselischaftsordnung, die Einsicht in die Notwendigkeit der proletarischen Revoltution und schließlich der Sozialismus als die neve, vernüntig und damit gerecht organisierte Gesellschaftsform ${ }^{25}$ ).

Pavels Glaube an die einzig erlösende Kraft der Vernunft wird thematisch in dem zentralen Kapitel I, 11, wo der Heizer Rybin inn nach seiner wahrheit befragt und das Gespräch auf das Problem der "Inneren" Erneuerung des Menschen bringt. 
Der religionskritische Tell dieses Gesprächs stellt elne narrative Ausführung der Religlonskritik Gor'kijs in seinem Enquêten-Text dar, entspricht aber auch den Vorstellungen Lunatarskijs zu diesem Thema. Pavels standpunkt ist eben der von Lunacarskij als mangel haft empfundene der orthodoxen Marxisten in Sachen Religion. Rybin faßt zusammen:

Also, deiner Melnung nach hat man uns sogar mit Gott betrogen? Gut. Ich denke auch, daß unsere Religion falsch ist 26 ).

Pavel präzisiert für die Mutter: er spreche von jenem Gott, mit dem uns die Popen wie mit einem stock drohen... von dem Gott, in dessen Namen man alle Menschen zwingen will, sich dem bösen willen elniger weniger zu unterwerfen ${ }^{27)}$.

Wie weit Rybins Ergänzungen und Erwiderungen den Einwänden Lunacarskijs gegen den religionskritischen standpunkt des orthodoxen Marxismus entsprechen, wird noch zu klären sein; für die Bestimmung von Pavels Standpunkt genügt hier, daB Rybin den Finger genau auf jene Schwachstelle legt, die Lunacarskif im Wissenschaftlichen Sozialismus ausgemacht hat. Auf Pavels Behauptung, elnzig die Vernunft werden den Menschen befreien ${ }^{28}$ ) erwidert er:

Die Vernunft gibt kelne Kraft. (...) Das Herz gibt Kraft - nicht der Kopf, so ist das ${ }^{29) \text { ! }}$

Für Rybin gleicht "Gott dem Feuer" (was immer hier unter der Chiffre Gott $z u$ verstehen sein mag) und "lebt im Herzen"; und Rybin begründet dies mit einer elgentümlichen Auslegung des Elngangshymnus' des Johannes-Evangeliums: "Gott ist das Wort. Und das wort ist Geist (duch)"30). Pavel aber beharrt darauf: "Ist Vernunf ${ }^{31}$ )! 
Halten wir also fest:

Pavel erkennt die bestehende Gesellschaftsordnung und inre Geschichte von seinem marxistischen standpunkt her als ungerecht. Er setzt ihr den Wissenschaftilchen Sozialismus als gerechte und vernünftige Ordnung entgegen, für die es zu kämpfen gilt. Seine Religionskritik endet am Punkt, wo die bestehende Religion als unvernünftig, als falsches Bewußtsein, entlarvt ist, welches der herrschenden Gesellschaftsform als Stütze dient. Das "Wesen der Religion", der Mensch als religiöses Wesen - um mit Lunacarskij/Feuerbach zu sprechen -, der emotionale Bedarf des Menschen spielt für Pavel keine Rolle.

Genau dies aber wird von der Mutter, die als perspektivisches Zentrum die erzähltechnische sowie die ideelle struktur des ganzen Romans bestimmt, als Mangel empfunden und führt bisweilenzur karrikierenden Darstellung Pavels ${ }^{31 a)}$.

Was wird dem entgegengesetzt?

In dem oben erwähnten Traum singt Pavel mit der stimme des 'Herzens', mit der stimme Andrej Nachodkas.

\section{b) Andref Nachodka als Repräsentant des Gefühls}

Während die Mutter immer wieder vergeblich um den emotionalen Zugang zu Pavel bemüht ist, sieht sie sich schon bei der ersten Begegnung mit Nachodka von dessen Offenheit entwaffnet ${ }^{32)}$. Allein aufgrund seiner psychischen Konstitution, seines sozialen Verhaltens bildet der kleinrusse das Gegengewicht zu Pavel und wird einer der schärfsten Kritiker von dessen nüchterner Härte. Bel Pavel hat die Nilovna das Gefühl, daß die Revolutionäre inn wegen seiner Strenge fürchten - aber nicht lieben; von Andrej dagegen heiBt es: 
Wenn die Wortgefechte in den Versammlungen einen allzu stürmischen Charakter annahmen, stand der Kleinrusse jedesmal auf und machte, wie ein Glockenklöppel hin und her schwingend, mit seiner klangvolien, tönenden stimme elne schlichte, gütige Bemerkung, worauf alle ruhiger und ernster wurden ${ }^{33}$ ?

Nachodkas Begriff vom Sozlalismus und der neuen Gesellschaft ist emotional-religiös fundiert in dem sinne, wie Gor'kij das "religiöse Gefühl" und Lunacarskij den wissenschaftlichen Sozialismus als Religion verstehen. Das ist auch der Grund dafür, daß er zum eigentlichen Lehrer der Mutter in Sachen Sozialismus wird. Er ist es auch, der die emotionale Qualität der Nilovna erkennt und anerkennt - unabhängig von ihrer konkreten Aktivität für die Revolution (im Gegensatz zu Pavel). In einer Auseinandersetzung mit Pavel wegen dessen tärte und falschen Heldentums 34 ) nebt er im Blick auf die Mutter hervor: "Dies Herz ist reicher als deins" 35 ).

Nachodkas religiöser Zugang zu Revolution und Sozialismus findet seinen Ausdruck sowohl im Inhalt seiner Reden wie in seiner sprechweise (religiöse Diktion). Für inn hat der Sozialismus die Qualität einer universalen Religion. Wenn er zum Beispiel von den Aktivitäten der ausländischen Arbeiter-Genossen spricht, so ist er "erfült vom Gefühl einer alle umschließenden Liebe" ${ }^{36)}$. Diese Arbeiter "bekennen" sich zu "demselben Glauben" wie die russischen Arbeiter; "ein Sozialist ist uns stets durch seine Gesinnung ein Bruder, jetzt und in alle Ewigkeit" ${ }^{37}$ )!

Nachodkas religiöse Haltung wird am deutlichsten bel der Demonstration zum 1. Mai ${ }^{38)}$. Von den Liedern, die die Sozialisten singen, sagt er, daß darin inr "Glaube" liege"39). (Schon früher helBt es, daß die Revolutionäre manche Lieder 
"halblaut und ernsthaft wie in der Kirche" sangen ${ }^{40)}$.) Den Sinn der Mai-Demonstration erklärt Nachodka so:

"Im Namen des neuen Gottes, des Gottes der Wahrheit und des Lichtes, der Vernunft und des Guten, haben wir uns jetzt aufgemacht zu einer Prozession. Weit in der Ferne liegt unser ziel, die Dornenkronen aber sind nahe! Wer an die kraft der Wahrheit nicht glaubt, wer nicht den Mut hat, bis zum Tode für sie einzutreten, wer sich selbst nicht traut und Leiden fürchtet - der trete weg von uns" ${ }^{41)}$.

Hier wird klar, daß für den Kleirrussen der Einsatz für die Revolution dieselbe Qualität hat, wie das Erlösungswerk Christi ("Dornenkrone") und das Bekenntnis der Märtyrer; an anderer stelle verdeutlicht er: "Die Wahrheit gedeint, wenn unser Blut die Erde wie reichlicher Regen bef euchtet" 42 ).

Verbunden mit Nachodkas Religiosität ist ein weiteres Merkmal, das ihn von Pavel unterscheldet und $f$ ür die Mutter wichtig macht. Wahrend es von Pavel heißt, $d a ß$ er nie über die zukunft spricht ${ }^{43}$ ), scheint es der Nilovna, daß der Kleinrusse "stets mit einem Teil seines Herzens in der Zukunft" lebt ${ }^{44}$ ). "Aus seinen Reden klang das Märchen vom zukünftigen Felertag für alle Menschen auf Erden"45). Nachodkas religiöse Begeisterung für die revolutionäre Tätigkeit speist sich nicht zuletzt aus dem Besitz eines 'Entwurfes' von der neuen Gesellschaft und dem neuen Menschen. In einer vision von der Zukunf t der Menschheit greift er die Weissagung des alttestamentlichen Propheten Ezechiel auf ${ }^{46}$ ) und sieht inre (säkularisierte) Erfüllung nahe; bei Ezechiel heißt es:

Und ich werde euch ein neues Herz geben und einen neuen Geist in euer Inneres geben, euer steinernes 
Herz wegnehmen und euch ein Herz von Fleisch geben und bewirken, $d a ß$ ihr nach meinen Satzungen wandelt und meine Vorschriften beobachtet und danach handelt. Dann sollt ihr im Lande wohnen, das ich euch gegeben habe, und ihr sollt mein volk sein, und ich werde ever Gott sein.

Nachodkas sozialistische, säkulare Version dieser Prophezeihung lautet:

"Denn es ist ein neues Herz im Wachsen, liebes Mütterchen, ein neues Herz wächst im Leben. Da kommt jemand, erleuchtet das Leben mit dem Licht der Vernunft und ruft laut: 'Ihr Menschen aller Länder, vereinigt euch zu einer Familie!' Und auf seinen Ruf fügen sich alle Herzen mit ihren gesunden Teilen zu einem großen, starken Herzen zusammen, volltönend wie eine silberglocke" 47 ).

Hier ist zum einen bemerkenswert, daß Nachodka aus den "Proletarlern aller Länder" "Menschen" und aus ihren Reihen eine "Familie" macht - wieder ein Hinweis auf seinen emotionalen Zugang zu der Sache. Zum andern repräsentiert auch für inn die Lehre des wissenschaftlichen sozialismus das "Licht der Vernunft".

Diese (biblische) Sprache kann die Mutter verstehen, da Andrej zwar vom "Licht der Vernunft" spricht, jedoch nicht an die Vernunft (der Nilovna) appelliert, sondern an das religiös ausgebildete Gefühl. Es ist deshalb für die Mutter auch durchaus 'verstehbar', wenn Nachodka ihr erklärt, daß seine Vision von der neuen Gesellschaft eben nicht nur in der möglicherwelse noch weit ausstehenden zukunft angesiedelt ist, sondern für ihn - Im Sinne christlicher Eschatologie - schon begonnen hat: "Ich bin schon reich, wie ein stern reich ist an strahlen"48). 
Zwar spürt die Mutter hinter den Reden und Handlungen aller Revolutionäre, mit denen sie zusammenkommt, einen "festen Glauben"49); den emotionalen zugang jedoch zu diesem Glauben ermöglicht inr die Religlosität des Kleinrussen. Er verschafft ihr das Gefühl für die Sache der Revolution und den Kampf um eine bessere zukunft, ein Gefühl, das Pavel ihr nicht vermitteln kann. Es hat deshalb durchaus die Bedeutung einer symbolischen Adoption, und damit einer Vorausdeutung auf den Traum von der Synthese beider 'Söhne' ${ }^{50}$ ), wenn die Nilovna Nachodka in inr Haus aufnimmt 51 ).

So wird der Kleinrusse zum wichtigsten Gegenpol Pavels, zu seiner Antithese, und er ist es, der der Mutter den Weg zum revolutionären Gedanken und damit zur neuen Religion zeigt. Über ihn erst lernt sie ihren Sohn verstehen. Er bleibt jedoch nicht der einzige, der die elnseitige orientlerung Pavels an der Vernunft kritisiert und beharrlich auf das 'religiöse Wesen' des Menschen verweist. Nachodka lelstet dies vor allem durch sein verhalten und seine Sprechwelse. Argumentativ bezieht Rybin Stellung gegen Pavel.

c) Der Bauer Rybin als Verteldiger der Religiosität des Volkes

Während Nachodka begeistert seinem neuen Glauben lebt und aus dieser religiösen Praxis heraus Pavels emotionalen Mangel zu kritisieren weiB, begegnet Rybin dem Beharren Pavels auf der allein wirkmächtigen kraft der Vernunft mit Argumenten. Der Mann aus dem Volk, der im Verlauf der Romanhandlung wieder zum Bauern wird, weiB, welche Bedeutung die Religion für das volk hat.

Auf der Ebene der Kritik von Staat und Kirche sieht er sich mit Pavel und seinem Kreis einig. Mit "Gott" betrügen 
Kirche und Staat im Verein das Volk. Dieser Gott ist eine Perversion seiner selbst; deshalb sind auch die Menschen nicht mehr seine "Ebenbilder", sondern "wilden Tieren" gleich ${ }^{52)}$.

Den biblischen Satz von der Erschaffung des Menschen nach dem Bilde Gottes kehrt Rybin - ähnlich wie Feuerbach/ Lunacarskif - um und versteht inn als Appell an den Menschen: Gott gleicht dem Menschen, "wenn der Mensch ihm ähnlich ist". Darum muß Gott "geläutert werden"53).

Rybin zieht also aus der Kritik der falschen Religion und des falschen Gottes nicht den Schluß Pavels (und der orthodoxen Marxisten), daß Religion überhaupt falsch sei, bzw. er bleibt (wie Lunacarskif) nicht bei der Kritik der positiven Religionen stehen; vielmehr erkennt er das emotional sich äußernde metaphysische Bedürfnis des Menschen als dessen religiöses Wesen an. Die erschreckte Reaktion der Mutter auf die "gottlosen" Reden der beiden dient inm als Argument und Beispiel gegen Pavel:

"Siehst du, Pavel! Nicht im Kopf, sondern im Herzen liegt der Anfang! Da ist so eine stelle in der Menschenseele, wo nichts anderes gedeint..."54)

- Nichts anderes als Religion, kann man ergänzen.

Ein bloß rational begründetes Modell zur Neugestaltung der Gesellschaft, zur Erneuerung des Menschen, genügt Rybin nicht. Der Mensch muß auch und zuerst "innerlich" gereinigt werden ${ }^{55)}$. Diese innerliche Reinigung hat aber Im 'Herzen' anzusetzen. "Das Herz gibt Kraft - nicht der Kopf, so ist das" ${ }^{56)}$ :

Rybins wichtigste Entgegnung auf die Vernunf torientiertheit Pavels faßt Lunacarskijs Religionsphilosophie (der 
Mensch ist ein zutiefst religiöses wesen, also muß der Wissenschaftliche Sozialismus seine religiöse Kraft beweisen) und Gor'kijs Gotterbauertum zusammen:

"Das Heiligtum darf nicht leer bleiben" 57 ). Dort, wo Gott lebt, ist eine empfindliche stelle. Wenn er aus der seele verschwindet, bleibt eine Wunde zurück - so ist es! Pavel, wir müssen einen neuen Glauben erfinden, einen Gott erschaffen (sotvorit' boga), der ein Freund der Menschen ist ${ }^{58)}$.

Man sieht, daß die Vorstellung des "Gott-Bauens" (auch der Begriff) keineswegs erst mit dem Roman "Ispoved"" bei Gor'kij auftritt; also nicht erst unter dem vermeintlichen EinfluB von Lunacarskij oder Bogdanov entstanden sein kann, wie die sowjetische Literaturwissenschaft benauptet.

Mit der Idee Rybins, eine neue Religion und einen neuen Gott zu schaffen, ist noch ein anderer Aspekt verbunden, auf den zunächst nur hingewiesen werden soll. Mit seinem Beharren auf dem "Herzen" als der Stelle, an der die Umgestaltung des Menschen anzusetzen hat, beruft er sich auf die zutiefst religiöse seele des einfachen (Bauern-) Volkes. Mit der Rücksichtnahme auf die Volksfrömmigkeit setzt er eine Tradition fort, die inre wurzeln in jenem Teil des Narodnicestvo hat, der von den Kreisen der Cajkovcy und Dolgusynncy, bzw. deren Lehrer Bervi-flerovskij repräsentiert wird ${ }^{59)}$. Diese volkstümlerische Tradition wird von Rybin auch in die Tat umgesetzt, indem er nämlich - zunächst nur mit der Bibel in der Hand aufs Dorf zurückgent, um das "Volk aufzuwiegeln"60).

Auch nachdem er, vom Dorfe zurückkehrend, sein MiBtrauen gegen die sozialistische Theorie als möglicherweise neue 
Lehre der "Herren" überwunden hat und Pavel um Bücher für die Arbeit am Bewußtsein der Bauern bittet, behält er seine religiöse Ausrichtung bei. Seine Arbeit hat für inn messianisch-erlösende Bedeutung:

"... und hat den Tod mit dem rod überwunden - das ist es: Also stirb, damit die Menschen auferstehen. Und mögen noch Tausende sterben, damit das Volk auf der Erde zum Leben aufersteht"61)!

Für die Romanperspektive sowie für die innere Entwicklung der Mutter hat Rybin eine ähnliche Funktion wie der kleinrusse. Er dient als Korrektiv zu Pavels einseitiger Position und hilft der Mutter, sich dem sozialistischen Gedanken des Sohnes zu nähern, ohne ihre religiöse Grundelnstellung aufgeben zu müssen, dadurch daß er Ihre Sprache spricht 62 ).

d) Die Entwicklung der Mutter als narrative Entsprechung zu Lunacarskijs Religions-Philosophie und als Weg zu Gor'kijs 'Synthese'

Die Veränderung der Nilovna beginnt an dem Punkt, wo die (geistige) Entwicklung Pavels zum Revolutionär abgeschlossen ist. Bis zu dem Zeitpunkt, wo dieser das Bild der Emmaus-Jünger aufhängt, führt die Mutter das normale Leben einer Arbeiterfrau, bzw. -witwe, das die Merkmale von Unterdrückung, Angst und naiver Religiosität (als "stütze"63), aufweist.

Als Pavel inr zum ersten Mal von seiner 'Wahrhelt' erzählt, versteht sie nur eins: "Du rennst in dein Verderben"64). Der rationale Gehalt dieser wahrheit bleibt inr unzugänglich. Dies ändert sich erst, als sie den anderen Arbei- 
tern, vor allem aber Nachodka begegnet. Inrer religiösemotionalen Grundstruktur entsprechend gewinnt sie auf eben dieser Ebene allmählich Zugang zu der Sache der Revolutionäre.

Deren Lektüre kommt inr vor wie ein "Märchen"65), und als bei einer Versammlung Nachodka von den ausländischen Arbeitern erzählt, wird auch die Mutter von "einem Gefühl der geistigen Verwandtschaft mit den Arbeitern der ganzen Welt" ergriffen, welches "alle zu einer einzigen Seele" verschmelzen $1 a ̈ \beta t^{66)}$. Für sie, die in der christlichen Nächstenliebe das höchste Gebot sieht, ist es of fensichtlich keine Schwierigkeit, den sozialistischen Kollektivgedanken auf der Ebene des Gefühls zu erfassen und ihrer religiösen Grundhaltung zu integrieren.

Die solidarische Haltung der Arbeiter untereinander - auch über nationale Grenzen hinweg - und ihr hohes Gerechtigkeitsethos (pravda) lassen die Nilovna hinter dem scheinbaren Unglauben einen tiefen Glauben als Movens aller revolutionären Aktivitäten erspüren ${ }^{67)}$;

(Sie) fühl te unwillkürlich, daß wahrhaftig etwas Großes und Helles, der sichtbaren Sonne des Himmels Ähnliches in der welt geboren war ${ }^{68)}$.

Im Romanverlauf gelingt es ihr nach und nach, immer mehr von den Handlungen der Sozialisten und inrer Theorie zu begreifen. Dies führt aber nicht dazu, daß sie ihre religiöse Ebene verläßt; vielmehr integriert sie die sozialistische Theorie Baustein um Baustein inrem religiösen Weltbild und verändert damit den Charakter ihrer Religiosität ebenso wie den des wissenschaftlichen Sozialismus.

Deutet sie zunächst noch alle ihr zugänglichen Phänomene beharrlich vom christlichen Grundmuster her - in den 
Revolutionären sieht sie Märtyrer, "Gerechte"69) ; niemand anders als Gott kann deren Arbeit lohnen; sie verstehen ihren Glauben selbst nicht ${ }^{70)}$ usw. - also unter dem Aspekt christlicher Nächstenliebe und Opferbereitschaft, so weicht dieses Deutungsmuster allmählich einem profaneren, dafür aber umfassenderen und allgemeineren.

Diese Ausweitung und Verallgemeinerung des Begriffs der christlichen Nächstenliebe geht parallel zur Erweiterung des Muttergefühls der Nilovna.

Hat sie schon bald nach den ersten kontakten mit den Revolutionären den Kleinrussen in ihr Haus aufgenommen und damit begonnen, den Bereich inrer mütterlichen Liebe $z u$ erweitern, so ist es auch gerade Nachodka, der sie auf ihre große Liebesfähigkeit hinweist und damit auf inre spätere integrative Bestimmung (die synthese herzustellen):

Alle lieben, was innen nahesteht, aber einem großen Herzen steht auch das Ferne nahe! Sie vermögen viel. Inr mütterliches Gefühl ist groß ${ }^{71)}$,

Die Mutter muß dies bestätigen; seit sie begonnen hat, selbst in der revolutionären Arbeit aktiv zu werden, ist für sie das "ganze Leben ... anders geworden, und die Angst auch, ich ängstige mich jetzt um alle"72). Gleichzeitig glaubt sie auch, den Grundgedanken der sozialistischen Lehre begriffen zu haben:

"Solange es Reiche gibt, wird das Volk niemals etwas erlangen, weder wahrhelt noch Freude, nichts" 73)!

Nachodka, der selbst den 'religiösen' Gehalt des Sozialismus praktiziert, wird schließlich zum eigentlichen Lehrer 
der Mutter. Er begegnet ihr zunächst auf der ihr ureigensten Ebene (Religion, Emotion) und kann sie so auch langsam auf die andere Ebene führen, auf die der Vernunft. Dies findet seinen symbolischen Ausdruck in der Hilfestellung, die der Kleinrusse der Mutter gibt, als sie wieder zu lesen beginnt.

Nachdem sie emotional und praktisch bereits auf der Seite der Revolution steht, artikuliert sie auch das Bedürfnis, den "neuen Glauben" rational zu erfassen ${ }^{74}$ ). Damit verliert die Religion die Trostfunktion, die sie früher für die Mutter hatte. ("Aber worauf soll ich alte Frau mich denn stützen, wenn ihr mir den Herrgott nehmt?" 75) Der abstrakte, fern wohnende Gott macht dem 'irdischeren' Christus Platz und findet bereits eine kollektive Umdeutung:
Aber in den Augen der Mutter hatten alle (Revolu- tionäre) etwas gleich Hartnäckiges, Zuversichtliches, und obwohl jeder sein eigenes Gesicht hatte, flossen für sie alle diese Gesichter zusammen: in ein ein- ziges, hageres, ruhig entschlossenes, helles Gesicht mit tiefem, freundlichem und strengem Blick der dunk- len Augen, wie der Blick Christi war auf dem Weg nach Emmaus ${ }^{76)}$.

Die Mutter greift nun also selbst Pavels symbol für seine Wahrheit auf und integriert es ihrer Religiosität, die nun allerdings vom 'Himmel' auf die 'Erde' zurückgekehrt ist.

Dabei erfährt die Wahrheit Pavels eine Umdeutung und wird um das religiöse Element erweitert, das zur Tradition des Pravda-begriffes gehört ${ }^{77)}$. 
Mit dem Bewußtwerdungsprozeß der Mutter gekoppelt ist die Entwicklung Ihres Bewußtseins von der Rolle, die sie als Person im Kreis der Revolutionäre spielt. Im Gegensatz zu früher sieht sie jetzt,

daß viele ihrer bedurften, und das war ihr neu und angenehm und ließ sie den Kopf hoch tragen ${ }^{78}$ ).

Sie erlebt genau das, wovon Gor'kij im Enquêten-Text spricht, daß nämlich der Mensch stolz entwickelt, sobald er seiner Bedeutung in der Geschichte gewahr wird.

Bei der Mai-Demonstration, dem 'Palmsonntag' der revolutionären Arbeiter, auf dem Höhepunkt (zugleich Ende) des ersten Romanteils ist die Bewußtwerdung, vor allem aber die Identifikation der Nilovna mit der Sache der Sozialisten bereits so weit gediehen, daß sie selbst etwas von inrem neuen Glauben nach außen tragen kann. In einer visionären Predigt nach dem Scheitern der Demonstration stellt sie die Revolutionäre als die neuen Erlöser ${ }^{79}$ und deren Lebensweg als Passion dar:

"Da gehen unsre Kinder, unser Blut, sie gehen in die Welt, die Wahrhelt zu suchen, für alle! Für euch alle, für eure kleinen haben sie das schwere Kreuz auf sich genommen... bessere Tage suchen sie. Sie wollen ein anderes Leben, in wahrheit und Gerechtigkeit... sie wollen das Gute für alle"80)!

Die Reaktionen der Zuhörer lassen auf die religiöse Kraft dieser ersten öffentlichen Rede der Mutter schließen: "Aus inr spricht Gott"81)!

An diesem Punkt der Romanhandlung ist die Umwandlung der Mutter von ihrer traditionell passiven Religiosität zur neuen aktiven sozialistischen im Wesentlichen vollzogen. 
Sie hat den fernen Gott gegen den nahen Christus eingetauscht und 'erkannt', daß dieser neue Gott das Produkt der kollektiven Arbeit für den Sozialismus (die "Wahrheit") ist, daß er erst durch die revolutionäre Tätigkeit geschaffen wird. Mit anderen Worten, inr vormals christlicher Glaube hat eine Wandlung und Umdeutung im Sinne des Gotterbauertums Gor'kijs und Lunacarskijs erfahren, wenn sie jetzt sagt:

"Es ist ein heiliges Werk ... Bedenken Sie, es gäbe ja auch Christus nicht, wenn die Menschen nicht seinetwegen in den Tod gegangen wären" 82 ).

Zwar hat Pelageja Nilovna noch nicht den vollen BewuBtseinsstand eines Revolutionärs erreicht, jedoch hat sie den Durchbruch aus der bloß unbewußten Emotionalität und Religiosität zur Vernunft gefunden, dabei ihr religiöses Wesen aber nicht aufgegeben, sondern mit der vernunft zur Synthese gebracht. Dies dokumentiert inr Traum in der Nacht nach der Mai-Demonstation ${ }^{83}$ ), der zugleich den zweiten Teil des Romans einleitet.

Dieser zweite Teil bringt für die Person der Mutter keine qualitativ neue Entwicklung; vielmehr läßt er den gotterbauerischen Keim, der am Ende des ersten aufgebrochen ist, zur vollen Entfaltung gelangen.

Nach ihrer Umsiedlung in die stadt beginnt die Nilovna, ihre Gefühls- und Verstandeswelt zu erweitern; über die Musik Sofjas bekommt sie den ersten kontakt zur kunst und Kultur. Im Zuge dieser Bewußtseinserziehung reflektiert sie immer mehr ihr eigenes Leben und versucht es rückschauend aufzuarbeiten.Dabei stellt sich inr noch einmal das 'Konovalov-Problem', mit dem Gor'kijs suche nach der Synthese von Gefühl und Vernunft ihre Richtung gefunden hatte: 


\begin{abstract}
"Wlr Menschen des dunklen Lebens fühlen alles, aber es wird uns schwer, uns auszudrücken, wir schämen uns, daß wir etwas verstehen, es aber nicht ausdrükken können. ....84)
\end{abstract}

Dieses Konovalov-Stadium hat die Mutter nun überwunden, "well ich angefangen habe $z$ begreifen, well ich vergleichen kann" 85 ).

Im Verlauf der Weiterentwicklung der Nilovna auf dem schon eingeschlagenen Weg verändert sich auch ihre Religiosität nun endgültig und bewußt zur neuen Religion. Am Morgen nach der Mai-Demonstration (und nach dem programmatischen Traum) steht sie zum ersten Mal ohne das gewohnte Gebet auf. In der stadt, wo inr revolutionäres BewuBtsein und ihre Aktivitäten immer mehr zunehmen, nimmt ihre Fähigkeit, im traditionellen sinne zu beten, ständig ab ${ }^{86)}$ - Dafür denkt sie mehr und mehr über

Christus und die Menschen nach, die zwar seinen Namen nicht erwähnten, (...) aber, wie ihr schien, doch nach seinen Geboten lebten, und gleich inm die Erde für das Reich aller Armen hielten und daher alle Reichtümer der Erde glelchmäßig unter die Menschen vertellen wollten. (...), dieser Gedanken wuchs und nahm das helle Antlitz eines Gebetes an, das über die dunkle Welt, das ganze Leben und alle Menschen gleichmäßiges Licht ergoß 87 ).

Im zweiten Teil des Romans wird die Nilovna allmählich zur Symbolfigur stilisiert, gleichzeitig stilisiert sie selbst ihren Sohn Pavel zum Symbol für ihren neuen Glauben. In den Augen seiner Mutter gerät er zum Märtyrer für Gottes Wahrheit und zum "Märchenhelden"89). Er erfüllt damit für sie die Funktion des Ideals, von dem in den früheren Kapiteln immer wieder die Rede war: 
Sie sprach (von Pavel), und das stolze Gefühl in ihrer Brust schwoll immer höher, es verlangte nach Worten für das Heldenbild, das es schuf, preßte ihr die Kehle zusammen. Sie brauchte unbedingt ein helles, sinnvolles Gegengewicht für all das Düstere, das sie an diesem Tage gesehen hatte und das ihren Kopf beschwerte mit sinnlosem Entsetzen, mit schamloser Grausamkeit. Ganz unbewußt gab sie diesem Bedürfis inrer gesunden seele nach und trug alles Helle und Reine, das sie gesehen hatte, zu einem Feuer zusammen, das sie mit seiner reinen flamme blendete ${ }^{90)}$.

Mit ihrer endgültigen Reifung zur Revolutionärin entwickelt die Mutter auch jene visionäre Kraft, mit der Nachodka inr den Traum von der neuen Gesellschaft nahegebracht hatte. In ihrer Vision bei einem Gespräch mit Nikolaj wird noch einmal das Hauptmotiv aus dem Poem "Celovek": der "Mensch" mit großem Buchstaben aufgegriffen, der jetzt allerdings Inhalt und Konkretisierung in der proletarischen Bewegung gefunden hat:

Warmer Schatten hüllte die Frau freundlich ein, erwärmte inr Herz mit dem Gefühl der Liebe zu den unbekannten Menschen, und diese flossen in ihrer Vorstellung sämtlich zu einem einzigen gewaltigen Menschen von unerschöpflicher, heldenmütiger Kraft zusammen. Er schreitet langsam, aber unermüdlich über die Erde, reinigt sie mit arbeitsfrohen Händen vom tausendjährigen Schimmel der Lüge und zeigt den Augen der Menschen die einfache und klare Wahrheit des Lebens 91 ).

Dieses Bild gewinnt für die Mutter religiöse Bedeutung; es weckt in ihr "ein Gefühl, mit welchem sie fraher vor dem Heiligenbild niederkniete" ${ }^{92}$ ), um einen guten Tag abzuschließen. 
Der zweite Höhepunkt des Romans, Pavels Gerichtsrede, markiert den Abschluß der 'intellektuellen' Entwicklung der Nilovna. Hatte sie früher immer nur bruchstückhafte Teile seiner "Wahrheit" begriffen oder eher erfühlt, so versteht sie jetzt den ganzen Argumentationszusammenhang der Sozialisten. Dieser Eindruck wird jedenfalls suggeriert durch die vollständige wiedergabe der Gerichtsrede, während bis dahin aufgrund der perspektivischen Konstruktion des Romans immer nur soviel Theorie zur sprache kommt, wie die Mutter verstehen kann, das heibt sehr wenig.

Diese intel lektuelle Reifung der Nilovna zur bewußten Revolutionarin ist vor allem im Dienste einer stilisierung der Mutter zum "Ideal"93) zu sehen und kann weniger im Sinne einer psychologisch glaubwürdigen Veränderung verstanden werden. Immerhin sagt sie jetzt, nach der Gerichtsverhandlung, von den Revolutionären, daß sie "Wege der Wahrheit und Vernunft gehen"94). Dennoch ist es wohl mehr das praktische Beispiel inres Sohnes und seiner Freunde, das sie an den religiösen Gehalt, der diese Lehre und das aus inr resultierende verhalten trägt, glauben läßt. So weckt die Verurteilung der Arbeiter durch das Gericht In der Mutter nicht mehr Angst, sondern religiöse Begeisterung, die sie das Werk des Sohnes fortsetzen Iäßt. Letzteres hat nun allerdings in der Aneignung durch die Mutter eine neue Qualitat bekommen:

"Das ist $j a$, als würde den Menschen ein neuer Gott geboren! Alles - für alle, alle - für alles. So verstehe ich euch alle. Ihr seid wahrhaft alle Genossen, alle eines Geschlechts, alle seid ihr Kinder einer Mutter - der Wahrheit" "95).

Damit ist die stilisierung der Mutter zum Symbol für die neue Religion abgeschlossen. Die Wahrheit, von der sie jetzt spricht, ist nicht mehr nur die wahrheit Pavels, 
welche für eine vernünftig organisierte und damit gerechte Gesellschaft stand; es ist dies auch die Wahrheit als Liebe zu den Menschen, welche im religiös-emotionalen Bereich verankert ist ${ }^{96)}$.

An dieser soeben zitierten Stelle fallen die beiden symbole: "pravda" und "Mutter" in eins und besiegeln so die Synthese von Emotion und Vernunft im neuen Glauben.

\section{e) Zusammenfassung}

Wir kommen damit zu dem Ergebnis, daß der später zum Prototyp des Sozialistischen Realismus avancierte Roman "Die Mutter" eine Ausführung des Themas 'Bogostroitel'stvo' darstellt. Die Entwicklung der Mutter "von einem bloß passiven Glauben zu einer aktiven Religiosität" ${ }^{97)}$ ist nichts anderes, als die narrative Entsprechung des religionsphilosophischen Gedankengangs Lunacarskijs und die Ausführung dessen, was Gor'kij in seiner Antwort auf die Umfrage des Mecure de France als das "religiöse Gefühl" bezelchnet hat.

Für dieses steht zunächst der Kleinrusse Nachodka, dessen sozialistische revolutionäre Praxis ganz von jenem "religiösen Gefuhl" getragen ist, das dem neuen Glauben entspringt. Dessen emotionales und antizipatorisches Element repräsentiert Nachodka, er macht jedoch im Verlauf der Romanhandlung keinerlei Entwicklung durch.

Das gleiche gilt für Pavel, der - abgesehen von seiner 'Entwicklung' zum Revolutionär - keinerlei qualitative Entwicklung mehr erfährt. Seine "pravda", die für die Mutter zum Symbol des neuen Glaubens wird, steht zunächst für dessen rationale seite und ermangelt noch des antizipatorischen Elements; sie wird aber im Zuge ihrer Aneignung durch die Nilovna erweitert und umfaßt am Ende die 
beiden Zentren Gefühl und Vernunft. Verkörpert wird diese neue pravda durch den "neuen Gott" - Christus, der das kollektive Produkt der revolutionär tätigen Sozialisten ist ${ }^{98}$ ).

So entspricht die Wandlung von Pavels "pravda"-Begriff der Veränderung, die die rein rationale Lehre des wissenschaftlichen Sozialismus durch Lunacarskij erfährt:

Die Beschränkung dieser Lehre auf die Ratio erweist sich als Mangel und macht es notwendig, die Frage nach dem "Wesen der Religion", bzw. die nach dem metaphysischen Bedürfnis des Menschen, noch einmal zu stellen, von Marx noch einmal zu Feuerbach zurückzukehren, um dem wertenden Subjekt wieder zu seinem Rechl zu verhelfen, den Monismus der Vernunft durch die synthese mit dem Gefühl zu brechen. Dieser in Sachen Religionskritik und Emotionalität revidierte Marxismus kommt an der Person der Nilovna zur Darstellung.

Verfolgt man die einzelnen stadien der Religiosität der Mutter, so wird dies deutlich:

$\mathrm{Zu}$ Beginn des Romans steht sie für jene Art Religion, die von Marx als falsches BewuBtsein, als "Opium des Volkes" entlarvt wird. Hier hat Gott die Funktion, über die schlechte Wirklichkeit hinwegzutrösten 99 ).

Auf die Religionskritik Pavels reagiert die Nilovna zunächst verstört, eignet sich aber nach und nach, vor allem unter dem Elnfluß Rybins und Nachodkas den religionskritischen standpunkt der Marxisten an - ohne allerdings inren eigenen religiösen Boden $z u$ verlassen. Der endgültige Verlust inrer kirchlichen Bindung wird signalisiert durch den vorübergehenden Abbruch ihres Gebetslebens ${ }^{100)}$; jedoch wird das so entstandene Vakuum sehr schnell aufgefült durch die Entfaltung des gotterbauerischen Keims ${ }^{101)}$ und durch neue, der revolutionären wirklichkeit zugewandte Gebete ${ }^{102 \text { ) }}$. 
Am Ende ihrer Entwicklung steht die von Gor'kij und Lunacarskij von ihren je verschiedenen Ausgangspunkten her angestrebte Synthese von Emotion und Vernunft, die für Gor'kij eine Aufhebung der Emotion in der Vernunft ist und Basis der neuen aktiven Religion ${ }^{103 \text { ). }}$

Die idealisierende Form, in der dies alles dargestellt wird: die Veränderung der Nilovna; die soziale Praxis der Revolutionäre, welche eine nachrevolutionäre Praxis bereits antizipiert - diese Idealisierung deckt den didaktischen Charakter des Romans auf ${ }^{104)}$. Es geht Gor'kij darum, gerade solch ein Ideal zu schaffen, wie es die Mutter gegen die schlechte Realität setzt (Pavel als Märchenheld) und wie es in den früheren Werken Gor'kijs immer wieder von der Literatur gefordert wurde anstelle der tödlichen kleinen Wahrheiten ${ }^{105)}$. Die Rezeption des Romans in der Arbeiterwelt scheint das Gelingen gerade dieser Absicht zu bestätigen ${ }^{106)}$.

Gor'kijs eigene Biographie zeigt jedoch auch eine Gefahr, die im utopischen Charakter dieses Ideals angelegt ist: Seine 1917 bis 1918 in der Tageszeitung "Novaja zizn" veröffentlichte Artikelserie ("Unzeitgemäße Gedanken"107)) dokumentiert eindringlich seine Schwierigkeiten mit der revolutionären wirklichkeit und seine Enttäuschung über deren wahres Gesicht.

Mit der didaktischen Ausrichtung des Romans eng verbunden ist ein weiterer Aspekt, auf den im Zusammenhang mit der Figur des Bauern und Narodniks Rybin verwiesen wurde.

Gor'kij verwendet in diesem Roman auffallend häufig Elemente aus dem traditionelien religiösen Bereich. Sprachlich zeigt sich dies vor allem in den Reden Nachodkas, die Merkmale einer liturgischen sprechweise tragen ${ }^{108 \text { ). }}$. 
Die Handlung selbst ist von biblischen Motiven durchzogen und orientiert sich in groben Zügen an der Geschichte der Evangelien. So erinnert das Verhältnis zwischen Pavel und seiner Mutter sehr oft an das zwischen Jesus und Maria. (Sie ringt sich zu der Bereitschaft durch, das 'Erlösungsopfer' inres Sohnes zu akzeptieren ${ }^{109)}$; sie ordnet ihre mütterlichen Bedürfnisse der Aufgabe ihres Sohnes unter ${ }^{110)}$; sie folgt dem Sohn auf dessen Weg nach).

Die "Prozession" der Arbeiter am 1. Mai ist entsprechend dem Einzug nach Jerusalem (Palmsonntag) inszeniert; zum ersten Mal of fenbaren sich Pavel und seine Freunde als der neue proletarische Messias. Gleichzeitig wird der Weg der Revolutionäre immer wieder als Leidensweg des Erlösers dargestellt.

Die Gerichtsszene schließlich, in der Pavel zum eigentlichen Richter (und dennoch verurteilt) wird, hat ihr literarisches Pendant nicht nur in den Gerichtszenen von Tolstojs "Auferstehung" und stendhals "Le rouge et le noir", sondern auch und vor allem (für die Rezipienten) am Beginn der Passionsgeschichte, wo Jesus vor dem Hohen Rat steht (Mt 26, 57-66 par). Durch sein Schweigen demonstriert Jesus, $d a ß$ er dieses Gericht nicht anerkennt, und wenn er schließlich ankündigt: "Von nun an werdet ihr den Menschensohn sehen, sitzend zur Rechten der Kraft und kommend auf den Wolken des Himmels." - so beansprucht er damit für sich die Rolle des wahren Richters (Vergleiche Pavel in der Perspektive der Mutter).

Ein weiteres of fensichtlich bewußt aufgegriffenes neutestamentliches Motiv bietet die Szene ${ }^{111)}$, wo der Bauer Ignat die Nachricht Rybins für die Mutter überbringt : Die vermeintlichen "Herren" (Städter) waschen inm, dem Bauern die Füße; aber "in dieser Sache gibt es keine Herren, alle sind Genossen"112). Ebensowenig wie die Jünger 
Jesu bei der Fußwaschung, kann Ignat diese neue wirklichkeit begreifen: "Dort haut man mich in die Fresse, hier wäscht man mír die Füße"113)! (Jh 13, 1-15)

Diese Methode, biblische und liturglsche Motive zu verwenden, die das Volk kennt, und sie mit einem anderen Kontext zu versehen, das heißt, eine neue soziale Lehre in einer Sprache zu verkünden, die das einfache Volk versteht, setzt eine Tradition des Narodnicestvo fort, für welche vor allem der Schriftsteller und Revolutionär Bervi-Flerovskij steht, in den siebziger Jahren Lehrer der revolutionären Jugend, besonders der Dolgusincy und Cajkovcy ${ }^{114)}$. 
2. "Ispoved""

... Während all dieser Zeit bedrängte mich neben den Gedanken und Beobachtungen, von denen ich schon sprach, ein quälendes Gefühl. Ich kann dieses Gefühl nicht anders nennen als ein suchen nach Gott.

$$
\text { L.N. Tolstoj, Beichte }
$$

Die Rezeption der Romanerzählung "Ispoved" (Eine Beichte), veröffentlicht 1908, bereitete und bereitet der Kritik erhebliche Schwierigkeiten. Sie wird meist als der literarische Kulminationspunkt von Gor'kijs religiöser Phase - bzw. in der sowjetischen wissenschaft zusammen mit dem Aufsatz "Razrusenie licnosti" als Gipfel seiner religiösen und philosophischen Abirrungen angesehen. Auf sowjetischer Seite ist nach wie vor das von Lenin dominierte Rezeptionsmuster gültig, welches die religiöse Thematik dieses Romans dem Einfluß Lunacarskijs und Bogdanovs zuschreibt, mit denen Gor'kij während der Niederschrift auf Capri zusammenlebte 116 )

Es hat sich jedoch gezeigt, daß In Gor'kijs Schaffen die 'religiöse Frage' keineswegs erst $1908 / 09$ gestellt wird, sondern schon früher, und $d a B$ sie bereits im Roman "Mat"" inre Antwort im Sinne des Gotterbauertums gefunden hat. Zu fragen ist also, ob mit diesem Roman Gor'kijs religiöse Thematik eine qualitativ neue Wendung nimmt - was dann durchaus die Frage nach dem Einfluß Lunacarskijs und Bogdanovs, bzw. dessen Relevanz für Gor'kijs Ausprägung des Bogostroitel'stvo, nach sich ziehen würde; oder ob "Ispoved" nichts anderes als die intensivierte Erkundung schon gewonnenen Terrains darstellt.

Der Titel der Erzählung, die dem Typus des 'Sucherromans' zuzuordnen ist, greift bewußt ein literarisches vor- und Gegenbild auf: 
Seiner in den Jahren 1879 bis 1881 entstandenen Bekenntnisschrift über das eigene "Suchen nach Gott" hat L.N. Tolstoj ebenfalls den Titel "Ispoved" gegeben. Die Lösung für seine religiöse Frage glaubt Tolstoj nach langem Umherirren in verschiedenen philosophischen Systemen im Glauben an eine "sittliche Vervollkommnung"117), im Glauben des "einfachen arbeitenden Volkes, des Volkes, welches das Leben schafft"118), gefunden zu haben:

Der Mensch hat im Leben die Aufgabe, seine Seele zu retten; will er seine seele retten, muß er gottgefällig leben, und um gottgefällig leben zu können, muß man allen Lebensfreuden entsagen, sich mühen, sich in sein schicksal fügen, dulden und barmherzig $\operatorname{sein}^{119)}$

Gor'kij hatte zwar im Februar 1900 an Tolstoj geschrieben:

Gott ... begreife ich als das unbändige streben nach Vervollkommnung, nach wahrheit und Gerechtigkeit ${ }^{120)}$;

er sah jedoch den Weg zu dieser Vervollkommnung niemals in der passiven Haltung des Sich-Fügens und Duldens. Gerade in der Wirksamkeit der Tolstojschen Lehre, sich dem Bösen nicht mit Gewalt zu widersetzen, sah Gor'kij eine der größten Gefahren seiner Zeit, da sie, wie er glaubte, der von inm attackierten Mentalität des mescanstvo das wort redete.

Wie gezeigt wurde, ist Gor'kijs Bogostroitel'stvo als eine Religion der Aktivität eben im Kontext seines Kampfes gegen die Passivität und den Pessimismus des mescanstvo und damit auch im Rahmen seiner Frontstellung gegen die Lehren Tolstoijs (und Dostoevskijs) zu verstehen. 
Wenn also Gor'kij mit dem Titel seiner Romanerzählung die Tolstoijschen Bekenntnisse zitiert ${ }^{121}$ ), so muß diese wohl auch als eine Erwiderung an Tolstoj gelesen werden. Der passiven und damit fortschrittsfeindlichen religiösen Lehre Tolstojs wird Gor'kijs Religion der Aktivität und des Glaubens an den unbegrenzten Fortschritt gegenübertreten, wie wir sie in ihrer Grundausprägung aus dem rext von 1907 (Mercure de France) kennen. Dies soll gezeigt werden.

\section{a) Matve 1: Vom Gott-Suchen zum Gott-Bauen}

Während Gor'kij in der "Mutter" die innere Umwandlung eines Individuums von der alten, kirchlich gebundenen und damit 'falschen' Religion zur neuen Religiosität in der Mitarbeit am Aufbau des Sozialismus (stroit' boga stroit' socializm) gezeichnet hat, stellt er in der "Beichte" diese Entwicklung prononcierter in der Form eines Entwicklungs- (Sucher-) romans dar: Die stationen, die der Held durchwandert, sind stufen seiner geistigen Reifung.

In einem Brief an seine Frau von 1908 schreibt Gor'kij:

In meinem neuen Roman habe ich mich bemüht, den Weg zur Verschmelzung mit dem Ganzen zu beleuchten das Glück und die Quelle höchster Genüsse des Geistes liegen eben in diesem Verschmelzen und nirgendwo anders. Jede Persönlichkeit muß - wenn sie ein geistig gesundes Individuum ist - zur Welt streben, nicht aber von inr weg, das ist die These meines Romans ${ }^{122)}$.

In den zwanziger oder dreiBiger Jahren präzisiert Gor'kij - wohl in der Absicht, Vorwürfe wegen religiösen Abirrens abzuwehren: 
Ich bin Atheist. In der "Beichte" meinte ich zeigen zu müssen, auf welchen Wegen ein Mensch von Individualismus zu einer kollektivistischen Weltauffassung gelangen kann... Der Held der "Beichte" versteht unter "Gottbildnertum" eine Organisation des Volkslebens im Geiste des Kollektivismus, Im Geiste der Vereinigung aller für ein ziel - die Befreiung des Menschen von innerer und äußerer Sklaverei ${ }^{123)}$.

In der Tat nimmt schon äußerlich der Held Matvej seinen Weg von der totalen Vereinzelung - versinnbildlicht in seiner Ausgangssituation als Findelkind - zur positiven Aufhebung seiner Individualität im "Volk" - symbolisiert durch sein Einswerden mit der Masse während des "Wunders" am Ende des Romans.

Die Stationen, die Matvej durchläuft, ergeben ein Panorama des religiösen Lebens in Rußland und zugleich dessen bittere Kritik. Immer wieder muß der Held zu dem Ergebnis kommen, daß es 'so nicht das Richtige' sei.

Zu Beginn seines geistigen Lebens finden wir ihn noch eingebunden in eine Form und Praxis echter und fröhlicher naiver Volksfrömmigkeit. Bel Larion und Savelka lernt Matvej den "ganzen unermeßlichen Gott"124) kennen; den Gott, der "in den Menschen wohnt" ${ }^{125)}$, von Kirche und staat aber ermordet wird. Larion und Savelka haben ihre eigene Religiosität außerhalb der Institutionen, dafür in enger Verbindung - wenn auch unreflektiert - mit dem Volk. Diese Einbindung religiösen Verhaltens ins Volk findet inren Ausdruck unter anderem im Gesang der beiden. Das Singen von Volksliedern nimmt hier die Qualität des Vollzugs einer sakralen Handlung an ${ }^{126)}$.

Larion führt Matvej in die Welt seines Glaubens ein; er unterweist inn nicht in der Lehre vom institutionalisierten Gott, den staat und Kirche sich nutzbar machen (vgl. 
die Geschichte mit der Ikone im Brunnen), sondern "am schönsten erzählte Larion von Christus", von dessen "unaussprechlicher Liebe zum Volk"127). In Larions Antwort auf Matvejs Frage, ob Christus denn bald wiederkomme, ist dessen zukünftiger Weg vorgezeichnet: "Schon bald. Es heißt, die Menschen suchen inn erneut"128).

Mit dem Tode Larions verliert Matvej seine Basis echter Volksfrömmigkeit, welche zugleich das soziale Element der Gemeinschaft (später Kollektiv) beinhaltet. Er wird von nun an suchen, was er bis jetzt in naiv-unbewußter form besaß.

"Ich begann Gott zu lieben"129)! - Diese Liebe zu Gott wird zu einer Suche; denn Matvej kann seinen Glauben an einen guten allmächtigen, über allem thronenden Gott nicht mit der bösen Realität in Einklang bringen. Das Verlangen, die alte Theodizee-Frage für sich zu lösen, treibt inn von einer kirchlichen Institution zur anderen. Er muß jedoch erkennen, daß der in den $K i r c h e n$ und Klöstern verwaltete Gott tot ist.

Erst nachdem er alle Formen kirchlicher und traditioneller Frömmigkeit erprobt und als nicht tragfähig und falsch abgelegt hat, ist der Held offen für die neue, wahre Religion.

Der Pilger und ehemalige Pope Iona-Iegudili zeigt Matvej, daß seine Suche nach Gott in die falsche Richtung geht. Gott ist nicht irgendwo jenseits der Menschenwelt zu finden, sondern im Gegenteil: Es ist das Volk, der "ewige Gottbildner" ${ }^{130)}$, das aus seiner kollektiven kraft heraus immer wieder seinen Gott schafft. Der Weg zum wahren Gott ist also identisch mit dem Weg zum Volk.

Durch Iegudill wird Matvej der Weg zurück zu seiner anfänglichen unbewußt-religiösen Erfahrung wiedereröf fnet 
(er erinnert inn an Savelka ${ }^{131}$ ), und viele der Reden Ionas scheinen ihm längst bekannt); zugleich wird er für die neue Lehre empfänglich.

Iona schickt Matvej zu Freunden in elne Fabrik. Dort sieht er bel den revolutionären Arbeitern die neue Religion wachsen, die nicht eine Religion des Individuums ist, sondern eine des Volkes, der "gesamten geistigen Kraft der Erde"132). Von dem jungen Lehrer und Revolutionär Michajla lernt Matvej, daß diese neue Religion eine Religion der Tat 1st: "Wahrer Glaube ist ... zwangsläufig elne Quelle des Handelns"133).

Mit dem Ende des Aufenthalts bei den Arbeitern ist Matvejs Unterweisung im neuen Glauben abgeschlossen. Er kennt jetzt die Lehre und kann sie anderen vermitteln; jedoch ist er noch nicht vollgültiges Mitglied der Glaubensgemeinschaft "Volk".

So stellt das Heilungswunder am Ende des Romans den nunmehr berechtigten "Glauben (des Volkes) an seine Macht, Wunder zu vollbringen" 134 ), unter augenfälligen Beweis und bedeutet zugleich - was für die Entwicklung des Helden m.E. wichtiger ist - die endgültige rituelle Aufnahme des Individuums Matvej in das Kollektiv "Volk"135). Von jetzt an fühlt sich Matvej "für immer untrennbar mit dem Volk, dem Beherrscher und Wundertäter der Erde, verbunden" 136 ).

\section{b) Die Elemente der Religion des Gott-Bauens}

1. Vom Individuum zum Kollektiv: "Volk"

Der Lebensweg Matvejs, von dem die Romanhandlung bestimmt wird, thematisiert eines der zentralen Elemente von Gor'kijs 
Bogostroitel'stvo. Es geht um die Kollektivität, die zwar ursprünglich Bestandteil einer jeden Religion, meist aber zu einem schlechten Individualismus verkommen ist und erst in der neuen Sozialistischen Religion zum Eckpfeiler wird.

Gor'kijs Kritik am (kleinbürgerlichen) Individualismus (mešcanstvo) ist gekoppelt mit seiner Kritik an der traditionellen Religion ${ }^{137)}$; diese wird von Matvej in ihren verschiedenen Ausprägungen erprobt und entlarvt sich immer neu als der himmlische Ausdruck der irdischen Vereinzelung der Menschen. Matvef erfährt dies an seinem eigenen Schicksal: Sein Weg zu Gott, dem Gott der alten Religion, führt ihn in die völlige Vereinzelung, "weit von den Menschen fort"138). Aber auch allgemein gilt dies: Der vermeintlich "lichte Gott" wohnt weitab von den Menschen, und diese fristen jeder für sich ein "hartes und tristes Dasein"139).

Der Vereinzelung der Menschen entspricht die Zerlegung Gottes in "lauter einzelne Teile"140); jeder Vertreter der traditionellen Religion, dem Matvej begegnet, verehrt den 'Gott', der inm selbst am nützlichsten ist. Die Auflösung Gottes in seine Bestandteile bedeutet letztlich dessen totale Abwesenheit: "Die Menschen haben keinen Gott, solange sie leder für sich und in Feindschaft leben"141).

In der materialistischen Sprache des Lehrers Michajla lautet derselbe Tatbestand: Gott ist tot aufgrund der Teilung der Gesellschaft in Herren und sklaven ${ }^{142}$ ).

Matvej erfährt den Unterschied $z$ wischen der alten individualistischen und der neuen kollektivistischen Religion in der Veränderung seines Gebetslebens:

Ich erinnere mich meiner einstigen Vereinigungen mit Gott in meinen Gebeten. War das schön gewesen, wenn 
1ch aus dem eigenen Bewußtsein verschwand und aufhörte zu sein! Beim Einswerden mit den Menschen aber entfernte ich mich nicht von mir, sondern wuchs gleichsam, erhob mich über mich selbst, und die kraft meines Geistes nahm um ein vielfaches $2 u^{143)}$.

Das "Einswerden mit den Menschen" ist das Kennzeichen der neuen Religion. Deren Träger sind nicht Einzelne, sondern das Volk, "die gesamte geistige Kraft der Erde", die "alles geschaffen" hat ${ }^{144)}$ ).

Auch 'Gott' ist nichts anderes als das Produkt aus der Sammlung und Konzentration seines Willens: "Der Gottschöpfer - das ist das Volk"145). Das Volk ist der "wahre Tempel des lebendigen Gottes"146). Für den Lehrer und Revolutionär Michajla ist der ungeteilte Gott der neuen Religion Symbol des "Gemeinsamen in allen Menschen", für die "wunderwirkende Kraft", die dem Volke innewohnt ${ }^{147)}$.

Im Gegensatz zur alten Religion gibt es im "neuen Glauben" keine "Einsiedler", vielmehr führt er zu den Menschen hin: "mitten in die Welt hinein"148).

Matvej leidet an dem zerstückelten Gott der alten Religion, sein weg ist ein Passionsweg, der inn - nun bewußt - zu seinen unbewußten Anf ängen zurückführt: Seine endgültige Heilung von der "Gotteskrankheit" ${ }^{149)}$ erfährt er durch ein volkslied, durch ein Produkt des kollektiven Schaffens des volkes $^{150}$;

Oft schon hatte ich Räuberlleder gehört, aber nie gewußt, aus wessen worten sie gebildet waren, wessen Seele in ihnen lebte; doch diesmal erkannte ich es. wie mit tausend zungen sprach das volk aus alten zeiten durch das Lied zu mir:

"Ich vergeb dir, o Mensch, die große Sünde wider mich für einen auch noch so kleinen Dienst" ${ }^{151)}$. 
Damit ist Matvej wieder zu seinem Ausgangspunkt zurückgekehrt, den er allerdings jetzt als richtig erkannt hat: Bei Larion und Savelka hatte er unbewußt genau jene Religlosität erlebt, die, abseits von der institutionalisierten, aus der Verwurzelung im Volk lebt und das kollektive Element bewahrt hat.

Nach Matvejs Heilung hat das Wunder am Ende des Romans lediglich noch die Funktion einer Manifestation und eines Initiationsritus': Es wird zum Taufzeichen für die wunderwirkende Kraft des Kollektivs "Volk" und für die endgültige Aufnahme Matvejs in die große Gemeinschaft: "für immer untrennbar mit dem Volk, dem Beherrscher und Wundertäter der Erde verbunden" 152 ).

Der Wandlung Matvejs vom vereinzelten Individuum zum vollwertigen Mitglied des Kollektivs "Volk" entspricht die wandlung seines Gottesbildes.

2. von "Gott" zu "Christus"

Kann man die soziale Entwicklung Matvejs mit einer Spiralbewegung vergleichen (vom unbewußten Mitglied elnes unbewußten Kollektivs - Larion und Savelka - über die Negation zum bewußten Teil des neuen Kollektivs) so gilt dies in gleicher Weise für die Veränderung seines Gottesbegriffs. Auch hier kehrt er auf einer qualitativ höheren, weil nun auch vernünftigen, stufe zu seinem Ursprung zurück; noch in der Negation begriffen, stellt der Ich-Erzähler fest: "Nur Larion hatte den ganzen, unermeBlichen Gott" ${ }^{153}$ ).

Es ist allerdings mit gewissen Schwierigkeiten verbunden, auf einen konzisen Begriff zu bringen, was Gor'kij meint, wenn er 'Gott' sagt - ein eindeutiger sprachgebrauch ist leider nicht gegeben. Es empfiehlt sich daher, der Bewegung des Romans zu folgen, um zu einer positiven Bestimmung zu kommen. 
Auf seiner Suche nach Gott erfährt Matvej die Negation Gottes: Der Gott der Institutionen (K1rche und staat) ist tot; schon zu Beginn sagt Larion, daß Kirche und staat Gott "In den Menschen ermorden"154).

Oder Gott ist abwesend und hat nichts mit der Menschenwelt zu tun:

Der 1 ichte Gott thronte 1 rgendwo fernab in seiner Macht und Herrlichke1t, und die Menschen hausten ebenfalls für sich in el nem harten und tristen Dase in 155).

Gott ist nur noch ein zerrbild seiner selbst ${ }^{156)}$, so wie die Menschen nur noch Zerrbilder ihrer selbst sind: Durch Ihre Erniedrigung erniedrigen sie Gott, denn sie sind nach seinem B1lde geschaffen ${ }^{157}$ ). Dadurch, daß die Menschen in der Vereinzelung, "Jeder für sich und in Feindschaft leben"158), haben sie Gott in "lauter elnzelne Telle zerlegt, (...), Jeder wie es $1 \mathrm{hm}$ gerade paßt"159). Also "haben (sie)keinen Gott"160).

Schon in der Negation wird deutlich: Die Qualität, die 'Gott' Jeweils annimmt, ist abhäng1g von der Beschaffenheit der sozialen Basis. Das gesellschaftliche 'Seln' bestimmt das 'Bewußtsein', und die Aussagen über Gott sind Aussagen über den Menschen - eine Illustration zu Feuerbach: "Aus seinem Gotte erkennst du den Menschen"161).

Nachdem Matvej diesen Zusammenhang erkannt hat, durchschaut er das "Gottsuchen" des in Bewegung geratenen Volkes als Suche nach dem falschen Gott; denn es ist in wahrhelt elne Flucht vor dem "wahren Gesicht des Lebens"162), welches kelnen 'ganzen' Gott hervorbringen kann. Matvej kann allerdings hier, am Ende seiner elgenen Suche nach Gott, noch nicht zu einer positiven Bestimmung gelangen, 
er resümiert lediglich: "So ist es nicht das Richtige"163). Zur Handlungsanweisung wird diese Bestandsaufnahme erst bei Iegudill und den Gotterbauern (Michajla): "Gott ist noch nicht geschaffen"164) ; was ins Positive gewendet heiBt: Gott muß geschaffen werden durch die veränderung der sozialen Grundlage.

Somit zeigt sich hinter der Religionskritik, der die Entfaltung des religiösen Panoramas durch die Wanderung Matvejs dient, als kritisches und handlungsauslösendes Potential das Bild von einem 'ganzen Gott', der nichts anderes ist als der 'ganze Mensch', bzw. der die Aufforderung bedeutet, diesen ganzen Menschen (wieder-)erstehen zu lassen.

Larion befindet sich also völlig im Einklang mit den Gotterbauern Iegudili und Michajla, wenn er am Anfang des Romans in einem streit mit den Bauern über Gott und den Teufel sagt:

"Euer Teufel aber - das ist Armut und Unwissenheit (d.h. das, was dem Bilde vom ganzen Menschen widerspricht, R.S.). Das Gute ist in Wahrheit das Menschliche, denn es ist das Göttliche; euer Böses dagegen ist nicht das reuflische, sondern das - Viehische"165).

'Gott. oder das "Göttliche" ist etwas im Menschen, vorausgesetzt, der Mensch ist wirklich Mensch. So wie die Gesellschaft jetzt organisiert ist, wird sein Bild verzerrt und somit Gott "ermordet"166).

Der Gott der Gottbildner ist nicht mehr die "Krücke"167), die die Unzulängl ichkelt der Menschen auszugleichen hat: Er wird nicht aus der Schwäche heraus geboren, "sondern 
aus einem Übermaß an Kraft heraus. Und nicht außerhalb von uns lebt er, Bruder, sondern in uns"168). Gott ist im Menschen oder Mensch ist Gott; aber nicht der in der Vereinzelung für sich lebende Mensch, sondern - wie in der Negation klar wurde - der in der Gemeinschaft (Kollektiv) aufgehobene Mensch: Aus der sich formierenden Kraft des sich sammelnden arbeitenden Volkes, so Iegudill, "wird dann licht und schön der allumfassende Gott erstehen"169). Nicht der einzelne Mensch ist Gott, sonder "die gesamte geistige Kraft der Erde, das Volk"170). Gott ist ein "Geschöpf des Volksgeistes"171); als symbol hierfür steht Christus, der erste wahrhaft "volkstümliche Gott"172).

Schon bei Larion hatte Matvej Christus als den 'menschlichen' Gott kennengelernt. Von ihm und von seiner "unaussprechlichen Liebe zum Volk" sprach er "am schönsten"173). Larions Antwort auf Matvejs Frage, ob Christus bald wiederkommen werde, ist eine Vorausdeutung auf die Wendung, die dessen Suche nach Gott nehmen wird: zurück zu Larions Gott. ("Schon bald. Es heißt, die Menschen suchen inn erneut"174) ()

In Christus hat sich das Volk etwas bewahrt, das es (als Protest) gegen den institutionalisierten Gott von Kirche und staat einsetzen kann; dies vergiBt auch Matvef nicht auf seiner Wanderung.

Gegen die Theologie des Protopopen, der vor inm das Bild von Gott als einem gnadenlosen Richter entwirft, der auf der Selte des 'Gesetzes', also des Staates, steht, wendet Matvef ein: "Wo bleibt bei Innen Christus"175)?

Der volksnahe Christus ist auch der Gott der Gotterbauer: Christus, so Iegudiil, "steht uns näher (als Gott)"176); er ist das Produkt der Menschen, denn die "Kraft inres 
Glaubens war es, durch die er zur Gottheit erhoben wurde"177).

Die gegenwärtige Gesellschaft verzerrt das "Wesen der Seele Christi", denn der "lebende Christus" ist gegen die Herschaft von Menschen über Menschen 178). Folglich ist der $\mathrm{Tag}$, an dem die Menschen sich (wieder) der Gleichheit aller bewußt werden und also die Umorganisierung der Gesellschaft beginnen, der $T a g$ der "Geburt Christi"179).

Auf verschiedene Weise haben viele völker versucht, ihrer Wunschvorstellung von Gerechtigkeit in einer Persönlichkeit von Fleisch und Blut Gestalt zu verleihen, einen Herrn zu schaffen, der für alle gleich ist, (...). Und nachdem alle diese Gedanken zu einem Gedanken zusammengefügt waren, erstand aus ihnen ein lebendiger Gott, der teure Sohn des Volkes - Jesus Christus"180)!

Schon in "Mat"" war dies zu beobachten: Christus, das Symbol für den volksnahen Gott der Gotterbauer, steht für einen Aspekt des Christentums, der für eine synthese mit marxistischen Gedanken of en ist; es ist das kritische Element des Protestes gegen die Institutionen Kirche und staat um einer gerechteren Geselischaft willen. So gesehen kann man beim Bogostroitel'stvo Gor'kijs tatsächlich von einem Versuch sprechen, Christentum und Marxismus zu versöhnen.

Ist 'Gott' einerseits der Verwendung des Christus-symbols gemäß das Produkt der Menschen, die Ihn "aus einem Bestandteil ihres Denkens geschaffen haben, um die Finsternis ihres Denkens zu erhellen"181); so wird er andererseits auch direkt mit dem Volk identifiziert: Gott ist gleich dem Volk; aber nicht dem real existierenden, sondern dem sich zum Kollektiv organisierenden volk. 
Der neue Gott, das neue Volk, entsteht "aus der Flamme des süßen Bewußtseines der geistigen Verwandtschaft eines jeden mit allen"182). Infolgedessen ist die marxistische/ proletarische Revolution, deren ziel es ist, eben diese geistige Verwandtschaft aller $z$ u realisieren in Gestalt einer gerechten Gesellschaft, "Gottes Werk"183). Und das "neue Leben" Matvejs, der sich diese Theologie angeeignet hat, wird zum nneuen Gottesdienst"184), zum Dienst am Volk und seiner Sache, der Revolution.

Matvejs Suche nach Gott, die inn durch ein breites spektrum seiner Gesellschaft gefüht hat, um inm diese als zerrüttet und zutiefst unmenschlich ("sie entstellen deinen Gott, nimm dich in Acht"185)!) vor Augen zu führen, läßt ihn wieder zu seinen Anfängen in neuer Qualität zurückkehren. Nachdem er den zusammenhang zwischen dem Bilde Gottes und dem Menschenbild einer Gesellschaft erkannt hat, bekennt er sich zu dem kollektiv organisierten volk, in dem der Mensch als Ganzer aufgehoben ist, als zu seinem Gott:

"Du bist mein Gott und Schöpfer aller Götter, die du gewebt hast aus der Schönheit deines Geistes in der Mühsal und dem Aufruhr deines Suchens! Und die Welt wird keine anderen Götter haben neben dir, denn du bist der einzige Gott, der Wundertäter. Das glaube ich und bekenne ich"186).

Durch die Gleichsetzung Gottes mit dem kollektiv organisierten volk ist auch die anfangs von Matvej gestellte Theodizee-Frage ${ }^{187)}$ beantwortet worden: Das Böse, das sich nicht mit der Definition Gottes als des absolut Guten in Übereinstimmung bringen läßt, hat seine Ursache in der Aufsplitterung Gottes, die inrerseits wiederum Zeichen der Aufsplitterung der Gesellschaft ist. Die Prä- 
dikate Gottes müssen also als Handlungsanweisungen für geselischaftliches/revolutionäres Handeln begriffen werden.

Auf einen ersten Blick mag es tatsächlich so scheinen, als habe der religiöse Gedanke Gor'kijs mit der emphatischen vergöttlichung des Volkes im vergleich mit vorangehenden Texten eine qualitativ neue stufe erreicht; betrachtet man jedoch genauer, was mit den Begriffen "Volk", "Gott", "Christus" verbunden ist, so wird viel eher die Kontinuität im Denken Gor'kijs deutlich, und Baranovs Vorwurf hinsichtlich eines platten "Demotheismus" in "Ispoved"" muß dann zumindest relativiert werden ${ }^{188)}$.

3. Die Synthese von Vernunft und Gefühl führt zur "Religion der Aktivität"

Der kollektive Aspekt, für den die Chiffre Gott in der Religion der Gotterbauer steht, bedarf der Ergänzung. Gott steht nicht nur für das kollektiv organisierte "Volk", sondern auch für das, was diese Organisierung ermöglicht und dauerhaft macht: die vernunft. Das Kollektiv als die Emanation der Vernunft entsteht aus der Erkenntnis des "Geistes" als des "Gemelnsamen" in allen Menschen"189). Erst auf der Basis dieser Erkenntnis ist die Schaffung der neuen Gesellschaft ("Gottes") möglich. Die bestehende Gesellschaft, die Matvej in ihrer zersplitterung kennenlernt, ist schlecht, weil unvernünftig:

"Gottes Gesetz ist die Milch des Geistes, aber zu uns gelangt nur die Molke"190).

Matvej ist ein später Nachfolger Konovalovs; denn seine Suche nach Gott ist nichts anderes als die suche nach einer vernünftigen Ordnung. Er erlebt es als einen Mangel der institutionalisierten Religion, daß sie den Gebrauch des Verstandes verteufelt 191), während für inn die "Kon- 
templation im Gebet eine Versenkung in die Tiefen meines Geistes" bedeutete, "wo die Wurzeln alles Seins Ilegen und wo der Gedanke wachsend emporstrebt wie ein obstbaum" 192). Das Gefühl, das den Ursprung von Matvejs Gottessuche bildet, sucht nach einem Halt in der Erkenntnis einer vernünftigen Ordnung; im Gespräch mit Vater Antonif heibt es:

"Wenn ich Gott auch nicht sehe", entgegenete ich, "so spüre ich Ihn doch, und nicht danach frage Ich, ob Er existiert, sondern wie die Gesetze zu fassen sind, nach denen Er das Leben organisiert"193).

Ebenso wie für Konovalov liegt für Matvej das Ziel seines Suchens in der Synthese von Gefühl und Vernunft; Iegudili weist inn darauf hin, daß es letztlich das ist, was er sucht:

"Die Gottbildner indes leben noch, sie sind unsterblich; gegenwärtig sind sie eifrig dabei, insgeheim einen neuen Gott zu schaffen, eben jenen, über den du dir den Kopf zerbrichst: den Gott der schönheit und Vernunft, der Gerechtigkeit und Liebe" $^{194)}$.

Der neue Glaube der Gottbildner verteufelt weder die Vernunft, noch vernachlässigt er das Gefühl; er läßt vielmehr die Synthese aus beiden zu einem Instrument der Erkenntnis werden - dies ist Iegudilis Vermächtnis beim Abschied von Matvej:

"Schau du nur mit allem, was du hast!" stieß er hervor. "Mit dem Herzen und mit dem Verstand! Sag ich dir denn: Glaube? Nein. Erkenne! sag ich"195). 
Erkenntnis aber dient dem Handeln; und hier tritt die Stoßrichtung der von Iegudill/Gor'kif propagierten neuen ReIigion zutage:

Es gilt, der falschen, weil von den Menschen und vom Leben wegführenden, Religiosität der "Geduld und Demut"196), die nichts anderes als eine Flucht vor dem Leben ist 197), eine Religion der Aktivität entgegenzusetzen, eine Religion, die zum verändernden Handeln führt. Diesen Sinn hat Iegudilis Gleichnis vom stein, das er einem falschen Verständnis vom Evangelium als einer Aufforderung zur Passivität entgegensetzt:

"Der Stein hier ist kraftlos. Warum? Weil er bewegungslos daliegt, Bruder! Und zu einem Menschen muß man nicht sagen: 'Bleib hier stehen!', sondern: "Geh von hier aus weiter!'"198)

Zunächst kann Matvej dies nur als Selbstneglerung des Menschen verstehen ${ }^{199)}$; erst später erkennt er, daß mit der neuen Religion eine Aufforderung zur Selbsttranszendierung des Menschen gemeint ist. Während er im alten Glauben Selbstaffirmation gesucht ${ }^{200)}$, aber nicht gefunden hat, gibt inm die neve Religion im "Einswerden mit den Menschen"201), das zunächst eine selbstaufgabe zu sein scheint, eben die gesuchte Bestätigung seines Ich. Im Kollektiv transzendiert der Mensch sich selbst, ohne sich zu verlieren.

Da diese neue Religion nicht aus der Defensive heraus, als "Krücke", entsteht, sondern aus einem "übermaß an Lebenskraft" entspringt, fürt sie nicht zu duldender Passivität, sondern "treibt den Menschenzur Tat"202) "Wahrer Glaube" - und der Glaube der Gottbildner ist ein Erkennen mit Herz und Verstand - "ist zwangsläufig eine Quelle des Handelns"203) . Damit ist Gor'kijs "Beichte" tatsächlich eine Erwiderung an Tolstoj ${ }^{204}$ ). Daher ist 
der "neue Gottesdienst", $2 u$ welchem der bekehrte Matvej "Im Namen eines neuen Lebens"205) aufruft, die Tat"206), die Sache der Revolution, und seine Botschaft wird zum "Evangelium des Proletariats"207):

Und so kehre ich denn dorthin zurück, wo die Menschen die Seelen ihrer Nächsten aus der Gefangenschaft der Finsternis und des Aberglaubens befreien, das Volk einen, inm sein wahres Gesicht zeigen und ihm helfen, sich der Kraft seines willens bewußt zu werden, wo sie ihren Mitmenschen den einzigen, den wahren Weg weisen, der zur Vereinigung aller führt, um der grossen Sache, der Erschaffung des Wel tengottes willen! (Vsemirnogo bogostroitel'stva radi) 208)

c) "Ispoved" - Kontinuität oder 'Abweichung'?

Auch für die Nilovna hatte das Eintreten für die Sache der Revolutionäre die Qualität eines Gottesdienstes angenommen. Auch sie hatte, durch die Hilfestellung anderer, den Weg vom alten zum neuen Glauben gefunden. Ebenso wie in "Mat"" sind in "Ispoved" Arbeiter Vermittler der neuen Religion. Insofern steht die Kontinuität von "Mat'" zu "Ispoved"" außer Zweifel. Dies gilt auch nach der eingehenderen Analyse der Elemente der gotterbauerischen Religion in diesem letzteren Roman. Trotz einzelner Akzentverschiebungen sind die Bestandteile von Gor'kijs Bogostroitel'stvo, wie sie sich aus dem Text von 1907 ergaben (Enquête), voll erhalten: die Kritik an der traditionelien Religion, die vision von einem neuen kollektiv organisierten Menschentypus, der Ansatz der Veränderung im Bewußtsein des Einzelnen, die Vergöttlichung des Menschen und schließlich die Synthese von Herz und Verstand, die eln durchgängiges Thema Gor'kijs ist und im Bogostroitel'stvo inren (vorläufigen) Abschluß findet 209 ). 
Verschiebungen im Akzent ergeben sich aus der unterschiedIichen Leserorientierung, die sich schon darin zeigt, daß Matvej nicht Arbeiter, sondern Baver ist, oder wie Lunatarskij betont: "Halbbauer"210). Während "Mat"" an Arbeiter adressiert war, die schon mehr oder weniger bewußt stellung (gegen den staat) bezogen hatten, denen aber die emotionale/religiöse Qualität ihres Kampfes bewußt gemacht werden sollte, ist "Ispoved" wieder deutlicher im Rahmen von Gor'kijs Kampf gegen die Mentalität des mescanstvo $z u$ sehen und im Zusammenhang damit gegen eine Literatur, die dieser Mentalität das Wort redet oder sie zumindest unangetastet läßt durch den verlust ihrer Verbindung mit dem Volk ${ }^{211}$ ). Dies ist aber nicht neu, sondern, wie schon gezeigt wurde, der Hintergrund, auf dem das Gotterbauertum Gor'kijs in seiner gesamten Entwicklung zu sehen ist.

Im Rahmen seiner Mitarbeit an der Capreser Parteischule, die von inm, Lunacarskij und Bogdanov organisiert wurde, hatte Gor'kij begonnen, sich intensiv mit der Geschichte der russischen Literatur zu befassen - und zwar eben unter dem Bllckwinkel von Individualismus und Kollektivismus, von Verbindung der Literatur, bzw. inrer Repräsentanten, der Intelligencija, mit dem Volk und inrem Getrenntsein. In den hierbei entstandenen vorlesungen zur russischen Literatur ${ }^{212}$ ) führt Gor'kij seinen kampf gegen den Individualismus ${ }^{213)}$ und die "Befürworter elner passiven Haltung gegenüber dem Leben"214) fort. Letzteren, zu denen er auch die "bogoiskateli" zählt, hält er eine realistische Literatur des "aktiven Prinzips" entgegen $^{215)}$.

Einer "individualistischen Romantik"216), die keine Bindung an volk und Geschichte kennt, stellt Gor'kij (s)eine "soziale oder kollektivistische Romantik"217) gegenüber: 
Diese Art (von Romantik) ist gerade im Entstehen begriffen, formiert sich gerade, und als ihre Trägerin sehen wir jene Klasse, die ins Leben tritt als Führerin der sozialistischen Idee der Befreiung der ganzen Menschheit aus den Fesseln des Kapitalismus, als Führerin der Idee der weltweiten Brüderschaft und freier Arbeit, - der sozialistischen Gesellschaf ${ }^{218)}$.

Was aber Gor'kij konkret unter solcher "sozialer Romantik" verstanden wissen will, illustriert sein Roman "Ispoved" 219). Die überstarke Betonung des Volkes als des göttlichen Kollektivs ist ebenfalis unter diesem Blickwinkel zu sehen. In der "Geschichte der russischen Literatur" - und noch expliziter in dem 1909 erschienenen Aufsatz "Razrusenie licnosti", der die teilweise Ausführung des in der "Geschichte" angelegten Planes ist - geht es Gor'kij darum, das Volk als den "unerschöpflichen Quell der schöpferischen Kräfte"220) zur Geltung zu bringen. Alles, was an Großem geschaffen wurde (und wird) war nur möglich auf der Grundlage einer engen Verbindung des Schöpfers mit dem Volk: der eigentliche schöpfer ist das Volk ${ }^{221}$.

War der Versuch einer Synthese von Gefühl und Vernunft als das Spezifikum der gotterbauerischen Religion Gor'kijs erkannt worden, so kann die Romanerzählung "Ispoved" weder als Abweichung noch als Wendepunkt 222) in seinem Werk qualifizlert werden.

Gor'kij zeigt in "Ispoved" in Anlehnung an das Marxsche Theorem der Abhängigkeit des Bewußtseins vom gesellschaftlichen Sein, daß die Beschaffenheit der Religiosität (des Einzelnen) Ausdruck für den zustand der Gesellschaft ist. Ist der Gegenstand religiöser Verehrung ein aufgesplitterter Gott, so bedeutet dies, daß die Geselischaft aufge- 
splittert ist. Matvejs Weg zu dem 'ganzen Gott' ist also identisch mit seinem Weg aus der Vereinzelung in das Kollektiv "Volk", weshalb Gor'kij auch "Gott" und "Volk" gleichsetzen kann. Wenn er dies tut, so bedeutet dies aber richtig gewendet nichs anderes als die Aufforderung, eine Gesellschaftsform zu schaffen, in der der Mensch als Einzelner aufgehoben ist ${ }^{223}$ ). Daß der Sozialismus eine solche Gesellschaftsform darstelle, glaubte Gor'kif schon 1907 in seinem Enquêten-Text.

Daß für Gor'kif die Synthese von Gefühl und Vernunft der (poetische) Ausdruck für eine solche angestrebte politische Realität war, zeigt eine Bemerkung von inm aus dem Jahre 1923:

Das beunruhigende Gefühl der geistigen Trennung der Intelligenz - als des rationalen Prinzips - von der elementaren Volksmasse (als des emotionalen) hat mich mein ganzes Leben mehr oder weniger verfolgt. Ich berührte in meinen 1 iterarischen Arbeiten unaufhörlich dieses Thema. (...) Wenn die Trennung von willen und Verstand ein schweres Drama im Leben des Individuums ist - so ist diese Trennung im Lehen eines Volkes eine Tragödie ${ }^{224)}$.

In ihrer Heftigkeit und vielfalt unerwartet für Gor'kij war die Reaktion auf seinen neuen Roman. Er wurde gelobt und verworfen von allen politischen Lagern ${ }^{25}$ ). Gor'kij fühlte sich zuletzt miBverstanden und distanzierte sich von seinem werk, das er jetzt als zu "didaktisch" einstufte 2 26).

Es konnte natürlich nicht ausbleiben, daß "Ispoved'" mit dem Gotterbauertum Lunacarskijs in Verbindung gebracht wurde, zumal der erste Band von "Religija i socializm" im gleichen Jahr erschienen war. Im marxistischen Lager 
waren es vor allem Plechanov und Lenin, die in Gor'kijs neuestem Produkt den Einfluß der Gruppe um Bogdanov sehen wollten.

In seinem 1909 erschienenen Artikel "O tak nazyvaemych religioznych iskanijach $v$ Rossil" (über das sogenannte religiöse suchertum in Rußland ${ }^{227)}$ konstatiert Plechanov, daß "Ispoved'", wie schon "Mat", ein Beweis dafür sei, wie wenig sich Gor'kif für die Rolle eines "Denkers und Verkünders" eigne:

Gor'kif, der in dem Roman "Mat"" die Rolle eines Verkünders des Sozialismus übernommen hatte, tritt in diesem Roman in der Eigenschaft eines Verkünders der 'fünten Religion' des Herrn Lunatarskif auf. Und dieser Umstand verdirbt die ganze Sache ${ }^{228)}$.

Nun kann man allerdings keineswegs behaupten, daß Gor'kij sich hier als Sprachrohr Lunacarskijs betätige; dafür sind die Unterschiede allzu deutlich ${ }^{229}$.

Matvejs/Gor'kifs Problem, das im Gotterbauertum seine Lösung findet, die Frage nämlich nach der synthese des "alten romantischen Paars Herz und Kopf"230), wille und vernunft, die Kernfrage, um die es im Roman und im Bogostroitel'stvo überhaupt geht ${ }^{231}$ ), lautet in Plechanovs materialistisch-marxistische Terminologie ubersetzt: "Wie ist der Begriff der Naturnotwendigkeit mit dem Begriff der menschlichen Aktivität in Einklang zu bringen"232)? Er sieht also sehr richtig, daß es Lunacarskij (und Gor'kij) um eine vermittlung von subjektivität und objektivität geht. Die "Subjektivisten" - und damit meint plechanov neben den Neukantianern hier Lunacarskij und Gor'kij hätten, ähnlich wie Matvej, die Marxisten gefragt: "Und wo bleibt der Mensch"233)? 
Mit großer Schulmeisterlichkeit, die dem Anliegen Lunacarskijs und Gor'kijs absolut nicht gerecht wird, weist Plechanov darauf hin, daß dieses Problem schon längst von Hegel und dann von Marx gelöst worden sel; daß allerdings deren Lösung die subjektivisten nicht habe befriedigen können, verstehe sich "von selbst"234).

Wenn Plechanov nun auch noch glaubt, im einzelnen nachweisen zu müssen, daß der Religions- und Gottesbegriff, den Gor'kif im Roman entfaltet, wissenschaftlich nicht haltbar, da mit den neuesten Forschungen zur Religionsgeschicht $e^{235)}$ nicht im Einklang sei, so argumentiert er voliends an der Sache vorbei. Dies gilt im übrigen auch für seinen Hinweis auf Hegel und Marx. Wenn "Subjektivisten" und manche Marxisten sich mit der von Hegel und Marx gefundenen Lösung für die frage nach subjekt und objekt nicht zufrieden geben mögen, so kann dies eben auch auf eine unbefriedigende Lösung hinweisen ${ }^{236)}$ ). Plechanov verhält sich unbeweglich wie ein Hüter kirchlicher Lehrmeinung.

Lenins Einschätzung des gesamten Gotterbauertums (in der Ausprägung von Gor'kif und Lunacarskif) läßt sich in seinem bekannten Satz vom "gelben und blaven Teufel" zusammenfassen 237), der hinfort die Rezeption dieser variante des Marxismus in der sowjetischen wissenschaft geprägt hat.

Stelit man sich die Frage nach der Verwandtschaft von "Ispoved"" mit dem religionsphilosophischen Marxismus Lunatarskijs nun erneut, so kann die Antwort nicht so eindeutig ausfalien wie bei Plechanov und Lenin.

Das Urteil V.L. L'vov-Rogacevskijs erscheint differen zierter und richtiger: Der "Gott" Lunacarskijs sei bei weitem nicht dasselbe wle das göttliche "Volk" bei Gor'kif; und das Bogostroitel'stvo Gor'kijs vertrage sich schlecht 
mit dem "Wirtschaftsprozeß" bei Lunatarskij; die Gotterbauer in "Ispoved" erinnerten eher an die frühen Christen.

Groß ist Gor'kijs Verdienst darin, daß er als künstler die Frage nach dem Zusammenfließen des zerstückelten Ich mit der Klasse gestellt hat, aber er selbst hat seine Lösung $z u$ einem negativen Resultat geführt,

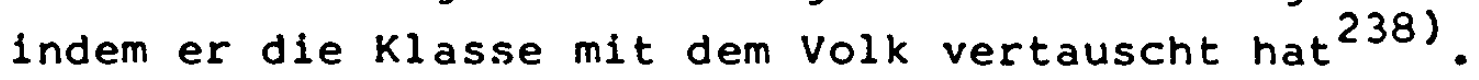

In der Tat, während man bei dem Roman "Mat" sagen kann, daß er das religionsphilosophische System Lunacarskijs ziemlich genau in Handlung umsetzt (ohne dessen Sprachrohr sein zu wollen!), muß man im Vergleich dazu feststellen, daß Gor'kij sich in "Ispoved" deutlich wieder von der Position Lunacarskijs entfernt. Zwar bleibt er sich selbst treu, insofern ist der Roman durchaus keine Ausnahme. Aber trotz des immer wieder beschworenen und für "Ispoved"" sogar wahrscheinlichen 239) Einflusses von Lunacarskif wird die Übereinstimmung deutlich geringer. Letzterer macht 1925 selbst darauf aufmerksam, daß der Roman in einigen Aspekten "ohne Zweifel über den Rahmen meiner damaligen Überzeugungen hinausging"240). Er selbst habe in den "fehlerhaften Terminus 'Bogostroitel'stvo' volikommen materialistische Ideen eingebracht", nämlich die von der "Umgestaltung der Welt, von der auch Marx gesprochen hatte"241). Gor'kif habe jedoch "in seine Romanhandlung einige Züge einer gewissen kollektiven Mystik oder einer Mystik des Kollektivismus gelegt" 242 ).

Letzteres läßt sich nicht bestreiten und gibt auch der wundergeschichte einen anderen Akzent als Gor'kif (im Nachhinein) beabsichtigt haben möchte ${ }^{243)}$.

wichtiger als mögliche Einflüse im Detall ist es für uns, die Punkte zu sehen, die Gor'kijs Bogostroitel'stvo, wie 
es in "Ispoved" zur Gestaltung kommt, von dem seines vermeintlichen Lehrers trennen. Es ist dies zuerst und vor allem die "soziale Romantik"244), die spätestens am Ende des Romans in eine "Mystik des Kollektivismus" umschlägt. Sodann die Ersetzung des Proletariats als Erlöser durch das "Volk" als den neuen Gott. Das Erlösermotiv,bei Lunacarskij zentral, und in "Mat'" ausgeführt, wird hier nur noch einmal angedeutet, wo die Verfolgung der Revolutionäre als "Herodesmorden" apostrophiert wird"245). Ein Anklang an die struktur von "Mat" "bleibt noch erhalten dadurch, daß Matvej einen Teil seiner Unterweisung im neuen Glauben in einer Fabrik bei Arbeitern erhält, zu denen inn Iegudilil schickt.

Weiterhin im Zusammenhang mit der neuen Größe "Volk" und dessen Mystifizierung ist der Verlust des materialistischen Geschichtsbildes $z u$ verzeichnen, das in "Mat" "durch die Figur Pavels gewährleistet war, und das aus Lunacarskijs System nicht wegzudenken ist. Die 'Geschichte' des Volkes, die Iegudili vor Matvej entrollt, ist nicht materialistische Analyse, sondern weit eher religiöser Mythos.

Somit fälit Gor'kijs (relative) Selbständigkeit, die für alle Phasen seines Gotterbauertums festgestelit werden mußte, auch hier weit mehr ins Gewicht als die ubereinstimmungen mit Lunacarskij.

\section{3. "Leto" (1909) 246)}

Wăhrend die Romanhandlung von "Mat"" vollständig, die von "Ispoved" zumindest in entscheidenden Teilen in der Fabrik, im proletarischen Milieu angesiedelt war, hat sich Gor'kij in der Romanerzählung "Leto" nun voll dem Dorf zugewandt. War der "Halbbauer" Matvej keinem der Bereiche Stadt, Dorf, Proletariat eindeutig zuzuordnen, so sind 
die Helden von "Leto" - bis auf den ICh-Erzähler Egor Petrovic Trofimov - allesamt Bauern ${ }^{247)}$.

Trofimov, der "aus der Niederschlagung der Volkserhebung (1905) seine Lehren gezogen und sich vorgenommen hat, die Menschen zu einigen"248), berichtet von einem Sommer agitatorischer Tätigkeit in dem Dorf Vysokie Gnezda, die durch seine Verhaftung im Herbst abgebrochen wird.

Daß es in diesem Roman nicht um die Wandlung eines religiösen Bewußtseins ("Mat'") und nicht um eine religiöse suche ("Ispoved") geht, zeigen schon die Figurenkostellation und der aktuelle Zeitbezug ${ }^{249)}$ : Aus dem MiBerfolg der Revolution von 1905, der nicht zuletzt durch den mangelnden Kontakt 2 wischen Arbeitern und Bauern und durch den mangel haften Bewußtseinsstand der letzteren zu erklären war, zieht der (intellektuelle) Revolutionär Trofimov die Konsequenz und geht aufs Land. Inm zur Seite steht eine Gruppe junger revolutionärer Bauern, an inrer Spitze Egor Dosekin mit hochentwickeltem Bewußtsein und scharfer analytischer Begabung. Daneben unzufriedene Bauern, deren Existenz durch die Stolypinsche Landreform, die Zerschlagung des 'mir' bedroht ist, die aber die zusammenhänge nicht verstehen; und auf der anderen Seite die reaktionären Kräfte des Dorfes, im Roman symbolisiert durch den finsteren Dorfpolizisten Semen. Das Thema des Romans lautet also - in einer aktuellen Formulierung Lenins von 1908:

Wählt ihr, die ihr euch noch eine Spur Bürgermut und Mitgefühl mit der Bauernmasse bewahrt habt! Das Proletariat hat seine Wahl bereits getroffen, und jetzt wird die Sozialdemokratische Arbeiterpartei entschlossener denn je die Parole des Bauernaufstandes gemeinsam mit dem Proletariat erklären, propagieren, in die Massen tragen, als das einzig mögliche Mittel, die Stolypinsche Methode der "Erneuerung" Rußlands zu verhindern ${ }^{250)}$. 
Trotz dieses anders gelagerten Themas soll der Roman hier kurz zur sprache gebracht werden, da zu zeigen ist, daß die Kontinuität der gotterbauerischen Vorstellungen Gor' kijs nicht nur schon vor "Ispoved" gegeben ist, sondern auch noch danach weiterbesteht. Daß dies der Fall ist, ist in "Leto" sehr leicht zu sehen, da hier alle für das Bogostroitel'stvo konstitutiven Elemente vorhanden sind.

Abgesehen von Egor Dosekin, der - wie Pavel - die rein rationale Seite der neuen Lehre verkörpert und dafür auch kritisert wird ${ }^{251)}$, messen die revolutionären Bauern inre Argumentation immer wieder an religiösen vorstellungen und bringen sie in religiöser Sprechweise zum Ausdruck:

"Wle sich zeigt, hat das Christentum Arme und Reiche vereinigt. Bringt das der Sozialismus auch fertig"252)?

Inhalt der neuen Lehre ist die "Wahrheit" (vgl. Pavel!):

"Sehen Sie, von neuem treten Propheten der Volkswahrheit in Erscheinung, und wenn diese heute auch anders, schärfer formuliert ist, so ist es dennoch die gleiche, alte, vom Volk selbst gründlich durchdachte Wahrheit.

Gemeint ist mit dieser Wahrheit eine gerechte (sozialistische) Lebensordnung - der Soldat Gnedoj hat sie bei den revolutionären Arbeitern erlebt ${ }^{254)}$; darum sagt der Waldhüter zurecht: "Eure Wahrheit ist genau die, die alle brauchen um leben zu können"255).

Während für den (orthodoxen) Dosekin die religiöse Frage "restlos"256) abgetan ist, hat der Sozlalismus für den im Kirchenslavischen gebildeten und von den Revolutionären 
als zuständig für Kirchenfragen angesehenen ${ }^{257)}$ Vanja Malysev, sowie für den alten Kuzin und Trofimov (IchErzähler) eine religiöse Dimension:

Die Zukunft ist das "gelobte Land"258), dagegen ist die Gegenwart ein Babylonisches Exil259). Die Lehre des Sozialismus ist ein lebensspendender Glaube ${ }^{260)}$, und in der revolutionären Sache ist das Leben selbst am Werk; der IchErzähler versteht sich als "Sachwalter des Lebens"261).

Es ist der Bauer Kuzin, der die jungen Revolutionäre vor einem bloßen Rationalismus warnt: "Ihr werdet euch noch im Dunkel eures sachlichen wissens verirrenl"262), und der die Ansicht vertritt, daß über den Begriff "Gott" noch nicht das letzte wort gesprochen sei 263). Sein Gottesbegriff ist der der Gotterbauer ${ }^{264)}$ :

"Helft Gott (...) Ihr seid vereinzelte Körnchen und Teilchen seiner unermeßlichen Macht, und wenn ihr euch zusammenschließt, so vergrößert inr diese seine Macht, seid ihr aber uneins, so vermindert inr sie" 265).

Dies meint dasselbe wie Trofimovs "heiliger Glaube an die Unüberwindlichkeit der vereinten menschlichen Kräfte"266). Das Glück einer zukünftigen Gesellschaft liegt im Kollektiv; das heißt, es gilt, eine Gesellschaftsform zu überwinden, die eine "verhängnisvolle Zweigötterei" ("Gott" - "Teufel" usw. - Dualismus) zur Folge hatte und "die Seele auseinanderriß, so daß diese kein einheitliches Ganze mehr bildete" 267).

Ein "einheitliches Ganzes" wird der Mensch für Gor'kij erst dann sein, wenn er den Dualismus von wille und Vernunft, Emotion und Ration in der neuen Gesellschaft überwunden haben wird; deren Synthese wurde als das Kernstück 
des Gotterbauertums erkannt. Sie bildet das zentrum von Trofimovs Glaubensbekenntnis. Dieser sieht sich als einer, der

bescheiden die Grube für das Fundament des Tempels der gerechten Vernunft und der seelischen Schönheit aushebt...268).

Diese Synthese ist auch die Antwort auf die Frage Vanjas (vgl. Konovalov, Matvej), die in das alte Theodizee-Problem mündet:

"Und ich will ja gar nicht höher sein als er (Gott), aber seine Gesetze will und muß ich begreifen. Warum gelten inm Babels Taten mehr als Zions" 269)?

So ist also zu sehen, daß in diesem Roman das Gotterbauertum zwar nicht eigens thematisiert wird, daß es aber anwesend ist, sofern vom Sozialismus immer im sinne des Gor'kijschen Bogostroitel'stvo gesprochen wird ${ }^{270)}$.

Der Ort, an dem dies geschient, das Dorf, und die an biblischen/volksreligiösen Mustern orientierte Sprech- und Denkweise der Revolutionäre 271 ) eröffnen noch eine weitere Dimension des Gor'kijschen Gotterbauertums, auf die schon am Ende des Kapitels über "Mat" hingewiesen wurde. Gemeint ist die Tradition des Narodnicestvo, verkörpert durch die Figur Bervi-Flerovskijs. 


\section{Anmerkungen}

1) A.V. Lunacarskij, RiS, I, S. 91.

2) ebd.

3) Lunatarskijs erste bekannte Äußerung zu "Mat"" flndet sich in "23-1j sbornik 'Znanifa'". In: Literaturnyj raspad, II, SPb 1909, S. 88.

4) R.D. KIuge, M. Gor'k1j. "Dle Mutter". In: B. Zelinski (Hrg.), Der Russlsche Roman. Düsseldorf 1979 , S. 242 .

5) dazu und auch welterführende Literatur bel Kluge, a.a.o.

6) Kluge, a.a.0., S. 245.

7) Kluge, ebd. S. 249.

8) PSS, 8, S. 168 .

9) Kluge, a.a.0., S. 252.

10) "Mat"", Kap. I, 3.

11) PSS, 8, S. 16

12) ebd., S. 17 .

13) U. Wilkens, Das Neue Testament. Übersetzt und kommentlert. Hamburg 1970, S. 304.

14) Zum pravda-Begriff s. Kluge, a.a.0., S. 259; D. Kegler, Untersuchungen zur Bedeutungsgeschichte von Istina und Pravda Im Russischen. Bern-Frankfurt/M. 1975 (= Europäische Hochschulschriften Reithe XIV, Bd. 4), S. $63-66$.

15) PSS, 8, S. 17; ebd. S. 41 .

16) ebd., S. 41 .

17) "Mat"", I, 8.

18) PSS, 8, S. 66.

19) "Mat", I, 16.

20) ebd., S. 87 .

21) ebd., S. 88 .

22) "Mat"", I, 8; 24.

23) ebd., S. 130. 
24) "Mat"", II, 9; 14; 21; 27. Vgl.R.W. Mathewson, Jr., The Positive Hero in Russian Literature. Stanford, California 21975 , S. 168.

25) PSS, 8, S. $314-317$.

26) ebd., S. 55 .

27) ebd., S. 56 .

28) ebd., S. 57 .

29) ebd.

30) ebd.

31) ebd.

31 a) gegen Mathewson, a.a.0., S. 169.

32) "Mat"", I, 5.

33) ebd., S. 34 .

34) "Mat"", I, 23.

35) ebd., S. 120.

36) ebd., S. 37 .

37) ebd.

38) "Mat'", I, 27.

39) ebd., S. 148.

40) ebd., S. 38 .

41) ebd., S. 153. Unterstr. v. m1r.

42) ebd., S. 127.

43) ebd., S. 96.

44) ebd.

45) ebd., S. 96/97; Unterstr. v. mir.

46) Ez. 36, $26-28$.

47) PSS, 8, S. 123.

48) ebd.

49) ebd., S. 58.

50) "Mat"", II, 1.

51) ebd., I, 7 .

52) ebd., S. 56.

53) ebd.

54) ebd.

55) ebd., S. 55. 
56) ebd., S. 57.

57) Es handelt sich hier um ein russisches sprichwort.

58) ebd., S. 57; Unterstr. v. mir.

59) s.u. Kap. VII.

60) PSS, 8, S. 134 .

61) ebd., S. 136.

62) Man kann aber nicht so weit gehen wie Borras

(a.a.0., S. 110), der behauptet, Rybin habe mit seinen gottbildnerischen Ideen den größten Einfluß auf die religiöse Entwicklung der Mutter.

63) PSS, 8, S. 56.

64) ebd., S. 20.

65) ebd., S. 28 .

66) ebd., S. 37.

67) ebd., S. 55; S. 78 u. pass.

68) ebd., S. 37.

69) ebd., S. 51.

70) ebd., S. 78 .

71) ebd., S. 87 .

72) ebd., S. 88 .

73) ebd.; die Mutter verwendet den Begriff "pravda", d.h., hier bedeutet "Wahrheit" zugleich "Gerechtigkeit".

74) "Mat"", I, 17, 18.

75) ebd., S. 56 .

76) ebd., S. 108 .

77) S.0. Anm. 14).

78) PSS, 8, S. 110.

79) Vgl.ebd., S. 108 (dle Revolutionäre als kollektiver Christus).

80) ebd., S. 163;

81) ebd.

82) ebd., S. 154; Hare (a.a.0., S. 73) betont, daß die Möglichkeit, in den Revulutionären Märtyrer zu sehen, es der Mutter erleichterte, sich von 
der Orthodoxie zu entfernen, "ohne ihrem Glauben untreu zu werden."

83) "Mat"", II, 1.

84) ebd., S. 183; Unterstr. v. mir.

85) ebd.

86) "Mat"", II, 8.

87) ebd., S. $213 / 14$.

88) Dies wird im Roman selbst thematisiert: II, 3; S. 184 .

89) ebd., S. 242.

90) ebd., S. $267 / 68$.

91) ebd., S. 282 .

92) ebd.

93) S.0. Anm. 88).

94) ebd., S. 338; Unterstr. v. mir.

95) ebd., S. 339; Unterstr. v. mir.

96) R. Meincke, a.a.0., S. 16 sieht Gor'kij mit

Recht als einen, der die "Wahrheit" nicht "besitzt", sondern an Ihre (religlöse) "Hellskraft" glaubt.

97) Kluge, "Die Mutter", a.a.0., S. 255.

98) Es ist also falsch, wenn B.D. Wolfe (a.a.0., S.91) behauptet, Gor'kif habe den pravda-Begriff durch den Sozialimus ersetzt. Gor'kij hat inn neu angefullt und inm elne antizipatorische Dynamik verliehen. Auf den antizipatorischen Charakter des Gor'kischen pravda-Begriffs weist schon eine frühe Briefstelle (1896) hin: "Ich habe (...) melne elgene Wahrheit, die gänzlich verschieden von der im Leben akzeptierten ist." (Archiv Gor'kogo, t.v, Moskau 1955, s. 13). Gerade dieses Antizipatorische im pravda-Begriff, wie er in "Mat"" entwickelt wird, macht das aus, was später als wesentlich fur den sozialistisch- 
realistischen Charakter des Romans reklamiert wird: das Aufzeigen des "Zukünftigen im Gegenwärtigen". (N. Gej, Metod, rozdennyj epochoj. In: Voprosy 11teratury. Nr. 5 (1963), S. 74.

99) PSS, 8, S. 56.

100) ebd., S. $169 / 70$.

101) "Mat"", I, 29.

102) ebd., II, 8; Borras, a.a.0., S. 110 : Die Mutter entwickelt sich von "elner Art religlöser Anschauung zur anderen, von der, die Gott im Himmel verehrt, zu der, die der Errichtung des Reiches auf Erden entgegenschaut."

103) Es genügt also nicht allein die Feststellung, die Nilovna habe die "Last religlöser Irrtümer abgeworfen." (P.J. Sumarev, Gor'kif o religil. Moskau 1960, S. 39.).

104) Borras, a.a.0., S. 109 sleht in diesem Simme die Haltung der Revolutionäre als Kontrast zu den gängigen zeitgenössischen Verhaltens- und Literaturmustern. (Pessimismus, militanter Individualismus).

105) s. "Citatel"", "O ciže..."

106) B.D. Wolfe unbegreiflich, wenn er behauptet, Gor'kif habe den Roman "aus seiner Vereinsamung und seinem ohnmächtigen Verdruß (wegen der gescheiterten Revolution 1905, R.S.) heraus" gescirieben. (a.a.0., S. 47.).

107) M. Gor'kij, Unzeitgemäße Gedanken über Kultur und Revolution. Hrg. von Bernd Scholz, dt. Frankfurt/M. 1974.

108) vor allem "Mat"", I, 7.

109) PSS, 8, S. 121.

110) ebd., S. 146, vgl. Jo 2,4 .

111) "Mat"", II, 20. 
112) ebd., S. 285 .

113) ebd.

114) S.u. Kap. VII.

115) In: Lew Tolstoi, Philosophische und sozialkritische Schriften. Berlin (Ost) 1974, S. 130 .

116) Schachnowitsch, Lenin und die Fragen des Atheismus. Berlin (Ost) 1966, S. 455.

117) L. Tolstoj, a.a.o., S. 134.

118) ebd., S. 135.

119) ebd.; Unterstr. v. mir.

120) M. Gork1, Briefe. Berlin (Ost) 1960, S. 37.

121) Zu denken ist auch an die Rousseauschen "Confessions"; zur Bedeutung, die Tolstojs "Beichte" für Gor'kif hatte, vgl. seinen Brief an Tolstoj, in dem er diesen um ein Stück Land bittet, um nach dem Vorblld anderer Tolstojaner elne Landkommune zu gründen: Brief vom 25. Apr11 1889; (G-30, $t .28$, Nr. 1).

122) Arch1v Gor'kogo, t. XI, S. 46.

123) Arch1v Gor'kogo, ChPG-34-1-5; zit. n. PSS, 9, S. 556.

124) PSS, 9, S. 271 .

125) ebd., S. 229.

126) ebd., S. $224 \mathrm{f}$.

127) ebd., S. 228.

128) ebd.

129) ebd., S. 233.

130) ebd., S. 341 .

131) ebd., s. 348 .

132) ebd., S. 343 .

133) ebd., s. 370 .

134) ebd., s. 388 .

135) Das Wunder am Ende von "Ispoved", das die endgültige Konversion Matvejs besiegelt, hat sofort nach Erscheinen des Romans eine kontroverse Diskussion ausgelöst. In der Tat ist es schwierig, 
darin nicht den Ausdruck elnes mystischen Bedürfnisses zu sehen. Für die Gesamt-Argumentation des Romans hat es nicht annähernd dle Bedeutung, die man inm zuspricht. Vermutlich trifft sich hier tatsächlich Gor'kljs Versuch, die Wandlung Matvejs durch einen vorweggenommenen, jetzt noch übernatürlich erscheinenden, Akt zu besiegeln, mit energet ischen Vorstellungen, für die Gor'k1j ein reges Interesse hatte. (Vgl. H. Setzer, Die Bedeutung der Energlelehre für die Literaturkonzeption Maksim Gor'kijs nach der ersten russischen Revolution. In: Die Welt der Slaven. JG. XXV, 2, N.F. IV, 2 (1980), S. $394-427)$. Setzer sleht darin die Umsetzung der Lehre $N$. Kotiks von der "psychologischen Gehirnstrahlung". (a.a.0., S. 400). Aus elnem Brief Kotiks an Gor'k1j vom 23.1.1909 geht jedoch hervor, daß Gor'k1j dessen Lehre zur zelt der Abfassung von "Ispoved" noch gar nicht gekannt hat. (PSS, 9, 540). Das "W1rken von hunderten von Kraftströmen" (PSS, 9, S. 388) spricht dennoch für den Elnfluß einer wie auch immer gearteten Energielehre. S. dazu U. Kap. VII.

136) PSS, 9, S. 389.

137) Vgl. PSS, 9, S. 538 (Dle Reaktion der offlziellen Kirche auf "Ispoved").

138) ebd., S. 235.

139) ebd., S. 256.

140) ebd., S. 271.

141) ebd., S. 315; Unterstr. v. mar.

142) ebd., S. $361 f$.

143) ebd., S. 366.

144) ebd., S. $343 ; 344$.

145) ebd., S. 342; vgl. S. 361 .

146) ebd., S. 359 .

147) ebd., S. 363. 
148) ebd., S. 370.

149) ebd., S. 377.

150) Vgl. "Razrusenie licnosti".

151) PSS, 9, S. 377 .

152) ebd., S. 389.

153) ebd., S. 271.

154) ebd., s. 229.

155) ebd., S. 256.

156) ebd., S. 264.

157) ebd., S. 282/83; 353; vgl. "Mat"".

158) ebd., S. 315 .

159) ebd., S. 271 .

160) ebd., S. 315.

161) Feuerbach, Sämtliche Werke. Stuttgart-Bad Cannstadt, 1960 - 1964, Bd. VI, S. 15.

162) PSS, 9, S. 322 .

163) ebd.

164) ebd., S. 361 .

165) ebd., S. 228 .

166) ebd., S. 229; 263.

167) "Casy", PSS, 3, S. 458.

168) PSS, 9, S. 341; Unterstr. v. mir.

169) ebd., S. 342 .

170) ebd., s. 343 .

171) syn ducha narodnogo, ebd., s. 346.

172) ebd., s. 347 .

173) ebd., S. 228 .

174) ebd.

175) ebd., S. 263; vgl. S. 268.

176) ebd., S. 339 .

177) ebd., vgl. "Mat'".

178) ebd., S. 341 .

179) ebd., S. 348 .

180) ebd.

181) ebd., S. $361 / 62$. 
182) ebd., S. 363; Unterstr. v. mir.

183) ebd., S. 380.

184) ebd., S. 384 .

185) ebd., S. 264.

186) ebd., S. 390.

187) ebd., S. 236.

188) Baranov hatte diesen Vorwurf gegen Gor'kif auf einer Versammlung der Petersburger ReliglösPhllosophischen Gesellschaft erhoben, worauf Inm Blok in einem Aufsatz erwiderte (A. Blok, Poezija 1 intelligencifa. In: Zolotoe runo, 1909, Nr. 1, S. 79ff).

189) PSS, 9, S. 363.

190) ebd., S. 325 .

191) ebd., S. 279.

192) ebd.; Unterstr. v. mir.

193) ebd., S. 302; Unterstr. v. mir.

194) ebd., S. 341; Unterstr. v. mir.

195) ebd., S. 349; Unterstr. v. mir.

196) ebd., S. 235; 259; 314.

197) ebd., S. 322 .

198) ebd., S. 339.

199) ebd.

200) ebd.

201) ebd., S. 366 .

202) ebd., s. 340 .

203) ebd., s. 370 .

204) In diesem Sinne wertet auch N.L. L'vov-Rogacevsklf die "Belchte" "als Versuch, (dem von Tolstoj aufgeworfenen Problem, R.S.) elne andere Lösung zu geben und einen Ausweg zu zeigen nicht nur fü: sich selbst, sondern für alle." (Obrazovanle, 1908, Nr. 7, otd. III, S. 20.). Und damit ist Iegudill mit sicherheit nicht, wie 
B.D. Wolfe (a.a.0., S. 73) behauptet, der alte Tolstof, sondern elne Replik auf Tolstoj.

205) PSS, 9, S. 384 .

206) Nach $R$. Hare ist es gerade der "Ruf zur Tat", der

Gor'kif zu den Marxisten zog. (a.a.0., S. 54).

"Istorifa russkof literatury", t. X. Moskau-Leningrad 1954, S. 331 falsch, wenn dort behauptet wird, Gor'kif bringe in "Ispoved"", im Gegensatz zu "Mat" "kelne aktiven Kräfte" zur Darstellung. Diese sind gerade sein Thema!

207) PSS, 9, S. 538 .

208) PSS, 9, S. 390.

209) Wolfe richtig: "Gork1 hatte derartige Gedanken schon lange gehegt." (a.a.0., S. 75).

210) Literaturnyf raspad, II, S. 90.

211) Vgl. "Dacniki", "Zametki o mescanstve".

212) "Istorija russkof literatury. Archiv Gor'kogo, I, Moskau 1939.

213) ebd., S. 264 u. pass.

214) ebd., S. 117 .

215) ebd.

216) ebd., S. 70.

217) ebd.

218) ebd.; vgl. Gor'kij, Dve dusi.dt. In: M.G., Die Zerstörung der Persönlichkelt. Aufsätze. Dresden 1922, S. 164. (Russisch erschienen 1915).

219) Vgl. zu der antilindividualistischen und antimodernistischen Stoßrichtung des Romans den Brief Gor'kijs an die Peskova (April 1909) Archiv Gor'kogo, IX, S. 46.

220) Istorifa russkof literatury, S. 43.

221) Vgl. "Razrusenie licnost1". In: Ocerk1 fllosof 11 kollektivizma, t. I. SPb 1909, S. 353. Diese Vorstellungen haben ihre wurzeln in der europälschen Romantik. 
222) L. Andreev, Literaturnoe nasledstvo. t. 72, S. $531 \mathrm{f}$.

223) Da es sich hier um elne Aufhebung im dialektischen sinne handelt, bedeutet dies nicht zwingend den Verlust der Individualität und eines persönlichen Gottes.

224) G'-30, t. 15, S. 81; Vgl. auch Borras, a.a.0., S. 31f. Das Thema: Trennung von volk und Intelligenz behandelt Gor'kij am ausführlichsten in seinen Dramen: "Varen'ka Olesova", "Daknik1", "Varvary", "Det 1 solnca".

Vgl. dazu auch Istorifa russkoj literatury, t. X. Moskau-Leningrad 1954, S. 237.

225) PSS, 9, S. 535 - 560 .

226) G'-30, t. 29, S. 75.

227) G.V. Plechanov, Soxinenifa, t. XVII, S. 197 - 309.

228) ebd., S. 259.

229) S.u.

230) R. Barthes, Mythen des Alltags. Frankfurt/M. 21970 , S. 34 .

231) s.o.

232) Plechanov, a.a.0., S. 267.

233) ebd.

234) ebd.

235) E.B. Tylor, J. G. Frazer u.a.

236) Vgl. Lunatarskif, Kap. IV.

237) Lenin, PSS, 48, S. 226, vgl. I, Anm. 18).

238) Obrazovanie, 1908, $\mathrm{Nr} .7$, otd. III, S. 30.

239) In dem Artikel "M.Gor'k1j - chudoznik" schreibt Lunacarskij: "Es gibt ein gewisses - wenn auch kleines - Quentchen meiner Schuld an diesem Produkt." (Lunacarskif, Sobranie socinenif $v$ $8 \mathrm{ml}$ tt., t. 2 Moskau 1964, S. 128.).

240) A.v. Lunacarskij, Kriticeskie ètjudy. Leningrad 1925, S. 4.

241) ebd. 
242) ebd.

243) Anläßlich elner Neuauflage des Romans schrelbt Gor'kif 1930 an A.B. Chalatov, man solle dem Buch Auszüge aus einem Artikel Vojtolovskijs belfügen, in dem dieser das Wunder als "Hypnose der Masse" - d.h. "naturwissenschaftlich" erkläre. Archiv Gor'kogo, t. X, s. 194.

244) S.0. S.283.

245) PSS, 9, S. 370.

246) Begonnen 1908 (PSS, 9, 569).

247) Nach PSS, 9 , 569ff; 571 gehört "Leto" in den Zusammenhang von Plänen Gor'kij zu einem Roman "Syn".

248) PSS, 9, 466.

249) Gor'kif benutzte neben anderem Material die Aufzeichnungen eines Bauern, der auf dem Lande Aufklärungsarbelt betrieb. (PSS, 9, S. 569). Aus dem zeltbezug resultiert wohl auch das publizistische und didaktische Element, das schon von Zeitgenossen moniert wurde. (PSS, 9, S. 581).

250) Lenin, werke, Bd. 13. Berl in ${ }^{4} 1972$, S. 465. 251) PSS, 9, S. 431;433;436;461;463;487; 500 . 252) ebd., S. 398.

253) ebd.; vgl.S. 401; 416; 433 (Unterstr. v.m1r.). 254) ebd., S. 430.

255) ebd., S. 433.

256) ebd., S. 461; 462 .

257) ebd., S. 462; 61 .

258) ebd., S. 415; 440.

259) ebd. S. 430.

260) ebd. S. 418.

261) ebd., S. 467.

262) ebd., S. 481.

263) ebd.; s.a. 460. 
264) "Ispoved".

265) PSS, 9, S. 504 .

266) ebd., S. 511 .

267) ebd., S. 456 .

268) ebd., S. 467 .

269) ebd., S. 458 .

270) Dabel fällt (als kompositorlsche Schwäche) auf, daß nicht eine Figur dem Bogostroitel'stvo eindeutig zugeordnet werden kann.

271) ebd., S. 415;418;430;435;440;462;465f; $508 ; 513$. 
VII. Das Narodnicestvo als Erbteil in Gor'kijs

Bogostroitel'stvo: v.v. Bervi-Flerovskij ${ }^{1}$ )

Nach Gor'kijs eigenem Zeugnis beginnt seine politische Lehrzeit in den Kreisen der Narodniki. Während seiner Kazaner zeit besucht er deren sämtliche zirkel, hört Vorträge eines aus der Verbannung zurückgekehrten Volkstümlers und beteiligt sich an der revolutionären Lektüre, zu der neben Lavrovs "Historischen Briefen" auch das "ABC der Sozialwissenschaften" von Bervi-Flerovskij gehörte. $\mathrm{Ja}$, er betätigt sich sogar selbst als volksaufklärer. ${ }^{2)}$

Über Bervis "Azbuka" ${ }^{3)}$ nält er in dieser zeit ein Referat $^{4}$ ). Seine aktive Laufbahn als Narodnik findet ihren Höhepunkt und ihr jähes Ende im Sommer/Herbst 1888, als er mit dem Volkstümler Romas zur Aufklärungsarbeit aufs Dorf gent ${ }^{5}$ ).

1892 lebt Gor'kij in der sogenannten "Kommune", die zu einem Zentrum der "studierenden und arbeitenden Jugend" wird6). Dort hat er häufigen persönlichen Kontakt mit Bervi-Flerovskij ${ }^{7)}$. Im Sommer desselben Jahres unternehmen Gor'kif und Bervi gemeinsam eine Wanderung durch Transkaukasien:

Mit Flerovskij stand ich in einem ausgezeichneten Verhältnis, ich wanderte mit inm durch Transkaukasien $^{8)}$.

Aufgrund des recht intensiven Kontaktes ist die Annahme also berechtigt, daß die Vorstellungen dieses etwas aussenseiterischen Vertreters des Narodnicestvo einen gewissen Einfluß auf die Formierung von Gor'kijs revolutionärem Bewußtsein hatten ${ }^{9}$ ). 


\section{Der revolutionäre Außenseiter}

Bervi-Flerovskij war publizistisch äußerst aktiv; so veröffentlichte er mehr als fünfig Werke über Ökonomie, Sozialpolitik, Philosophie, Naturwissenschaften, darunter auch Romane, die aber nur mühsam in Handlung verkleidete ideologische Abhandlungen darstellen ${ }^{11}$ ). Die meisten seiner Schriften sind heute vergessen; jedoch war er in den siebziger Jahren einer der geistigen Führer der revolutio nären Jugend. Seine Schriften "ABC der Sozialwissenschaften" (1871) sowie die "Lage der Arbeiterklasse in Rußland" (1869) bildeten deren "unentbehrliche Lektüre"12).

Das "ABC" hatte er für den Kreis der Cajkovcy verfaßt"13), und auch mit den Dolgusincy stand er in enger Verbindung; für sie schrieb er verschiedene Broschüren ${ }^{14}$ ). Wie die meisten seiner revolutionären zeitgenossen hatte er in seinem ideologischen Gepäck die Schriften von Cernysevskij, Herzen, Saint-Simon, Fourier, Owen. Den Sozialismus wollte er auf friedlichem Wege - durch Aufklärung - eingeführt wissen, als Keimzelle dafür sollte die russische obscina dienen. Seine Vorstellung von der Veränderung der Geschichte kommt ohne die Kategorie des Klassenkampfes aus, wenn er sagt, im Bewußtsein der Menschen müßten an die Stelle von Feindschaft und Konkurrenz ("Kampf ums Dasein"15), solidarität und Brüderlichkeit ("Bund fürs Dasein"16), treten.

Für unseren Zusammenhang von Bedeutung ist die Tatsache, daß Flerovskij sein Ideal einer neven Gesellschaftsordnung, die auf Gleichheit, Brüderlichkeit und Liebe basiert, zum Teil als Lehre von einer "neuen Religion" formulier$t e^{17)}$. 
2. "Azbuka social'nych nauk" (1871) und "Kak dolzno zit' po zakonu prirody i pravdy" (1873)

In der "Azbuka" entwickelt Bervi eine Art "Philosophie und Moral des Kollektivismus"19).

In der bisherigen Geschichte, die, so Bervi, ein Kampf zwischen "Anarchie" und "Zähmung" (d.h. zwischen ungeordnetem Gegeneinander und organisierter Gesellschaft = Organismus) ist ${ }^{20)}$, wurde das "religiöse Gefühl" (Gor'kij!) der Menschen mißbraucht, indem die alten Religionen im Verein mit den jeweiligen Machthabern daraus ein Unterdrückungsinstrument gemacht haben ${ }^{21}$ ). Wenn nun gegen die Religion der Unfreiheit das Ideal der "Freiheit" gesetzt wird, so tritt an die stelle der "Gottheit" die "Geselischaft"22).

Wenn aber der religiöse Enthusiasmus durch den gesellschaftlichen ersetzt wird, der Gott durch die Gesellschaft, so wird auch der Durst nach Macht durch das Streben zur Bruderschaft und zur Gleichheit, das Glück der Herrschaft durch das Glück der brüderlichen Liebe ersetzt ${ }^{23}$ ).

Dies zu erreichen ist letztlich ein Erziehungsproblem; denn das "religiöse Gefühl" kann nur miBbraucht werden, solange es instinktiv, unbewußt ist, solange der Dualismus "Religion" - "Rationalismus" besteht. Wenn aber das "religiöse Gefühl" bewußt gemacht wird (Erziehung), und dem als richtig erkannten ziel, nämlich der Organisierung der neuen Gesellschaft, zugeordnet wird - Bervi nennt dies "selbstbewußter Rationalismus"24) - so fällt der alte Dualismus weg, und (religiöses) Gefühl und Ratio gelangen zur Synthese: 
Das wahre ziel des entzückten Enthusiasmus (= religiöses Gefühl R.S.) soll die Sympathie des Menschen zum Menschen bis zum Maximum entfalten ${ }^{25)}$.

Diese neve Religion, deren Gegenstand der Organismus "Gesellschaft" ist, behauptet von sich, eine "rationalistische Religion" $z u$ sein"26), denn es könne nur darum gehen, ein "Naturgesetz" zu erkennen:"die organische Solidari$\underline{t a ̈ t " 27)}^{2}$

So wie die einzelnen Zellen eines Organismus' im Interesse des Ganzen zusammen- und füreinander arbeiten ("Solidarität"), so müssen auch die Individuen einer Gesellschaft um des Wachstums des Ganzen willen zusammenarbei$\operatorname{ten}^{28)}$.

So wird in der neuen Religion das Volk anstelle von Christus oder Gott zum Gegenstand der Verehrung und Liebe ${ }^{29)}$. Der Elnzelne findet sein Glück im kollektiven Handeln:

Der Mensch kann nur dann fühlen, daß er in der Richtung des Planes seiner Organisation handelt, wenn er aus seinem eigenen wohl und dem allgemeinen Wohl ein Ganzes bildet; nur dann fühlt er sich vollkommen glücklich, wenn er solidär mit den ihn umringenden Menschen handelt ${ }^{30}$ ).

Daß er dies tut, daß er das allgemelne Gesetz der "organischen Solidarität" als Gesetz seines eigenen Handelns erkennt und annimmt, ist eine Frage der Bewußtmachung, der "Bildung" (Gor'kij):

Die Bildung ist ein unumgänglicher Grundstein, um die Idee der Solidarität zu entwickeln ${ }^{31}$ ). 
Die Inteligenz (gemeint sind die Narodniki) habe als erste begriffen, daß sie sich aus einer "durch Gewalt" in eine "durch überzeugung herrschende Macht" wandeln müsse 32 ).

Nun war zwar die Affinität von Sozialismus und Religion schon zur Tradition geworden: seit Saint-simon, Fourier, Babeuf, Lamennais, Owen; und Bervi betrachtete die frühen Sozialisten als seine Vorläufer, wobel er ihnen allerdings die Vernachlässigung des erzieherischen Moments anlastete. Es gab für ihn jedoch nach seinem eigenen Zeugnis auch einen ganz konkreten AnlaB dafür, seine kollektive Gesellschaftslehre als eine "Religion der Gleichheit" zu formulieren ${ }^{33 \text { ) }}$.

Durch den "selbstlosen Enthusiasmus" 34 ), mit dem sich die jungen Revolutionäre auf den "Gang ins Volk" vorbereiteten, sah er sich an die ersten christen erinnert und kam zu der Überzeugung,

daß man einen Erfolg (der Propagandatätigkeit R.S.) nur dann erwarten könne, wenn der Ausbruch von Enthusiasmus, der die Jugend erfaßt hatte, in ein beständiges, nicht auszurottendes Gefühl umgewandeli würde 35 ).

Ergebnis dieser überlegungen war die oben dargelegte "neue Religion":

Man muß das Volk lehren, alle selne Kräfte sich selbst zu widmen, man muß es fähig machen, zu leben und alles zu ertragen um seiner Brüder willen; und sie (die Brüder) allein sollen Gegenstand seiner Liebe und brennenden wünsche sein; an sie allein sollen seine glühenden Gefühle gerichtet sein; sie allein sollen in seinen Augen höher als alles stehen und sollen das ganze ziel seines Lebens ausmachen, sie (die Brüder) sollen seine (des Volkes) Religion sein ${ }^{36}$ ). 
Es geht also einerseits darum, daß die jungen Narodniki inre Propagandatätigkeit als einen 'religiösen Akt' begreifen oder vielmehr empfinden - Bervi hat schon den gleichen verkürzten Religionsbegriff wie nach inm Gor'kij und Lunacarskij, indem er das Wesen der Religion auf den Enthusiasmus, das Gefühl reduziert; die jungen Revolutionäre sollen sich als "Apostel" der neuen Religion verstehen" 37 ).

Andererseits soll aber dasselbe "religiöse Gefühl" das Vehikel sein, auf dem die Botschaft von der neuen Gesellschaft zu ihren Adressaten, dem Volk oder den Bauern gelangt.

Der Bauer, der an die Sprache von Sektierern und Wanderpredigern gewöhnt war und in einer eigenen Welt von Volksreligiosität lebte (vgl. z.B. Larion und Savelka), konnte am besten erreicht werden, wenn man sich eben dieser sprache bediente.

Diesem Aspekt trugen die Broschüren Rechnung, die Bervi in den siebziger Jahren für volkstümlerische Kreise auf deren Bitten verfaßte 38 ).

Über "Kak nado zit"" schreibt Bervi in seinen Memoiren, die Broschüre sei verfaßt

in Jener sprache, in welcher die Propheten schrieben, welche den raskol (spaltung) predigten. Sie rief die Gläubigen auf, ihr Blut zu vergießen und alle Qualen zu erdulden und $z u$ leiden für ihre Brüder bis zum Ende 39 ).

Zwar werde in der Schrift kein einziger Evangelientext direkt zitiert, dennoch habe sie bei den Bauern einen "rein religiösen Eindruck" hinterlassen ${ }^{40)}$ : 
Das ist er, der wahre Glaube! rief der Bauer, wenn er das Buch gelesen hatte. So muß man nach der Wahrheit (pravda!) leben! Und er legte das Buch zu den Ikonen, wo bei inm alles Hellige untergebracht war ${ }^{41)}$.

Tatsächlich ist diese Schrift nach dem Muster eines Lehrgesprächs Jesu mit seinen Jüngern aufgebaut und gebraucht biblische Wendungen, die sofort mit Jesus-Worten assozilert werden, ohne solche direkt zu zitieren: Statt "geht in alle welt und lehret alle völker...!" heißt es am Beginn:

Gehet ins Volk und sagt inm die ganze Wahrheit bis aufs letzte Wort, und wie der Mensch leben soll nach dem Gesetz der Natur ${ }^{42}$. Nach dem Gesetz sind alle gleich ${ }^{43)}$.

Die "Jünger fragen den Melster", und er antwortet "Wahrlich, ich sage euch..!"44). Seine worte sind das "Gesetz der Wahrheit", und aus dem biblischen Himmel reich wird so das "Reich des Gesetzes" 45 ).

Als er von seinen Jüngern ging, sprach er zu ihnen ein letztes Wort. Als er sich an die Gesetzlosigkeit erinnerte, die überall auf Erden herrschte, und an die Leiden der Menschen, flossen über sein Angesicht, (...) heiße Tränen, (...). Das Glück für die Menschen und die irdischen Freuden werden allein aus der brüderlichen Liebe geboren. (...) o, ihr finsteren und unvernünftigen Menschen, hört die Große Wahrheit, ihr werdet nur dann Glück erfahren, (...), wenn ihr beginnt, einander mit der süßesten Liebe zu lieben und daraus nicht euch über den andern erhebt, sondern gleich sein wollt. Wer mit reinem Herzen und mit hellem Verstand das Gesetz der Gleichheit versteht, der allein ist würdig, und er allein ist tugendhaft ${ }^{46)}$. 
In der gleichen Manier ist auch die Broschüre "K russkomu narodu" (An das Russische Volk) verfaßt.

Zwar lag nach Bervis Einschätzung in den siebziger Jahren eine "neue Religion in der Luft"47), und er bezweifelte daher zunächst nicht, daß eine "tätige, kämpfende Religion (Gor'kij! R.S.) der Gleichheit eine große Macht" werden könne ${ }^{48)}$; doch mußte er später erkennen, daß sein Projekt einer Synthese des "religiösen Gefühls" mit der rationalen (weil "gesetzmäßigen") Ordnung einer Gesellschaft von Gleichen von Anfang an zum Scheitern verurteilt war:

Das Volk war nicht fähig, ein religiöses Gefühl zu seinen Brüdern zu heben, dies vermochte es nur gegenüber der Gottheit, und damit wurde alles verdorben ${ }^{49}$ ).

Die Einsicht, daß der Enthusiasmus allein als Vehikel zur Erkenntnis und Annahme der "Wahrheit", des "Gesetzes der Gleichneit" nicht ausreichte, veranlaßte Bervi dazu, seine Gesellschaftslehre neu auszuarbeiten als eine "rationale Religion" 50 ) und in einem programmatischen Roman darzulegen.

\section{3. "Na Zizn' i smert'" (1877)}

In diesem Roman, der im literarischen Sinne kaum als Roman, sondern als ein Konglomerat von Gedanken $z$ bezeichnen ist, entwickelt der Held Skripicyn, akkompagniert von einigen Nebenfiguren, seine (=Bervis) "rationalistische Religion"51). Während Bervi im "ABC" die "organische Solidarität" 52 als das Grundyesetz der Natur bezeichnet hat, das auf die Gesellschaft übertragen die Religion der "brüderlichen Gleichheit" verlangte, so nennt er das Gesetz jetzt das "zueinander von Gleichem"; Sympathie und Harmonie (was dasselbe 
meint) - dies seien Prinzipien, die sich aus der Natur ablesen ließen, und die auf die Gesellschaft zu übertragen $\operatorname{seien}^{53}$ ).

Fortschritt bedeute folglich wachsen der Sympathie ${ }^{54)}$. Des Menschen "Sympathie zur ganzen Welt" manifestiere sich als "religiöses Gefühl"55).

Wenn Bervi nun fordert, daß dieses Sympathie-Prinzip zum Organisationsprinzip der Gesellschaft werden ${ }^{56}$ ) müsse: "Ein Organismus, das ist es, was die menschliche Natur aus der Menschheit zu machen bestrebt ist" 57), so wird offensichtlich, aus welcher Quelle er hier geschöpft hat. Es ist dies das Grundgesetz der "universellen sozialen Harmonie", das Fourier entdeckt zu haben glaubte:

Ich bin der Entdecker der mathematischen Berechnung des Schicksals, einer Berechnung, die Newton auf der Hand $l$ ag und die er dennoch nicht einmal flüchtig erahnte; er hat die Gesetze der Anziehung der Materie aufgestelit und ich nun diejenigen der leidenschaftlichen Anziehung (Zueinander von Gleichem, Sympathie R.S.), deren Theorie vor mir kein Mensch erörtert hat. Die leidenschaftliche Anziehung ist der Urgedanke, dem Gott alle Veränderungen der Materie, die Ordnung der universellen Bewegung und der sozialen Bewegung der Menschen in allen Welten unterstellt hat $^{58)}$.

Auch die aus dem Gesetz der Sympathie hervorgehende vorstellung, daß man unter den Menschen eine "Zelle" bilden müsse, "die sich durch die solidarische Sensibilität eines Organismus auszeichnet" ${ }^{59)}$, läßt an Fourier und seine Phalansterien denken. 
Das zu propagierende neue Ideal der Menschheit besteht darin, daß das Kampfelement aus der Geschichte verschwindet und der "Sympathie" Platz macht ${ }^{60)}$. Dieses Ideal sei aber kein Traum, sondern eine "Tugend", ein "aktives Verhalten"61). (Gor'kij!)

Die Anerkennung und Erkenntnis des Gesetzes der Sympathie führt nun endlich dazu, daß der in der Menschheitsgeschichte miBbrauchte und fehlgeleitete "religiöse Instinkt" seinen richtigen Gegenstand findet: In der aktiven Verfolgung des Ideals kann er zum "religiösen Gefühl" werden"62).

Das Ende religiöser Irrtümer besteht also darin, daß der Mensch für seinen "religiösen Instinkt" den richtigen Gegenstand $f$ indet:

Das, was für dein Herz das zentrum alles Heiligen sein soll, das nimm aus der Natur (Sympathie, Harmonie R.S.); wenn du dein Ideal schaffst, geh nicht über die Fakten hinaus, sondern verstehe, ihren Sinn zu erfassen. Wenn du erst deine Religion auf dieser Grundlage errichtet hast, dann wirst du dich freuen an jeder neuen wahrheit und an der Entwicklung der wissenschaft, und wirst sie nicht verfolgen ${ }^{63}$ ).

Bis hierher unterscheidet sich die "rationalistische Religion" noch nicht sehr von der "Religion der Gleichheit und Brüderlichkeit" - wenn man einmal davon absieht, daß die Quellen deutlicher sichtbar werden. Doch nun wird der Analogieschluß von der Natur auf die menschliche Gesellschaft (Sympathie, Anziehung usw.) wieder umgekehrt (von der Gesellschaft auf die Materie): Die Sympathie unter den Menschen als Teilen eines Ganzen ist nicht die 'magnetische Anziehungskraft', sondern hat etwas mit Bewußtsein zu tun. 
Die eine Wahrheit, die in der Natur zu erkennen ist und die auch für die Geselischaft gilt, heißt jetzt "Denken": Das Organisationsprinzip in der Natur ist das "selbständige Denken der Teile"64) . Das "Rationalistische" an der neven Religion ist also das energetische Prinzip, nämlich daß das Denken als organisierende Kraft den gesamten Kosmos beherrscht ${ }^{65)}$. Wenn die Menschen ihre Religion aus der Natur schöpfen, wo das Gesetz der selbständig denkenden Telle eines Ganzen zu finden ist, dann bedeutet dies die endgültige überwindung des Dualismus "religiöses Gefühl" - "Vernunft"; denn nun ist alles unter dem einen Prinzip des "Denkens" begriffen ${ }^{66)}$ und zur synthese gebracht.

Sowelt die "rationale" Begründung der "Religion der brüderlichen Liebe"67).

Daß die Organisationsform einer auf diesem Prinzip aufgebauten Gesellschaft das $\frac{\text { kollektiv }}{69}{ }^{68)}$, und daß dies durch Erziehung erreicht wird ${ }^{69)}$, ist nur logisch. Zusammengefaßt lautet die neue Lehre:

Damit die Menschheit endich den großen Gedanken des Fortschritts in der Natur verwirklichen und aus der Sammlung der Menschen ${ }^{70)}$ einen Organismus schaffen könne, muß jeder Mensch vom allerersten $\mathrm{Tag}$ seiner Bewußtwerdung an in sich jenes Ideal tragen, Jenen Grundgedanken ${ }^{71}$, aus welchem heraus ein Leben fedes einzelnen für alle und aller für jeden einzelnen ${ }^{72}$ ) sich entwickeln muß, ein Organismus, der sich zusammenschließt und wächst durch die erhabenen und die Menschen anziehenden Gefühle. Dieses Ideal soll das ziel sein (...), es soll für die Menschheit das Heiligste und Größte sein, ihre Religion $^{73 \text { ). }}$ 
4. Der Anteil des Narodnicestvo (Bervi) in Gor'kijs Bogostroitel'stvo

Kunkl. 74) berichtet in seinem Buch über die Dolgusincy, daß man im Gepäck eines gefangengenommenen Narodnik neben den "Paroles d'un croyant" ("Slova verujuscego $k$ narodu") des Abbé Lamennais, den Evangelien und anderen Schriften Bervis "Azbuka", "K russkomu narodu" und "Kak dolzno zit"" gefunden habe ${ }^{75}$ ) . Man muß schon aufgrund der biographischen Fakten ${ }^{76)}$ davon ausgehen, daß auch Gor'kij den Inhalt dieser Schriften in seinem geistigen Gepäck hatte und, wie sich zeigt, auch bewahrte.

Äußerliches Verwandtschaftsmerkmal zwischen Gor'kif und Bervi ist die Sprache; Bervi hält sich bei der Abfassung seiner Propagandaschriften, die bei der Verbreitung der neuen Lehre helfen sollen, an die Sprache der Volksreliglosität, die mit Bildern und Redewendungen aus den Evangelien durchsetzt ist. Im selben sinne schreibt Gor'kij leser-/adressatenorientiert, wenn es darum geht, die neue Lehre, den Sozialismus, als Religion zu verkünden, wobel selbst der Aspekt "Sozialismus als Religion" schon ein Stück Leserorientierung ist ${ }^{77}$ ).

Auch die Tatsache, daß bel beiden - Bervi und Gor'kij die neue Geselischaftslehre im religiösen Gewand auftritt, ist noch relativ äußerlich und begründet nicht unbedingt ein Vaterschaftsverhältnis. Gor'kij folgt Bervi jedoch nicht nur in der Form, sondern auch in der inneren Struktur des Religionsbegriffes. Für belde ist Religion, Religiosität reduziert auf ein emotionales Moment, das seinen richtigen Gegenstand und damit seine wahre Aktualisierung erst durch die Elnbettung in ein bewußt, das heißt vernüntig organisiertes gesellschaftliches Gefüge (Sozlalismus, Kommunismus) erfährt. 
Zentrum der Bervischen Geselischaftslehre ist der Begriff "pravda" mit seinen religiösen und ethischen Konnotationen ${ }^{78)}$. Bervis pravda beruht in einer vernünftigen und dadurch gerechten gesellschaftlichen Ordnung; 'vernünftig' ist hier synonym mit 'gerecht', weil das Organisationsprinzip der neuen Geselischaft (aus der Natur) erkannt werden kann: Es ist das "Gesetz der Gleichheit" oder der "Sympathie", das zur Grundlage einer kollektiven "Religion der brüderlichen Liebe" wird. In dieser 'Religion' sind dann Emotion ("religiöses Gefühl") und Ratio zur Synthese gebracht.

Vergegenwärtigt man sich nun Gor'kijs pravda-Begriff, wie er am deutlichsten in "Mat" entwickelt wird, so ist die übereinstimmung auffallend. Auch dort meint pravda zunächst eine gerechte, weil vernünftige Gesellschaftsordnung (Pavel - "meine Wahrheit"). Pavels pravda erfährt inre religiöse Synthese in der Annahme durch die Nilovna und wird so zum Zentrum der neuen sozialistischen Religion. Das Vernunftmoment in der pravda hat zur Folge, daß ihre Verwirklichung, das Inkrafttreten der neuen aktiven Religion, zur Erziehungsfrage wird. - Bervi kann die Bedeutung der Blldung und Erzlehung als Voraussetzung für eine neue Gesellschaft nicht of genug betonen. Bei Gor'kij ist das nicht anders. Sein ganzer Begriff von Literatur beruht auf deren erzieherischer Funktion (Ideal!).

Wenn nun Bervi in der 'gereinigten' Fassung seiner religiösen Gesellschaftslehre die Wahrheit, nämlich das "Gesetz der Gleichneit" als allwaltendes Organisationsprinzip "rationalistischer" bestimmt, nämlich als "Denken selbständiger Teile" 79$)$; wenn er "Denken" als die allwirkende Kraft und den Fortschritt in der welt durch die "Denktätigkeit der Materieeinheiten" bedingt sieht ${ }^{80)}$ so handelt es sich hier genau um jene "Seinskonzeption, 
die sowohl rational überprüfbar, als auch idealistischantizipatorisch ist", und deren der "Gedanke" (mysl')

"als tragendes Konstituens der Dichtung" bei Gor'kij bedarf, um mit ihr eine "organische Assimiliation" einzugehen $^{81)}$.

So ist es dann zwar richtig, beispielsweise das Wunder in "Ispoved" energetisch zu deuten 82 ), es wäre jedoch falsch, hier den Einfluß der Energetik Ostwalds oder Kotiks (den Gor'kij zum Zeitpunkt der Abfassung von "Ispoved"" noch gar nicht kannte) am Werk zu sehen.

Gor'kij konnte sowohl, was die 'religiöse' Dimension eines sozialistischen Gesellschaftsbegriffes betrifft, als auch hinsichtlich einer wie unklar auch immer gefaßten energetischen weltsicht auf viel ältere Identifizierungsmuster zurückgreifen, als dies die Forschung gerne sehen möchte ${ }^{83}$ ).

Die Bedeutung Bervi-Flerovskijs für die Herausbildung von Gor'kijs Gotterbauertum muß also sehr hoch veranschlagt werden. 
Anmerkungen

1) Flerovskif ist Pseudonym; Bervi-Flerovsk1f lebte von 1829 bis 1918, erlebte also, wie der Titel einer seiner zahlreichen Autoblographien betont (Tri politiceskich sistemy; dt.: Unter drel russischen Kalsern. Berlin 1898), die politischen Systeme dreler russischer Kaiser. Er wurde in Rjazan als Sohn eines Professors geboren und begann nach Gymnasium und Jurastudium elne stelle Karriere - er arbeltete bis 1862 im Justizministerlum -, die $j$ ăh abgebrochen wurde, als er 1862 gegen die Ungerechtigkelten im Zusammenhang mit der Bauernbefrelung offen zu Felde zog. Man lieferte inn zuerst in ein Irrenhaus ein, um inn dann in die Verbannung zu schicken. Bls 1895 lebte er ständig im Exil und danach weiter unter Polize1aufsicht.

2) $G^{\prime}-30,25, \mathrm{~S} .308,330,331,342 ; G^{\prime}-30,13, \mathrm{~S} .528$, $532,536,540$.

T. Yedlin (M. Gorky: His Early Revolutionary Activity. In: Canadian Slavonic Papers Vol. XVII (1975), H.l, S. 78) hält es fur offensichtlich, daß Gor'klf "bis zur Jahrhundertwende vornehmlich mit der Ideologie des Narodnicestvo befaßt war." Dies gehe aus der Analyse der journalistischen Tatigkeit Gor'kijs in den 9o-er Jahren hervor. Vgl. auch Kaleps (a.a.0., S. 69), der auf das Narodnicestvo als Quelle für das Gor'kljsche Denken verwelst, ohne dies allerdings năher nachzuwe1sen.

Vgl. a. Istorifa russkoj 11 teratury, $x$, S. $214 \mathrm{f}$.

3) "Azbuka soclal'nych nauk", 1871; dt.: N. Flerovsky, Das ABC der sozialen Wissenschaften. Lelpzig 1898. 
4) I. Gruzdev, Gor'kij 1 ego vremja, t.I, S. 122.

5) Letopis' zizni i tvorłestva A.M. Gor'kogo, t. 1. Moskau 1958, S. 57.

6) ebd., S. 86 .

7) Schachnowitsch, Lenin und die Fragen...., S. 608, Anm. 68.

8) Gruzdev, a.a.0. S. 373; über weitere Begegnungen ebd., S. $559 f$.

9) Vgl. Schachnowitsch, a.a.0., S. 457ff; drs., A.M. Gor'kif o prolschozdenil religil. S. 75ff; Schachnowitsch weist zwar auf Bervis Einfluß hin, führt dies aber nicht aus und zieht nicht die nötigen Schlüsse.

11) z.B. Na zizn' i smert', Genf 1877.

12) M. Klevenskif, Vorwort zu: Zapiski revoljucioneramextatel ja. Moskau 1929, S. 5.

13) Klevenskij, ebd., S. 4.

14) "Kak nado zit" po zakonu prirody i pravdy", "Russkomu narodu".

15) Unter drei russischen Kaisern, S. 7.

16) ebd.

17) "Azbuka", "Kak nado/dolzno zit"", "Na zizn" i smert".

18) Von letzterer Schrift gab es zwei varianten, eine in der Schweiz und eine in Rußland gedruckt.

(Aptekman, V.V. Bervi-Flerovsk1\}. Leningrad 1925, S. 178 ).

19) Klevenskif, a.a.0., S. 7.

20) "ABC" (dt.), S. 36.

21) ebd., S. 61 .

22) ebd., S. 46.

23) ebd., S. 47; Unterstr. v. mir.

24) ebd., S. 53.

25) ebd., S. 61.

26) ebd., S. 115. 
27) ebd., S. 152.

28) ebd.

29) ebd., S. 264.

30) ebd., S. 335f; Unterstr. v. mir.

31) ebd., S. 337 .

32) ebd.

33) Zapiski revolfucionera..., S. 142.

34) ebd., S. 141.

35) ebd.

36) ebd., S. 14lf; vgl. Lamenna1s: "Dle allgemeine Brüderlichke1t ist das letzte Wort der Menschhe1t." (In: Die Frühen Sozlalisten, Bd. 1, Hrg. V. F. Kool U. W. Krause. München 1972, S. 274)

37) Zapiski, S. 142 .

38) Zapisk1, S. 142.

39) ebd., S. 144.

40) ebd., S. 145 .

41) ebd.

42) 5.0 .5 .310$.

43) "Kak dolźno zit'..." In: A.A. Kunkl', Dolguslncy. (- Istoriko-revol juclonnaja blblioteka (1931)

Nr. LXXII) Moskau 1931. Prilozenija, S. 205.

44) ebd., S. $205-212$.

45) ebd., S. 207.

46) ebd., S. 211f; Unterstr. v. mir.

47) Zapisk1, S. 145.

48) Unter Orel russischen Kalsern, S. 248.

49) Zaplsk1, S. 146.

50) ebd., S. 147.

51) Der Roman enthäl viel Autoblographisches.

52) S.0. S. 310 .

53) Na zizn' i smert', II, S. $189 f^{\circ}$

54) ebd., S. 190.

55) ebd., S. 191. 
56) ebd., S. 196.

57) ebd., S. $197 f$.

58) Ch. Fourier, Brief an den Justizminister. In:

Die frühen Sozlalisten, 8d. 1, S. 202. Unterstr. v. mir.

59) Na zizn', S. 133.

6o) ebd, II, S. 8 .

61) ebd.

62) ebd.

63) ebd., II, S. 10.

64) Na zizn', III, S. 11.

65) Vgl. Setzer, a.a.0., S. $402 f$ (auf Ostwald bezogen).

66) Na zizn', III, S. 45.

67) ebd., S. 70; vgl. "ABC".

68) ebd., S. 126.

69) ebd., S. 74 .

70) Von Bogdanov erschien 1904 ein Aufsatz: "Sobiranie celoveka".

71) "Sympathie" usw.

72) Vgl. Lamennais, In: Die frühen Sozialisten, Bd. I, S. 267.

73) Na żzn', III, S. 181.

74) Kunkl', a.a.0., S. 140.

75) ebd.

76) S.0.S. So7.

77) "Mat"" - Rybin, Nachodka; "Ispoved" - Iegudiil, Michafla; "Leto" - die revolutionăren Bauern.

78) Kluge, Mat', S. 424, Anm. 14.

79) S.0.S. $316 f$.

80) $A B C$ der sozialen wissenschaften, The Theses, S. 609.

81) Setzer, a.a.0., S. 396.

82) Setzer, ebd., S. 402 .

83) Sehachnowitsch (Lenin..., S. 449) sieht z.B. noch in "Razrusenie licnosti" den EInfluß Bervis am Werk; aber nur, was Gor'kijs Auslassungen über 
den Zusammenhang von Kunst, Wissenschaft und Religion in den frühen Stadien der Menschhelt betrifft. 
VIII. SchIUß

\section{Zusammenfassung}

Diese Arbeit hatte das $Z$ iel, die fraglich gewordene Festlegung des "Gotterbauertums" auf den Zeitraum von 1905 bis 1910 zu überprüfen; ferner sollte gezelgt werden, daß das Bogostroitel'stvo bei Gor'kij weder eine Episode noch dem Einfluß Lunatarskijs (und Bogdanovs) zuzuschreiben war; sodann waren die Konsequenzen für die Interpretation einiger wichtiger Werke Gor'kijs zu bedenken.

Es hat sich gezeigt, daß weder bei Lunacarskij noch bei Gor'kij das Gotterbauertum als eine Reaktion auf das Scheitern der Revolution von $1905 \mathrm{zu}$ verstehen ist. Lunacarskij hatte sich schon 1898 für den zusammenhang von Religiosität und Wissenschaftichem Sozialismus interessiert; und die Genese von Gor'kijs religiösem Sozialismus war bis in seine ersten Werke zurückzuverfolgen.

Damit konnte aber auch die zentrale Frage nach einer "Gruppe" der "Bogostroiteli", unter deren Einfluß Gor'kij geraten sein soll, eine Antwort finden. Schon für die belden am nächsten beleinanderstehenden Figuren dieser vermeintlichen Gruppe: Lunacarskif und Gor'kij konnte gezeigt werden, daß diese Sicht nicht zulässig ist, gerade, wenn man bel innen die Entstehung des gotterbauerischen Gedankens ins Auge faßt. Ihr Ausgangspunkt war so verschieden wie inr Anliegen: Was der eine beibehalten wollte, suchte der andere dazuzugewinnen.

Lunacarskij hatte seine Ausgangslage und sein ziel sehr früh formuliert:

Es galt, für den russischen Marxismus, der in den Kleidern eines "pessimistischen Sozialismus" ${ }^{1)}$ auftrat, die 
subjektiv-emotionalen und ethischen Dimensionen zurück(oder dazu-) zugewinnen; am Ende sollte elne Religionsphilosophie stehen, die die Synthese von subjekt und objekt, von objektiver (vernünftiger) Beschrelbung der Entwicklungsbedingungen des Sozialismus und subjektiver (emotionaler, ethischer) Entscheldung für dieses Weltmodell gewährleistete.

Umgekehrt Gor'kij:

Er ging von einem subjektiven, ethisch-moralischen Engagement für den Menschen aus, das seinen Ausdruck in dem von romantischem Pathos geprägten Menschenbild f.and. An der Wandlung seiner literarischen Bilder ließ sich aber beobachten, wo Gor'kij an die Grenzen dieses Menschenbildes stleß: Ihm mangelte die Aufhebung in elner vernüntigen Ordnung, die seine unpervertierbare Verwirklichung überhaupt erst ermöglichen konnte. Gor'kif suchte nach der Synthese von 'Gefühl' und 'Vernunft', Herz und Kopf. Die tragende vernünftige ordnung und damit das syntheseglied glaubte er 1906 im wissenschaftlichen Sozialismus gefunden zu haben.

Das Ende seiner Suche war das "Gotterbauertum", das sich erstmals 1906 in erzählerischer Ausformung in dem Roman "Mat" und im Früjahr 1907 theoretisch in Gor'kijs Antwort auf die Umfrage des Mercure de France als Religion der Aktivität manifestierte. Kurze Zelt später (Herbst 1907) legte Lunatarskij die komprimierte Fassung seiner Religionsphilosophie vor ${ }^{2}$.

Bei Lunacarskij war zu sehen, daß er für seine Erneuerung des Marxismus entscheidende Impulse von Feuerbach und Nietzsche bezogen hatte:

Der Rückgriff auf Feuerbach konnte die Respektierung des Menschen als eines religiösen Wesens garantieren; die für den "Sprung" in den "Entwurf" von einer neuen Gesellschaft und einem neuen Menschen erforderliche Dynamik bezog Lunacarskif von Nietzsche. 
Auch Gor'kij brachte das Erbe Nietzsches in sein Gotterbauertum ein:

Für inn wurde das symbol des übermenschen zum symbol für den Menschen, der sich aus einer Gegenwart heraus voll stolz und Aktivität in eine neue zukunft hinein transzendiert. Die bedingungslose Bejahung des Lebens und die sinngebung durch ein schaffendes Umwerten - dies sind Nietzscheanische Kategorien, die Gorkij in seinem Kampf gegen das mescanstvo benutzt, in dessen größerem zusammenhang das Bogostroitel'stvo Gor'kijs zu sehen ist.

Ferner konnten wir im Gotterbauer Gor'kij den Erben des Narodnicestvo ausmachen, vor allem in seiner Ausprägung durch Bervi-Flerovskij:

In der an der naiven Volksreligiosität orientierten sprache; in der damit zusammenhängenden Respektierung des religiösen Bedürfnisses des Volkes; in dem Verständnis von der "pravda", die elne vernüntige und dadurch gerechte gesellschaftliche Ordnung fordert (das aufklärerische Moment in diesem pravda-Begriff macht die Schaffung einer neuen Gesellschaft vorrangig zum Erziehungsproblem); und schließlich war zu sehen, daß das (undialektische) monistisch-energetische Geschichtsbild Gor'kijs (das für das Gotterbauertum zwar nicht konstitutiv ist, aber gleichzeitig mit inm an Bedeutung gewinnt) nicht erst durch Ostwald oder Bogdanov hervorgerufen wird, sondern durch Bervi-Felrovskij entscheidend vorgeprägt ist. Hier ist nun kurz auf die Problematik des Religions- und Gottesbegriffes bei Lunacarskif und Gor'kif hinzuweisen ${ }^{3)}$.

Lunacarskijs 'neue Religion' basiert auf dem Glauben an den unendlichen Progreß:

"Voraussetzung für den Fortschrittsglauben ist die Behauptung einer Wechselwirkung zwischen dem Wachsen des menschlichen Wissens, den Erfolgen der Wissenschaft einerseits 
und dem moralischen und sozialen Fortschritt anderer$\operatorname{seits"}^{4)}$.

Diese Elndimensionalität des Geschichtsverständnisses war bel Lunacarskif zu beobachten: Das Fortschreiten auf eine bessere Gesellschaft wurde ablesbar an der Entwicklung von Technik und Wissenschaft. Auch der Religionsbegriff wird bei Lunacarskif elndimensional; er reduziert sich auf das subjektiv-emotionale Element. Der transzendente Bezug, konstitutives Merkmal von Religion im theologischen sinne, wird nur vorgetäuscht und ersetzt durch den 'utopischen' Charakter der zielbeschreibung "neuer Mensch", "neue Gesellschaft" als sinngewăhrendes Gegenuber der Realität.

Entsprechend dem evolutionistischen Geschichtsbild ist auch das Gottesbild dieser 'Religion' prozeßhaft verstanden; dies kommt schon in der Bezelchnung "Gotterbauertum" bildlich zum Ausdruck. Wenn in den traditionelien (Offenbarungs-) Religionen Gott als das absolut Transzendente den sinngebenden Horizont für die menschliche Geschichte abgibt, so ist es jetzt der Prozeß "Gott"; genau dies aber betont Lunacarskif: Der Sinn von geschichtlichem Handeln liegt in diesem Handeln als vorwärtstrelbendem selbst.

Die Thomanische Definition fur Religion: "religio proprie importat ordinem hominis ad deum" ${ }^{2}$ gilt hier nur noch formal, da das für sie konstitutive metaphysische Element wegfällt; der "ordo hominis ad deum" ist $2 u$ einer Ordnung des Menschen auf seinen von ihm selbst zu organisierenden Geschichtsprozeß hin (= Gott) geworden ${ }^{6}$ ).

Lunacarskijs Reduzierung des Religiösen auf das bloB Emotionale macht die Fragwürdigkeit der Anwendung des Begriffes 'Religion' auf seine Geschichtsphilosophie deut$1 \operatorname{lch}^{7)}$. 
Für den Theoretiker Gor'kij ist prinzipiell dasselbe zu sagen. Auch bei inm liegt eine Verengung des Verständnisses von Religion auf das Emotionale im Vollzug der menschlichen Geschichte (Fortschritt) vor.

Anders verhält es sich bel dem Romancier:

In der "Mutter" versucht er sich nicht an einer objektivierenden Beschreibung dessen, was das religiöse Gefühl, was Religion und was Gott sei - und inwiefern überhaupt der Mensch dies alles brauche. Durch die konsequent perspektivische Konstruktion des Romans aus der Sicht der $\mathrm{Ni}-$ lovna präsentiert sich diese dem Leser von Anfang bis Ende unter dem Anspruch des für sie (also subjektiv) Unbedingten, das den Namen Gott trägt, jedoch undefiniert blelbt. Dieser Gott, ob er nun zu Beginn der Kirchengott ist oder am Ende der Gott der Bogostroiteli, wird von inr erfahren und für den Leser miterfahrbar nur aufgrund und vermittels der Handlungen der Mutter, welche eine Antwort auf dieses Angesprochensein durch inren Gott sind ${ }^{8)}$.

Man geht mit Sicherheit nicht zu weit mit der Behauptung, daß dieser subjektive Weg der Mutter seinen ebenso subjektiven Erfahrungshintergrund in Gor'kijs eigener Biographie hat. Damit wäre jedenfalls eine Antwort möglich auf die Frage, weshalb Gor'kij zeit seines Lebens nicht von der religiösen Problematik ließ: Immerhin hatte er in seiner Kindheit (kirchliche) Religiosität zwar in inren finstersten und negativsten Ausprägungen erlebt, jedoch gleichzeitig auch als ein System von Gefühls- und Verhaltensweisen, das den täglichen Lebensvollzug sinnvoll erscheinen ließ.

Es war in selnem erzählerischen Schaffen von Anfang an zu sehen, daß es Gor'kij um die wiedergewinnung eben einer solchen Ordnung ging. Aber erst die synthese des religiösemotionalen Vollzugsbereiches mit einer inn vor Pervertierung schützenden vernünftigen ordnung konnte diesen Anspruch Gor'kijs befriedigen ${ }^{9}$. 


\section{Die "Bogostroiteli" - eine Gruppe?}

Das Jahr 1909 bildet den chronologischen Endpunkt unter dieser Untersuchung.

In diesem Jahr erschien Gor'kijs Roman "Leto"; seine im Vorjahr als Artikelserie im "Proletarij" abgedruckte Abrechnung mit dem Individualismus und der zeitgenössischen Literatur "Razrusenie licnosti" erschien in dem Sammelband "Ocerki fllosofil kollektivizma,t.1". Das darin abgehandelte Problem: Individualismus contra Kollektivismus hatte seine literarische Gestaltung in "Ispoved"" gef unden ${ }^{10)}$.

In diesem Jahr nun taucht eine weitere Gestalt im Zusammenhang mit dem "Bogostroltel'stvo" auf: A.A. Bogdanov.

Von August bis Dezember 1909 fand die Parteischule von Capri statt, bei der Gor'kif, Lunacarskif und Bogdanov neben anderen als Lektoren wirkten, und aus der sich am Ende die Gruppe "Vpered" rekrutierte. Im Februar 1909 hatte Kamenev mit seinem Artikel "Ne po doroge"11) die öffentliche bolschewistische Kritik am Bogostroitel'stvo eingeleitet, die mit der Verurtellung der "gotterbauerischen Tendenzen in der Sozialdemokratie"12) als mit dem Wissenschaftlichen Sozialismus nicht vereinbar und für die Arbeit der Sozialdemokratie schädlich endete; Bogdanov wurde aus dem bolschewistischen Zentrum ausgeschlossen. Dies geschah auf einer von Lenin initilerten erweiterten Redaktionssitzung des "Proletarij" im Juni 1909"13).

Ebenfalls in diesem Jahr erschien Lenins auf Bogdanov und seine Gruppe gezielte Abrechnung mit Machismus, Empiriokritizismus und Empiriomonismus: "Materializm 1 Empiriokriticizm. Kriticeskie zametki ob odnof reakcionnoj filosofil"14). Offizlell war damit die 
Geschichte des Bogostroitel'stvo zu Ende, noch bevor die eigentliche Diskussion in der Partei darüber begonnen hatte. Lenins Verdikt über die idealistische Abweichung Bogdanovs und seine Verteufelung der Gotterbauer als Machisten bestimmte von nun an die Rezeption dieses versuchs einer kritischen Erneuerung des Marxismus. Seit Lenins Urteil ist von den "Bogostroiteli" als einer Gruppe die Rede.

In den einschlägigen sowjetischen Darstellungen wird dem Muster Lenins folgend - der Eindruck erweckt, als sei Bogdanov das ideologische Haupt der Bogostroiteli gewesen und habe zusammen mit Lunacarskij Gor'kij zu diesem Irrtum verführt. Zwar wird die Bedeutung Bogdanovs für die ideologische Entwicklung Gor'kijs erst dann klar auszumachen sein, wenn das Quellenmaterial zu ihrer Beziehung voll zugäng1 ich ist ${ }^{15)}$; dennoch müssen der verbreiteten Ansicht von der Mitgliedschaft Bogdanovs in einer Gruppe von Gotterbauern die Zeugnisse der Beteiligten entgegengehalten werden.

Von einer religiösen Terminologie, die jener Lunatarskijs oder Gor'kijs vergleichbar wäre, ist bei Bogdanov keine Spur zu finden; im Gegenteil verwahrt er sich gegen die religiösen Konstruktionen Lunatarskijs ${ }^{16)}$.

Offensichtlich, so Grille, benutzte Lenin das Bogostroitel'stvo lediglich als "Vorwand für die Trennung der Lenin-Gruppe von den 'linken Bolschewisten' um Bogdanov"17). Für diese sicht spricht eine Darstellung Lunatarskijs von $1926^{18)}$ : Ausgangspunkt der Meinungsverschiedenheiten waren politisch-taktische Fragen (Otzovismus, Ultimatismus).

Bogdanov sagte mir of $t, d a ß$ er keinesfalls direkte Aktionen gegen die Partei unternommen hätte - ausgenommen reguläre Formen der Diskussion - , we nn ihm 
von Lenins Seite nicht das Bestreben begegnet wäre, die Opposition sozusagen zu beseltigen, inre Autorität zu untergraben, ihren EInfluß zu zerstören ${ }^{19)}$.

Politisch, so Lunatarskif, selen die damaligen Ansichten der Bogdanov-Gruppe aus der jetzigen sicht zwar zu verurtellen, sle selen jedoch harmlos und kelneswegs schädlich gewesen $^{20 \text { ). }}$.

Anders verhalte es sich in Sachen Phllosophie:

Ich erkühne mich zu sagen, daß hier noch lange nicht alles gesagt 1st, und daß dle wirklichen Grenzen zwischen Häresle und Rechtgläubigkelt noch nicht gezogen $\operatorname{sind}^{21)}$.

Daß nicht alles gesagt wurde, was hätte gesagt werden müssen, lag in Lenins (partei-) politischem Interesse:

Die Diskreditierung elner philosophischen Ansicht mit allen Mitteln ${ }^{22}$ diente der Diffamierung und Ausschaltung des Rivalen Bogdanov; das Verdikt der "religiösen" und "1dealistischen" Abwelchung brachte inn politisch außer Konkurrenz.

Die Verelnnahmung Bogdanovs für das Bogostroltel'stvo Lunacarskijs und Gor'kljs durch Lenin war nicht nur terminologisch nicht gerechtfertigt:

Während Bogdanov die Überwlndung des bürgerlichen, individualistisch begrenzten Bewußtseins aus der besonderen Produktionsweise in hochindustrialisierten Gesellschaften begründete und einseltig auf elne möglichst funktionale Organisation der Arbeltsprozesse bezog, waren Gor'kif und Lunacarskif primär an einer ethisch-ästhetischen Fundlerung der sozialistischen Ideologie interessiert ${ }^{23}$ ). 
Zwar sind die Anleihen Gor'kijs z.B. in seinem Aufsatz "Razrusenie licnosti" bei Bogdanov "evident, wenn auch in stark simplifizierter Form vorgetragen"24), sie betreffen jedoch nicht das Bogostroitel'stvo Gor'kijs. Beiden gemeinsam ist die Idee der Erziehung des Volkes/Proletariats im Geiste des Kollektivismus 25 ) und das undialektische Geschichtsbild 26$)$. Zu der Frage eines Einflusses Bogdanovs auf Gor'kij vor der Capreser Zeit erlaubt das Quellenmaterial keine eindeutigen Aussagen, so daß man hier auf spekulationen angewiesen wär $e^{27)}$.

Man kann also ab $1906 / 07$ von einem "Gotterbauertum" bei Gor'kij und Lunackarskij sprechen; jedoch weder davon, daß sie dieses gemeinsam entwickelt hätten ${ }^{28)}$, noch davon, daß sie - als "Bogostroiteli" - mit Bogdanov eine Gruppe gebildet hätten.

\section{War das Gotterbauertum $1910 \mathrm{zu}$ Ende? - Ein Ausblick}

In seinem Artikel "Ne po doroge" hatte Kamenev auf Lunacarskijs Beitrag in "Literaturnyj raspad, t.2"29) reagiert, in welchem dieser auf die weitgehende Übereinstimmung seines Gotterbauertums mit dem Gor'kijs hingewiesen natte.

Für Kamenev ging die Auseinandersetzung um die Frage, ob das Volk, das Proletariat, die Bauern in der Lage seien, den Wissenschaftlichen Sozialismus als reine Lehre aufzunehmen; indem Lunacarskij dies verneint, verläßt er für Kamenev die gemeinsame Basis. Lunacarskij lasse die Möglichkeit zu, dem Sozialismus eine form zu geben, die inn für die schichten mit weniger entwickeltem proletarischen Bewußtsein verständlicher und akzeptabler mache. Durch die Definition des Sozlalismus als "Religion" gebe Lunacarskij dem Sozialismus ein reaktionäres Gewand, statt dessen re- 
ligionskritische Gestalt herauszuarbeiten und die Denkformen zu zerstören, die den Menschen nach Gott fragen $1 \operatorname{assen}^{30)}$.

Auf diese Vorwürfe reagierte Lunacarskij mit einem Artikel "O moem bogostroitel'stve" in einer mit Bogdanov zusammen herausgegebenen Flugschrift ${ }^{31}$ ). Darin verwahrt er sich gegen den Übernamen eines "Gotterbauers", da er, wenn überhaupt, diesen Begriff nur im übertragenen Sinne gebraucht habe.

Ich glaube, wenn ich mehrmals aufs entschiedenste ausgesprochen habe, der Sozialismus sei eine besondere Art Religion, ohne Gott und ohne Jenseits, und er enthalte kein Gramm Mystik und Metaphysik - daß ich mich damit abgesichert habe gegen jede unsinnige Vermengung des Sozialismus als Religion mit anderen, abgelebten oder gerade verschwindenden formen des Denkens und Fühlens. Aber ich wollte die vergessene, überhaupt bei uns gleichsam ausgewischte seite der proletarischen Weltanschauung unterstreichen, die dem Gefühl zugewandt ist, den höchsten und konsequentesten Idealismus der neuen $\mathrm{Klasse}^{32}$ ).

Lunaçarskif räumt allerdings ein, daß seine Terminologie problematisch sei, da sie vom bürgerlichen Lager, vor allem von seiten der "bogoiskateli" als Annäherung aufgefaßt werden könne.

Hier ist an die Diskussion zu denken, die durch einen Artikel Filosofovs in der "Russkaja mysl"" entfacht worden war ${ }^{33 \text { ). }}$

Wegen der Möglichkeit, mißverstanden und vereinnahmt zu werden, distanziert sich Lunacarskij nun von seiner Terminologie: 
Jedenfalls schuf meine Terminologie um meine Ideen herum elne dichte Atmosphäre von Lüge, willentlichen und unabsichtlichen Mißverständnissen, erschwerte deren richtiges Verständnis dermaßen, daß die Nachteile der Terminologie im Vergleich zu inren Vorteilen vollkommen deutlich wurden - auch für mich selbst ${ }^{34}$ ).

Daß Lunacarskijs Rückzug - wenn auch nur in der Terminologie - mit dem Druck Lenins zu tun hatte, zeigt die Tatsache, daß von 1910 an eine mehrjährige Unterbrechung in der Beziehung zwischen beiden erfolgte 35 ).

Erst 1926, in dem bereits erwähnten Vorwort zu Livsic' Artikel über die Parteischule von Bologna, äußert sich Lunacarskij wieder zu seinen damaligen 'Irrtümern':

Seine philosophischen Schriften hätten viele wertvolle und wichtige Gedanken enthalten ${ }^{36)}$, die allerdings durch "eine schädliche und falsche Terminologie verzerrt" worden seien 37). Vom standpunkt der "Parteihygiene" her gesehen sei daher Lenins Strenge durchaus am Platz gewe$\operatorname{sen}^{38 \text { ) }}$

Noch ein weiteres Mal nimmt Lunacarskij zur Frage des Bogostroitel'stvo 1931 stellung ${ }^{39)}$. Hier erklärt er, wie er auf den Gedanken des Bogostroitel'stvo gekommen war: Rücksicht auf das religiöse Bedürfnis von Bauern und Arbeitern. Von den philosophisch-ethischen Mängeln des Marxismus ist nicht mehr die Rede.

Nunmehr distanziert er sich aber nicht nur von seiner "falschen Terminologie", sondern qualifiziert den gotterbauerischen Gedanken uiberhaupt als falsch $a b^{40)}$. Lunacarskij übt - aus welchem Anlaß auch immer - harte Selbstkritik an seinem damaligen Schaffen und hält eine kritische Revision aller seiner schriften für notwendig ${ }^{41}$. 
Anders verlief die Entwicklung bel Gor'kij, wie an einigen Beispielen belegt werden kann.

Im Februar 1909 hatte er wegen seines Aufsatzes "RazruSenie licnosti" von Lenin Schelte bezogen ${ }^{42}$. Da dieser Artikel zwar nichts von Gor'kifs Bogostroitel'stvo im Sinne des Aufbaus einer kollektivistischen Geselischaft als einer religiösen Handlung enthielt, sondern

Bogdanovs szientistisch-technizistische Organisationstheorie (...) zu einer spekulativen 'geschichtsphilosophisch' begründeten Entwicklungsgeschichte der Menschneit (transformierte), die im Resultat allerdings ebenfalls auf die Vereinheitlichung aller menschlichen Erfahrung abzielt, 43)

konnte Gor'kij sich kaum für seine gotterbauerischen Vorstellungen gescholten fühlen. Dies um so weniger, als er Im selben Jahr für die französischen "Documents du progrès"einen Artikel geschrieben hatte ("über den Zynismus"), der zugleich russisch in "Literaturnyf raspad" und deutsch in den "Dokumenten des Fortschritts" erschien; dieser Artikel war im Gegensatz $z u$ "Razrusenie licnosti" ganz vom Gotterbauertum gekennzeichnet:

Das Volk, der "unerschöpfliche Born jener Energie, die allein imstande (ist) alles Mögliche ins Notwendige, alle Träume in wirklichkeit zu verwandeln" ${ }^{44)}$, steht vor seiner wiedergeburt 45). Das "Volk" ist der "Riesendichter", der "allererste Schönheitsbildner"46). Elne neue Religion ist im Entstehen, welche die "Möglichkeit eines Menschenreiches auf Erden" ${ }^{47}$ ) verkündet.

"Gott ist nur für denjenigen da, der inn in der eigenen Seele durch die Macht des Glaubens zu schaffen und durch inr Feuer zu beleben vermag" 48 ). - "Metaphysik ist erst nach dem Siege am Platze", sie ist "schöpferische Arbeit" 49 ). 
Der "wahre Individualismus liegt in der Zukunft, hinter dem Sozialismus"50). "Eine harmonische Persönlichkeit ist nur dann möglich, wenn die Helden verschwunden sind und die Menge gewesen ist, wenn Menschen erschienen sind, die das Gefühl gegenseitiger Achtung miteinander verbin$\operatorname{det}$ "51).

"Mit der Zeit aber wird dies Gefühl der Achtung von Mensch zu Mensch sich zu einer Religion verwandeln" ${ }^{52}$ ).

Dieser Artikel (und damit zunächst also auch Gor'kijs Gotterbauertum) blieb von Lenins Kritik unberührt. Gor'kif blieb auch weiterhin bei seiner Vorstellung vom Aufbau des Sozialismus als einer religiösen Sache.

1913 protestierte er in zwei Artikeln gegen die Inszenierung von Dostoevskijs "Dämonen" Im Moskauer Künstlertheater. Der zweite ("Esce o karamazovscine"53), endete mit dem Absatz:

Die Gottsucherei muß eine Zeitlang eingestellt werden - das ist eine nutzlose Beschäftigung: es gibt nichts zu suchen, wo man nichts hingelegt hat. Wer nicht säet, wird auch nicht ernten. Ihr habt keinen Gott, inr habt inn noch nicht erschaffen. Götter sucht man nicht - man erschafft sie; das Leben wird nicht erdacht, sondern erschaffen ${ }^{54}$ ).

Dieser Abschnitt rief Lenins helle Empörung hervor 55 ) und fürte zu seinem vielzitierten Ausspruch, die Gottsucherei unterscheide sich von der Gotterschafferei, wie sich ein gelber Teufel von einem blauen unterscheldet ${ }^{56}$ ).

Gor'kij versuchte wohl, sich in einem Brief an Lenin $z u$ rechtfertigen, bekam jedoch eine weitere Abfuhr ${ }^{57}$ ). Von da an brachen die Bezlehungen zwischen Gor'kij und Lenin für einige Jahre $a b^{58)}$. 
Aber Gor'kif hielt auch weiterhin an seinem Gotterbauertum fest.

Von April 1917 bis zu ihrem Verbot im Juni 1918 schrieb er in der Tageszeitung "Novaja Zizn" "regelmäßig Skizzen und Leitartikel zum Thema Kultur und Revolution ${ }^{59)}$. Auch hier greift er in seinem Kampf um die Erziehung zu einer menschlichen Gesellschaft (Kultur) immer wieder auf seine gotterbauerischen Gedanken zurück.

Kultur ist für inn jenes Element, das als Ausdruck der Synthese von Vernunft und Gefühl die neu entstehende Gesellschaft davor bewahren soll, zu einem bloßen technokratischen Gebilde zu werden oder in die Barbarei abzusinken. Jenes würde bedeuten, daß der "Sozialismus nur eine ökonomische Doktrin"60) bliebe; dieses würde die Revolution zu einem Ausbruch von "Emotionen" degradieren, die von neuem "die Freiheit seines (des Volkes R.S.) Denkens und seines willens versklavten"61).

Dies zu verhindern ist die Aufgabe einer "moralischen und ästhetischen Erziehung"62), welche "neue Gefühle, neue Ideen"63) im Menschen weckt:

"Die Revolution, die allein den Menschen veredeln kann, muß in seinem Innern stattinden"64).

Das Ideal des wahren Revolutionärs ist der Mensch als physisch starkes und schönes Tier; aber diese physische Schönheit soll mit der Macht und Schönheit des Geistes vollkommen harmonieren. Das Menschliche ist das Geistige, alles, was von der Vernunft geschaffen wird 65 ).

Gor'klj verlangt vom Revolutionär einen "sozialen Idealismus"; denn ohne diesen Idealismus (das emotionale Element) "würde sich eine Revolution - und das ganze Leben in eine trockene Mathematikaufgabe verwandeln, in die Ver- 
teilung materieller Güter"66). Auch hier noch geht es Gor'kif also um jene Synthese von Gefühl und Vernunft ( = der sozialistische 'Glaube'): Einerseits erinnert er daran, daß der Sozialismus eine "wissenschaftliche Wahrheit" se1 ${ }^{67)}$; andererseits dürfe aber der Arbeiter auch das "idealistische Prinzip" (d.h. das religiös-emotionale $\mathrm{e}^{68}$ ), im Sozialismus nicht vergessen, nur so könne er sich als "Apostel einer neuen Wahrheit" fühlen ${ }^{69)}$.

Am deutlichsten kommt Gor'kijs 'Religion' in einem Artikel zum Weihnachstag 1917 zum Ausdruck:

Christus ist die unsterbliche Idee der Barmherzigkeit und Menschlichkeit; Prometheus ist der Feind der Götter, der erste Rebell gegen das Schicksal.(...) Der Tag wird kommen, an dem die beiden symbole - Stolz und Barmherzigkeit, Demut und Tollkühnheit beim Verfolgen eines ziels - in der Seele des Menschen zu einem großen einzigen Gefühl verschmelzen werden und alle Menschen ihre eigene Bedeutung, die Schönheit ihres Strebens und ihre gemeinsame Herkunft erkennen, die sie alle miteinander verbindet ${ }^{70}$ ).

Im Jahre 1927 bekennt sich Gor'kif schließlich noch immer als Gotterbauer. In einem Artikel zur Zehnjahrfeier der Oktoberrevolution, der in "Pravda" und "Izvestija" abgedruckt wurde, schrieb er noch einmal sein Credo:

Vor Jahren nannte ich den Menschen einen Gottschöpfer; das bedeutet, daß der Mensch, in sich selbst wie in der Außenwelt, die Macht schafft und verkörpert, Wunder zu wirken, Gerechtigkeit und Schönheit zu erschaffen, und daß er alle jene Fähigkeiten besitzt, mit denen die Idealisten eine Macht ausstatten, die angeblich außerhalb und unabhängig vom Menschen existiert. 
Der Mensch weiß, daß außerhalb von ihm keine wunderwirkenden Kräfte vorhanden sind... Er ist dessen sicher, daß "einzig und allein der Mensch existiert, während alles andere nur das Ergebnis seiner elgenen Anschauung und das Werk seiner Hände ist."... Es ist dieser Mensch, der die Riesenaufgabe übernommen hat, die arbeitenden Massen "In seinem Bilde und seinem Gleichnis zu erziehen" 71 ).

Es zeigt sich also, daß das Gotterbauertum in mehr oder weniger deutlichen Ausprägungen zeit seines Lebens ein zentrales Thema Gor'kijs blieb. Es geriet sogar unerkannt in die Grundlagen des Sozialistischen Realismus hinein: "Mat"", der erste proletarische Roman, zum Prototyp des Sozialistischen Realismus kanonisiert, entfaltet eben dieses Thema am genauesten. Aber es ist auch noch in Gor'kijs Rede auf dem ersten sowjetischen Schriftstellerkongre $B$ 1934 latent vorhanden. "Gott bauen" heißt jetzt allerdings "den Sozialismus" oder das "neue Leben bauen"72). Und aus den "Meistern des Wortes" ("Xitatel") sind jetzt die "Ingenieure der seele" geworden 73), die das "Werden des neuen Menschen" ${ }^{74}$ ) zu gestalten und zu fördern haben.

Es ist ein bedauerliches Faktum, daß diese Erbschaft des Vaters des Sozialistischen Realismus nicht erkannt und diskutiert, sondern nach dem von Lenin vorgegebenen Muster rezipiert und zur Episode ${ }^{75)}$ erklärt wurde. So muß man feststelien, daß trotz der Ausweitung der sowjetischen Gor'kij-Forschung $z u$ einer regelrechten 'Gor'kij-Wissenschaft' (gor'kovedente) hier eine Lücke offenbleibt, deren Schließung von der sowjetischen wissenschaft aus ideologischen Gründen vorerst nicht zu erwarten ist.

In diesem Sinne versteht sich vorliegende Arbeit als Beitrag zur Vervollständigung unseres Gor'kij-Bildes. 


\section{Anmerkungen}

1) A.Thun, Die Geschichte der revolutionären Bewegungen in Rußland. 0.0. 1883, S. 335 .

2) Buduscee religil. a.a.0.

3) Eine elingehendere Erörterung dieser Frage wăre Aufgabe einer theologisch-philosophischen Untersuchung.

4) D.V.Filosofov, Druz'ja 111 vragl. In: Russkaja mysl' Nr. 8, 1909, S. 122.

5) Thomas von Aquin, S.th. II, II, 81, 1.

6) Dieser evolutionistische Religionsbegriff leitet sich von Comte, Spencer und Tylor her.

7) Man könnte allenfalls von elner philosophischen Religion' sprechen:

"Religion (philosophisch R.S.) als aufgeklärte Verwelgerung des Einverständnisses weiB sich stets verwiesen auf die menschliche Rationalität und Freiheit, d.h. auf die Notwendigkeit, durch Handeln die Welt zu verbessern oder, wenn man lleber will, zu verändern." H.-R. Schlette, Religion. In: Handbuch philosophischer Grundbegriffe (Hrg. H. Krings U.a.), Bd. 5 München 1974, Sp. 1248.

8) Vgl. Hans Küng, Christ sein. München ${ }^{3} 1978,5.86$ : Religion gründet, "wie die Religionspsychologie deutlich macht, in elner erfahrungsmäßigen Einhelt von Erkennen, Wollen und Fühlen, das nicht als elgene Leistung, sondern als elne Antwort auf eine wie auch immer geartete Begegnung mit Gott oder elne Erfahrung von ihm verstanden wird." (Unterstr. v. mir.).

9) In diesem Sinne ist Borras, a.a.O. S. 24 zu bestätigen: Die zunehmende Feindschaft Gor'kljs gegen das offizlelle Christentum ändere "nichts 
an der Tatsache, $d a ß$ er in seinem geistigen Zuschnitt wesentlich religiös war, in dem Sinne, daß er nicht ohne eine Idee von Gott als einem erstrebenswerten Ideal leben konnte." N. Valentinov (Vstreci s Gor'kim. In: Novyj zurnal (New York) Nr. 78 (1965), S. 128) berichtet, daß Gor'kij in den Jahren 1914 - 1916 gern von dem "Gefühl des Maßes, das dem Intellekt unterworfen ist", sprach.

10) Vgl. Borras, a.a.0., S. 115;

Fülöp-Miller (Geist und Gesicht des Bolschewismus. Zürich 1928, S. loff) interpretiert diesen Aufsatz fälschlicherwelse so, als gehe es Gor'kif darin um die totale Negation des Individuums. Das Gegenteil ist der Fall: Gor'kij sucht eine höhere Qualität von Individualität zu gewinnen.

11) L.B. Kamenev, Ne po doroge. In: Proletarif Nr. 42, 25. Febr. 1909.

12) KPSS $v$ rezoljucijach 1 resenijach. M. 1953, Bd. 1, S. 222 .

13) Literaturnoe nasledstvo, t.l. M. 1931, S. 17ff; vgl. Grille, a.a.0., S. 34 .

14) Moskau 1909.

15) Vgl. $2 u$ der geplanten Herausgabe des Briefwechsels zwischen Bogdanov und Gor'kif: G. Haupt und J. Scherrer, Gor'kif, Bogdanov, Lenin. In: Cahiers du monde russe et soviétique. Vol. XIX, 3, 1978 .

16) Lunacarskij, RiS, II, S. 377f; Literaturnoe nasledstvo t.l, s. 30 .

17) Grille, a.a.0.S. 34; vgl. einen Lenlnausspruch zitiert bel Hare (a.a.0. S. 75): "Es ist fur uns nichts Helliges und Unantastbares an irgendwelchen Theorien oder Hypothesen; sle dienen uns lediglich als Instrumente.". 
18) Lunatarskij, Vmesto predislovija. Vorwort $2 u$ S. Livicic, Partijnaja skola v Bolon'e (19lo - 191lgç). In: Proletarskaja revoljucija Nr. 3, 1926 (50).

19) ebd., S. 112.

20) ebd., S. 115 .

21) ebd., S. 116 .

22) Vgl. A. Pannekoek, Lenin als Philosoph. Frankfurt 1969, S. 87 u. pass.

23) J.-U. Peters, Kunst als organisierte Erfahrung. Über den Zusammenhang von Kunsttheorie, Literaturkritik und Kulturpolitik bel A.V. Lunacarskij. Unveröff. Manuskript (Habil.) Konstanz O.J.

24) Haupt/scherrer, a.a.0., S. 327.

25) Vgl. Borras, a.a.0., S. 56; Feifel, a.a.0., S. 795; ausgehend von dem Gor'kij-Zitat S. 96 (Anm. 5)) kann man mit Hare (a.a.0., S. 79) die Betelligung Gor'kijs an der Capri-schule als einen Versuch sehen, seine Idee einer Allianz zwischen Intelligenz und Arbeiter-, bzw. Bauernelite in die Tat umzusetzen.

26) Vgl. Kaleps, a.a.0., s. 33.

27) Siehe Anm. 15).

28) Hier 1st Peters, a.a.0., S. 63f zu korrigieren.

29) A.V. Lunacarskij, 23-1j sbornik "Znanija".

30) Zusammenfassung nach $K$. Ostrouchova, Gruppa "Vpered" (1909 - 1917). In: Proletarskaja revo1 jucija Nr. 1, 1925 (36), S. 204.

31) Ko vsem tovariscam. Genf 1910.

32) Lunacarskil, o moem bogostroitel'stve. Z1t. be1 Ostrouchova, a.a.0., s. 205; Unterstr. v. mir.

33) S. Anm. 4).

34) Lunatarskij, o moem bogostroltel'stve. a.a.0., S. 205 .

35) Vgl. Literaturnoe nasledstvo, t.80, M. 1971, S. $43 f$. 
36) Wohl aus diesem Grund hatte er 1925 "dle besten" Kapitel aus Ris mit neuem Vorwort als Aufsatzsammlung veröffentlicht: Ot Spinozy do Marksa. M. 1925. Vgl. Literaturnoe nasledstvo, t.82., M. 1970, S. 501 .

37) Lunacarskij, Vmesto predislovija.a.a.0., S. 115.

38) ebd.

39) Lunałarskij, $K$ voprosu o filosofskoj diskussii 1908 - 19logg. Nach einem Typoskript veröffentlicht In Literaturnoe nasledstvo, t. 82, M. 1970.

40) ebd., S. 498.

41) ebd., S. 501 .

42) Brief Lenins an Gor'kij vom 25. Febr. 1908.

Lenin und Gorki. Eine Freundschaft in Dokumenten. (Hrg. E. Kosing U. E. Mirowa-florin). BerlinWeimar 1974 , S. $97 f f$.

43) Peters, a.a.0., S. 146.

44) M. Gorki, Zynismus und Zyniker. In: Dokumente des Fortschritts $1(1908)$, H.4, S. 323.

45) ebd.

46) ebd., S. 329.

47) ebd., S. 327.

48) ebd., S. 324.

49) ebd.

5o) ebd., S. 333 .

51) ebd.

52) ebd.; Unterstr. v. mir.

53) In: Russkoe slovo, 27 . Okt. 1913.

54) Zitiert nach: Lenin und Gorki, S. 175.

55) Brief Lenins an Gor'kij vom 13./14. Nov. 1913. Lenin und Gorki, S. $175 \mathrm{f}$.

56) ebd., S. $175 f$.

57) ebd., S. $179 f$.

58) Zur Auseinandersetzung zwischen Lenin, Gor'kij, Lunałarskij und Bogdanov vgl. M.F. Andreeva, 
Perepiska, vospominanija... M. 1961, S. $99 \mathrm{ff}$.

59) Deutsch: Unzeitgemäße Gedanken über Kultur und Revolution. Frankfurt 1974.

60) ebd., S. 191.

61) ebd., S. 225.

62) ebd., S. 224.

63) ebd.

64) ebd., S. 225.

65) ebd., S. 229.

66) ebd., S. 209.

67) ebd., S. 190.

68) ebd., S. 141.

69) ebd., S. 190.

7o) ebd., S. 129.

71) Pravda, 6. Nov. 1927; Izvest1fa, 23. Okt. 1927;

zitiert nach B.D. Wolfe, a.a.0., S. $85 f$.

72) M. Gor'kif, über sowjetische Literatur. In: SoziaIistische Realismuskonzeptionen. Hrg. H.-J.

Schmitt und G. Schramm. Frankfurt 1974, S. 82.

73) ebd.

74) G. Ziegengeist u.a., Multinationale Sowjetliteratur. Kulturrevolution, Menschenbild, Weltilterarische Leistung. 1917 - 1972. Berlin-Weimar 1975, S. 15.

75) Vgl. die Broschüre von M. Laskovaja, Bogostroitel'stvo 1 bogolskatel'stvo prezde 1 teper'. Moskau 1972; vgl. auch dazu Kap. I, Anm. 27). 


\section{Literatur}

\section{Textausgaben und Einzeltexte}

Literaturnyj raspad. Sbornik $1+2$. SPb 1908 .

oxerki fllosofil kollektivizma I. SPb 1909.

oterk1 po filosof 11 Marksizma. Sbornik. SPb 1908. ocerki realisticeskogo mirovozzrenija. SPb ${ }^{2} 1905$.

Versiny I. SPb 1909.

A. Bogdanov, Filosofija zivogo opyta. Populjarnye Iekcil. Moskau 1920.

A. Bogdanov U. A.v. Lunacarskij, Ko vsem tovariscam. Genf 1910.

A. Bogdanov, Inžener Menn1. Moskau 21913.

A. Bogdanov, Krasnaja Zvezda. Moskau ${ }^{2} 1918$.

A. Bogdanov, O proletarskoj kul'ture. 1904-1924. Moskau-Leningrad 1925.

A. Bogdanov, Tektologija I-III. Berlin-PetrogradMoskau 1922 .

V. Bazarov, Bogoiskatel'stvo 1 "bogostroitel'stvo". In: Versiny, I. SPb 1909.

V. Bazarov, Christijane 3-ego zaveta 1 stroiteli basni Vavilonskoj. In: Literaturnyj raspad, II.

M. Gor'kij, Sobranie socinenif. Tt. I-XXX. Moskau 1949-1955. ( = G'-30, Bd. Nr., S.).

M. Gor'kij, Polnoe sobranie socinenij. Moskau 1974( = PSS, Bd. Nr., S.).

M. Gor'kij, Der alte und der neue Mensch. In: Das neue Rußland, 9 (1932), H. 5/6, S. 3-11. 
M. Gor'kil, Antwort auf die Enquête des Mercure de France. In: Mercure de France Nr. 233, Tome LXVI, 1. Mars 1907.

M. Gor'k11, Istorija russkoj 11 teratury. Moskau 1939.

M. Gorki, Der Kleinbürger und die Revolution. Essay. Köln 1973 (= Zametk1 o mescanstve 1905).

M. Gor'kij, o cinizme. In: Literaturnyj raspad 1.

M. Gorki, Zynismus und Zyniker. In: Dokumente des Fortschritts 1 (1908), H. 4, S. 323 - 333 .

M. Gor'k11, O Literature. Moskau 1955.

M. Gor'kil, Razrusenie lichosti. In: Oxerki

fllosofil kollektivizma I. SPb 1909.

M. Gor'k11, Stat'1. 1905 - 1916gg. Petrograd ${ }^{2} 1918$.

M. Gor'klj, Die Zerstörung der Persönlichkelt.

Aufsätze. Dresden 1922.

A.V. Lunacarskil, Sobranie socinenif v 8tt. Moskau 1967.

A.V. Lunacarsk11, Ateizm. In: Oterki po fllosofi1 marksizma. Sbornik. SPb 1908.

A.V. Lunałarsk1j, Buduscee religil. In: Obrazovanie 1907, Nr. 10+11.

A.V. Lunacarskij, 23-1j sbornik "Znanifa". In: Literaturnif raspad 2. SPb 1909.

A.V. Lunacarskil, Etjudy kriticeskie 1 polemiceskie. Moskau 1905.

A.W. Lunatscharski, Faust und die Stadt. Leipzig 1973.

A.V. Lunacarskil, Iskusstvo 1 religija. In: Ant1religloznik, Nr. 1 (1934), S. $17-23$. 
A.V. Lunatarskij, Kriticeskie étjudy. Leningrad 1925.

A.V. Lunacarskif, Literaturnye siluety. MoskauLeningrad 1925.

A.V. Lunačarskij, Mescanstvo i individualizm. In: Oとerki filosofil kollektivizma. SPb 1909.

A.V. Lunačarskij, Nauka, religija, iskusstvo. Sbornik stat'ej. Moskau 1923.

A.V. Lunatarskif, Problema idealizma s totki zrenija kriticeskogo realizma. In: Obrazovanie Nr. 2, 1903.

A.V. Lunačarkij, Problemy Idealizma. In: Obrazovanie, Bd. $12(1903), \mathrm{Nr} .2$.

A.W. Lunatscharsk1, Profile der Revolution.

Einleitung von Isaac Deutscher. Frankfurt/M. 1968.

A.V. Lunatarskij, O Gor'kom. Moskau 1975.

A.V. Lunačarskij, Osnovy pozitivnoj èstetiki.

In: Ocerki realisticeskogo mirovozzrenija. SPb ${ }^{2} 1905$.

A.V. Lunacarskil, Otkliki zizni. Sbornik stat'ej. SPb 1906.

A.V. Lunatarskif, Religija i socializm I+II. SPb $1908 / 11(=R$ IS, I II).

A.V. Lunatarskif, Russkif Faust. In: Voprosy filosofli i psichologi. $\mathrm{Nr}$. 3, 1902.

A.V. Lunatarski1, T'ma. In: Literaturnyj raspad 1.

A.V. Lunatarskij, Vospominanija 1 vpetatlenija. Moskau 1968. 
II. Nachschlagewerke

Bol'saja Sovetskaja Énciklopedija (BSÉ) 1. izd. Moskau $1926-48$.

BSE் 2. 12d. Moskau $1949-58$.

BSÉ 3. izd. Moskau $1970-$ -

Énciklopediceskif slovar' (Brokgaus/Efron). $\mathrm{SPb} 1890-1904$.

EnciklopediCeskif slovard (Granat). Moskau 1912 - 40.

Filosofskaja Enciklopedija tt. 1-6. Moskau $1960-70$.

Historisches Wörterbuch der Philosophie Bd. 1Darmstadt 1971-

Kratkaja Literaturnaja Énciklopedija tt 1-9. Moskau $1962-78$.

Lexikon für Theologie und Kirche Bd. 1-10.

Freiburg $21957-65$.

Literaturnaja Énciklopedija tt 1-11. Moskau 1929 - 1939.

Religion in Geschichte und Gegenwart. Bd. 1-6. Tübingen $1957-62$.

Religionswissenschaftliches Wörterbuch (Hrg. F. König). Freiburg 1956 .

Sovetskaja Istoriceskaja Énciklopedifa tt. 1-16. Moskau 1961-76.

Sowjetsystem und Demokratische Gesellschaft Bd. 1-6. Freiburg-Base1-Wien $1966-72$.

The Encyklopedia of Philosophy, Vol. 1-8 (Ed. P. Edwards). London-New York 1967. 
The Modern Encyklopedia of Russian and Soviet History. (Ed. J.L. Wieczynski) Vol. IAcademic International Press 1976.

The Modern Encyklopedia of Russian and Soviet Literature. Vol. I- Academic International Press 1977-.

\section{Sonstige Literatur}

M. F. Andreeva, Perepiska, vospominanija, stat'i, dokumenty. Moskau 1961.

D. Angres, Die Beziehungen Lunatarskijs zur deutschen Literatur. Berlin (Ost) 1970.

O.V. Aptekman, V.V. Bervi-Flerovskij. Leningrad 1925.

L.M. Archangelski, Kategorien der marxistischen Ethik. Berín (Ost) 1965 .

E.I. Babajan, Rannij Gor'kij. U idejnych istokov trorcestra. Moskau 1973.

R. Barthes, Mythen des Alltags. Frankfurt/M. ${ }^{2} 1970$.

D. Bathrick U. P. Breines, Marx und/oder Nietzsche. Anmerkungen zur Krise des Marxismus. In: R. Grimm U. J. Hermand (Hrg.), Karl Marx und Friedrich Nietzsche. Acht Beiträge. Königstein/Ts. 1978.

E. Benz, Das Bild des übermenschen in der europälschen Geistesgeschichte. In: drs. (Hrg.), Der Übermensch. Eine Diskussion. Zürich-stuttgart 1961, S. $19-129$.

B. Bjallk (Hrg.), Lenin und Gorki. Eine Freundschaft in Dokumenten. Berlin-Weimar 1974.

B. Bjalik, Revolution und Kunst. Betrachtungen über die Beziehungen zwischen Lenin und Gorki. Berlin-weimar 1974.

B. Bjal1k, Sud'ba Gor'kogo. Moskau 1968. 
B. Bjalik, M. Gor'kij - Dramaturg. Moskau 1962.

B. Bjalik, O Gor'kom. Moskau 1947.

E. Bloch, Geist der Utopie. Frankfurt/M. 1973.

A. Blok, Intelligenz und Revolution. In: A. Blok, Ausgewählte Aufsätze. Frankfurt/M. 1964.

A. Blok, Volk und Intelligenz. In: A. Blok, Ausgewählte Aufsätze. Frankfurt/M. 1964 .

I. Bock, Besprechung: Ju. Lotman, K probleme tipologii kul'tury und 0 metajazyke tipologiceskich opisanif kul'tury. In: WdSI XVII/l, S. $237 \mathrm{ff}$.

F.M. Borras, Maxim Gorky the Writer. Oxford 1967.

P. Brang, Fortschrittsglauben in Rußland einst und

jetzt. In: Rudolf W. Meyer, Das Problem des Fortschritts einst und jetzt. Darmstadt 1969, S. $29-53$.

G.V. Bulackif U. A.A. Plavnik, Lunacarskij revoljucioner-publicist (1905 - 1907gg.). Minsk 1971.

B. Bursov, Roman M. Gor'kogo "Mat". MoskauLeningrad 1962.

L. Bykovceva, Gor'kij v Italii. Monografija. Moskau 1975.

D. Cizevskij, On Romanticism in Slavic Literatures. $T=$ Musagetes 1). 's Gravenhage 1957.

D. Cizevski1, Russische Geistesgeschichte. München ${ }^{2} 1974$.

B.D. Davies, Nietzsche in Russia, 1892 - 1917 : A Prellminary Bibliography, Part 1+2. In: Germano-Slavica. Vol. II $(1976 / 77) \mathrm{Nr} \cdot 2+3$.

G. Deleuze, Nietzsche ein Lesebuch. Berlin 1979.

G. Deleuze, Nietzsche und die Philosophie. München 1976. 
W. Deresch (Hrg.), Der Glaube der religiösen

sozialisten. (Textauswahl). Hamburg 1972.

V.A. Desnickil, A.M. Gor'k1j. Ocerki zizni 1 tvorkestva. Moskau 1958.

J. Dietzgen, Das Wesen der Kopfarbeit und andere Schriften. Darmstadt-Neuwled 1973.

R. Dithmar, Die Fabel. Geschichte, Struktur, Didakt1k. Darmstadt 1971.

A. Elk1n, Lunacarsk1\}. (a zizn' zamecatel'nych Ijudej. vyp 6 (434)) Moskau 1967.

G. Erler, Der Proletkul't. Unveröffentl. Manuskript. Frelburg $0 . \mathrm{J}$.

E. Feifel, Gork1 oder der "Proletarische Humanismus". In: Wort und Wahrhe1t, 1961, 12, S. 792 - 796.

H. Fenner, Die Propagandaschulen der Bolschewisten. Ein Beltrag zur Vorgeschichte der Proletkultbewegung. Berlin 1919.

I. Fetscher, Karl Marx und der Marxismus. Von der Philosophle des Proletariats zur proletarischen Weltanschauung. München 1967.

I. Fetscher, Lenins Größe und Grenze. In: drs., Marxistische Porträts, Bd. I Politika. I = Problemata 19.1). Stuttgart-Bad Cannstadt 1975, S. $153-178$.

I. Fetscher, Der Marxismus. Seine Geschichte in Dokumenten. Bd. 1. München-Zürich 1976.

I. Fetscher, Sozialismus und Sinnfrage. In: Jenselts der Erkenntnis. Fragen statt Antworten. (Hrg. L. Reinisch.) Frankfurt/M. 1977.

I. Fetscher, Von Marx zyg Sowjetideologle. Frankfurt/M.-Beri in-Munchen ${ }^{29} 1975$.

L. Feuerbach, Das Wesen der Religion. (Hrg. A. Esser) Köln 1967. 
D.V. Filosofov, Druz'ja 111 vragi. In: Russkaja mysl', Nr. 8, 1909, S. $120-147$.

O. Finger, Joseph Dietzgen. Beitrag zu den philosophischen Leistungen des Arbeiterphilosophen. Berlin (Ost) 1977.

E. Fink, Niętzsches Philosophie. Stuttgart-BerlinKöln-Malnz 1973 .

J.M. Fischer, Fin de siècle. Kommentar zu einer Epoche. München 1978 .

N. Flerowskij, $A B C$ der sozialen Wissenschaften. Die gegenwărtige westeuropäische Zivilisation. Leipzig 1898.

N. Flerovskij, Azbuka social'nych nauk. XIX. vek sovremennoj zapadno-evropejskof civilizacil. London 1894 .

V.V. Bervi-(Flerovsk1j), Izbrannye ékonomičskie proizvedenifa 1+2. Moskau 1958/59.

V.V.Flerovskif (-Bervi), Kak dolzno zit' po zakonu prirody 1 pravdy. In: A.A. Kunk l', Dolgusincy. Moskau 1931. (Anhang).

V.V. (Bervi-) Flerovskij, Kratka ja avtobiografija. In: Russkaja mysl', Jahrg. 26, Bd. 5, 1905 .

V.V. Flerovskif (-Bervi), Na zizn' 1 smert'. Izobraženie Idealistov. Roman $v 3-c h$. Genf 1877.

N. Flerovski1, Unter drei russischen Kaisern. Das politische System Nikolaus I., Alexander II. und Alexander III. Erlebnisse, Studien und Beobachtungen. Berlin 1898 .

v. (Bervi-) Flerovskif, Zapiski revol jucionera mectatelja. Predislovle M. Klevenskogo. MoskauLeningrad 1929.

G. Florovsk11, Puti russkogo bogoslovija. Paris 1937. 
V. Frice, "Ispoved"" Gor'kogo. In: P.E. Budkov IK.K. Fiksanov, Maksim Gor'kif. Moskau-Leningrad 1929.

R. Fulöp-Miller, Gelst und Gesicht des Bolschewismus. Zürich'ig28.

N. Ge 1, Metod, rozdennyf épochof. In: Voprosy iteratury 1963, Nr. 5, S. $75-77 ; 83-87$.

M. Gel'rot, Nicse 1 Gor'kif: Ėlement nicseanstva v tvorcestve Gor'kogo. In: Russkoe Bogatstvo 5 $(1903)$, S. $24-68$.

Geschichte der KPdSU (B). Kurzer Lehrgang. Beriln (Ost) 1946.

R. Girtler, Kulturanthropologle. München 1979.

W. Goerdt ( $\mathrm{Hrg}$ ), Die Sowjetphllosophie. Wendigkelt und Bestimmthe1t. Darmstadt 1967.

Gor'kovskle Cten1 Ja. Moskau-Leningrad 1940 ff.

Gor'k11 v èpochu revol Jucil 1905 - 1907gg. Materialy, vospominanija, issledovanija. Moskau $195 \%$.

M. Gor'k11, Materialy 1 issledovanija. t. 1Leningrad i934-

P. Gorsen U. E. Knödler-Bunte, Proletkult $1+2$.

7. Problemata 22. $1+2$ ) Stuttgart-Bad Cannstadt $1974 / 75$.

D. Grille, Lenins Rivale. Bogdanov und seine philosophle. (" Abhandlungen des Bundesinst1tuts für ostwissenschaftliche und internationale Studien Bd. XII). Köln 1966.

R.H. Grützmacher, Die Stellung Oskar Wildes und Maxim Gorkis zu Religion und Christentum. In: Konservative Monatsschrift für Politik, L1teratur und Kunst. $63(1906)$, H. 5, S. 485-493; H. 6, S. $599-605$.

I.A. Gruzdev, Gor'k1f 1 ego vremfa. Leningrad 1938. 
H. Günther, Sozialistischer Realismus. In: Reallexikon der deutschen Literaturgeschichte, Bd. 4. Berlin-New-York 1979, S. 57 - 64 .

G. Habermann, Maxim Gork1. Berlin 1968.

R. Hamann U. J. Hermand, Epochen deutscher Kultur von 1870 bis zur Gegenwart. Bd. 4, Stilkunst um 1900. Frankfurt/M. 1977.

R. Hare, Maxim Gorki, Romantic Realist and Conservative Revolutionary. London 1962.

R. Hare, Portraits of Russian Personalities Between Reform and Revolution. London $0 . J$.

G. Haupt U. J. Scherrer, Gor'kij, Bogdanov, Lenin. In: Cahiers du monde russe et soviéthique. Vol. XIX, 3 , 1978 .

A. Hepner, Ein utopischer Sozialist unserer Tage. In: Sozialistische Monatshefte 1 (1909), S. $112-114$.

B. Hillebrand (Hrg.), Nietzsche und die deutsche Literatur Bd. 1. Texte zur Nietzsche-Rezeption 1873 - 1969. Tübingen 1978.

J. Holthusen, Russische Gegenwartsliteratur Bd. 1. Bern-München 1963.

F. Holtzmann, The Young Maxim Gorky. 1868 - 1902. New York 1948.

J. Idzikovski, Einige Entwicklungsilinien des sozialistischen Menschenbildes bel M. Gor'kij. In: ZfSlaw. Berlin 1968, S. 644ff.

H. Imendörffer, Die perspektivische Struktur von Gor'kijs Roman "Zizn" Klima Samgina". Berlin 1973.

H. Imendörffer, Nachworte zu: M. Gork1, Ein Sommer, Das Städtchen Okurow, Matwej Koshemjakin. München 1977. 
M. Gork1, Konovalow und andere Erzählungen. München 1978;

M. Gork1, Dre1 Menschen, Die Mutter. München 1977;

M. Gorki, Foma Gordejew, Eine Beichte, Das Werk der Artamonows. München 1978;

M. Gork1, Der Vagabund und andere Erzählungen. München 1979.

A.N. Iezuitov, Lenin 1 Lunacarskij. In: A.V. Lunacarskij. Issledovanija 1 materaly. Leningrad 1978.

Istorila russkol literatury. t. X. Moskau-Leningrad 1954.

Istorila russkogo romana $v$ dvuch tomach. t. II. Moskau-Leningrad 1964.

A. Izmallov, Russkif telovek na duchu. In: Obrazovanle, $1908, \mathrm{Nr} .7$.

W. Jollos, Die heutige Russische Literatur. In: wissen und Leben, $16(1922 / 23)$ Bd. 25, S. $796-800$.

S.J. Juzorskif, "Na dne" M. Gor'kogo. Moskau 1968.

B.A. Kaleps, Gor'kijs Glaube und seine verschiedenen Konflikte mit der Umwelt. Heidelberger Dissertation 196?.

L.B. Kamenev, Ne po doroge. In: Proletarif Nr. 42, 25. Febr. 1909.

S.V. Kastorsk1, Nekotorye 1togi 1 zadaci izucenija povesti "Mat"" M. Gor'kogo. In: Voprosy sovetskoj literatury VII, IAN SSSR, Moskau-Leningrad 1958, S. $305-358$.

S. Kastorsk1, Das Thema der Arbeit in den Werken Gork1s. In: Die neue Gesellschaft, 6 (1953), H. 6, S. $450-456$.

S. Kastorsk11, "Leto" - Povest' o revol fucionnom dvizen11 $v$ derevne 900-ch godov. In: Stat' 10 Gor'kom. Leningrad 1955, S. $405-462$.

A.S. Kaun, Maxim Gorky and his Russia. New York 1968. 
D. Kegler, Untersuchungen zur Bedeutungsgeschichte von Istina und Pravda Im Russischen. ( E Europäische Hochschulschriften Reihe XIV, Bd. 4, S. $63-66$ ). Bern-Frankfurt/M. 1975 .

V.A. Keldyš, Problemy dooktjabr'skof proletarskoj literatury. Gor'k1j 1 russkaja revoljucionnaja poézija. Moskau 1964.

H. Kern, Technischer Fortschritt. In: Die Neue Herder Bibliothek Bd. 12. Frelburg-Basel-Wien 1972.

J.G. Klabunovskif (Hrg.), Gor'kif v skole. Sbornik stat'ej. Moskau 1960.

G. Kline, Nietzschean Marxism in Russia. In: Boston College Studies in Philosophy 2 (1969), S. $166-183$.

G. Kline, Religlous and anti-religlous thought in Russia. Chicago-London 1968.

G. Kline, Theoretische Ethik im russischen Frühmarxismus. In: Forschungen zur osteuropäischen Geschichte 9 (1963), S. $269-279$.

R.-D. Kluge, Gor'kif. Die Mutter. In: Der Russische Roman. Hrg. Bodo Zelinsk1. Düsseldorf 1979, S. $242-264$.

R.-D. Kluge, Vom kritischen zum sozialistischen Realismus. München 1973.

J. Kobetz, Maxim Gorkijs Gottsuchertum. In: Der Remter, 7 (1961), H. 6, S. 333 - 343 .

I.P. Kochno, Certy portreta. Stranicy zizni 1 dejatel'nosti A.V. Lunacarskogo. Minsk 1972.

S. Körner, Kant. Göttingen 1967.

L. Kolakowski, Die Hauptströmungen des Marxismus. Bd. 2. München-zürich 1978.

F. Kool und $w$. Krause, Die frühen Sozialisten $1+2$. München 1972. 
KPSS v rezol jucljach 1 resenijach, t. 1. Moskau 1953.

P. Kropotkin, Ideale und Wirklichkeit in der

russischen Literatur. Frankfurt/M. 1975.

H. Küng, Christ sein. München ${ }^{3} 1978$.

A.A. Kunkl', Dolgusincy. S vstupitel'nof stat'ef B.P. Koz'mina. ( $=$ Istoriko-revol jucionnaja Blblioteka Nr. 8 LXXIII). Moskau 1931.

I.K. Kuzmicev, Gor'kij publicist I narodnik. In: 'Uennye zaplski Gor'kovskogo Pedagogiceskogo Instituta. Gor'kij 1961.

W. Lang, Gork1 und Nietzsche. In: Horlzont, 2 (1947), H. 17, S. 18 - 19 .

M. Laskovaja, Bogolskatel'stvo 1 bogostroltel'stvo prezde 1 teper'. Moskau 1972.

D. Lecourt, Lenins philosophische Strategle. Von der Widerspiegelung (ohne Splegel) zum Prozeß (ohne Subjekt). Frankfurt/M.-Berlin-Wien 1975.

H. Lehbert, Maxim Gork1. Ein Bild seines Lebens uns Schaffens. Stuttgart 1905.

W.I. Lenin, Materialismus und Empiriokritizismus. Kritische Bemerkungen über eine reaktionäre Philosophle. Lelpzig 1974.

Letop1s' $212 n 11$ tvorcestva Gor'kogo. vyp. $1+2$. Moskau 1958.

D. Levin, Stormy Petrel. The Life and Work of

M. Gorky. New York 1965.

G. Lichtheim, Kurze Geschichte des Sozialismus. Minchen 1975.

H.-J. Lieber, Die Philosophie des Bolschewismus In den Grundzügen inrer Entwicklung. Frankfurt/M.Berlin-Bonn 1961 . 
Literaturmagazin 12, Nietzsche. Hamburg 1980.

Literaturnoe nasledstvo, t. 1. Moskau 1931.

Literaturnoe nasledstvo, t. 72. Moskau 1965.

Literaturnoe nasledstvo, t. 80. Moskau 1971.

Literaturnoe nasledstvo, t. 82. Moskau 1970.

S. Livsic, Partijnaja Skola v Bolon'e (1910-1911gg.)

In: Proletarskaja revoljuclja 1926, Nr. 3 (50),

S. $109-144$.

K. Löw1th, 6 Weltgeschichte und Hellsgeschehen. Stuttgart 1973 .

R. Lorenz (Hrg.), Proletarische Kulturrevolution in Sowjetrußland (1917 - 1921). München 1969 .

N. Ludwig, M. Gork1. Sein Leben und Werk. Berlin 1968.

A.V. Lunatarsk11. Issledovanifa 1 materialy. Leningrad 1978.

E. Mach, Die Analyse der Empfindungen. Jena ${ }^{3} 1903$.

K. Marx, Die Frühschriften. Stuttgart 1968.

Marx/Engels, Über Religion. Berlin (Ost) 1976.

Th.G. Masaryk, Rußland und Europa. Zur Geschlchtsund Religionsphilosophie. Jena 1913.

R. W. Mathewson Jr., Positive Hero in Russian Literature. Stanford California ${ }^{2} 1975$.

N.F. Matvifeuk, Tvorcestvo M. Gor'kogo 1 fol'klor. Kiev 1959.

G. Mayer, Der Junge Gor'k1f (1868 - 1904). He1delberger Dissertation 1960. 
R. Meincke, Maxim Gorkif, seine Persönlichke1t und seine Schriften. Hamburg 1908.

F. Mierau, M. Gork1. Leipzig 1966.

E. Mirowa-Florin, Zur Herausbildung des sozialistischen Humanismus bei Gor'kif. (Dargestelit anhand der "Rasskazy 1922 - $1924 \mathrm{gg} \cdot "$ ) In: ZFS, Bd. VIII, H. 6, 1963, S. 924 - 938 .

D. Mirskij, Geschichte der russischen Literatur. München 1964.

W. Müller-Lauter, Nietzsche. Seine Philosophie der Gegensätze und die Gegensätze seiner Philosophie. Berlin-New York 1971.

K.D. Muratova, M. Gor'kij na Kapri. 1911 - 1913. Leningrad I97i.

F. Nletzsche, Werke I-V. (Hrg. V. Karl Schlechta). Frankfurt/M.-Berlin-wien 1976.

W. Oelmüller u.a., Philosophische Arbeitsbücher Bd. 3. Diskurs: Religion. Paderborn-München-WienZürich 1979.

A. Ovtarenko, Publicistika M. Gor'kogo. Moskau 1965.

J. Paech, Das Theater der russischen Revolution. Theorie und Praxis des proletarisch-kulturrevolutionären Theaters in RuBland 1917 - 1924. Kronberg/Ts 1974 .

A. Pannekoek, Lenin als Philosoph. Frankfurt/M.Wien 1969.

J.-U. Peters, Kunst als organisierte Erfahrung. Uber den Zusammenhang von Kunst theorie, Literaturkritik und Kulturpolitik bei A.V. Lunatarskij. Unveröffentl. Manuskript (Habil.) Konstanz o.J.

"Phil", Maxim Gorki und Fr. Nietzsche. In: Wiener Zeitung, Beil. Wiener Abendpost. 1901, Nr. 152, $5-7,5.1-3$. 
G.V. Plechanov, Antwort auf die Umfrage des Mercure de France zur Religion. In: Mercure de France Nr. 233, Tome LXVI, 1. Mars, 1907.

G.V. Plechanov, Socinenija t. XVII, Moskau 1924.

J.E. Poritzky, Heine, Dostoevskij, Gor'kij. Essays. Leipzig 1902 .

E. Pracht U.a., Elnführung in den sozialistischen Realismus. Beriln (Ost) 1975.

V.P. Preobraženskij, Fridrich Nicš: Kritika morali al'truizma. In: Voprosy Filosofil 1 Psichologi1, 15 (1892), S. 115 - 160 .

Problemy idealizma. Sbornik stat'ej pod red. P.I. Novgorodceva. Moskau 0.J.

Th. Ramm ( $\mathrm{Hrg}$ ), Ber Frühsozialismus. Quellentexte. Stuttgart ${ }^{2} 1968$.

H. Rischbieter, Gork1. Hannover 1973.

J. Ritter, Fortschritt. In: Historisches Wörterbuch der Philosophie, Bd. 2. Darmstadt 1972, Sp. 1032 - 1059 .

N.I. Rodny U. Ju. I. Solowjew, Wilhelm Ostwald. LeIpzig 1977.

A. Roskin, Maxim Gor'kij. Berlin 1947.

J. Rühle, Gorki und die Geburt des sozialistischen Realismus. In: drs., Das gefesselte Theater. Berlin 1957.

Russkaja Literatura $x x$. veka. Dooktjabr'skij period. Kiev 1977.

M.I. Sachnovic, A.M. Gor'kif o proischożenil religil. In: Ezegodnik Muzeja istoril religil 1 ateizma, $t$. I, 1957, S. 75 - 143. 
M.I. Schachnowitsch, Lenin und die Fragen des Athelsmus. Berilin 1966.

L. Schapiro, Geschichte der kommunistischen Partel der Sowjetunion. Frankfurt/M. 1961 .

P. Scheibert, Der Übermensch in der Russischen Revolution. In: E. Benz (Hrg.), Der Übermensch, a.a.o.S. $179-196$.

J. Scherrer, "Ein gelber und ein blauer Teufel." Zur Entstehung der Begriffe "bogostroitel'stvo" und "bogoiskatel'stvo". In: Festschrift für Werner Philipp ( = Forschungen zur osteuropäischen Geschichte Bd. 25). Berlin 1978, S. 319-329.

J. Scherrer, Intelligentsia, Religion, Révolution: Premieres manifestations d'un socialisme chrétien en Russie. 1905 - 1907. In: Cahlers du Monde Russe et Soviéthique Vol XVII (1976), 4+Vol. XVIII, (1977) $1-2$.

J. Scherrer, Die Partelschulen von Capri und Bologna und die Frage der Bildung der Parteiintelligencija. Unveröffentl. Manuskript eines Referats. Berlin 1978.

J. Scherrer, Die russischen religiös-philosophischen Vereinigungen als Ausdruck des religiösen Suchens der

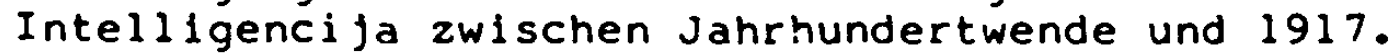
In: Forschungen zur osteurop. Geschichte Bd. 20.

J. Scherrer, Die Petersburger Religiös-Philosophischen Vereinigungen. ( = Forschungen zur osteurop. Geschichte Bd. 19) Berlin 1973.

H.-R. Schlette, Religion. In: Handbuch philosophischer Grundbegriffe (Hrg. H. Krings U.a.)

Bd. 5. München 1974.

H.-J. Schmitt und G. Schramm (Hrg.), Sozialistische Realismuskonzeptionen. Dokumente zum 1. Allunionskongreß der Sowjetschriftsteller. Frankfurt/M. 1974.

R. Schröder, Maxim Gorki (1868 - 1936). In: Positionsbestimmungen. Zur Geschichte marxistischer Theorie von l,iteratur und Kunst. Frankfurt/M. 1977. 
R. Schröder, Lenin, der Freund und Lehrer Gorkis. In: Russischunterricht 7 (1954), H. l. S. 1-6.

H. Setzer, Die Bedeutung der Energielehre für die Literaturkonzeption Maxim Gor'kijs nach der ersten russischen Revolution. In: WdSIav XXV, N.F. IV, 2 (1980), S. $394-427$.

S. Sinequb, Zapiski Cajkovca. Moskau 1929.

M. Slonim, Die Sowjetliteratur. Eine Einführung. Stuttgart 1972 .

K. Städtke, Das Erbe der klassischen russischen Literaturwissenschaft. A.N. Veselovskij und A.A. Potebnja. In: Zs. f. Slav., 17 (1972), S. $215-233$.

K. Stählin, Geschichte Rußlands von den Anfängen bis zur Gegenwart I-IV.

G. Stökl, Russische Geschichte. Stuttgart ${ }^{2} 1965$.

R. Streltzow, Die Krise der russischen Intelligenz. In: Sozialistische Monatshefte, 13 (1909), H.2, S. $102-108$.

P.I. Sumarev, A.M. Gor'kij o religil. Moskau 1960.

A. Thun, Die Geschichte der revolutionären Bewegungen in Rußland. 0.0 .1883$.

W. Timofejew, Kommunismus und Religion. Über die sozialen Prinzipien. Berlin (Ost) 1975.

L. Tolstol, Beichte. In: drs., Philosophische und sozialkritische Schriften. Berlin (Ost) 1974, S. 73 - 152 .

N. Trifonov, Vorwort zu: A.V. Lunatarskij, O Gor'ton. Moskau 1975.

N.A. Trifonov, A.V. Lunacarskij i M. Gor'kij. K istoril literaturnych 1 licnych otnosenil do oktjabrja. In: M. Gor'kij 1 ego sovremenniki. Leningrad 1968, S. $110-157$. 
N.A. Trifonov, A.V. Lunatarskij 1 sovetskaja iteratura. Moskau 1974.

F. Trommler, Sozialistische Literatur in Deutschland. Ein historischer Überblick. Stuttgart 1976.

S.V. Utechin, Geschichte der politischen Ideen

in Rußiand. Stuttgart-Berlin-Köln-Paris 1966.

N. Valentinov (Vol'skij), Vstreci s Maksimom

Gor'kim. In: Novyj zurnal Nr. 78 (1965), S. $120-139$.

F. Venturi, Il populismo russo. 2 Bde. Turin 1952.

N. Vojtilinskij, O gruppe "Vpered" (1909-1917).

In: Proletarskaja revolfucija, 1929, Nr. 12.

M.B. Vol'fson I G.M. Gak, Ocerki Istoriceskogo Materializma. Moskau 1931.

P. Vranick1, Historija marksizma. 1+2. Zagreb 1971.

K.-H. Weger, Religlonskritik von der Aufklärung bis zur Gegenwart. (Autorenlexikon von Adorno bis Wittgenstein) Freiburg-Basel-Wien 1979.

G.A. Wetter, Der Dialektische Materialismus. Seine Geschichtg und sein System in der Sowjetunion. Freiburg ${ }^{5} 1960$.

B.D. Wolfe, Brücke und Abgrund. Wien-Frankfurt/M.Zürich 1970.

T. Yedlin, Maxim Gorky: His early revolutionary activity and his envolvement in the Revolution of 1905. In: Canadian Slavonic Papers Vol. XVII (Nr. 1, 1975) S. 76 - 106.

V.V. Zenkovsky, A History of Russian Philosophy 2 vols. New York-London 1953.

G. Zlegenge1st U.a., Multinationale Sowjetliteratur. Kulturrevolution, Menschenbild, Welthistorische Leistung 1917 - 1972. Berlin-Weimar 1975. 
F.J H.-G. Zmarzlik, Sozialdarwinismus. In: SDG, Bd. 5 ,

1 ,

( I

(1)

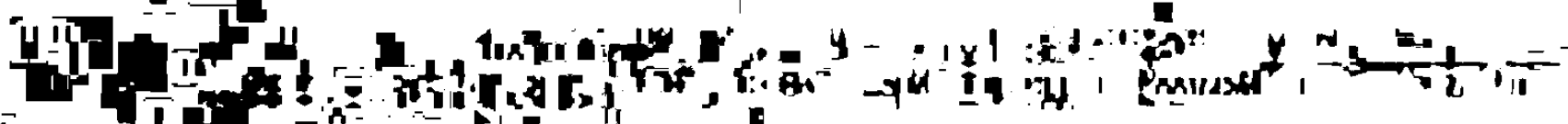

II

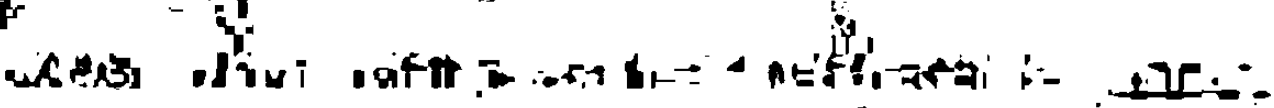

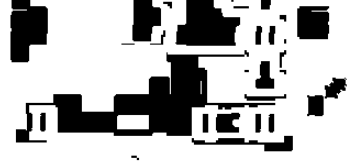

II

ilin

Ir - inn

$=$

$\therefore$

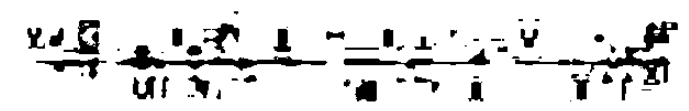

$\therefore \underline{\prime \prime}$

8

$$
\begin{aligned}
& \text { - } 1 \text { ' } \\
& \text { il }
\end{aligned}
$$

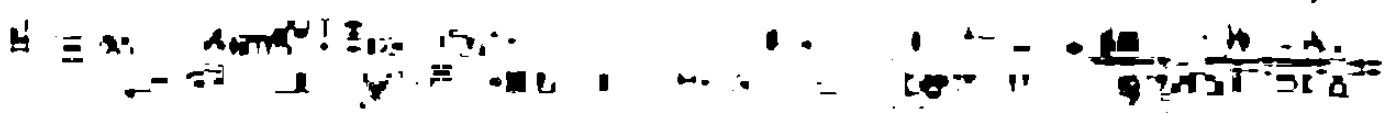

$$
\begin{aligned}
& \text {-. 1-. Jx } \\
& 1.0-11.1+-11 .+\%
\end{aligned}
$$

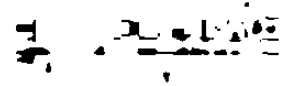

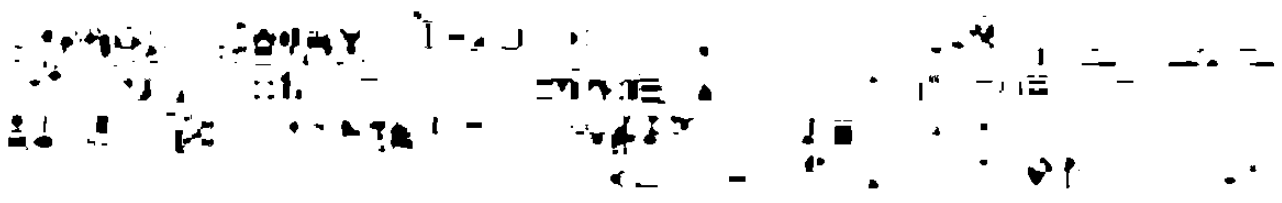

$$
\begin{aligned}
& 4 \\
& \text { L. } 12-1
\end{aligned}
$$

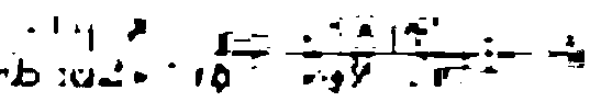

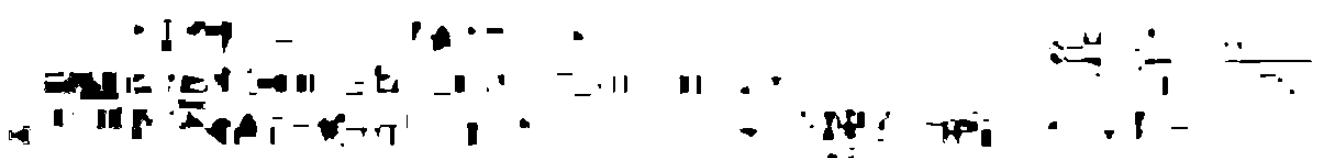

ע.

-1 
136. Jachnow, H. (u.a.): Zur Erklärung und Modellierung diachroner Wortbildungsprozesse (anhand russischer substantivischer Neologismen). 1980. IV, $230 \mathrm{~S}$.

137. Breu, W.: Semantische Untersuchungen zum Verbalaspekt im Russischen. 1980. X, $231 \mathrm{~S}$.

138. Slavistische Linguistik 1979. Referate des V. Konstanzer Slavistischen Arbeitstreffens Zürich 25.-27. Sept. 1979.

Herausgegeben von Daniel Weiss. 1980. $259 \mathrm{~S}$.

139. Franz, N.: Groteske Strukturen in der Prosa Zamjatins. Syntaktische, semantische und pragmatische Aspekte. 1980. $312 \mathrm{~S}$.

140. Baer, J.T.: Arthur Schopenhauer und die russische Literatur des späten 19. und frühen 20. Jahrhunderts. 1980. VIII, $194 \mathrm{~S}$.

141. Lempp, A.: Das zusammengesetzte Verbalprădikat mit "da" im Neubulgarischen. 1981. IV, $102 \mathrm{~S}$.

142. Stephan, H.: "Lef" and the Left Front of the Arts. 1981. XIV, 242 S.

143. Kempgen, S.: "Wortarten" als klassifikatorisches Problem der deskriptiven Grammatik. Historische und systematische Untersuchungen am Beispiel des Russischen. 1981. X, $309 \mathrm{~s}$.

144. Peters, J.: Farbe und Licht. Symbolik bei Aleksandr Blok. 1981. VIII, $315 \mathrm{~S}$.

145. Ebding, J.: Tendenzen der Entwicklung des sowjetischen satirischen Romans (1919-1931). 1981. VI, 294 S.

146. Schreiber, J.: Jerzy Andrzejewskis Roman "Ciemności kryja ziemie" und die Darstellung der Spanischen Inquisition in Werken der fiktionalen Literatur. 1981. VIII, 308 S.

147. Slavistische Linguistik 1980. Referate des VI. Konstanzer Slavistischen Arbeitstreffens Hamburg 23.-25. Sept. 1980. Herausgegeben von Peter Hill und Volkmar Lehmann. 1381. 243 S.

148. Hartenstein, K.: Das erklärend-kombinatorische worterbuch im , Smysl $\rightarrow$ Tekst'-Modell. Studien $z u$ den lexikologischen Grundlagen der Bedeutungsexplikation und ihrer lexikographischen Verwendbarkeit. 1981. VIII, 277 S.

149. Koestler, N.: Strukturen des modernen epischen Theaters. Stanisław Wyspiańskis "Teatr ogromny" erläutert am Beispiel des Dramas "Achilleis". 1981. X, 246 S.

150. Deppermann, M.: Andrej Belyjs ästhetische Theorie des sch⿰丿ferischen BewuBtseins. Symbolisierung und Krise der Kultur um die Jahrhundertwende. 1982. X, $256 \mathrm{~S}$.

151. Meichel, J.: Zur Entfremdungs- und Identitätsproblematik in der Sowjetprosa der 60er und 70er Jahre. Eine literatursoziologische Untersuchung. 1981. $217 \mathrm{~S}$.

152. Davydov, S.: "Teksty-Matreški" Vladimira Nabokova. 1982. $V I, 252 \mathrm{~S}$.

153. Wallrafen, C.: Maksimilian Vološin als Künstler und Kritiker. 1982. IV, $273 \mathrm{~s}$.

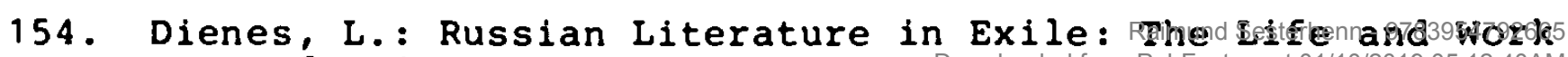

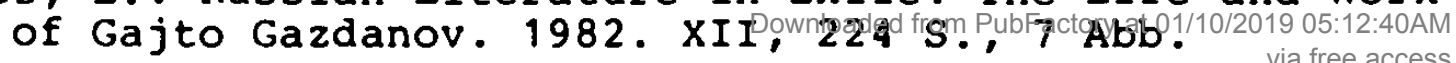


155. Bulgarien 1300. Referate der Sektion "Sprache und Literatatur des Symposiums "Bulgarien in Geschichte und Gegenwarart" Hamburg 9.-17. Mai 1981. Herausgegeben von Peter Hilill. 1982. $97 \mathrm{~s}$.

156. Bock, I.: Die Analyse der Handlungsstrukturen von Erzählwlwer ken am Beispie] von N. V. Gogol's "Die Nase" und "De'Jer Mantel". 1982. VIII, $168 \mathrm{~S}$.

157. Pihler, M.: Die, progressive' form des englischen Verbs ur und ihre Ubersetzungsmöglichkeiten im Slowenischen. 198232. $170 \mathrm{~s}$.

158. Sesterhenn, R.: Das Bogostroitel'stvo bei Gor'kij und Lunacarskij bis 1909. Zur ideologischen und literarieischen Vorgeschichte der Parteischule von Capri. 198232. VIII, $366 \mathrm{~s}$.

159. Kunstmann, H.: Vorläufige Untersuchungen uber den bairisçcher Bulgarenmord von 631/632. Der Tatbestand. Nachklängele in Nibelungenlied. 1982 . 